\title{
Smoking and bladder cancer risk and recurrence
}

Citation for published version (APA):

van Osch, F. H. M. (2019). Smoking and bladder cancer risk and recurrence. [Doctoral Thesis, Maastricht University, University of Birmingham]. Gildeprint Drukkerijen. https://doi.org/10.26481/dis.20190412fo

Document status and date:

Published: 01/01/2019

DOI:

10.26481/dis.20190412fo

Document Version:

Publisher's PDF, also known as Version of record

\section{Please check the document version of this publication:}

- A submitted manuscript is the version of the article upon submission and before peer-review. There can be important differences between the submitted version and the official published version of record.

People interested in the research are advised to contact the author for the final version of the publication, or visit the DOI to the publisher's website.

- The final author version and the galley proof are versions of the publication after peer review.

- The final published version features the final layout of the paper including the volume, issue and page numbers.

Link to publication

\footnotetext{
General rights rights.

- You may freely distribute the URL identifying the publication in the public portal. please follow below link for the End User Agreement:

www.umlib.nl/taverne-license

Take down policy

If you believe that this document breaches copyright please contact us at:

repository@maastrichtuniversity.nl

providing details and we will investigate your claim.
}

Copyright and moral rights for the publications made accessible in the public portal are retained by the authors and/or other copyright owners and it is a condition of accessing publications that users recognise and abide by the legal requirements associated with these

- Users may download and print one copy of any publication from the public portal for the purpose of private study or research.

- You may not further distribute the material or use it for any profit-making activity or commercial gain

If the publication is distributed under the terms of Article $25 \mathrm{fa}$ of the Dutch Copyright Act, indicated by the "Taverne" license above, 
Smoking and bladder cancer risk and recurrence 
(C) Frits van Osch, Maastricht, 2018

Smoking and bladder cancer risk and recurrence

Key words: smoking, bladder cancer, observational research, risk and prognosis

ISBN: $\quad 9789463234719$

Cover design: Mitch van Hensbergen \& Ilse Modder, www.ilsemodder.nl

Lay-out: XML2Publish

Printed by: $\quad$ Gildeprint, Enschede, The Netherlands.

The research presented in this dissertation was conducted at Maastricht University \& the University of Birmingham. 


\title{
Smoking and bladder cancer risk and recurrence
}

\author{
DISSERTATION \\ to obtain the degree of Doctor \\ at Maastricht University and Doctor of Philosophy at the University of \\ Birmingham \\ on the authority of the Rector Magnificus, \\ Prof.dr. Rianne M. Letschert \\ in accordance with the decision of the Board of Deans, \\ to be defended in public \\ on Friday $12^{\text {th }}$ of April 2019 at 14.00 hours
}

by

Frits Hubertus Marinus van Osch

Born in Schijndel 24 October 1990 
Supervisors:

Prof.dr. Maurice P. Zeegers, Maastricht University

Prof.dr. Frederik J. van Schooten, Maastricht University

Co-supervisors:

Dr. Anke Wesselius, Maastricht University

Dr. Richard T. Bryan, University of Birmingham, UK

Assessment Committee:

Prof.dr. Matty P. Weijenberg, Maastricht University (chair)

Prof.dr. Aalt Bast, Maastricht University

Prof.dr. Mike M. Hawkins, University of Birmingham, UK

Prof.dr. G. Neil Thomas, University of Birmingham, UK

Prof.dr. Roger Kockelbergh, University of Leicester, UK

Prof.dr. Daniel Kotz, University of Düsseldorf, Germany 


\section{ABSTRACT}

Smoking has been shown to be a major modifiable risk factor for bladder cancer. However, apart from distinguishing between current smokers and former smokers, not many detailed analyses have been performed on lifetime smoking behaviour and bladder cancer risk. Furthermore, smoking cessation after diagnosis of bladder cancer could improve bladder cancer prognosis, but this has not yet been studied prospectively over a longer period yet.

In this thesis, the current evidence on the association between smoking behaviour (duration, intensity, cessation, passive smoking exposure, cigarette type) and bladder cancer incidence and prognosis has been summarised through several meta-analyses. Furthermore, a prospective study on smoking and bladder cancer recurrence is described as well as a consortium study pooling data from 15 case-control studies to further decipher the interplay between smoking duration and intensity in determining bladder cancer risk.

Considering all evidence described in the results chapters of this thesis, it is suggested that duration of exposure to cigarette smoke is most important in determining bladder cancer risk and possibly also recurrence. Also, there does not seem to be any association between exposure to environmental smoke and bladder cancer. To provide more insight in how smoking causes bladder cancer, future studies should consider the possible association between molecular subtypes and smoking behaviours. 



\section{TABLE OF CONTENTS}

1 General introduction 9

2 Quantified relations between exposure to tobacco smoking and bladder 35 cancer risk: a meta-analysis of 89 observational studies

3 A stratified meta-analysis of the association between exposure to environmental tobacco smoke during childhood and adulthood and urothelial bladder cancer risk.

4 Tar, nicotine and carbon monoxide yield of UK cigarettes and the risk of nonmuscle-invasive and muscle-invasive bladder cancer.

5 Modelling the complex exposure history of smoking behaviour in predicting bladder cancer: a pooled analysis of 15 case-control studies.

6 Significant Role of Lifetime Cigarette Smoking in Worsening Bladder Cancer and Upper 7Tract Urothelial Carcinoma Prognosis: A Meta-Analysis

7 The association between smoking cessation before and after diagnosis and non-muscle-invasive bladder cancer recurrence: a prospective cohort study

8 Summary and general discussion

Nederlandse samenvatting

Valorisation addendum

Dankwoord / Acknowledgements

Curriculum Vitae 

General introduction
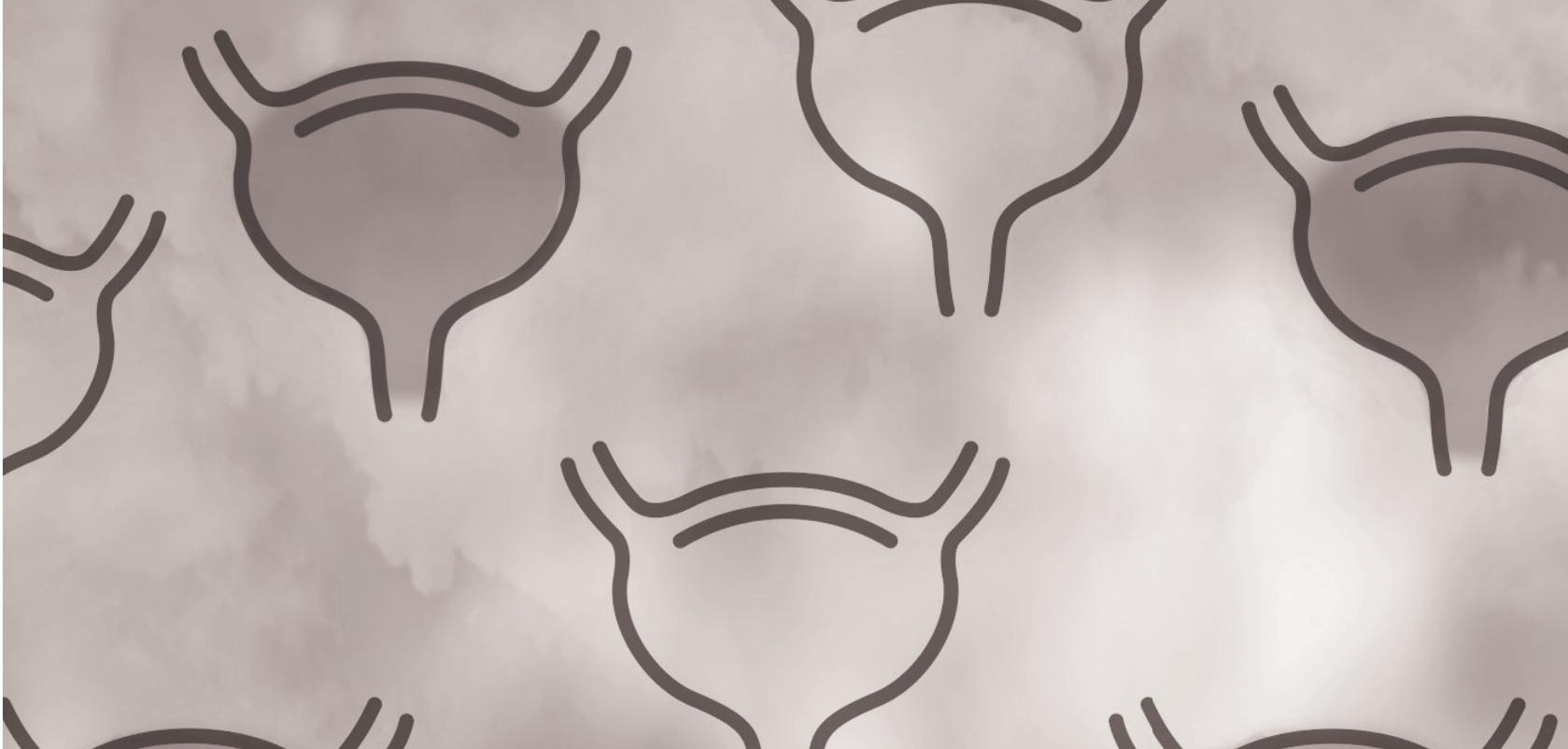

Smoking as risk factor alone is estimated to be responsible for 60,000 new cancer cases (19,4\% of all cancer cases) occurring in the UK in 2010 [1]. Of these cases, about one in six (10,000 people) are diagnosed with bladder cancer [2] and about half of these cases has been estimated to be attributable to smoking [3]. Worldwide, the estimated number of new cases of bladder cancer in 2012 was 430,000 and the number of deaths due to bladder cancer was 165,000 [4]. Moreover, the global prevalence of bladder cancer can be estimated at approximately 2,000,000, indicating that at any time there will be a very considerable number of patients requiring surveillance and treatment [4]. While smoking is mostly known as the primary risk factor for lung cancer, it is also an important contributor to the pathogenesis of bladder cancer. Although most of these cases can be attributed to cigarette smoking or occupational exposure to carcinogens [5], bladder cancer patients seem to be less aware of smoking being a primary risk factor when compared to patient knowledge on smoking and lung cancer $[6,7]$.

In addition to increasing bladder cancer risk, there are also reasons to believe that lifetime smoking behaviour might have a negative impact on bladder cancer prognosis [8]. There is also evidence that passive smoking (also known as exposure to environmental tobacco smoke) increases bladder cancer risk [9], although the evidence is not as strong as for lung cancer [10]. Bladder cancer is known for its high recurrence and progression rates after initial treatment [11], which impact on quality of life [12] and generate high disease management costs that result in considerable economic burden [13]. Since an estimated $18.4 \%$ of people smoke worldwide in more economically developed countries [14], research on the influence of smoking on the bladder cancer risk and prognosis is a highly relevant and dynamic field of study.

\section{THE EPIDEMIOLOGY OF BLADDER CANCER AND SMOKING}

Bladder cancer incidence is highest in more developed countries and about $75 \%$ of patients diagnosed are male [4]. Next to gender, several non-modifiable risk factors for bladder cancer have been identified, including age, family history, previous radio- or chemotherapy and long-term or repeated urinary tract infections [5]. Additionally, having a history of upper-tract urothelial carcinoma is also known to increase the risk of disease occurrence in the bladder as well as tumour recurrences or disease progression throughout the urothelium $[15,16]$. Large regional differences (e.g. only $5 \%$ of the total bladder cancer incidence is from low human development index countries) seem to indicate that there are also various modifiable risk factors known to attribute significantly to the bladder cancer risk. Some of the most studied factors include exposure to smoking and dietary behaviour, and exposure to certain chemicals [1]. Among these, smoking is the leading preventable risk factor for 
bladder cancer [3]. Although the number of smokers is declining in most countries, roughly $15-20 \%$ of the population in Western countries and much higher percentages (especially in men) in large parts of Asia are estimated to smoke regularly [17] (Figure 1). Therefore, and because smoking behaviour from 20 years ago will continue to generate new cases, it is likely that the smoking will continue to cause a significant number of bladder cancer cases.

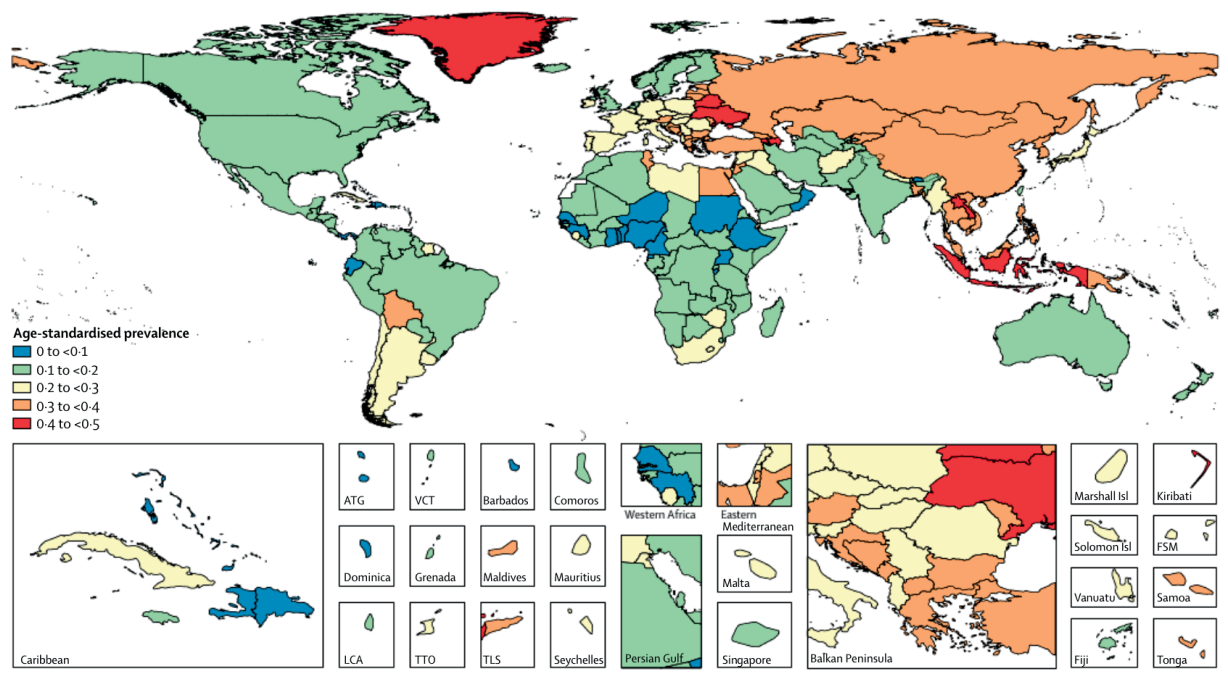

Figure 1. Worldwide, age-standardized smoking rates in males. Units of age-standardised prevalence in proportions ( 0 to $<0.1=0-10 \%, 0.1$ to $<0.2=10-20 \%$ etc.) Adapted from: Reitsma et al 2017 [17].

Generally, the incidence of bladder cancer is slightly decreasing over the past decades, probably due to the declining number of regular smokers in men living in countries with a high Human Development Index [4]. However, a study comparing two regional cohorts in the UK over a 20-year interval (1991-1992 versus 2005-2011) showed that the proportion of cases being diagnosed who have ever been exposed to cigarette smoking has remained similar [18]. This indicates that the overall number of current or former smokers remained stable over time and that other factors in smokers such as smoking behaviour (e.g. duration or intensity) or cigarette contents (e.g. high tar concentration) might have been different between both regional cohorts. Nevertheless, differences between both cohorts might be explained by the coding system which changed from coding papillary tumours of uncertain behaviour and carcinoma in situ differently than malignant bladder tumours to coding these as malignant bladder tumours after 2000 in the UK. Accordingly, the paper also shows that the most recent cohort had a larger percentage of patients presenting with multiple tumours $(p<0.001)$, tumours of more than 2 centimetres in diameter $(p<0.001)$ and grade 3 tumours $(P<0.001)$. In summary, studies investigating smoking 
behaviour in more detail in relation to bladder cancer incidence are warranted to better explain and predict bladder cancer trends in the future.

\section{MOLECULAR PATHOLOGY OF UROTHELIAL CARCINOGENESIS}

In developed countries, over $90 \%$ of bladder cancers are transitional cell carcinomas of urothelial origin, the other $10 \%$ originate from the glandular cells (adenocarcinoma) or from irritation and inflammation of the bladder lining (squamous cell carcinoma) [19]. Urothelial carcinoma is a type of solid malignancy that can be explained through mutational changes in DNA [20]. Generally, there are two pathways to developing urothelial tumours most often referred to as the papillary and the non-papillary pathways [21]. Transformation of the superficial urothelial cells generally results in papillary tumours. Therefore, papillary tumours are mostly non-muscle-invasive and of low histologic grade at diagnosis, but still have a high probability of recurring and the potential for progression. Non-papillary tumours are solid tumours that form through severe dysplasia and are more often high-grade at diagnosis and more likely to progress through the bladder wall and metastasize [22]. Although the pathways seem distinct, there is also some overlap between both pathways, because $10-15 \%$ of the non-muscle-invasive papillary tumours might eventually progress to high-grade muscle-invasive carcinoma.

Based on the evidence there is now on the molecular pathology of bladder cancer, it is believed that most urothelial carcinomas (both papillary and non-papillary) arise from early transformational changes that may affect large continuous areas of the urothelium, so-called field changes, giving rise to the synchronous and metachronous multifocality (i.e. multiple tumours in the urothelium) that is often observed. Such abnormal fields may have arisen from the progeny of a single transformed cell, and the subsequent tumours are genetically related and thus of monoclonal origin [23].

Alternatively, it is suggested that multiple tumours originate from independently transformed areas of the urothelium giving rise to genetically unrelated (oligoclonal) tumours [24]. Learning more about the underlying molecular patterns leading up to bladder cancer is of high clinical importance as appropriate treatment should be applied based on the molecular type of tumours observed [24]. Recent efforts have identified several forerunner genes that could be predisposing factors for bladder cancer and predict carcinogenesis earlier. For example, the P2RY5 gene in which an allele (G172T), which causes loss of function of tumour suppressor gene RB1, was found to be carried by $100 \%$ of smokers in a large case-control study [25]. 
Some factors like multifocality, pathological characteristics of the primary malignant tumour (papillary, non-papillary) and possibly implantation of remnant tumour cells in the bladder dome after transurethral resection are factors associated with increased recurrence rates and possibly also progression to muscle-invasive bladder cancer [26]. Apart from several possible molecular pathways leading up to bladder cancer, the tumour location within the urothelium can also explain different responses to therapy. Muscle-invasive bladder tumours in the basal cells are mostly associated with more aggressive disease at presentation and show up-regulation of p53 target genes while luminal muscle-invasive bladder cancers often show FGFR3 and PPAR mutations and are more resistant to several types of neoadjuvant chemotherapy $[27,28]$.

Data from The Cancer Genome Atlas (TCGA) initiative has proven that bladder cancer consists of many molecular subtypes with specific genetic alterations and differences in response to therapy [29]. Nevertheless, recently a molecular taxonomy for urothelial carcinoma called the "Lund taxonomy" [30] has been validated using TCGA data and, using an mRNA-based classifier, the taxonomy could distinguish between 7 major molecular subtypes to estimate survival rates [31]. Understanding molecular pathology helps improve clinical care, but can also be useful in explaining differences in bladder cancer risk or prognosis for smokers, when future studies merge epidemiological data with molecular data.

\section{THE AETIOLOGY OF SMOKING-RELATED BLADDER CANCER}

One of the first mechanisms through which smoking was believed to be related to bladder cancer development was established in the 1950s when the "o-aminophenol hypothesis" of arylamine-induced human bladder cancer was proposed [32]. This hypothesis suggests aromatic amines to be conjugated by the liver and excreted in the urine where it would liberate the carcinogen o-aminophenol [32,33], thereby causing DNA damage and potentially bladder cancer. Smokers are exposed to several carcinogenic compounds including tobacco-specific nitrosamines (TSNA), polycyclic aromatic hydrocarbons (PAH) and arylamines. Most of the current evidence points towards 2-naphtylamine and 4-aminobiphenyl as being the most common aetiologic agents in bladder cancer [34,35].

Arylamines need metabolic activation to become mutagenic metabolites with ultimately carcinogenic potential [36]. The result of metabolic activation through $\mathrm{N}$-oxidation are $\mathrm{N}$ hydroxylamines, which are extremely toxic and can bind to DNA and haemoglobin to form adducts [37]. For instance, 4-ABP haemoglobin adducts are increased in blood of smokers compared to non-smokers [38]. N-hydroxylamines are detoxified through conjugation with glucuronide that is catalysed by UDP-glucuronosyltransferases and subsequently 
excreted via the kidney and bladder. At the same time, these conjugates are hydrolysed in the urine because of its acidity, and may form highly electrophilic $\mathrm{N}$-acetoxy derivatives with possible further bio activation through $\mathrm{N}$-acetyltransferases (NATs). Because of the conditions in the bladder the detoxified compounds are reactivated and damage the urothelial cells and form DNA adducts, which are congregated parts of DNA with carcinogenic chemicals. If these DNA adducts are not repaired before cellular proliferation occurs, fixation of mutations in proto-oncogenes and/or tumour suppressor genes may occur. Such irreversible mutations have the potency to change a normal cell into a malignant phenotype. Therefore, having a phenotype associated with slow $\mathrm{N}$-acetyltransferase, has been shown to be a risk factor for bladder carcinogenesis through modulating the metabolism of carcinogens in cigarette smoke [39].

\section{BLADDER CANCER DIAGNOSIS AND TREATMENT}

At diagnosis, the commonest symptom of bladder cancer is visible or non-visible haematuria (blood in the urine), which prompts a direct referral to the urology department if visible [40]. Other important symptoms include noticeable changes in urinary frequency and urgency, as well as a burning sensation while urinating [40]. After diagnosis, bladder cancer can be broadly divided into two stage groupings which have some overlap in biology but differ in extent to which the tumour has grown and are therefore treated differently: non-muscle-invasive bladder cancer (NMIBC), previously also called "superficial" bladder cancer, and muscle-invasive bladder cancer (MIBC) [11,40]. Approximately $75 \%$ of all occurring bladder cancers are non-muscle-invasive at diagnosis [41,42]. NMIBC includes high grade carcinoma confined to the innermost layer of the bladder (Tis), papillary tumours confined to the mucosa (stage Ta) and tumours which have invaded the lamina propria (stage T1) according to the most recent update of the TNM classification guidelines [43].

In addition to this general classification of bladder cancer the World Health Organization also proposes a more detailed classification of diseases in International Classification of Diseases (ICD) codes. Currently, in the 10th revision of the ICD codes, bladder cancer is coded as ICD code C67 with 9 sub-codes, indicating the exact location of the malignant neoplasm such as the dome of the bladder (C67.1) or the posterior wall of the bladder (C67.4). Before the year 2000, no international coding system was widely applied for bladder cancer, so it is possible that studies published before 2000 include bladder neoplasms that are not recognised in the ICD codes which were adhered to in later studies [44].

NMIBCs are generally treated by transurethral resection of the tumour using a cystoscope/ resectoscope, followed by a single shot of mitomycin C (MMC) and long-term cystoscopic 
surveillance $[11,45]$. The European Association of Urology (EAU) updates guidelines on treatment recommended for patients showing different tumour characteristics frequently to ensure most effective treatment for every individual case. Currently, the EAU suggests three risk groups in which non-muscle-invasive bladder cancer patients can be categorised. Low-risk tumours consist of primary, solitary, Ta, low grade, $<3 \mathrm{~cm}$, no CIS tumours; high-risk tumours are T1, high grade (G3), carcinoma in situ or multiple, recurrent and large $(>3 \mathrm{~cm})$ tumours. Intermediate-risk tumours are those that have some but not all characteristics of either a low or high risk tumour (e.g. Ta, but grade 2) [11]. Apart from these clinical characteristics, there are no widely-accepted or validated tissue-based or urine-based biomarkers to complement this risk stratification yet [46].

Commonly used additional treatment options are forms of adjuvant intravesical chemotherapy such as Bacillus Calmette-Guerin (BCG) recommended for high risk (of recurrence and/or progression) patients and MMC for intermediate-risk patients $[11,45]$. The TNM stage 2 identifies tumour invading the detrusor muscle, so all tumours staged TNM 2 or further are classified as MIBC, meaning that MIBC also includes TNM stage 3 (tumour has expanded through the muscle layer) and TNM stage 4 (tumour invades adjacent tissues such as the abdominal wall or other organs) [43]. Figure 2 shows all the stages of bladder cancer schematically (Figure 2) [20].

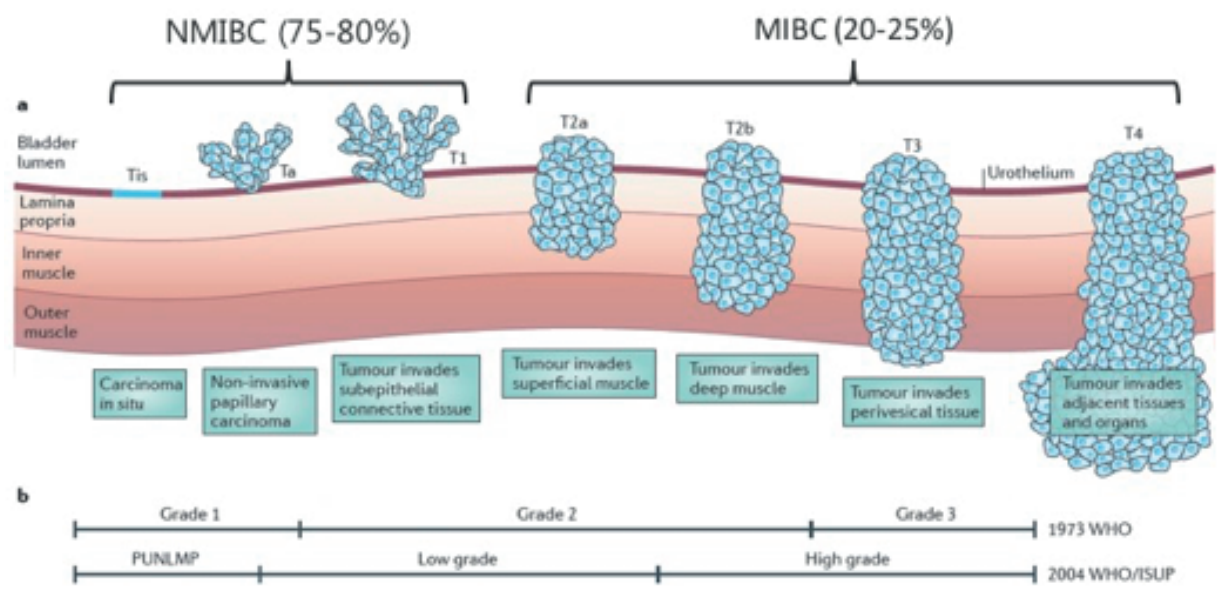

Figure 2. Bladder cancer stages and grades, showing the differences between non-muscleinvasive bladder cancer (NMIBC) and muscle-invasive bladder cancer (MIBC). Adapted from Knowles et al., 2015 [20].

Standard treatment for MIBC is neoadjuvant chemotherapy, sometimes followed by radical cystectomy (i.e. removal of the bladder) $[40,45]$. However, since cystectomy is a major surgical procedure associated with relatively high mortality rates in those over 80 years 
old [47], who represent a considerable proportion of the total bladder cancer population, there have been studies investigating alternative therapy options. For example, recently it has been shown that a combination of chemotherapy and radiotherapy can achieve long-term outcomes comparable to those of neoadjuvant chemotherapy and cystectomy in organ-confined disease (stage T2 and T3a) [48].

\section{LIFETIME SMOKING BEHAVIOUR AND BLADDER CANCER RISK}

The evidence on the harmful influence of smoking on cancer risk is consistent and convincing in showing that at least 12 different types of cancer are partially caused by smoking. Some of these cancers include cancer in the lungs, colon and rectum, head and neck, pancreas and kidneys [49]. Especially the evidence for smoking causing up to $50 \%$ of bladder cancer cases is compelling [3]. Nevertheless, still many studies focus on the relationship between smoking and bladder cancer because of the potentially large public health benefits of smoking cessation and the large proportion of cases attributed to smoking. Despite the large number of studies that focus on smoking, there have been only few attempts to model lifetime smoking behaviour including all its aspects in one model. However, acquiring a more wholesome view of how smoking causes bladder cancer, could be of high importance in determining which group(s) of smokers are most at risk for the development of (bladder) cancer, thereby providing cues for tailored prevention and smoking cessation programmes. In addition, analysis on different mode of inhalation, type of tobacco [50] and cigarette contents might also provide more detailed information on the relationship between smoking and bladder cancer risk.

\section{Duration of cigarette smoking and bladder cancer risk}

Longer lifetime exposure to increased levels of carcinogens in urine (e.g. from cigarette smoke) might lead to a higher cancer risk and those who smoke longer are at an increased risk of bladder cancer. Therefore, smoking duration is an important factor in establishing the risk of bladder cancer.

In a large meta-analysis published in 2000 , bladder cancer patients who had smoked for more than 20 years had a 2.13-fold higher rate of developing bladder cancer compared to those who smoked less than 20 years [3]. A similar finding was shown in a pooled analysis of 11 case-control studies, all contained data on smoking duration [51]. Those who had smoked for 5 to 9 years did not show an increased risk of developing bladder cancer compared to non-smokers, whilst those who smoked for 60 years or more had a 6.14-fold increased risk (95\% C.I. $=4.10-9.20)$, showing a marked increase in bladder cancer risk with longer duration of exposure. Even though several studies investigating this relationship 
appeared after 2000; no pooled analysis has been performed on smoking duration data since then.

Furthermore, starting smoking at a younger age, also seems to increase the risk of bladder cancer. A meta-analysis based on 5 observational studies, showed that subjects who started smoking at an age under $20(\mathrm{OR}=1.26,95 \%$ C.I.=1.12-1.42) had a higher proportion of bladder cancer cases compared to those who started smoking after the age of 20 [3]. Although, this effect may have been confounded by total duration of smoking, which is generally also longer when starting smoking at a younger age.

\section{Smoking intensity and bladder cancer risk}

Another important factor when establishing the relation between smoking and bladder cancer is "smoking intensity". Smoking intensity is most often expressed in number of cigarettes smoked daily; however sometimes the total number of cigarettes smoked over a lifetime is also used as a measure of smoking intensity. Smoking intensity is generally highly correlated with smoking duration (i.e. those who smoke many cigarettes per day often also smoke for many years) [52]. Therefore, considering smoking intensity (or duration) alone to predict bladder cancer risk is mostly too restrictive.

Nevertheless, previous research on smoking intensity showed that the higher smoking intensity leads to an increased bladder cancer risk. A pooled analysis showed that compared to non-smokers, smoking 1-20 cigarettes a day, regardless of the duration category, the risk of developing bladder cancer was increased by 2.17 (95\% C.I. $=1.75-2.70)$, while smoking more than 20 cigarettes a day increased the risk by $2.79(95 \%$ C.I. $=2.00-390)$. This effect for smoking more than 20 cigarettes a day, was more pronounced among men compared to women (OR: 2.91 95\% C.I.=2.09-4.06; OR: 2.57 95\%C.I.=2.24-2.94, respectively). Brennan et al. also investigated smoking intensity in the relation with the bladder cancer risk, and found that 1-2 cigarettes a day did not significantly increase risk, while smoking more than 40 cigarettes a day showed an increased risk of 3.08 (95\% C.I. $=1.74-5.47)$ [51].

\section{Pack-years of smoking, modelling lifetime smoking behaviour and bladder cancer risk}

Pack-years, the number of years smoking 20 cigarettes each day, are often used for estimating the effect of lifetime exposure to cigarette smoke on (bladder) cancer risk. This combined measure of smoking intensity and smoking duration has been useful in showing that there is an increasing dose-response relationship with larger total exposure to cigarette smoke [52-54]. However, because 20 pack-years can indicate both a smoker who has smoked 20 cigarettes per day for 20 years as well as a smoker who has smoked 40 cigarettes a day for 10 years, pack-years alone cannot completely explain smoking-related 
bladder cancer risk. Therefore, models which can discriminate between smokers with long duration and shorter duration within the same pack-year categories have been developed and tested in several types of cancers [55-57], including bladder cancer [58,59]. The results from these studies across smoking-related cancers are consistent in showing that longer duration of smoking is more deleterious than a short, high intensity exposure when comparing cases and controls with equal pack-years. Nevertheless, this has only been investigated using various modelling approaches in a few bladder cancer case-control studies [51,58-60].

\section{Smoking cessation and bladder cancer risk}

As with any potentially toxic exposure, reducing the exposure is expected to reduce harm. Similarly, smoking cessation reduces bladder cancer risk, although not immediately as it might take more than a decade to substantially reduce risk compared to someone who continues smoking.

There have been several observational studies investigating the effect of smoking cessation on bladder cancer risk. For example, the large NIH-AARP cohort, in which residents of eight states in California were followed between 1995 and 2006 and asked for their past smoking behaviour through questionnaires, showed that former smokers who stopped 1-5 years ago were still at a high bladder cancer risk ( $\mathrm{HR}=3.32,95 \% \mathrm{CI}=2.84-3.89)$ compared to never smokers and resembled the risk of current smokers ( $\mathrm{HR}=3.89,95 \% \mathrm{CI}=2.54-3.80)$. However, those who quit smoking more than 10 years ago were at a less increased bladder cancer risk $(H R=1.93,95 \% C I=1.73-2.14)$ compared to the risk estimate for current smokers [61]. These results suggest that the longer the smoking cessation, the lower the risk of developing bladder cancer. Estimates on years of smoking cessation and bladder cancer risk have also been pooled and confirm these findings. Nevertheless, a dose-response relationship between smoking cessation and bladder cancer risk has not been established as studies showing results on 20 or even 30 -year smoking cessation have not been pooled yet.

\section{Type of tobacco: cigarette, pipe and cigar smoking and bladder cancer incidence}

While smoking in general is a risk factor for bladder cancer, the type of tobacco and by what device tobacco is inhaled are also suspected to influence risk. From a pooled analysis of six case-control studies from Denmark, France, Germany and Spain, it was suggested that the harmful effect of smoking on bladder cancer risk differs between different smoking methods. It was shown that cigarette smokers were at the highest risk $(\mathrm{OR}=3.5,95$ $\%$ C.I. $=2.9-4.2)$ compared to non-smokers, while pure cigar smokers $(O R=2.3,95 \%$ $C . I=1.6-3.5)$ and pure pipe smokers $(O R=1.9,95 \%$ C.I. $=1.2-3.1)$ were at a relatively lower, but still substantial, risk of developing bladder cancer compared to non-smokers. 
However, these estimates were not adjusted for duration of smoking and are likely to be dose-dependent. Especially overall estimates for cigar smokers should have been corrected by duration, because those smoking cigars for more than 40 years were also at a 3.8-fold increased risk ( $95 \% \mathrm{CI}=2.1-7.1)$ compared to never smokers [50]. Because the electronic cigarette was only recently introduced on a large scale, there have not yet been population-based studies investigating e-cigarette smoking and risk of known smokingrelated diseases.

\section{Cigarette content, mode of inhalation and bladder cancer risk}

While cigarette smoking has been a well-studied risk factor for bladder cancer in epidemiological studies, the impact of different tar, nicotine and CO (TNCO) contents of cigarettes is less often considered in observational studies. Studies have shown that with the introduction of the filter tip, the bladder cancer risk decreased by more than two-fold compared to non-filter cigarettes [62-65]. Also, two observational studies considered total tar and nicotine intake where one study showed a linearly increasing risk of bladder cancer with increasing tar intake [66] while the other showed no differences in bladder cancer risk between low-tar versus higher tar cigarettes [67]. With the current evidence, it remains unclear whether cigarette content can explain regional differences in bladder cancer incidence between more developed and less developed countries.

\section{Environmental tobacco smoking and bladder cancer incidence}

Exposure to environmental smoking, also known as passive smoking, is known to be associated with slightly increased risks of smoking-related diseases such as lung cancer [10]. However, the evidence for bladder cancer is ambiguous. In a 2004 review, Zeegers et al concluded that there were not enough epidemiological studies published to confirm the mechanistically plausible link [68] between environmental smoking and bladder cancer risk [69], since there had only been one case-control study [70] and one cohort study [66] reporting on environmental smoking and bladder cancer risk. However, after 2004 several epidemiological studies investigated the effect of environmental smoking on bladder cancer risk and have recently been summarised in a meta-analysis [9]. In this meta-analysis, all exposure to environmental tobacco smoking was pooled and not stratified for childhood exposure or work-related exposure for example. However, these studies have different ways of estimating exposure to environmental smoke but, in common, they always gather data on smoking patterns of significant others, such as spouses or parents. Point estimates from these studies show differing results and therefore remain inconclusive. Therefore, updating this meta-analysis and stratified pooling of these data might elucidate the association between environmental smoking and bladder cancer risk further. 


\section{SMOKING AND BLADDER CANCER PROGNOSIS}

Fewer studies have been performed investigating smoking behaviour in relation to bladder cancer prognosis. Most prognostic studies do not focus on the effect of smoking behaviour, for example cessation, after diagnosis on bladder cancer prognosis, but take lifetime smoking into account as a confounding factor in prognosis. However, the number of studies reporting hazard ratios (HRs) for smoking categories in bladder cancer prognosis has increased and the body of evidence suggesting a role of smoking status at diagnosis in prognosis is growing, especially in NMIBC $[8,71]$. Studies on bladder cancer prognosis focus mainly on three endpoints: a) bladder cancer recurrence, defined as a new episode of bladder cancer within the same disease stage, b) bladder cancer progression: when bladder cancer recurs as muscle-invasive after a primary non-muscle-invasive tumour and c) disease-specific survival, measured in death due to bladder cancer. Since the known large differences in prognosis, studies should always make the division between non-muscleinvasive and muscle-invasive disease because of their large differences in prognosis $[11,40]$.

\section{Smoking and non-muscle-invasive bladder cancer prognosis}

No prospective studies on the association between smoking behaviour and NMIBC prognosis have been performed. However, there is a considerable amount of evidence on the role of smoking behaviour before diagnosis in NMIBC [72-81]. Results from these, mostly retrospective multicentre or large cancer or hospital registries, are reviewed in several systematic reviews $[8,71,82]$ and show that smoking before diagnosis, increases the risk of recurrence in NMIBC patients who are treated by transurethral resection of the bladder tumour. In addition, smoking also seems to increase the risk of progression after transurethral resection, however the evidence is less robust [8]. Although the impact smoking cessation after diagnosis has on bladder cancer recurrence and progression or mortality is not clear yet, there are examples of successful smoking cessation interventions in urology clinics [83] and patients have been shown to be more likely to quit smoking after a diagnosis of bladder cancer $[84,85]$.

\section{Smoking and muscle-invasive bladder cancer prognosis}

All studies until now on smoking behaviour and MIBC prognosis were in patient populations who were treated with radical cystectomy (i.e. removal of the bladder), possibly introducing bias since smokers often have more co-morbid conditions and therefore will likely have been excluded from such surgical cohorts [82]. Two systematic reviews concluded that there is some evidence that smoking behaviour before diagnosis influences MIBC prognosis [8,82]. A large $(n=1,506)$ retrospective studies performed by Rink et al, compared local recurrence and mortality rates in heavy long-term smokers with light short-term smokers. Heavy smokers had higher rates of disease recurrence $(H R=2.22$ 
95\% C.I. $=1.62-3.02)$ and higher bladder cancer mortality rates $(H R=2.0795 \%$ C.I. $=1.44-$ 2.99) compared to light smokers [86]. These results are corroborated by another large study $(n=2,287)$ which observed statistically different $(p=0.006)$ local recurrence rates for smokers (35.5\%) compared to non-smokers (33.0\%) and a risk estimate of 1.30 (95\% C.I. $=1.01-1.69)$ comparing disease-specific survival rates across smokers and non-smokers [87]. However, there are also studies which indicate that the effect of smoking on MIBC recurrence and survival is marginal. Boorjian et al. observed no association between tobacco use and urethral recurrence rate $(H R=0.97$ 95\% C.I. $=0.70-1.35)$ in 1,506 bladder cancer cases [88]. A similar finding was observed by Lee et al. and showed no association between smoking and recurrence free survival $(H R=0.9195 \%$ C.I. $=0.63-1.31)$ and bladder cancer specific survival (HR=0.94 95\% C.I. $=0.64-1.37)$ [89]. Recently, a meta-analysis on smoking status and bladder cancer mortality showed current smokers to be at a 1.53 -fold (95\% CI $=1.12-2.09)$ increased risk of bladder cancer-related death compared to never smokers [90], however the studies included in this analysis contained both NMIBC and MIBC populations. Summarising, it is possible that smoking plays a role in MIBC; however, prospectively gathered data is needed to confirm the earlier observed results from retrospective studies.

\section{Smoking and malignant potential of bladder cancer at diagnosis}

Besides studies on the association between smoking and bladder cancer recurrence or mortality, there are also studies that have investigated how lifetime smoking behaviour could influence the clinical and pathological characteristics of bladder tumours at diagnosis. One case-control study reporting on the effect of smoking on tumour subtypes at diagnosis (low grade NMIBC, high grade NMIBC and MIBC) found that risk estimates for smoking were higher for high grade non-muscle invasive and MIBC compared to low grade NMIBC, indicating that smoking might even stronger increase the risk of more aggressive disease [91]. This hypothesis is further strengthened by results from the Blad-

der Cancer Prognosis Programme which found that current smokers developed larger tumours (mean difference: $0.48 \mathrm{~cm}, 95 \%$ C.I. $=0.04-0.91$ ), showed a higher T stage (mean difference: 0.25 95\% C.I. $=0.08-0.41$ ), developed more high grade tumours (mean difference: $0.1595 \%$ C.I. $=0.00-0.30)$ and were on average 4.0 years younger at diagnosis $(95 \%$ C.I. $=-5.9$ to -2.0$)$ compared to never smokers [92].

\section{AIM AND HYPOTHESIS OF THE THESIS}

The aim of the research presented in this thesis is to more thoroughly investigate the association between smoking behaviour and bladder cancer risk and prognosis, by delving deeper into detailed information rather than only establishing that smoking is a risk 
factor. We hypothesize that i) smoking duration is most important in predicting risk of developing $B C$ and that ii) smoking cessation after diagnosis could potentially improve $\mathrm{BC}$ prognosis.

\section{GENERAL STUDY DESIGN}

More detailed insight into the association between smoking and $\mathrm{BC}$ risk and prognosis is provided through both meta-analysis research and primary research from a prospective cohort study of bladder cancer patients (BCPP) and an international consortium of observational studies investigating bladder cancer risk (BLEND).

\section{The Bladder Cancer Prognosis Programme (BCPP)}

The West Midlands Bladder Cancer Prognosis Programme (BCPP) is one of the largest prospective cohorts of bladder cancer patients worldwide including approximately 1300 NMIBC and MIBC patients at baseline. The study was initiated by the Cancer Research UK Bladder Cancer Group at the University of Birmingham. The Nottingham Multi-Centre Research Ethics Committee gave approval for the study (reference: 06/MRE04/65 and clinicaltrials.gov registration number: NCT00553215). The aims of this multi-centre (10 hospitals) study are to; i) improve knowledge on prognosis by identifying (modifiable) factors that influence recurrence or progression of bladder cancer, ii) to develop a prognostic tool that could better predict these outcomes in patients and iii) to better understand bladder cancer patient behaviour and self-perceived impact of diagnosis and treatment [93].

Individuals who visited one the participating hospitals in the West Midlands between December 2005 and October 2011 with symptoms suspicious of bladder cancer were included. Patients with previous cancer of the urethra, bladder, ureter, or renal pelvis within the last decade were excluded. Inclusion criteria to participate in the BCPP cohort study were being over 18 years of age, able to provide consent and being fit for cystoscopy and/or surgical biopsy/resection. To collect data on information on social-demographic information, dietary intake, smoking behaviour and other health-related lifestyle behaviours, social support and quality of life and medical and supplement usage history, all participants were asked to fill in a semi-structured questionnaire under supervision of a research nurse and Case Report Forms (CRFs) were also collected by research nurses. This was repeated 3 months after diagnosis and hereafter yearly until 5 years after inclusion. Moreover, patients' medical records were continuously examined for 5 years after inclusion to check for recurrence or progression events and information on clinical treatment. After pathological assessment, some of the initially included participants (for whom 
baseline data had already been collected by the research nurses) were not diagnosed with bladder cancer but with other non-malignant disease, such as bladder inflammation, so no follow-up data was collected for these participants. Results from this prospective cohort study are published in Chapter 7.

\section{The BLadder cancer Epidemiology and Nutritional Determinants (BLEND) consortium}

The BLadder cancer Epidemiology and Nutritional Determinants (BLEND) consortium currently consists of 19 case-control studies and 7 cohort studies, including data from the already pooled European prospective investigation into cancer (EPIC). Recruitment for the BLEND consortium is ongoing, but at this point there are 13,306 cases, 21,307 controls and 693,248 cohort members in the BLEND dataset. The aim of pooling these observational studies is to gain more knowledge on the impact of dietary patterns, nutrients and individual food items on bladder cancer risk [94].

Besides data on dietary intake and disease status, BLEND also provides data on smoking behaviour, age, gender, family history of cancer and tumour staging. After receiving datasets from the participating studies, datasets were cleaned and recoded to the same codebook and appended to form the BLEND database. Food items were coded according to the Eurocode 2 Core classification version 99/2, which contains coding for 2,362 food items [95].

The large sample size of this consortium allows for reliable estimation of relatively small effect sizes which are to be expected when investigating the impact of single food items or dietary patterns on (bladder) cancer risk which is the aim of the consortium. Although larger effect sizes are to be expected for smoking, this large sample size also allows for the application of complex statistical models that need sufficient power to yield reliable results as described in Chapter 4. 


\section{OUTLINE OF THE THESIS}

This thesis consists of two parts; the first part describes 4 studies that investigate smoking and bladder cancer risk and the second part described 2 studies looking at the association between smoking and bladder cancer prognosis. First, a large meta-analysis was conducted to investigate smoking behaviour in relation to bladder cancer risk chapter 2. Chapter $\mathbf{3}$ adds to this meta-analysis in summarising evidence on exposure to environmental tobacco smoke and bladder cancer risk, stratified by adult and childhood exposure. In chapter 4, the impact of both smoking duration and intensity on bladder cancer risk was assessed and compared within the BLEND consortium. Chapter $\mathbf{5}$ describes the impact of cigarette content on bladder cancer risk, as investigated in the BCPP cohort in collaboration with the UK department of health. After this, the second part starts with a meta-analysis summarising results from studies investigating smoking status at diagnosis and bladder cancer prognosis is presented in chapter 6. Chapter 7 describes the first study with prospective data (BCPP) on smoking cessation after diagnosis in relation to bladder cancer recurrence. Finally, chapter $\mathbf{8}$ summarises all research done for this thesis by discussing the results in general and come back to the hypotheses formulated in this chapter. 


\section{REFERENCES}

1. Parkin, D. M. 1. The fraction of cancer attributable to lifestyle and environmental factors in the UK in 2010. Br. J. Cancer 2011, 105, S2-S5.

2. CancerResearchUK Bladder cancer incidence rates UK Available online: http://www.cancerresearchuk.org/health-professional/cancer-statistics/statistics-by-cancer-type/bladdercancer/incidence\#theading-Zero (accessed on May 26, 2016).

3. Zeegers, M. P. A.; Tan, F. E. S.; Dorant, E.; van den Brandt, P. A. The impact of characteristics of cigarette smoking on urinary tract cancer risk. Cancer 2000, 89, 630-639, doi:10.1002/10970142(20000801)89:3<630::AID-CNCR19>3.0.CO;2-Q.

4. Antoni, S.; Ferlay, J.; Soerjomataram, I.; Znaor, A.; Jemal, A.; Bray, F. Bladder Cancer Incidence and Mortality: A Global Overview and Recent Trends. Eur. Urol. 2017, 71, 96-108, doi:10.1016/j.eururo.2016.06.010.

5. Burger, M.; Catto, J. W. F. F.; Dalbagni, G.; Grossman, H. B.; Herr, H.; Karakiewicz, P.; Kassouf, W.; Kiemeney, L. A.; La Vecchia, C.; Shariat, S.; Lotan, Y. Epidemiology and risk factors of urothelial bladder cancer. Eur. Urol. 2013, 63, 234-41, doi:10.1016/j.eururo.2012.07.033.

6. Guzzo, T. J.; Hockenberry, M. S.; Mucksavage, P.; Bivalacqua, T. J.; Schoenberg, M. P. Smoking Knowledge Assessment and Cessation Trends in Patients With Bladder Cancer Presenting to a Tertiary Referral Center. Urology 2012, 79, 166-171, doi:10.1016/j.urology.2011.06.055.

7. Westhoff, E.; Maria de Oliveira-Neumayer, J.; Aben, K. K.; Vrieling, A.; Kiemeney, L. A. Low awareness of risk factors among bladder cancer survivors: New evidence and a literature overview. Eur. J. Cancer 2016, 60, 136-145, doi:10.1016/j.ejca.2016.03.071.

8. Crivelli, J. J.; Xylinas, E.; Kluth, L. A.; Rieken, M.; Rink, M.; Shariat, S. F. Effect of Smoking on Outcomes of Urothelial Carcinoma: A Systematic Review of the Literature. Eur. Urol. 2014, 65, 742-754, doi:10.1016/j.eururo.2013.06.010.

9. Lee, P. N.; Thornton, A. J.; Hamling, J. S.; Lee, P. N. Epidemiological evidence on environmental tobacco smoke and cancers other than lung or breast. Regul. Toxicol. Pharmacol. 2016, 80, 134-163, doi:10.1016/j.yrtph.2016.06.012.

10. Taylor, R.; Najafi, F.; Dobson, A. Meta-analysis of studies of passive smoking and lung cancer: effects of study type and continent. Int. J. Epidemiol. 2007, 36, 1048-1059, doi:10.1093/ije/ dym158.

11. Babjuk, M.; Böhle, A.; Burger, M.; Capoun, O.; Cohen, D.; Compérat, E. M.; Hernández, V.; Kaasinen, E.; Palou, J.; Rouprêt, M.; van Rhijn, B. W. G.; Shariat, S. F.; Soukup, V.; Sylvester, R. J.; Zigeuner, R. EAU Guidelines on Non-Muscle-invasive Urothelial Carcinoma of the Bladder: Update 2016; 2017; Vol. 71;.

12. Roychowdhury, D. F.; Hayden, A.; Liepa, A. M. Health-related quality-of-life parameters as independent prognostic factors in advanced or metastatic bladder cancer. J. Clin. Oncol. 2003, 21, 673-678.

13. Sievert, K. D.; Amend, B.; Nagele, U.; Schilling, D.; Bedke, J.; Horstmann, M.; Hennenlotter, J.; Kruck, S.; Stenzl, A. Economic aspects of bladder cancer: what are the benefits and costs? World J. Urol. 2009, 27, 295-300.

14. Health at a Glance 2017; Health at a Glance; OECD Publishing, 2017; ISBN 9789264280397.

15. Hall, M. C.; Womack, S.; Sagalowsky, A. I.; Carmody, T.; Erickstad, M. D.; Roehrborn, C. G. Prognostic factors, recurrence, and survival in transitional cell carcinoma of the upper urinary tract: a 30-year experience in 252 patients. Urology 1998, 52, 594-601, doi:10.1016/ S0090-4295(98)00295-7. 
16. Matsui, Y.; Utsunomiya, N.; Ichioka, K.; Urology, N. U.-; 2005, undefined Risk factors for subsequent development of bladder cancer after primary transitional cell carcinoma of the upper urinary tract. Elsevier.

17. Reitsma, M. B.; Fullman, N.; Ng, M.; Salama, J. S.; Abajobir, A.; Abate, K. H.; Abbafati, C.; Abera, S. F.; Abraham, B.; Abyu, G. Y.; Adebiyi, A. O.; Al-Aly, Z.; Aleman, A. V; Ali, R.; Al Alkerwi, A.; Allebeck, P.; Al-Raddadi, R. M.; Amare, A. T.; Amberbir, A.; Ammar, W.; Amrock, S. M.; Antonio, C. A. T.; Asayesh, H.; Atnafu, N. T.; Azzopardi, P.; Banerjee, A.; Barac, A.; BarrientosGutierrez, T.; Basto-Abreu, A. C.; Bazargan-Hejazi, S.; Bedi, N.; Bell, B.; Bello, A. K.; Bensenor, I. M.; Beyene, A. S.; Bhala, N.; Biryukov, S.; Bolt, K.; Brenner, H.; Butt, Z.; Cavalleri, F.; Cercy, K.; Chen, H.; Christopher, D. J.; Ciobanu, L. G.; Colistro, V.; Colomar, M.; Cornaby, L.; Dai, X.; Damtew, S. A.; Dandona, L.; Dandona, R.; Dansereau, E.; Davletov, K.; Dayama, A.; Degfie, T. T.; Deribew, A.; Dharmaratne, S. D.; Dimtsu, B. D.; Doyle, K. E.; Endries, A. Y.; Ermakov, S. P.; Estep, K.; Faraon, E. J. A.; Farzadfar, F.; Feigin, V. L.; Feigl, A. B.; Fischer, F.; Friedman, J.; G/ hiwot, T. T.; Gall, S. L.; Gao, W.; Gillum, R. F.; Gold, A. L.; Gopalani, S. V.; Gotay, C. C.; Gupta, R. R.; Gupta, R. R.; Gupta, V.; Hamadeh, R. R.; Hankey, G.; Harb, H. L.; Hay, S. I.; Horino, M.; Horita, N.; Hosgood, H. D.; Husseini, A.; Ileanu, B. V.; Islami, F.; Jiang, G.; Jiang, Y.; Jonas, J. B.; Kabir, Z.; Kamal, R.; Kasaeian, A.; Kesavachandran, C. N.; Khader, Y. S.; Khalil, I.; Khang, Y.-H.; Khera, S.; Khubchandani, J.; Kim, D.; Kim, Y. J.; Kimokoti, R. W.; Kinfu, Y.; Knibbs, L. D.; Kokubo, Y.; Kolte, D.; Kopec, J.; Kosen, S.; Kotsakis, G. A.; Koul, P. A.; Koyanagi, A.; Krohn, K. J.; Krueger, H.; Defo, B. K.; Bicer, B. K.; Kulkarni, C.; Kumar, G. A.; Leasher, J. L.; Lee, A.; Leinsalu, M.; Li, T.; Linn, S.; Liu, P.; Liu, S.; Lo, L.-T.; Lopez, A. D.; Ma, S.; El Razek, H. M. A.; Majeed, A.; Malekzadeh, R.; Malta, D. C.; Manamo, W. A.; Martinez-Raga, J.; Mekonnen, A. B.; Mendoza, W.; Miller, T. R.; Mohammad, K. A.; Morawska, L.; Musa, K. I.; Nagel, G.; Neupane, S. P.; Nguyen, Q.; Nguyen, G.; Oh, I.-H.; Oyekale, A. S.; PA, M.; Pana, A.; Park, E.-K.; Patil, S. T.; Patton, G. C.; Pedro, J.; Qorbani, M.; Rafay, A.; Rahman, M.; Rai, R. K.; Ram, U.; Ranabhat, C. L.; Refaat, A. H.; Reinig, N.; Roba, H. S.; Rodriguez, A.; Roman, Y.; Roth, G.; Roy, A.; Sagar, R.; Salomon, J. A.; Sanabria, J.; de Souza Santos, I.; Sartorius, B.; Satpathy, M.; Sawhney, M.; Sawyer, S.; Saylan, M.; Schaub, M. P.; Schluger, N.; Schutte, A. E.; Sepanlou, S. G.; Serdar, B.; Shaikh, M. A.; She, J.; Shin, M.-J.; Shiri, R.; Shishani, K.; Shiue, I.; Sigfusdottir, I. D.; Silverberg, J. I.; Singh, J.; Singh, V.; Slepak, E. L.; Soneji, S.; Soriano, J. B.; Soshnikov, S.; Sreeramareddy, C. T.; Stein, D. J.; Stranges, S.; Subart, M. L.; Swaminathan, S.; Szoeke, C. E. I.; Tefera, W. M.; Topor-Madry, R.; Tran, B.; Tsilimparis, N.; Tymeson, H.; Ukwaja, K. N.; Updike, R.; Uthman, O. A.; Violante, F. S.; Vladimirov, S. K.; Vlassov, V.; Vollset, S. E.; Vos, T.; Weiderpass, E.; Wen, C.-P.; Werdecker, A.; Wilson, S.; Wubshet, M.; Xiao, L.; Yakob, B.; Yano, Y.; Ye, P.; Yonemoto, N.; Yoon, S.-J.; Younis, M. Z.; Yu, C.; Zaidi, Z.; El Sayed Zaki, M.; Zhang, A. L.; Zipkin, B.; Murray, C. J. L.; Forouzanfar, M. H.; Gakidou, E. Smoking prevalence and attributable disease burden in 195 countries and territories, 1990-2015: a systematic analysis from the Global Burden of Disease Study 2015. Lancet 2017, 389, 1885-1906, doi:10.1016/S0140-6736(17)30819-X.

18. Bryan, R. T.; Zeegers, M. P.; van Roekel, E. H.; Bird, D.; Grant, M. R.; Dunn, J. A.; Bathers, S.; Iqbal, G.; Khan, H. S.; Collins, S. I.; Howman, A.; Deshmukh, N. S.; James, N. D.; Cheng, K. K.; Wallace, D. M. A. A comparison of patient and tumour characteristics in two UK bladder cancer cohorts separated by 20 years. BJU Int. 2013, 112, 169-175, doi:10.1111/bju.12032.

19. Bladder Cancer: Introduction | Cancer.Net Available online: https://www.cancer.net/cancertypes/bladder-cancer/introduction (accessed on Jul 6, 2018).

20. Knowles, M. A.; Hurst, C. D. Molecular biology of bladder cancer: new insights into pathogenesis and clinical diversity. Nat. Publ. Gr. 2015, 15, doi:10.1038/nrc3817. 
21. Dinney, C. P. N.; McConkey, D. J.; Millikan, R. E.; Wu, X.; Bar-Eli, M.; Adam, L.; Kamat, A. M.; Siefker-Radtke, A. O.; Tuziak, T.; Sabichi, A. L.; Grossman, H. B.; Benedict, W. F.; Czerniak, B. Focus on bladder cancer. Cancer Cell 2004, 6, 111-6, doi:10.1016/j.ccr.2004.08.002.

22. McConkey, D. J.; Lee, S.; Choi, W.; Tran, M.; Majewski, T.; Lee, S.; Siefker-Radtke, A.; Dinney, C.; Czerniak, B. Molecular genetics of bladder cancer: Emerging mechanisms of tumor initiation and progression. Urol. Oncol. 2010, 28, 429-40, doi:10.1016/j.urolonc.2010.04.008.

23. Simon, R.; Eltze, E.; Schäfer, K. L.; Bürger, H.; Semjonow, A.; Hertle, L.; Dockhorn-Dworniczak, B.; Terpe, H. J.; Böcker, W. Cytogenetic analysis of multifocal bladder cancer supports a monoclonal origin and intraepithelial spread of tumor cells. Cancer Res. 2001, 61, 355-62.

24. Jones, T. D.; Wang, M.; Eble, J. N.; MacLennan, G. T.; Lopez-Beltran, A.; Zhang, S.; Cocco, A.; Cheng, L. Molecular evidence supporting field effect in urothelial carcinogenesis. Clin. Cancer Res. 2005, 11, 6512-9, doi:10.1158/1078-0432.CCR-05-0891.

25. Lee, S.; Jeong, J.; Majewski, T.; Scherer, S. E.; Kim, M.-S.; Tuziak, T.; Tang, K. S.; Baggerly, K.; Grossman, H. B.; Zhou, J.-H.; Shen, L.; Bondaruk, J.; Ahmed, S. S.; Samanta, S.; Spiess, P.; Wu, X.; Filipek, S.; McConkey, D.; Bar-Eli, M.; Issa, J.-P.; Benedict, W. F.; Czerniak, B. Forerunner genes contiguous to RB1 contribute to the development of in situ neoplasia. Proc. Natl. Acad. Sci. U. S. A. 2007, 104, 13732-7, doi:10.1073/pnas.0701771104.

26. van Rhijn, B. W. G.; Burger, M.; Lotan, Y.; Solsona, E.; Stief, C. G.; Sylvester, R. J.; Witjes, J. A.; Zlotta, A. R. Recurrence and Progression of Disease in Non-Muscle-Invasive Bladder Cancer: From Epidemiology to Treatment Strategy. Eur. Urol. 2009, 56, 430-442, doi:10.1016/J. EURURO.2009.06.028.

27. Choi, W.; Porten, S.; Kim, S.; Willis, D.; Plimack, E. R.; Hoffman-Censits, J.; Roth, B.; Cheng, T.; Tran, M.; Lee, I.-L.; Melquist, J.; Bondaruk, J.; Majewski, T.; Zhang, S.; Pretzsch, S.; Baggerly, K.; Siefker-Radtke, A.; Czerniak, B.; Dinney, C. P. N.; McConkey, D. J. Identification of distinct basal and luminal subtypes of muscle-invasive bladder cancer with different sensitivities to frontline chemotherapy. Cancer Cell 2014, 25, 152-65, doi:10.1016/j.ccr.2014.01.009.

28. Dadhania, V.; Zhang, M.; Zhang, L.; Bondaruk, J.; Majewski, T.; Siefker-Radtke, A.; Guo, C. C.; Dinney, C.; Cogdell, D. E.; Zhang, S.; Lee, S.; Lee, J. G.; Weinstein, J. N.; Baggerly, K.; McConkey, D.; Czerniak, B. Meta-Analysis of the Luminal and Basal Subtypes of Bladder Cancer and the Identification of Signature Immunohistochemical Markers for Clinical Use. EBioMedicine 2016, 12, 105-117, doi:10.1016/J.EBIOM.2016.08.036.

29. Choi, W.; Ochoa, A.; McConkey, D. J.; Aine, M.; Höglund, M.; Kim, W. Y.; Real, F. X.; Kiltie, A. E.; Milsom, I.; Dyrskjøt, L.; Lerner, S. P. Genetic Alterations in the Molecular Subtypes of Bladder Cancer: Illustration in the Cancer Genome Atlas Dataset. Eur. Urol. 2017, 72, 354-365, doi:10.1016/j.eururo.2017.03.010.

30. Sjodahl, G.; Lauss, M.; Lovgren, K.; Chebil, G.; Gudjonsson, S.; Veerla, S.; Patschan, O.; Aine, M.; Ferno, M.; Ringner, M.; Mansson, W.; Liedberg, F.; Lindgren, D.; Hoglund, M. A Molecular Taxonomy for Urothelial Carcinoma. Clin. Cancer Res. 2012, 18, 3377-3386, doi:10.1158/1078-0432.CCR-12-0077-T.

31. Marzouka, N.-A.-D.; Eriksson, P.; Rovira, C.; Liedberg, F.; Sjödahl, G.; Höglund, M. A validation and extended description of the Lund taxonomy for urothelial carcinoma using the TCGA cohort. Sci. Rep. 2018, 8, 3737, doi:10.1038/s41598-018-22126-x.

32. Clayson, D. B. A working hypothesis for the mode of carcinogenesis of aromatic amines. Br. J. Cancer 1953, 7, 460-71.

33. Case, R. A.; Hosker, M. E.; McDonald, D. B.; Pearson, J. T. Tumours of the urinary bladder in workmen engaged in the manufacture and use of certain dyestuff intermediates in the 
British chemical industry. I. The role of aniline, benzidine, alpha-naphthylamine, and betanaphthylamine. Br. J. Ind. Med. 1954, 11, 75-104.

34. Kirkali, Z.; Chan, T.; Manoharan, M.; Algaba, F.; Busch, C.; Cheng, L.; Kiemeney, L.; Kriegmair, M.; Montironi, R.; Murphy, W. M.; Sesterhenn, I. A.; Tachibana, M.; Weider, J. Bladder cancer: epidemiology, staging and grading, and diagnosis., doi:10.1016/j.urology.2005.07.062.

35. Vineis, P. Epidemiological models of carcinogenesis: the example of bladder cancer. Cancer Epidemiol. Biomarkers Prev. 1992, 1, 149-53.

36. Yu, M. C.; Skipper, P. L.; Tannenbaum, S. R.; Chan, K. K.; Ross, R. K. Arylamine exposures and bladder cancer risk. Mutat. Res. Mol. Mech. Mutagen. 2002, 506-507, 21-28, doi:10.1016/ S0027-5107(02)00148-3.

37. Ketelslegers, H. B.; Godschalk, R. W.; Eskens, B. J.; Dallinga, J. W.; Gottschalk, R. W. H.; van Schooten, F. J.; van Delft, J. H. M.; Kleinjans, J. C. S. Potential role of cytochrome P450-1B1 in the metabolic activation of 4-aminobiphenyl in humans. Mol. Carcinog. 2009, 48, 685-691, doi:10.1002/mc.20530.

38. Dallinga, J. W.; Pachen, D. M.; Wijnhoven, S. W.; Breedijk, A.; van 't Veer, L.; Wigbout, G.; van Zandwijk, N.; Maas, L. M.; van Agen, E.; Kleinjans, J. C.; van Schooten, F. J. The use of 4-aminobiphenyl hemoglobin adducts and aromatic DNA adducts in lymphocytes of smokers as biomarkers of exposure. Cancer Epidemiol. Biomarkers Prev. 1998, 7, 571-7.

39. Vineis, P.; Marinelli, D.; Autrup, H.; Brockmoller, J.; Cascorbi, I.; Daly, A. K.; Golka, K.; Okkels, H.; Risch, A.; Rothman, N.; Sim, E.; Taioli, E. Current smoking, occupation, N-acetyltransferase-2 and bladder cancer: a pooled analysis of genotype-based studies. Cancer Epidemiol. Biomarkers Prev. 2001, 10, 1249-52.

40. Witjes, J. A.; Compérat, E.; Cowan, N. C.; De Santis, M.; Gakis, G.; Lebret, T.; Ribal, M. J.; Van der Heijden, A. G.; Sherif, A. EAU guidelines on muscle-invasive and metastatic bladder cancer: summary of the 2013 guidelines. Eur. Urol. 2014, 65, 778-792, doi:10.1016/j. eururo.2013.11.046.

41. Wallace, D. M. A.; Bryan, R. T.; Dunn, J. A.; Begum, G.; Bathers, S.; on behalf of the West Midlands Urological Research, G. Delay and survival in bladder cancer. BJU Int. 2002, 89, 868-878, doi:10.1046/j.1464-410X.2002.02776.x.

42. Gephardt, G. N.; Baker, P. B. Interinstitutional comparison of bladder carcinoma surgical pathology report adequacy. A College of American Pathologists Q-Probes Study of 7234 bladder biopsies and curettings in 268 institutions. Arch. Pathol. Lab. Med. 1995, 119, 681-685.

43. Brierley, J.; Gospodarowicz, M. K. (Mary K. ; Wittekind, C. (Christian) TNM classification of malignant tumours; ISBN 9781119263579.

44. World Health Organization 2018/19 ICD-10-CM Codes C67*: Malignant neoplasm of bladder Available online: https://www.icd10data.com/ICD10CM/Codes/C00-D49/C64-C68/ C67- (accessed on Oct 3, 2018).

45. Bryan, R. T. Update on bladder cancer diagnosis and management. Trends Urol. Men's Heal. 2013, 4, 7-11.

46. Hedegaard, J.; Lamy, P.; Nordentoft, I.; Algaba, F.; Høyer, S.; Ulhøi, B. P.; Vang, S.; Reinert, T.; Hermann, G. G.; Mogensen, K.; Thomsen, M. B. H.; Nielsen, M. M.; Marquez, M.; Segersten, U.; Aine, M.; Höglund, M.; Birkenkamp-Demtröder, K.; Fristrup, N.; Borre, M.; Hartmann, A.; Stöhr, R.; Wach, S.; Keck, B.; Seitz, A. K.; Nawroth, R.; Maurer, T.; Tulic, C.; Simic, T.; Junker, K.; Horstmann, M.; Harving, N.; Petersen, A. C.; Calle, M. L.; Steyerberg, E. W.; Beukers, W.; van Kessel, K. E. M.; Jensen, J. B.; Pedersen, J. S.; Malmström, P.-U.; Malats, N.; Real, F. X.; 
Zwarthoff, E. C.; Ørntoft, T. F.; Dyrskjøt, L. Comprehensive Transcriptional Analysis of EarlyStage Urothelial Carcinoma. Cancer Cell 2016, 30, 27-42, doi:10.1016/j.ccell.2016.05.004.

47. Fairey, A. S.; Kassouf, W.; Aprikian, A. G.; Chin, J. L.; Izawa, J. I.; Fradet, Y.; Lacombe, L.; Rendon, R. A.; Bell, D.; Cagiannos, I. Age $\geq 80$ years is independently associated with survival outcomes after radical cystectomy: Results from the Canadian Bladder Cancer Network Database. In Urologic Oncology: Seminars and Original Investigations; Elsevier, 2012; Vol. 30, pp. 825-832.

48. James, N. D.; Hussain, S. A.; Hall, E.; Jenkins, P.; Tremlett, J.; Rawlings, C.; Crundwell, M.; Sizer, B.; Sreenivasan, T.; Hendron, C. Radiotherapy with or without chemotherapy in muscleinvasive bladder cancer. N. Engl. J. Med. 2012, 366, 1477-1488.

49. Department of Health, U.; Services, H. The Health Consequences of Smoking - 50 Years of Progress: A Report of the Surgeon General;

50. Pitard, A.; Brennan, P.; Clavel, J.; Greiser, E.; Lopez-Abente, G.; Chang-Claude, J.; Wahrendorf, J.; Serra, C.; Kogevinas, M.; Boffetta, P. Cigar, pipe, and cigarette smoking and bladder cancer risk in European men. Cancer Causes Control 2001, 12, 551-6.

51. Brennan, P.; Bogillot, O.; Cordier, S.; Greiser, E.; Schill, W.; Vineis, P.; Lopez-Abente, G.; Tzonou, A.; Chang-Claude, J.; Bolm-Audorff, U.; Jöckel, K.-H.; Donato, F.; Serra, C.; Wahrendorf, J.; Hours, M.; T'Mannetje, A.; Kogevinas, M.; Boffetta, P. Cigarette smoking and bladder cancer in men: A pooled analysis of 11 case-control studies. Int. J. Cancer 2000, 86, 289-294, doi:10.1002/(SICI)1097-0215(20000415)86:2<289::AID-IJC21>3.0.CO;2-M.

52. Doll, R.; Peto, R.; Boreham, J.; Sutherland, I. Mortality in relation to smoking: 50 years' observations on male British doctors., doi:10.1136/bmj.38142.554479.AE.

53. Peto, J. That the effects of smoking should be measured in pack-years: misconceptions 4 . Br. J. Cancer 2012, 107, 406-407, doi:10.1038/bjc.2012.97.

54. Lubin, J. H.; Caporaso, N. E. Misunderstandings in the misconception on the use of packyears in analysis of smoking. Br. J. Cancer 2013, 108, 1218-20, doi:10.1038/bjc.2013.76.

55. Lubin, J. H.; Caporaso, N. E. Cigarette smoking and lung cancer: modeling total exposure and intensity. Cancer Epidemiol. Biomarkers Prev. 2006, 15, 517-23, doi:10.1158/1055-9965. EPI-05-0863.

56. Lubin, J. H.; Purdue, M.; Kelsey, K.; Zhang, Z.-F.; Winn, D.; Wei, Q.; Talamini, R.; SzeszeniaDabrowska, N.; Sturgis, E. M.; Smith, E.; Shangina, O.; Schwartz, S. M.; Rudnai, P.; Neto, J. E.; Muscat, J.; Morgenstern, H.; Menezes, A.; Matos, E.; Mates, I. N.; Lissowska, J.; Levi, F.; Lazarus, P.; Vecchia, C. L.; Koifman, S.; Herrero, R.; Franceschi, S.; Wunsch-Filho, V.; Fernandez, L.; Fabianova, E.; Daudt, A. W.; Maso, L. D.; Curado, M. P.; Chen, C.; Castellsague, X.; Brennan, P.; Boffetta, P.; Hashibe, M.; Hayes, R. B. Total Exposure and Exposure Rate Effects for Alcohol and Smoking and Risk of Head and Neck Cancer: A Pooled Analysis of Case-Control Studies. Am. J. Epidemiol. 2009, 170, 937-947, doi:10.1093/aje/kwp222.

57. Vlaanderen, J.; Portengen, L.; Schüz, J.; Olsson, A.; Pesch, B.; Kendzia, B.; Stücker, I.; Guida, F.; Brüske, I.; Wichmann, H.-E.; Consonni, D.; Landi, M. T.; Caporaso, N.; Siemiatycki, J.; Merletti, F.; Mirabelli, D.; Richiardi, L.; Gustavsson, P.; Plato, N.; Jöckel, K.-H.; Ahrens, W.; Pohlabeln, H.; Tardón, A.; Zaridze, D.; Field, J. K.; 't Mannetje, A.; Pearce, N.; McLaughlin, J.; Demers, P.; Szeszenia-Dabrowska, N.; Lissowska, J.; Rudnai, P.; Fabianova, E.; Stanescu Dumitru, R.; Bencko, V.; Foretova, L.; Janout, V.; Boffetta, P.; Forastiere, F.; Bueno-de-Mesquita, B.; Peters, S.; Brüning, T.; Kromhout, H.; Straif, K.; Vermeulen, R. Effect Modification of the Association of Cumulative Exposure and Cancer Risk by Intensity of Exposure and Time Since Exposure 
Cessation: A Flexible Method Applied to Cigarette Smoking and Lung Cancer in the SYNERGY Study. Am. J. Epidemiol. 2014, 179, 290-298, doi:10.1093/aje/kwt273.

58. Lubin, J. H.; Kogevinas, M.; Silverman, D.; Malats, N.; Garcia-Closas, M.; Tardón, A.; Hein, D. W.; Garcia-Closas, R.; Serra, C.; Dosemeci, M.; Carrato, A.; Rothman, N. Evidence for an intensity-dependent interaction of NAT2 acetylation genotype and cigarette smoking in the Spanish Bladder Cancer Study. Int. J. Epidemiol. 2007, 36, 236-241, doi:10.1093/ije/dym043.

59. Baris, D.; Karagas, M. R.; Verrill, C.; Johnson, A.; Andrew, A. S.; Marsit, C. J.; Schwenn, M.; Colt, J. S.; Cherala, S.; Samanic, C.; Waddell, R.; Cantor, K. P.; Schned, A.; Rothman, N.; Lubin, J.; Fraumeni, J. F.; Hoover, R. N.; Kelsey, K. T.; Silverman, D. T. A case-control study of smoking and bladder cancer risk: emergent patterns over time. J. Natl. Cancer Inst. 2009, 101, 1553-61, doi:10.1093/jnci/djp361.

60. Polesel, J.; Bosetti, C.; di Maso, M.; Montella, M.; Libra, M.; Garbeglio, A.; Zucchetto, A.; Turati, F.; Talamini, R.; La Vecchia, C.; Serraino, D. Duration and intensity of tobacco smoking and the risk of papillary and non-papillary transitional cell carcinoma of the bladder. Cancer Causes Control 2014, 25, 1151-1158, doi:10.1007/s10552-014-0416-0.

61. Freedman, N. D.; Silverman, D. T.; Hollenbeck, A. R.; Schatzkin, A.; Abnet, C. C. Association Between Smoking and Risk of Bladder Cancer Among Men and Women. JAMA 2011, 306, 737, doi:10.1001/jama.2011.1142.

62. Howe, G. R.; Burch, J. D.; Miller, A. B.; Cook, G. M.; Esteve, J.; Morrison, B.; Gordon, P.; Chambers, L. W.; Fodor, G.; Winsor, G. M. Tobacco Use, Occupation, Coffee, Various Nutrients, and Bladder Cancer. J Natl Cancer Inst 1980, 64, 701-713, doi:10.1093/jnci/64.4.701.

63. Vineis, P.; Estève, J.; Terracini, B. Bladder cancer and smoking in males: Types of cigarettes, age at start, effect of stopping and interaction with occupation. Int. J. Cancer 1984, 34, 165-170, doi:10.1002/ijc.2910340205.

64. Clavel, J.; Cordier, S.; Boccon-Gibod, L.; Hemon, D. Tobacco and bladder cancer in males: Increased risk for inhalers and smokers of black tobacco. Int. J. Cancer 1989, 44, 605-610, doi:10.1002/ijc.2910440408.

65. Garcia-Closas, M.; Malats, N. N.; Silverman, D.; Dosemeci, M.; Kogevinas, M.; Hein, D. W.; Tard??n, A.; Serra, C.; Carrato, A.; Garc??a-Closas, R.; Lloreta, J.; Casta??o-Vinyals, G.; Yeager, M.; Welch, R.; Chanock, S.; Chatterjee, N.; Wacholder, S.; Samanic, C.; Tor??, M.; Fern??ndez, F.; Real, F. X.; Rothman, N.; García-Closas, M.; Malats, N. N.; Silverman, D.; Dosemeci, M.; Kogevinas, M.; Hein, D. W.; Tardón, A.; Serra, C.; Carrato, A.; García-Closas, R.; Lloreta, J.; Castaño-Vinyals, G.; Yeager, M.; Welch, R.; Chanock, S.; Chatterjee, N.; Wacholder, S.; Samanic, C.; Torà, M.; Fernández, F.; Real, F. X.; Rothman, N. NAT2 slow acetylation, GSTM1 null genotype, and risk of bladder cancer: Results from the Spanish Bladder Cancer Study and meta-analyses. Lancet (London, England) 2005, 366, 649-659, doi:10.1016/S01406736(05)67137-1.

66. Zeegers, M. P. A.; Goldbohm, R. A.; van den Brandt, P. A. A prospective study on active and environmental tobacco smoking and bladder cancer risk (The Netherlands). Cancer Causes Control 2002, 13, 83-90.

67. Castelao, J. E.; Yuan, J.-M.; Skipper, P. L.; Tannenbaum, S. R.; Gago-Dominguez, M.; Crowder, J. S.; Ross, R. K.; Mimi, C. Y. Gender-and smoking-related bladder cancer risk. J. Natl. Cancer Inst. 2001, 93, 538-545.

68. Vineis, P.; Alavanja, M.; Buffler, P.; Fontham, E.; Franceschi, S.; Gao, Y.-T.; Gupta, P. C.; Hackshaw, A.; Matos, E.; Samet, J. Tobacco and cancer: recent epidemiological evidence. J. Natl. Cancer Inst. 2004, 96, 99-106. 
69. Zeegers, M. P. A.; Kellen, E.; Buntinx, F.; van den Brandt, P. A. The association between smoking, beverage consumption, diet and bladder cancer: a systematic literature review. World J. Urol. 2004, 21, 392-401, doi:10.1007/s00345-003-0382-8.

70. Burch, J. D.; Rohan, T. E.; Howe, G. R.; Risch, H. A.; Hill, G. B.; Steele, R.; Miller, A. B. Risk of bladder cancer by source and type of tobacco exposure: a case-control study. Int. J. cancer $1989,44,622-8$.

71. Simonis, K.; Shariat, S. F.; Rink, M. Smoking and smoking cessation effects on oncological outcomes in nonmuscle invasive bladder cancer. Curr. Opin. Urol. 2014, 24, 492-499.

72. Rink, M.; Xylinas, E.; Babjuk, M.; Hansen, J.; Pycha, A.; Comploj, E.; Lotan, Y.; Sun, M.; Karakiewicz, P. I.; Abdennabi, J.; Fajkovic, H.; Loidl, W.; Chun, F. K.; Fisch, M.; Scherr, D. S.; Shariat, S. F. Impact of smoking on outcomes of patients with a history of recurrent nonmuscle invasive bladder cancer. J. Urol. 2012, 188, 2120-7, doi:10.1016/j.juro.2012.08.029.

73. Rink, M.; Furberg, H.; Zabor, E. C.; Xylinas, E.; Babjuk, M.; Pycha, A.; Lotan, Y.; Karakiewicz, P. I.; Novara, G.; Robinson, B. D.; Montorsi, F.; Chun, F. K.; Scherr, D. S.; Shariat, S. F. Impact of Smoking and Smoking Cessation on Oncologic Outcomes in Primary Non-muscle-invasive Bladder Cancer. Eur. Urol. 2013, 63, 724-732, doi:10.1016/j.eururo.2012.08.025.

74. Allard, P.; Fradet, Y.; Têtu, B.; Bernard, P. Tumor-associated antigens as prognostic factors for recurrence in 382 patients with primary transitional cell carcinoma of the bladder. Clin. Cancer Res. 1995, 1, 1195-202.

75. Lammers, R. J. M.; Witjes, W. P. J.; Hendricksen, K.; Caris, C. T. M.; Janzing-Pastors, M. H. C.; Witjes, J. A. Smoking Status Is a Risk Factor for Recurrence After Transurethral Resection of Non-Muscle-Invasive Bladder Cancer. Eur. Urol. 2011, 60, 713-720, doi:10.1016/j. eururo.2011.07.010.

76. Mitra, A. P.; Castelao, J. E.; Hawes, D.; Tsao-Wei, D. D.; Jiang, X.; Shi, S.-R.; Datar, R. H.; Skinner, E. C.; Stein, J. P.; Groshen, S.; Yu, M. C.; Ross, R. K.; Skinner, D. G.; Cortessis, V. K.; Cote, R. J. Combination of molecular alterations and smoking intensity predicts bladder cancer outcome. Cancer 2013, 119, 756-765, doi:10.1002/cncr.27763.

77. Serretta, V.; Altieri, V.; Morgia, G.; Di Lallo, A.; Carrieri, G.; Allegro, R.; Gruppo Studi Tumori Urologici (GSTU) Foundation Cigarette smoking status at diagnosis and recurrence in intermediate-risk non-muscle-invasive bladder carcinoma. Urology 2013, 81, 277-81, doi:10.1016/j.urology.2012.09.040.

78. Fleshner, N.; Garland, J.; Moadel, A.; Herr, H.; Ostroff, J.; Trambert, R.; O 'sullivan, M.; Russo, P. Influence of Smoking Status on the Disease-Related Outcomes of Patients with TobaccoAssociated Superficial Transitional Cell Carcinoma of the Bladder. 1998.

79. Grotenhuis, A. J.; Ebben, C. W.; Aben, K. K.; Witjes, J. A.; Vrieling, A.; Vermeulen, S. H.; Kiemeney, L. A. The effect of smoking and timing of smoking cessation on clinical outcome in non-muscle-invasive bladder cancer. Urol. Oncol. Semin. Orig. Investig. 2015, 33, 65.e965.e17, doi:10.1016/j.urolonc.2014.06.002.

80. Segal, R.; Yafi, F. A.; Brimo, F.; Tanguay, S.; Aprikian, A.; Kassouf, W. Prognostic factors and outcome in patients with $\mathrm{T} 1$ high-grade bladder cancer: can we identify patients for early cystectomy? BJU Int. 2012, 109, 1026-1030, doi:10.1111/j.1464-410X.2011.10462.x.

81. Sfakianos, J. P.; Shariat, S. F.; Favaretto, R. L.; Rioja, J.; Herr, H. W. Impact of smoking on outcomes after intravesical bacillus Calmette-Guérin therapy for urothelial carcinoma not invading muscle of the bladder. BJU Int. 2011, 108, 526-530, doi:10.1111/j.1464410X.2010.09874.x. 
82. Pietzak, E. J.; Malkowicz, S. B. Does quantification of smoking history correlate with initial bladder tumor grade and stage? Curr. Urol. Rep. 2014, 15, 416, doi:10.1007/s11934-0140416-3.

83. Bjurlin, M. A.; Cohn, M. R.; Kim, D. Y.; Freeman, V. L.; Lombardo, L.; Hurley, S. D.; Hollowell, C. M. P. Brief Smoking Cessation Intervention: A Prospective Trial in the Urology Setting. J. Urol. 2013, 189, 1843-1849, doi:10.1016/j.juro.2012.11.075.

84. Bassett, J. C.; Gore, J. L.; Chi, A. C.; Kwan, L.; McCarthy, W.; Chamie, K.; Saigal, C. S. Impact of a bladder cancer diagnosis on smoking behavior. J. Clin. Oncol. 2012, 30, 1871-8, doi:10.1200/ JCO.2011.36.6518.

85. Ostroff, J.; Garland, J.; Moadel, A.; Fleshner, N.; Hay, J.; Cramer, L.; Zauber, A.; Trambert, R.; O'Sullivan, M. E.; Russo, P. Cigarette smoking patterns in patients after treatment of bladder cancer. J. Cancer Educ. 2000, 15, 86-90, doi:10.1080/08858190009528663.

86. Rink, M.; Zabor, E. C.; Furberg, H.; Xylinas, E.; Ehdaie, B.; Novara, G.; Babjuk, M.; Pycha, A.; Lotan, Y.; Trinh, Q.-D.; Chun, F. K.; Lee, R. K.; Karakiewicz, P. I.; Fisch, M.; Robinson, B. D.; Scherr, D. S.; Shariat, S. F. Impact of Smoking and Smoking Cessation on Outcomes in Bladder Cancer Patients Treated with Radical Cystectomy. Eur. Urol. 2013, 64, 456-464, doi:10.1016/j.eururo.2012.11.039.

87. Yafi, F. A.; Aprikian, A. G.; Chin, J. L.; Fradet, Y.; Izawa, J.; Estey, E.; Fairey, A.; Rendon, R.; Cagiannos, I.; Lacombe, L.; Lattouf, J.-B.; Bell, D.; Drachenberg, D.; Kassouf, W. Contemporary outcomes of 2287 patients with bladder cancer who were treated with radical cystectomy: a Canadian multicentre experience. BJU Int. 2011, 108, 539-45, doi:10.1111/j.1464410X.2010.09912.x.

88. Boorjian, S. A.; Kim, S. P.; Weight, C. J.; Cheville, J. C.; Thapa, P.; Frank, I. Risk Factors and Outcomes of Urethral Recurrence Following Radical Cystectomy. Eur. Urol. 2011, 60, 1266-1272, doi:10.1016/j.eururo.2011.08.030.

89. Lee, C.; Kim, K. H.; You, D.; Jeong, I. G.; Hong, B.; Hong, J. H.; Ahn, H.; Kim, C.-S. Smoking and Survival After Radical Cystectomy for Bladder Cancer. Urology 2012, 80, 1307-1312, doi:10.1016/j.urology.2012.08.026.

90. Cumberbatch, M. G.; Rota, M.; Catto, J. W. F.; La Vecchia, C. The Role of Tobacco Smoke in Bladder and Kidney Carcinogenesis: A Comparison of Exposures and Meta-analysis of Incidence and Mortality Risks. Eur. Urol. 2016, 70, 458-466, doi:10.1016/j.eururo.2015.06.042.

91. Jiang, X.; Castelao, J. E.; Yuan, J. J.-M.; Stern, M. C.; Conti, D. V.; Cortessis, V. K.; Pike, M. C.; Gago-Dominguez, M.; Gago-Dominguez, M. Cigarette smoking and subtypes of bladder cancer. Int. J. Cancer 2012, 130, 896-901, doi:10.1002/ijc.26068.

92. van Roekel, E. H.; Cheng, K. K.; James, N. D.; Wallace, D. M. A.; Billingham, L. J.; Murray, P. G.; Bryan, R. T.; Zeegers, M. P. Smoking is associated with lower age, higher grade, higher stage, and larger size of malignant bladder tumors at diagnosis. Int. J. Cancer 2013, 133, 446-454, doi:10.1002/ijc.28017.

93. Zeegers, M. P.; Bryan, R. T.; Langford, C.; Billingham, L.; Murray, P.; Deshmukh, N. S.; Hussain, S.; James, N.; Wallace, D. M. A.; Cheng, K. K. The West Midlands Bladder cancer prognosis programme: Rationale and design. BJU Int. 2010, 105, 784-788, doi:10.1111/j.1464410X.2009.08849.x.

94. Goossens, M. E.; Isa, F.; Brinkman, M.; Mak, D.; Reulen, R.; Wesselius, A.; Benhamou, S.; Bosetti, C.; Bueno-de-Mesquita, B.; Carta, A.; Allam, M. F.; Golka, K.; Grant, E. J.; Jiang, X.; Johnson, K. C.; Karagas, M. R.; Kellen, E.; La Vecchia, C.; Lu, C.-M.; Marshall, J.; Moysich, K.; Pohlabeln, H.; Porru, S.; Steineck, G.; Stern, M. C.; Tang, L.; Taylor, J. A.; van den Brandt, P.; Villeneuve, 
P. J.; Wakai, K.; Weiderpass, E.; White, E.; Wolk, A.; Zhang, Z.-F.; Buntinx, F.; Zeegers, M. P. International pooled study on diet and bladder cancer: the bladder cancer, epidemiology and nutritional determinants (BLEND) study: design and baseline characteristics. Arch. Public Heal. 2016, 74, 30, doi:10.1186/s13690-016-0140-1.

95. Ian Unwin Eurocode Main Food Groups: classification and policy, version 99/2 Available online: http://www.ianunwin.demon.co.uk/eurocode/docmn/ec99/ecmgintr.htm (accessed on Mar 13, 2018). 


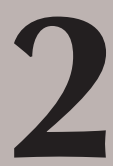

Quantified relations between exposure to tobacco smoking and bladder cancer risk: a meta-analysis of 89 observational studies

Frits H.M. van Osch, Sylvia H.J. Jochems, Frederik-Jan van Schooten, Richard T. Bryan, Maurice P. Zeegers

Adapted from:

International Journal of Epidemiology, Vol. 45, No. 3 (2016), 857-870
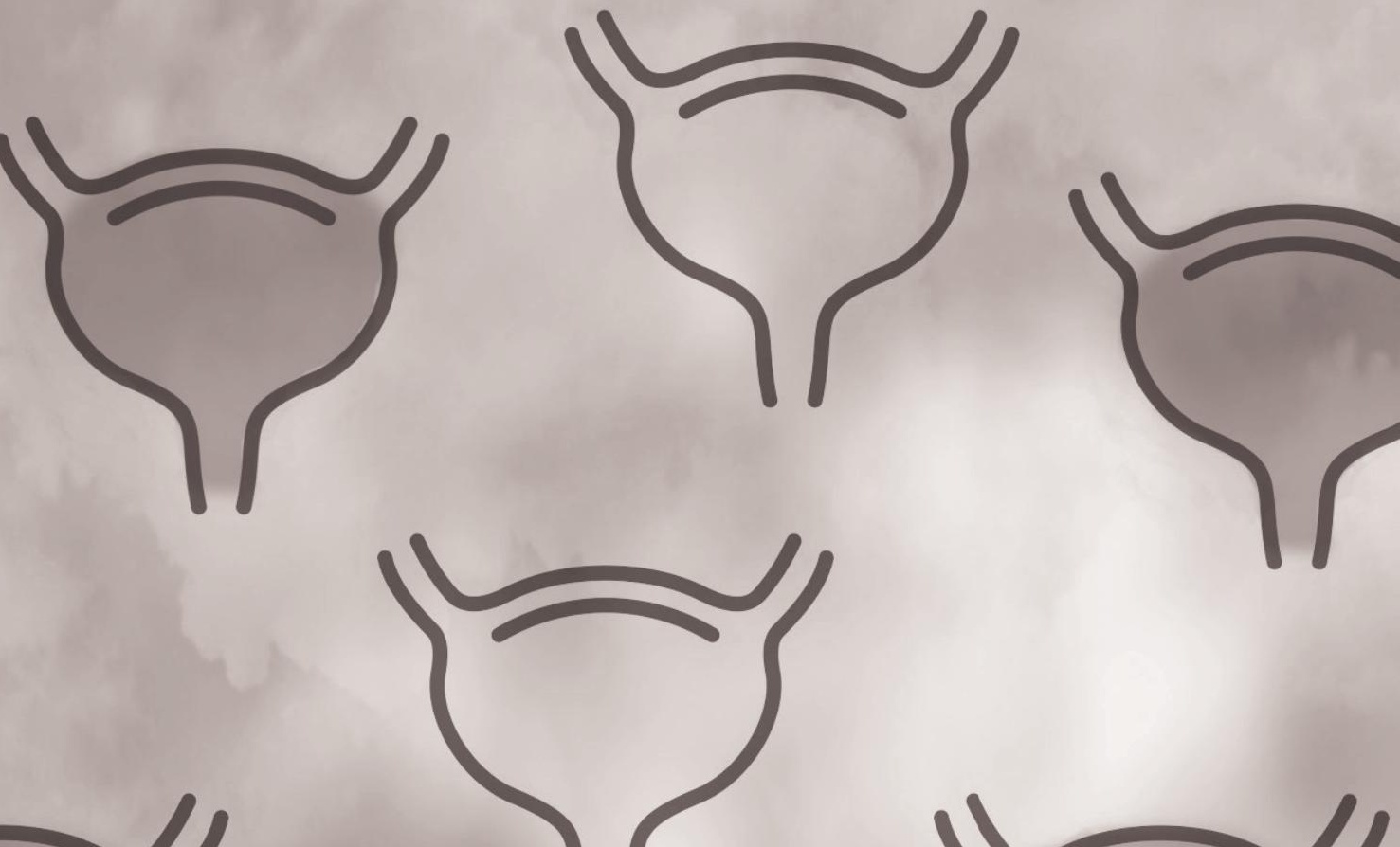


\section{ABSTRACT}

\section{Background:}

Smoking is a major risk factor for bladder cancer (BC). This meta-analysis updates previous reviews on smoking characteristics and $\mathrm{BC}$ risk, and provides a more quantitative estimation of the dose-response relationship between smoking characteristics and $\mathrm{BC}$ risk.

\section{Methods:}

In total, 89 studies with 57,145 BC cases were included and summary odds ratios (SORs) were calculated. Dose-response meta-analyses modelled relationships between smoking intensity, duration, pack-years and cessation and BC risk. Sources of heterogeneity were explored and sensitivity analyses were conducted to test the robustness of findings.

\section{Results:}

Current smokers $(\mathrm{SOR}=3.14,95 \% \mathrm{CI}=2.53-3.75)$ and former smokers ( $\mathrm{SOR}=1.83,95 \%$ $\mathrm{CI}=1.52-2.14)$ had an increased risk of $\mathrm{BC}$ compared to never smokers. Age at first exposure was negatively associated with $\mathrm{BC}$ risk. $\mathrm{BC}$ risk increased gradually by smoking duration and a risk plateau at smoking 15 cigarettes a day and 50 pack-years was observed. Smoking cessation is most beneficial from 20 years before diagnosis. The population attributable risk of BC for smokers has decreased from $50 \%$ to $43 \%$ in men and from $35 \%$ to $26 \%$ in women from Europe since estimated in 2000. Results were homogenous between sources of heterogeneity, except for lower risk estimates found in studies of Asian populations.

\section{Conclusions:}

Active smokers are at an increased risk of BC. Dose-response meta-analyses showed a $\mathrm{BC}$ risk plateau for smoking intensity and indicate that even after long-term smoking cessation, an elevated risk of bladder cancer remains. 


\section{BACKGROUND}

Bladder cancer $(B C)$ is estimated to be the ninth most incident cancer worldwide, with around 400000 new cases per year; the disease accounts for a larger share of total cancer incidence in more developed regions (1). Cigarette smoking is a major risk factor for urothelial cell carcinoma (which also includes cancers of the renal pelvis and ureter) (2). Since recent studies estimated $22.8 \%$ of Europeans (3), $18.1 \%$ of North Americans (4) and $52.9 \%$ of males from China (5) smoke, it is expected to remain an important BC risk factor in the near future. Studies investigating the association between smoking and BC risk were summarized in a meta-analysis 15 years ago (2) and several systematic reviews (6-8). However, further relevant studies have emerged since these reviews, allowing for more robust estimates, more detailed subgroup analyses, quantification of BC risk by dose-response investigations.

According to age- and gender-adjusted estimates from an earlier meta-analysis, those patients smoking at diagnosis (current smokers) had a 3.33-fold increased risk of developing BC compared to never smokers, and for former smokers the summary odds ratio (SOR) was 1.98; these age-adjusted risk estimates were comparable between males and females (2). Furthermore, BC risk increased with the number of cigarettes smoked per day and the number of years of smoking, although this was only assessed in a dichotomous way (e.g. 1-20 cigarettes per day vs. $>20$ cigarettes per day) in this meta-analysis (2).

The aim of this study was to provide an up-to-date estimation of the role of smoking in $\mathrm{BC}$ risk and to gain a more detailed quantification on several smoking characteristics (i.e. smoking intensity, duration and cessation) by performing dose-response meta-analyses.

\section{METHODS}

\section{Search strategy}

Both Medline and Embase online databases were used to search for epidemiologic studies on cigarette smoking and $\mathrm{BC}$ incidence. The search included the (MeSH) search terms "urinary bladder neoplasms", "incidence" "risk", "smoking" and "epidemiologic studies" in different combinations and resulted in a total count of 2112 articles after removal of duplicates. Publications were excluded if they did not involve humans. Publications that did not provide useable data to calculate risk estimates and the associated $95 \%$ confidence intervals for smoking characteristics and BC incidence were excluded. Included publications provided risk estimates for at least one of the selected cigarette smoking characteristics, including: smoking status (never, former, current), age at first exposure, 
daily cigarette consumption (intensity), duration of cigarette consumption, number of smoking pack-years and number of years since cessation. Publications reporting only on ever versus never smokers were excluded. Where a single study was described in several publications, the most recent publication was used for analysis.

\section{Data collection}

The Newcastle-Ottowa Scale (NOS) scale (9) was used to assess study quality and to extract information on possible sources of heterogeneity within individual publications by two of the authors (FvO and SJ). Information on the following variables was extracted and numerated in a dataset: year of publication, country and geographic area (North America, Europe, Asia, Africa, South America), anatomic site (bladder, upper tract urothelium, renal pelvis), cigarette smoking assessment (interview or questionnaire), case and control source (hospital, population or both) and factors adjusted for in the analysis. The association between smoking and $B C$ risk is expressed in odds ratios (ORs) for both case-control studies and cohort studies included in this review. Where possible, risk estimate data was extracted directly from included articles and included both unadjusted and adjusted estimates. When direct risk estimates were not available, two-way contingency tables were constructed separately and unadjusted ORs and 95\% confidence intervals were calculated. Since age and gender are major confounders of the association between smoking and BC, all included adjusted risk estimates adjusted for at least age and gender. For smoking duration, intensity, pack-years and cessation, risk estimates for smoking and $\mathrm{BC}$ risk were recorded per category, for example per 10 years of smoking duration, when data was available. Publications were excluded if the number of cases and/or controls or the number of person-years were not given. The definition of bladder cancer was broad in this study; this means we did not exclude studies that did not mention exact ICD codes of included bladder tumours in their papers, as this information is often lacking in publications. Therefore, it is likely that the included studies do not only include patients that were diagnosed according to ICD codes after 2000, but also a wider group of non-invasive disease. Studies that did not make clear whether cases showed non-muscle-invasive or muscle-invasive disease were also included.

\section{Statistical analysis}

To investigate publication bias, funnel plots were constructed, plotting the logarithmically transformed ORs against the standard error of the associated $\log (\mathrm{OR})(10)$. The distribution of study risk estimates across the funnel plot was examined visually and Egger's test for small study effects was performed to assess the degree of asymmetry (10). A random effects model was employed in all meta-analysis procedures. Between-study variance was estimated by 12 and subgroup analyses. Stata statistical software was used for all 
analyses (version 13; Stata Corp., College Station, TX) and a p-value smaller than 0.05 was considered statistically significant in all analyses.

Summary ORs were estimated using classical meta-analysis for smoking status, age at first exposure ( $>20$ years versus $\leq 20$ years) and these results were obtained separately for men and women if data were available from the included publications. A cumulative meta-analysis was performed to investigate whether the association between smoking and $B C$ incidence varied in time. Subgroup analyses were performed to explore differences in risk estimates between possible sources of heterogeneity, including geographic area, anatomic site, case and control source, study design and smoking assessment. The association of smoking duration, intensity, pack-years and cessation with BC risk was examined using a dose-response meta-analysis. The assigned dose for the dose-response analysis was determined by taking the median of each category (e.g. 15 cigarettes for category 10-20 cigarettes per day). Dose-response trends were estimated using both the variance weighted least squares (VWLS) and generalized least squares (GLS) regression methods (11). Since GLS is the most robust method which accounts for inevitable covariance between study observations in a meta-analysis, the results from the GLS method are presented. Restricted cubic splines, which set knots at the 5th, 35th, 65th and 95th percentile, were used to investigate statistical non-linearity for all curves. Finally, population attributable risk (PAR) of $B C$ for current smokers compared to never smokers was estimated for Europe, North America and China using the overall pooled risk estimates obtained by all included studies and the most recent estimates of proportions of smokers in these populations.

\section{RESULTS}

\section{Study characteristics}

For this meta-analysis, 99 articles that discussed cigarette smoking and BC incidence were identified between 1968 and 2015 based on their abstract. After full text evaluation, 89 articles were included for full analysis (Figure 1). Study characteristics including year of publication, country, case/control source, smoking assessment and anatomic site are summarized in Table 1. Six articles were excluded after full-text evaluation due to insufficient NOS score, duplicate populations in several articles or not being published in English (101-106). Furthermore, three articles only presented data on ever smokers, as opposed to current and former smokers (107-109), and one cohort study did not present $95 \%$ confidence intervals and omitted the case-control data to calculate these (110). 


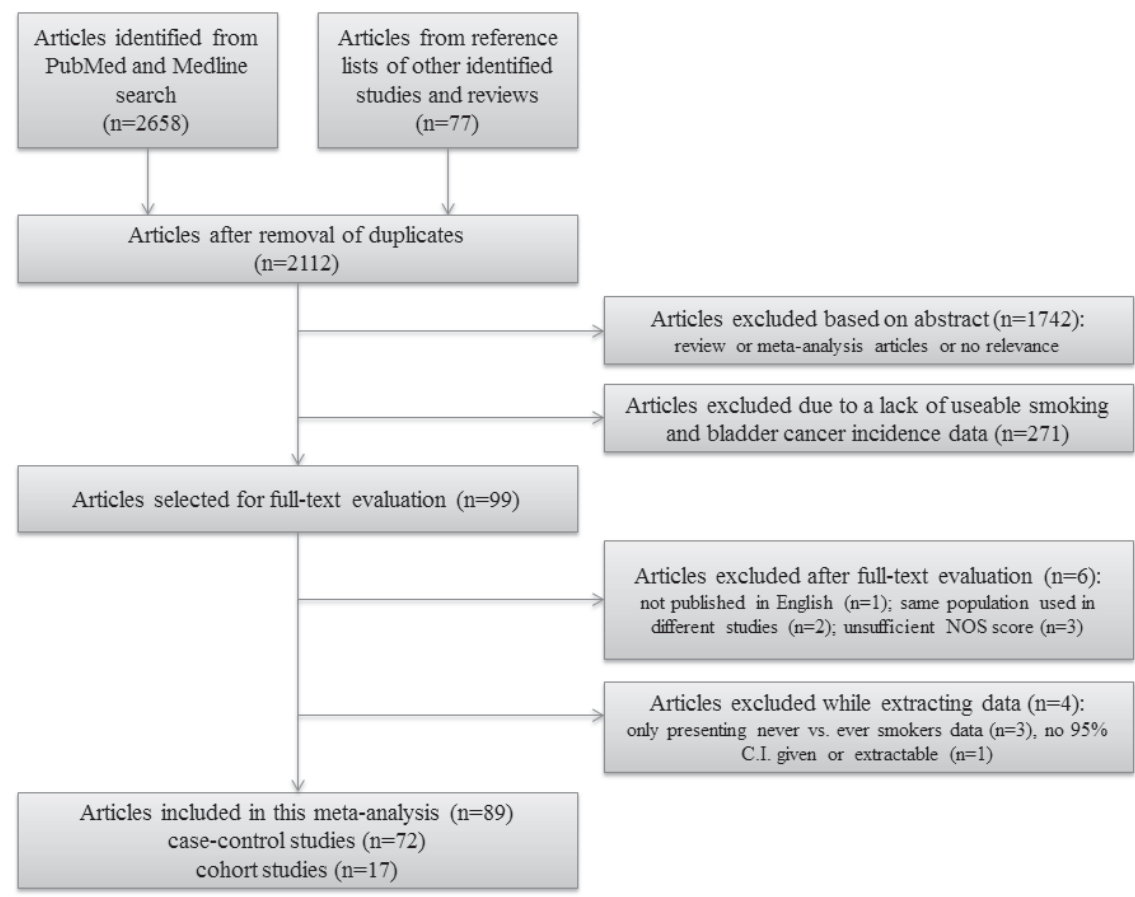

Figure 1. Flowchart of study selection and exclusion criteria.

Of the 89 included studies, 72 were case-control studies (12-27, 29, 30, 32-38, 40-42, 44$49,51,53-65,68,70-73,76,77,79,81-87,89,90,92,93,95-99)$ and 17 were cohort studies $(28,31,39,43,50,52,66,67,69,74,75,78,80,88,91,94,100)$. Three articles presented risk estimates from different study populations and were considered as separate studies in the analysis $(9,78,84)$. In the case-control studies, cases were identified from hospitals $(n=46)(13-15,17-23,26,29,33-38,40,41,46,49,53,54,57,58,64,65,70-73,76,77,81$, $83,85,86,89,90,93,96-99)$ or in predefined populations $(n=24)(16,24,25,27,32,35,42$, $47,48,55,56,59-63,68,79,82,84,87,92,95)$, and two studies used both hospital- and population-based cases $(12,30)$. Thirty-nine of the case-control studies recruited controls from hospitals $(12-14,16,17,19,21-24,26,29,33-37,40,41,44-46,49,50,53,54,57,58$, $63-65,68,70,71,73,74,76-79,81-83,85-87,89,91-93,96,97,99)$ and thirty-three casecontrol studies recruited population controls $(15,18,20,25,27,30,32,35,38,42,45,47$, $48,51,52,55-57,59,61-63,68,70,72,79,82,84,87,90,92,95,98)$. Detailed information on cigarette smoking habits was assessed by interview $(n=62)(12-18,21,23,25-27,29$, $30,32-38,40-46,48,49,51,53-55,58,59,61,62,64,65,70,72,73,77,79,81-87,89,90$, $92,93,95-99)$, questionnaire $(n=26)(19,20,24,28,31,39,47,52,56,57,60,63,66-69,71$, $74-76,78,80,88,91,94,100)$, and medical records $(n=1)(50)$. 


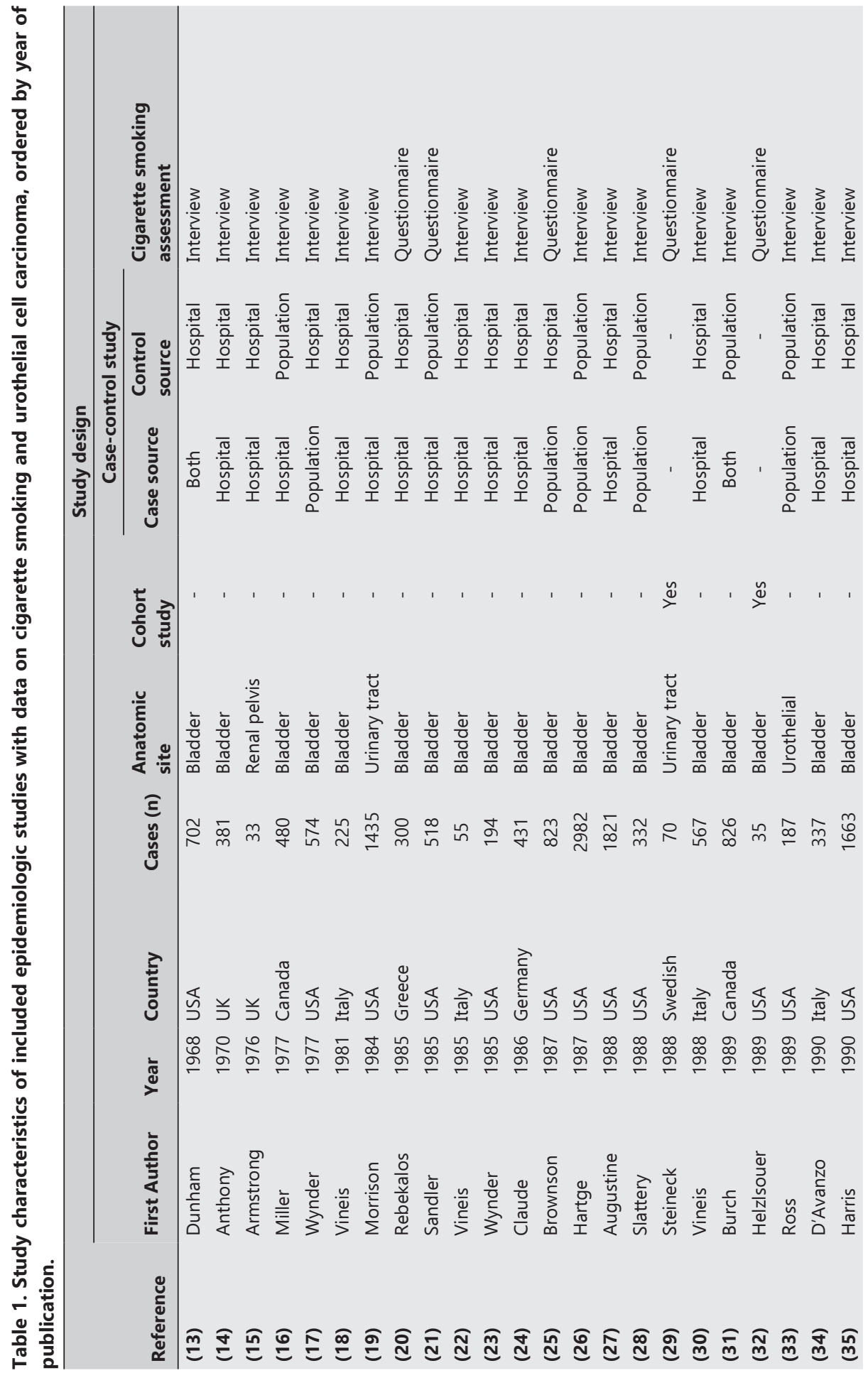




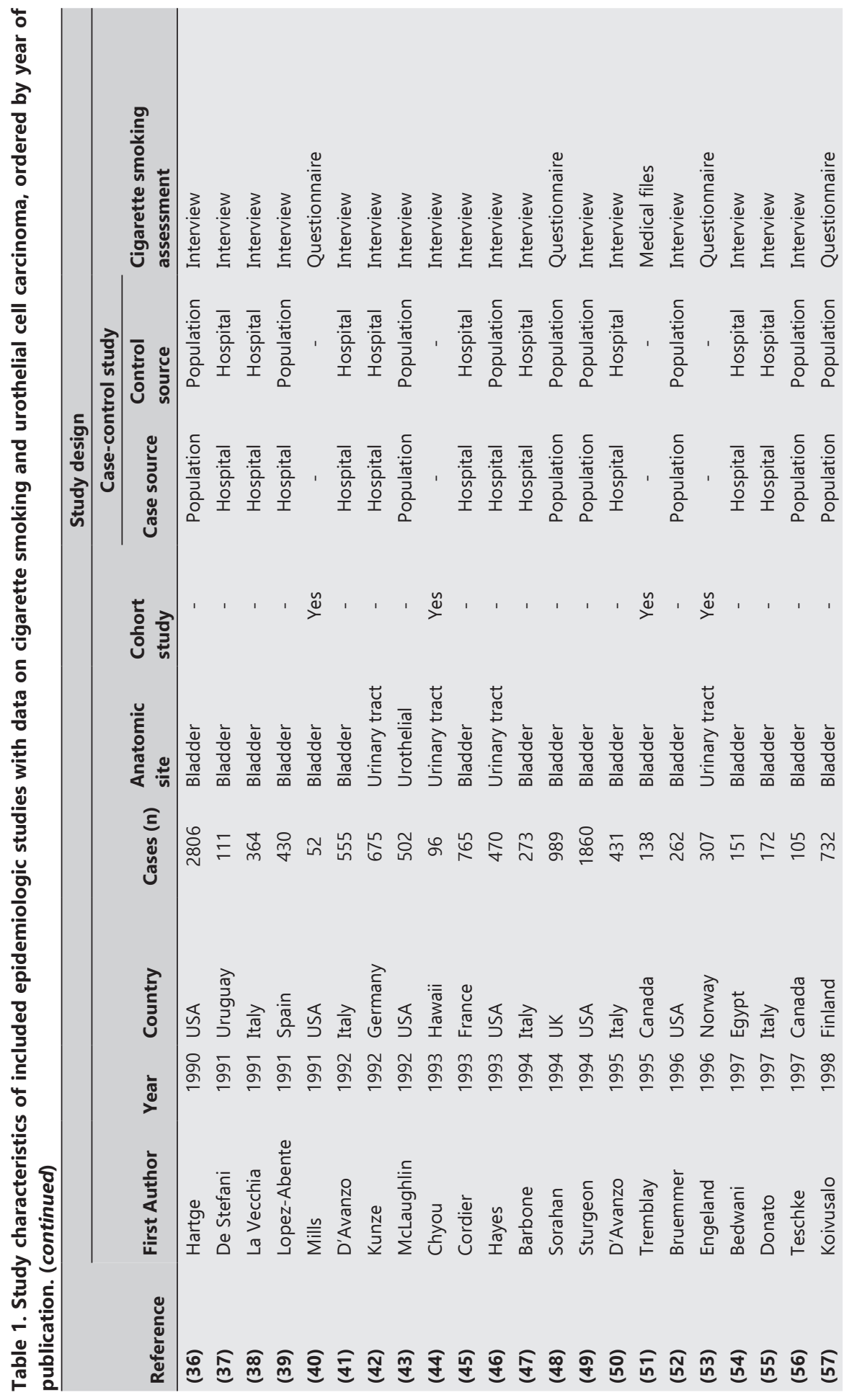




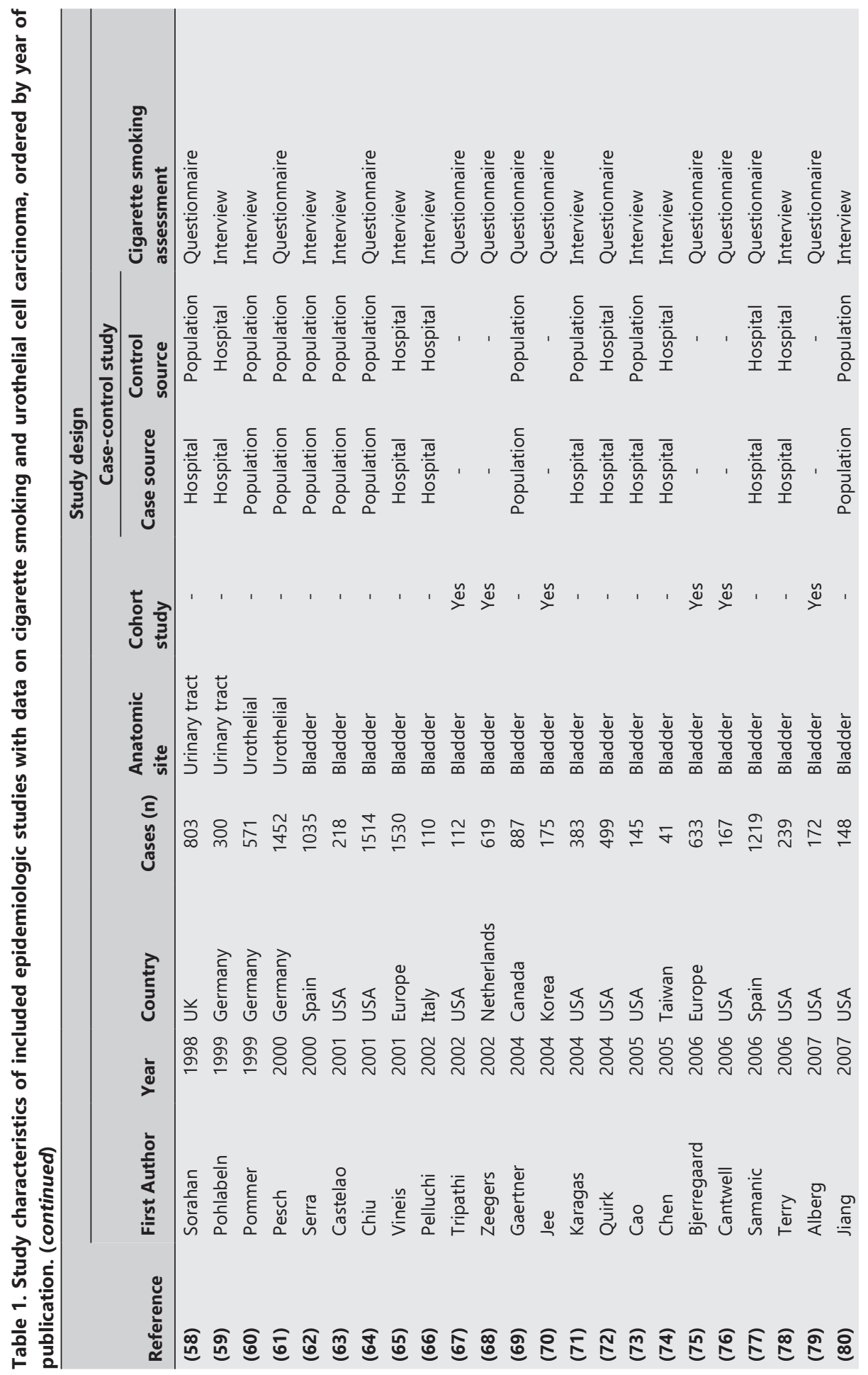




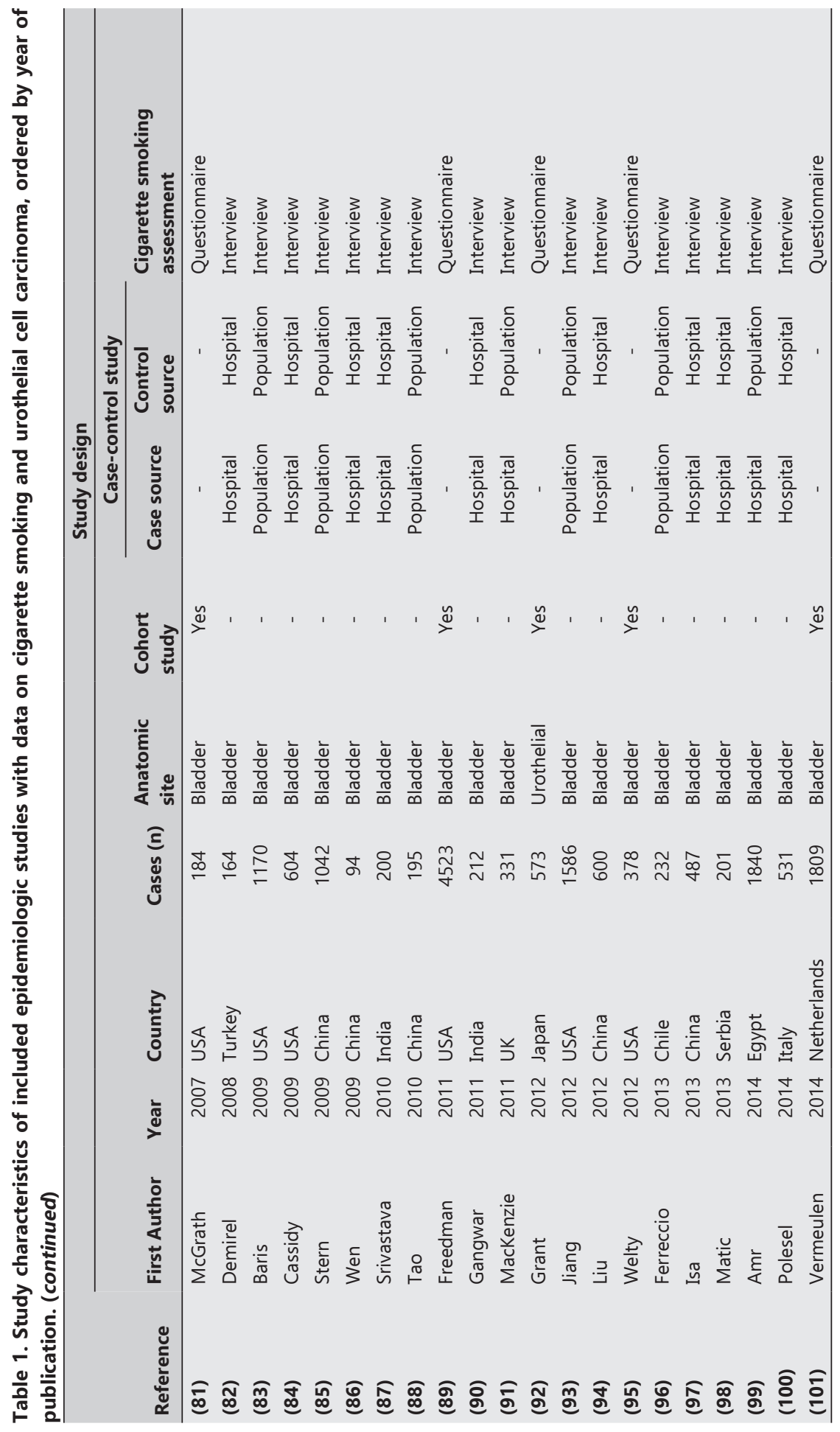




\section{PUBLICATION BIAS AND HETEROGENEITY}

Based on appraisal of funnel plots (Supplemental Figure 1), some publication bias (mostly large studies published) seemed to be present in studies that present unadjusted ORs $(n=45)$. Publication bias seemed to be of less importance in studies presenting age and sex adjusted $(n=11)$ and multiple-adjusted $(n=13)$ ORs. The usefulness of funnel plots is greatly reduced when less than 10 studies are included. Egger's test for small study effects demonstrated that there was no bias in the distribution of published results $(p=0.150)$. Judging from $\mathrm{I}^{2}$ statistics there may have been heterogeneity (most $\mathrm{I}^{2}$ values between $70 \%$ and $90 \%$ for both classical- and dose-response meta-analyses), however when assessing heterogeneity in subgroup analyses (Figure 2) there did not seem to be any substantial heterogeneity.

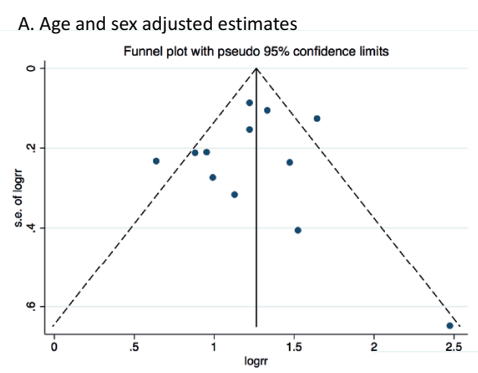

B. Multivariate adjusted
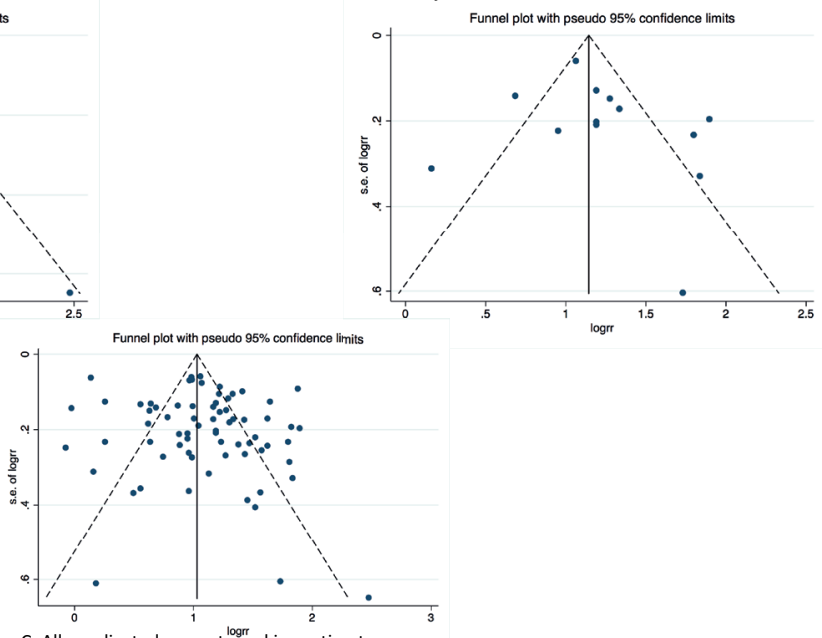

C. All unadjusted current smoging $^{\text {loking estimates }}$

Supplemental Figure 1. Funnel plots for (A) age and sex adjusted risk estimates, (B) multivariate adjusted risk estimates and (C) all unadjusted risk estimates.

\section{Risk estimates from classical meta-analysis}

Table 2 summarizes both unadjusted and adjusted estimates for smoking status and age at first exposure obtained from the classical meta-analysis. The adjusted SOR for current smokers compared to never smokers was 3.14 (95\% CI, 2.53-3.75). Former smokers had a 1.78 (95\% CI, 1.53-2.03)-fold increased risk of developing BC compared to never smokers. This association was comparable between men (3.44, 95\% CI=2.67-4.22) and women (3.56, 95\% CI=2.76-4.36). When investigating all obtained estimates, the observed SORs remained comparable to the adjusted estimates. For age at first exposure, 5 male-only 


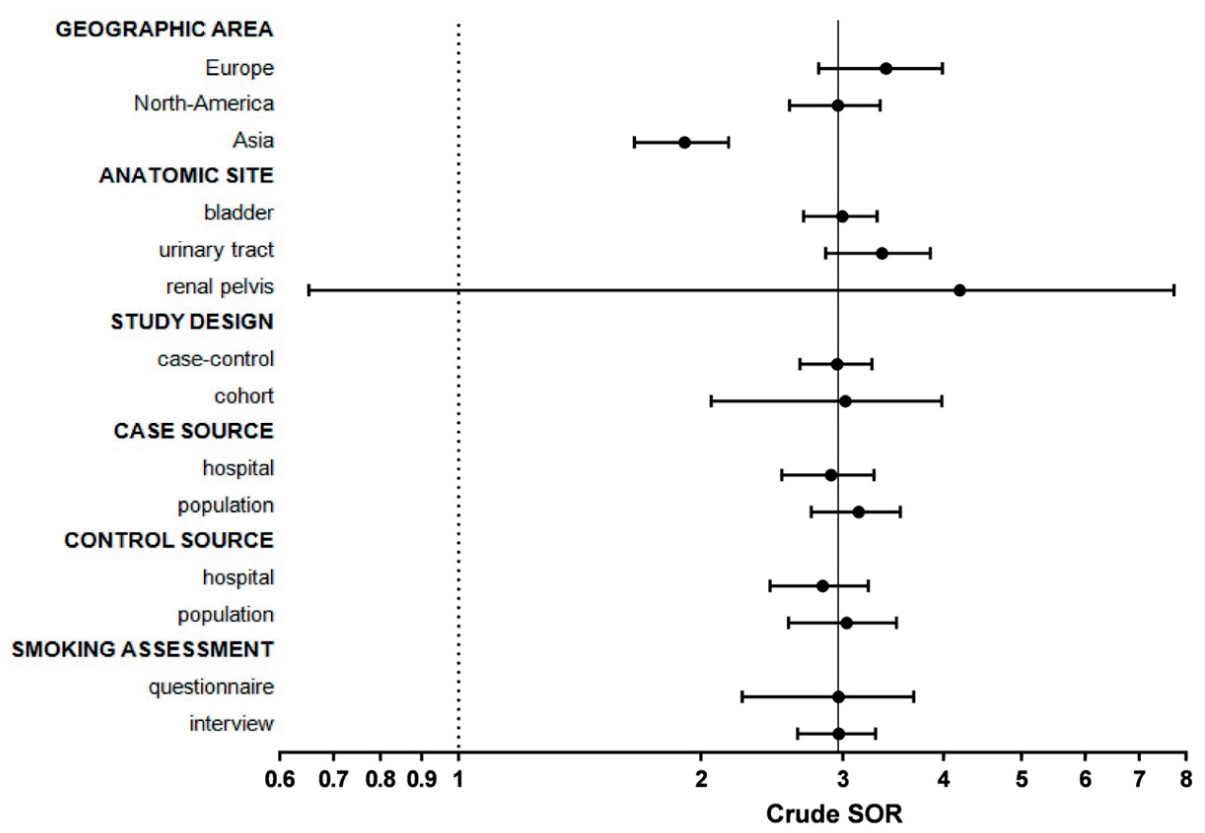

Figure 2. Forest plot depicting crude summary odds ratios (SOR) for current smokers versus nonsmokers, by several possible sources of heterogeneity. The dashed line represents no effect and the solid line stands for the overall crude SOR of 2.96.

studies presenting age-adjusted risk estimates were pooled which resulted in a SOR of 1.36 (95\% CI=0.91-1.80) comparing males who started smoking before the age of 20 to those who had started smoking after the age of 20. Unadjusted SORs showed no effect of age at first exposure in females $(0.99,95 \% \mathrm{CI}=0.31-1.68)$ as opposed to stronger associations for males only $(1.34,95 \% \mathrm{CI}=1.02-1.68)$ and studies including both sexes $(1.30,95 \%$ $\mathrm{CI}=1.13-1.47)$.

\section{Risk estimates from dose-response meta-analysis}

Dose-response curves estimated from studies reporting on smoking intensity $(n=23)(25$, $30,33-35,37-40,45-48,57,62,67,71,78,81,82,92,99)$, pack-years $(n=8)(34,50,61$, $71-73,82,94)$, duration $(n=15)(25,30,38,39,47,53,59,62,67,71,75,82,92,96,99)$ and cessation $(n=7)(25,33,38,67,72,92,94)$ and $B C$ risk are depicted in Figure 3 . The shape of both the intensity and pack-years curves is reminiscent of a logarithmic curve, showing a rapid increase of $B C$ risk before declining at a certain point. For intensity, $B C$ risk increases only marginally from smoking more than 15 cigarettes a day, and likewise for pack-years from 50 pack-years onwards. The risk of BC increases almost linearly increases by smoking duration in years, although statistical tests for non-linearity showed that it is non-linear ( $p<0.05$ at all investigated knots). Those who stopped smoking more than 25 years prior to diagnosis were approximately at a 1.5-fold higher risk of BC compared 


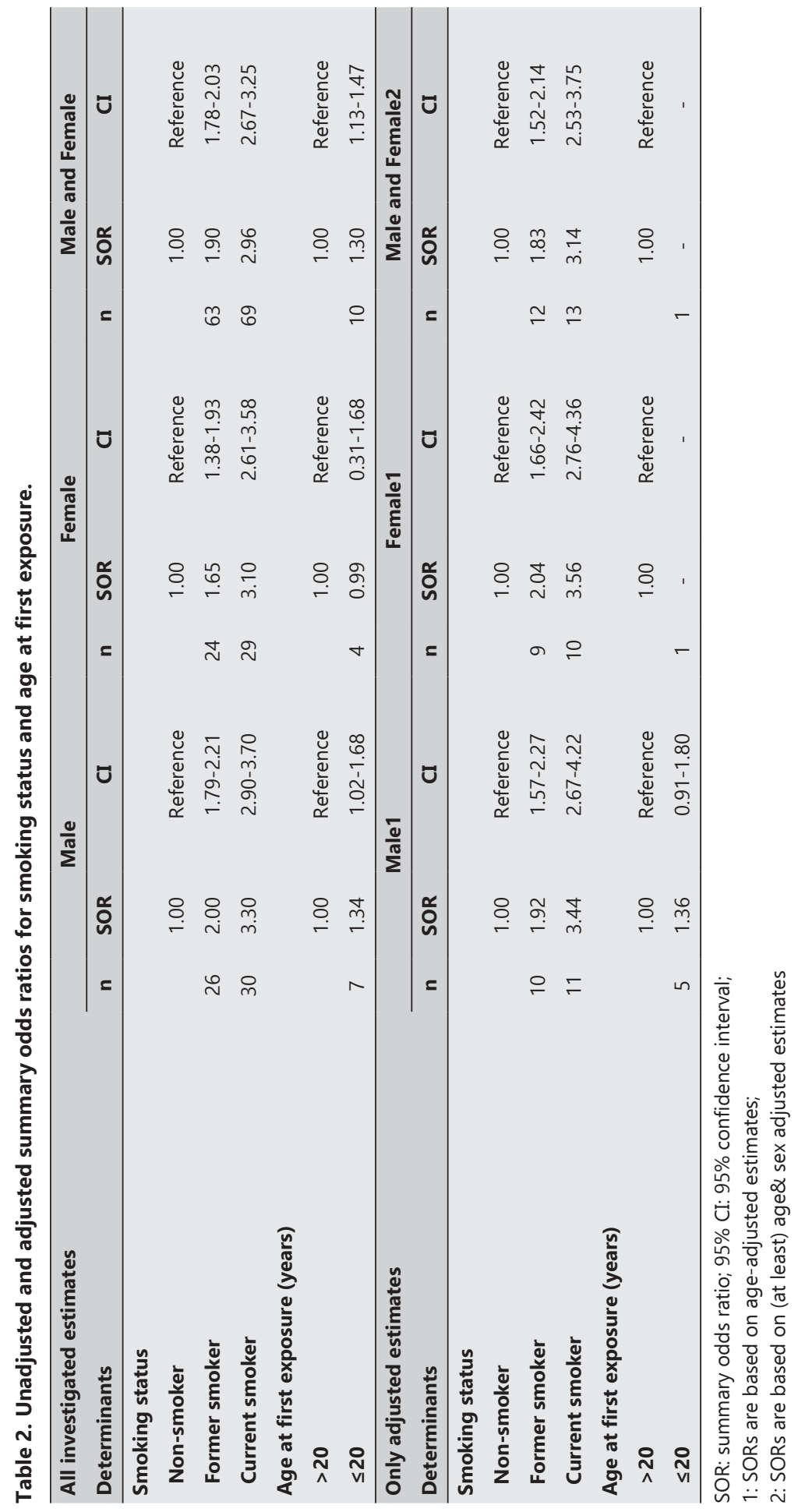


to never smokers, whereas those who stopped smoking between 5 and 15 years prior to diagnosis were at a two-to threefold increased risk of BC compared to never smokers. There is a slight stagnation around 10 years of cessation, indicating a relatively small risk reduction between 5 and 15 years of smoking cessation. Nevertheless, this stagnation might also be explained as an artefact in the analysis, caused by the inclusion of only categorical data which did not span every possible value of smoking cessation in years as most included studies reported data on 10 years of cessation and none on 6 years for example.

\section{Sensitivity analyses}

Subgroup analyses investigating the risk of $B C$ of current smokers versus never smokers were performed to check for the influence of potential sources of heterogeneity (Figure 2). Most subgroup estimates seemed to be consistent with each other and did not indicate heterogeneity. However, the SOR of 1.91 (95\% CI=1.65-2.17) for the 7 included Asian studies was lower compared to both European $\left(n=25, p=3.93^{*} 10^{-7}\right)$ and North-American estimates $\left(n=34, p=4.40 * 10^{-6}\right)$. Of these 7 studies (including 2.760 cases), 4 investigated Chinese populations $(84,85,93,96), 2$ investigated Japanese populations $(18,91)$ and there was one prospective study in a Korean population (69) to estimate the effect of smoking on $\mathrm{BC}$ risk.

Across these 7 studies, estimates consistently indicated a two-fold increase of BC risk as opposed to the overall (and European and American) estimate of a three-fold increased risk of $B C$ for current smokers compared to never smokers.

A cumulative meta-analysis, performed to check whether the risk estimate of BC for current smokers compared to never smokers changed over time since (included publications appeared in print between 1968 and 2015) indicated that there was a slight increase of $B C$ risk for current smokers versus never smokers over time (Supplemental Figure 2). However, when only considering multiple adjusted (at least adjusted for age and sex) estimates, there were no changes in estimated risk of BC (data not shown).

In addition to the presented dose-response curves estimated by GLS regression using restricted cubic splines, other methods (VWLS, linear regression) did not show different results compared to GLS regarding the estimated regression slope for all investigated smoking characteristics. Furthermore, the shape of the dose-response curves did not change substantially by varying with positioning of knots using the cubic splines method or when applying a fractional polynomials approach for curve estimation. 


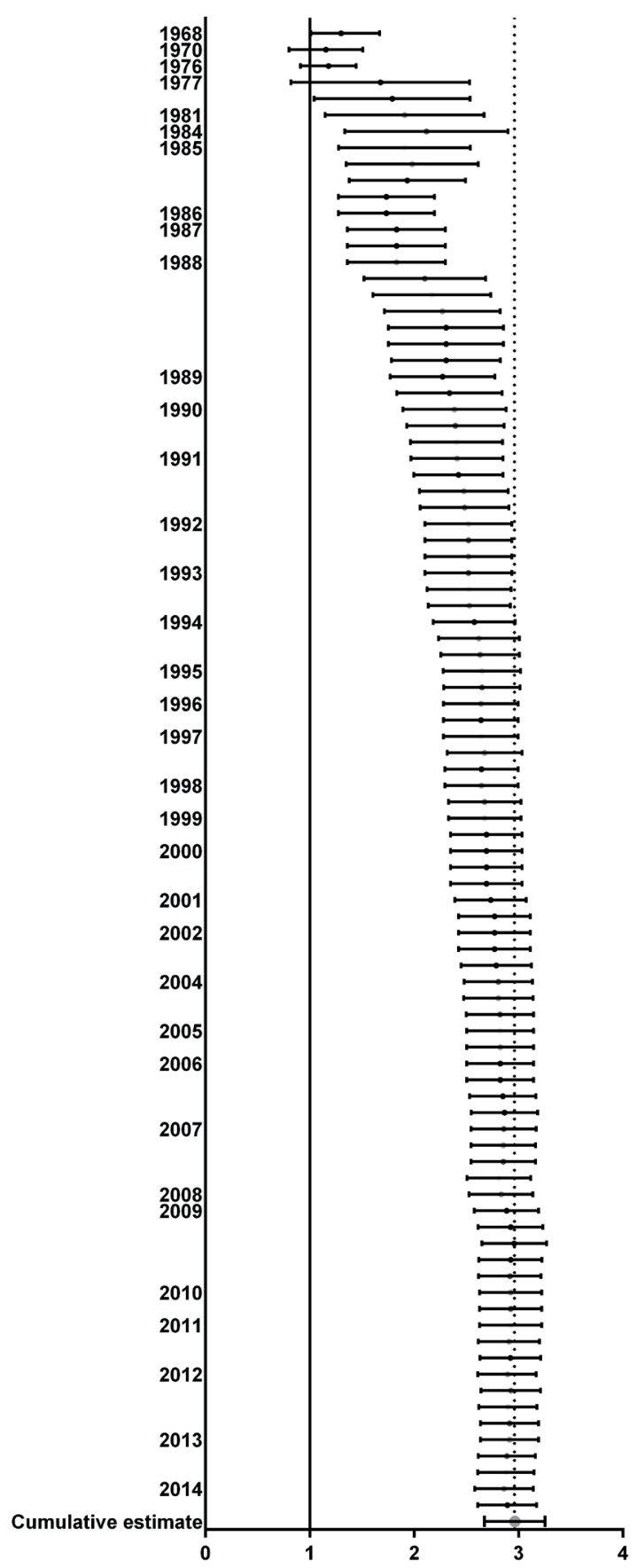

Supplemental Figure 2. Cumulative meta-analysis results including ORs from all studies comparing BC risk between current smokers and non-smokers. The dashed line represents the overall cumulative OR of 2.96 and the solid line represents no effect. 


\section{Population attributable risks}

In Europe, approximately $28 \%$ of males and $18 \%$ of females smoke (3), whereas in the USA these figures are estimated to be $21 \%$ and $16 \%$ (4). By combining these figures with the pooled risk estimates per continent from this meta-analysis PARs were calculated (Table 3). The fraction of $B C$ cases attributable to cigarette smoking is $43 \%$ for males and $26 \%$ for females in Europe and 34\% for males and 30\% for females in the USA. Unfortunately, no studies presenting gender-specific ORs were found for the Chinese population, however the PAR in the whole population seems smaller (20\%) compared to both Europe and the USA, while the prevalence of smoking is larger in China (5).

Table 3. Population attributable risk (PAR) of bladder cancer per exposure to cigarette smoking in North-America, Europe and China

\begin{tabular}{rrrrrr}
\hline Men and women ${ }^{*}$ & No. of studies & SOR & Pe (smoking) & PAR \\
\hline North-America & 13 & 3.08 & 0.18 & $27 \%$ \\
Europe & 9 & 3.62 & 0.23 & $37 \%$ \\
China & 4 & 1.87 & 0.28 & $20 \%$ \\
\hline Men-only & & & & $34 \%$ \\
\hline North-America* & 8 & 3.55 & 0.21 & $43 \%$ \\
Europe** & 13 & 3.67 & 0.28 & - \\
China & 0 & - & 0.53 & $30 \%$ \\
\hline Women-only & & & & $26 \%$ \\
\hline North-America* & 8 & 3.72 & 0.16 & - \\
\hline Europe** & 13 & 2.92 & 0.18 & 0.02 & \\
\hline China & 0 & - & & \\
\hline
\end{tabular}

$\mathrm{SOR}=$ summary odds ratio; $\mathrm{Pe}=$ prevalence of exposure (smoking);

$\mathrm{PAR}=$ population attributable risk

* based on age-and sex-adjusted estimates only

** based on both adjusted and unadjusted estimates

\section{DISCUSSION}

This meta-analysis summarizes the findings of 89 observational studies encompassing a total of 57145 BC cases investigating the association between cigarette smoking and BC risk.

\section{Smoking status and age at first exposure influence BC risk}

Our findings support earlier reviews in indicating an increased risk of BC for cigarette smokers. Age at first exposure is negatively associated with BC risk, however no studies adjusted for smoking duration or smoking intensity as possible effect modifiers in the included publications. 


\section{Dose-response relationship between smoking intensity and BC risk with a risk plateau at 15 cigarettes a day}

Increasing smoking intensity (i.e. smoking more cigarettes per day) seems to be of less additional impact on $\mathrm{BC}$ risk when smoking more than 15 cigarettes a day. Perhaps surprisingly, very heavy smokers (e.g. 50 cigarettes a day) do not experience a markedly increased risk compared to less heavy smokers. A similar relationship is observed for pack-years, but with a risk plateau at approximately 50 pack-years. These results are in line with experimental and molecular epidemiological studies in which saturation is observed of smoking-related DNA adduct levels in lymphocytes and lung cells at higher doses, leading to non-linear dose-response relationships (111). In the bladders of mice treated with the bladder carcinogen 4-aminobiphenyl (4-ABP), adduct levels in bladder-DNA and associated bladder tumours increased by dose at low doses, but saturation was observed at high doses (112). Similarly, in smokers, adduct levels (derived from the tobacco carcinogens Polycyclic Aromatic Hydrocarbons and 4-ABP) in blood cells plateaued at 20 cigarettes per day (113), which is in concordance with the presently observed dose-response relationship in BC risk. Although these studies might provide some biological explanation for the observed risk plateau it is not replicated in other smoking-related cancers such as lung cancer (114), where the association seems to be linear, or head-and neck cancer where some studies show a similar risk plateau (115) but others indicate a linear association (116). What might be reflected in the risk plateaus in the curves for bladder cancer are the reduced number of persons at risk of bladder cancer among heavy smokers, since they might have already died because of other smoking-related diseases such as lung cancer, cardiovascular disease or chronic obstructive pulmonary diseases. Nevertheless, more research is needed on the possible biological mechanism that underlies the observed association between smoking intensity and $\mathrm{BC}$ risk if there is any.

\section{Smoking cessation is most beneficial more than $\mathbf{2 0}$ years prior to diagnosis, but former smoking is still associated with a long- term BC risk increase compared to never smokers}

Many smokers believe that smoking cessation will cause their risk of several diseases to return to the risk of a non-smoker over a very short period (117). However, this analysis unambiguously shows that lowering BC risk after smoking cessation takes time. The beneficial effect of smoking cessation on $\mathrm{BC}$ risk is largest when having stopped smoking more than 20 years prior to diagnosis. Even then the risk of former smokers does not return to the risk of non-smokers. Even after 20 years of cessation, ex-smokers remain at a $50 \%$ increased risk compared to those who have never smoked. Furthermore, there does not seem to be a substantial risk reduction between 5 and 15 years of smoking cessation prior to diagnosis. Although smoking cessation seems to be the only efficient mechanism to counteract smoking-induced pathogenic processes leading to cancer (118), these 
results show that the malignant effects of exposure to tobacco-related carcinogens can linger for a lifetime in the bladder. The risk of BC per year of smoking increases gradually every year, indicating that smoking cessation programmes should aim to achieve smoking cessation as early in life as possible to effectively decrease BC risk due to smoking. The presented dose-response curves might be useful aids for developing such smoking cessation strategies.

\section{Lower risk of BC for smokers in Asian compared to Caucasian populations}

All studies in Asian populations observed lower ORs compared to pooled estimates from Europe and the USA. A similar difference was observed in lung cancer, where a metaanalysis showed a markedly lower pooled RR for smokers compared to never-smokers in Asian populations (pooled $\mathrm{RR}=5.52,95 \% \mathrm{CI}=2.83-10.78$ ) compared to studies in Caucasian populations (pooled $R R=9.94,95 \% C I=5.92,16.67$ ) (119). Even though the exact mechanism behind this lower susceptibility for tobacco-related cancers in Asian populations remains unclear, there is some evidence that nicotine intake from cigarette smoking is lower and that therefore Asian populations might be less susceptible genetically to the harmful effects of tobacco smoke compared to Caucasian populations (120) or that the high number of never smokers exposed to passive smoking, especially in females, might play a role in explaining the weaker association between active smoking and bladder cancer in Asian populations (121).

\section{Decreased population attributable risk (PAR) in Western countries for cigarette smoking in BC}

The PAR calculated for Europe was noticeably lower compared to the estimated PAR from the 2000 meta-analysis (2), where it was estimated that $50 \%$ of male cases and $35 \%$ of female cases were attributable to smoking, as opposed to the $43 \%$ and $26 \%$ for men and women respectively which were estimated in the current meta-analysis. This indicates that the burden of smoking on bladder cancer incidence has decreased. Although we have no earlier PAR estimate for the USA, it is likely that a similar decrease in BC risk attributable to smoking has occurred during the past 15 years. These lower figures are due to the currently decreasing number of smokers in these populations $(3,4)$, since the risk of $B C$ associated with smoking remains unaltered as we show in our cumulative meta-analysis. Even though the PARs were lower, the total number of worldwide incident BC cases only slightly decreased from 356557 in 2002 (122) to 330380 in 2012 (1), emphasizing the continuing importance of development of effective smoking cessation and prevention programmes. Interestingly, a pooled analysis from Nordic countries found very similar PARs (41\% in males and 32\% in females) to what we have observed now already in 1997 (123), indicating that there might be meaningful differences in PAR even at a regional 
level. Unfortunately, no PAR has been calculated previously for Eastern countries so we could not compare our estimated PAR for China to previous results. However, since smoking prevalence is still on the rise in China (5), it is highly unlikely that the PAR has decreased over the past years in China or other Eastern countries.

\section{Bias and heterogeneity}

Although the number of included studies was large, many articles did not present adjusted risk estimates. Since there was a difference in pooled OR between studies showing adjusted estimates compared to unadjusted estimates, we expect that not adjusting for at least age and sex might lead to underestimation of the strength of the association between smoking and BC incidence given the higher pooled OR for adjusted risk estimates. In the dose-response meta-analysis, both adjusted and unadjusted risk estimates were included and there was no heterogeneity between studies caused by the number of factors adjusted for.

In this meta-analysis, publication bias may have played a role since no attempts were made to include unpublished observations and several studies were excluded because of not meeting the selection criteria. However, since the number of included studies is very high, missing unpublished or excluded results will not have affected the presented risk estimates significantly. Additionally, when investigating funnel plots, the observed bias was bipolar (e.g. included both higher and lower estimates) and occurred mostly between larger studies. Since some degree of heterogeneity was likely to occur due to differences in study methodology (e.g. study population, design, smoking assessment) between the large number of studies included, a random effects approach to the meta-analyses was used. This approach allowed for more heterogeneity in studies beyond sampling error, as opposed to a fixed effects approach (124).

\section{Sensitivity analyses}

Subgroup analyses showed that SORs were similar across several possible sources of heterogeneity, except for studies from Asian populations. A cumulative meta-analysis showed no time effect on the overall risk estimate of smoking for BC. Although several regression methods were used for dose-response curve estimation, there were no differences between the shapes of the estimated curves resulting from the different analyses. Also, varying the knots (which determine how the curves are estimated) did not cause major changes in the shape of the curves. Both observations lead to the conclusion that the presented GLS curves are robust and can be interpreted as such. 


\section{Study limitations}

Because only 15 studies which adjusted for multiple factors (of which 8 adjusted their BC risk estimates for smokers for factors other than age and sex) were included, the pooled estimates obtained are not completely free of possible confounding due to other factors influencing $B C$ risk. The number of studies adjusting for multiple risk factors was probably low because especially the more recently published studies often do not focus solely on smoking but only considered smoking status as a stratifying factor in their molecular analyses for example. Nevertheless, apart from smoking, only occupational exposure to carcinogens has been identified as a major risk factor for BC. Since estimation of occupational exposure to carcinogens requires specific data collection on job history which is often only done in studies focussing on occupation and BC risk, none of the included studies on smoking and BC adjusted for occupational exposure in the risk estimates presented in their papers.

Additionally, most of the included studies were not clear on what classification for bladder cancer was used to indicate cases in the individual studies and merely stated broadly that a diagnosis of bladder cancer was needed for inclusion. Since the ICD coding, as well as the TNM classification, have changed over the approximately 45 years this meta-analysis spans, this might have caused some heterogeneity between the included risk estimates. Apart from not always showing data on tumour classification, studies included in this meta-analysis did not include sufficient data to stratify for important molecular aberrations which play a role in $B C$ development. Studies on molecular determinants of BC development have unveiled TP53 mutation and chromosome 9 defects as frequent molecular aberrations in BC aetiology $(125,126)$. Also, glutathione S-transferase M1 (GSTM1) and N-acetyl transferase2 (NAT2) deficiency are both associated with increased bladder cancer risk and are together estimated to account for about $30 \%$ of bladder cancer cases in Caucasian populations (127). Recently, several single nucleotide polymorphisms (SNPs) associated with increased risk of $B C$ have been identified on candidate genes such as fibroblast growth factor receptor 3 (FGFR3) and telomerase reverse transcriptase (TERT) (128). Some case-control studies focusing on molecular aberrations and BC also included data on smoking, however almost all the molecular studies found in our search did not present any useable smoking data for this meta-analysis.

\section{CONCLUSION}

Our findings are in line with results from earlier meta-analyses and reviews indicating an estimated threefold higher risk of $B C$ for cigarette smokers. Age at first exposure was negatively associated with $\mathrm{BC}$ risk. The proportions of $\mathrm{BC}$ cases attributable to smoking 
(PARs) were noticeably lower than estimated in 2000 for both males and females, driven by the decreasing number of smokers in Western countries. Furthermore, we estimated dose-response curves providing a more graphic quantification of the impact of smoking intensity, pack-years, duration and cessation on BC risk which provide opportunities for development of smoking cessation- and prevention programmes which should aim for smoking cessation at an early age. 


\section{REFERENCES}

1. Ferlay J, Soerjomataram I, Dikshit R, Eser S, Mathers C, Rebelo M, et al. Cancer incidence and mortality worldwide: sources, methods and major patterns in GLOBOCAN 2012. Int J Cancer. 2015;136(5):E359-E86.

2. Zeegers $\mathrm{M}$, Tan FE, Dorant $\mathrm{E}$, van den Brandt PA. The impact of characteristics of cigarette smoking on urinary tract cancer risk. Cancer. 2000;89(3):630-9.

3. OECD. Health at a Glance: Europe 2014. OECD Publishing (Internet). 2014. Available from: http://dx.doi.org/10.1787/health_glance_eur-2014-en.

4. Agaku IT, King BA, Dube SR, Control CfD, Prevention. Current cigarette smoking among adults_United States, 2005-2012. MMWR Morb Mortal Wkly Rep. 2014;63(2):29-34.

5. Li Q, Hsia J, Yang G. Prevalence of smoking in China in 2010. NEJM. 2011;364(25):2469-70.

6. Letašiová S, Medve'Ova A, Šovčíková A, Dušinská M, Volkovová K, Mosoiu C, et al. Bladder cancer, a review of the environmental risk factors. Environ Health. 2012;11(Suppl 1):S11.

7. Zeegers MP, Kellen E, Buntinx F, van den Brandt PA. The association between smoking, beverage consumption, diet and bladder cancer: a systematic literature review. World J Urol. 2004;21(6):392-401.

8. Danaei G, Vander Hoorn S, Lopez AD, Murray CJ, Ezzati M, group CRAc. Causes of cancer in the world: comparative risk assessment of nine behavioural and environmental risk factors. Lancet. 2005;366(9499):1784-93.

9. Wells G, Shea B, O'Connell D. The Newcastle-Ottawa Scale (NOS) for assessing the quality of nonrandomised studies in meta-analyses. Ottawa, ON-Ottawa Hospital Research Institute, 2013. 2014.

10. Egger M, Smith GD, Schneider M, Minder C. Bias in meta-analysis detected by a simple, graphical test. BMJ. 1997;315(7109):629-34.

11. Orsini N, Li R, Wolk A, Khudyakov P, Spiegelman D. Meta-analysis for linear and nonlinear dose-response relations: examples, an evaluation of approximations, and software. Am J Epidemiol. 2012;175(1):66-73.

12. Dunham LJ, Rabson AS, Stewart HL, Frank AS, Young JL. Rates, Interview, and Pathology Study of Cancer of the Urinary Bladder in New Orleans, Louisiana. Journal of the National Cancer Institute. 1968;41(3):683-709.

13. Anthony HM, Thomas GM. Bladder tumours and smoking. Int J Cancer. 1970;5(2):266-72.

14. Armstrong B, Garrod A, Doll R. A retrospective study of renal cancer with special reference to coffee and animal protein consumption. Br J Cancer. 1976;33(2):127-36.

15. Miller A, Howe G. Artificial sweeteners and bladder cancer. Lancet. 1977;310(8050):1221-2.

16. Wynder EL, Stellman SD. Comparative epidemiology of tobacco-related cancers. Cancer Res. 1977;37(12):4608-22.

17. Vineis P, Segnan N, Costa G, Terracini B. Evidence of a multiplicative effect between cigarette smoking and occupational exposures in the aetiology of bladder cancer. Cancer Lett. 1981;14(3):285-90.

18. Morrison AS, Buring JE, Verhoek WG, Aoki K, Leck I, Ohno Y, et al. An international study of smoking and bladder cancer. J Urol. 1984;131(4):650-4.

19. Rebelakos A, Trichopoulos D, Tzonou A, Zavitsanos X, Velonakis E, Trichopoulos A. Tobacco smoking, coffee drinking, and occupation as risk factors for bladder cancer in Greece. Journal of the National Cancer Institute. 1985;75(3):455-61. 
20. Sandler DP, Everson RB, Wilcox AJ. Passive smoking in adulthood and cancer risk. Am J Epidemiol. 1985;121(1):37-48.

21. Vineis $P$, Ciccone $G$, Ghisetti $V$, Terracini B. Cigarette smoking and bladder cancer in females. Cancer Lett. 1985;26(1):61-6.

22. Wynder EL, Dieck GS, Hall NE, Lahti H. A case-control study of diesel exhaust exposure and bladder cancer. Environ Res. 1985;37(2):475-89.

23. Claude J, Kunze E, Frentzel-Beyme R, Paczkowski K, Schneider J, Schubert H. Life-style and occupational risk factors in cancer of the lower urinary tract. Am J Epidemiol. 1986;124(4):57889.

24. Brownson RC, Chang JC, Davis JR. Occupation, smoking, and alcohol in the epidemiology of bladder cancer. Am J Public Health. 1987;77(10):1298-300.

25. Hartge $P$, Silverman $D$, Hoover R, Schairer C, Altman R, Austin D, et al. Changing cigarette habits and bladder cancer risk: a case-control study. Journal of the National Cancer Institute. 1987;78(6):1119-25.

26. Augustine A, Hebert JR, Kabat GC, Wynder EL. Bladder cancer in relation to cigarette smoking. Cancer Res. 1988;48(15):4405-8.

27. Slattery ML, Schumacher MC, West DW, Robison LM. Smoking and bladder cancer. The modifying effect of cigarettes on other factors. Cancer. 1988;61(2):402-8.

28. Steineck G, Norell SE, Feychting M. Diet, tobacco and urothelial cancer. A 14-year follow-up of 16,477 subjects. Acta Oncol. 1988;27(4):323-7.

29. Vineis P, Esteve J, Hartge P, Hoover R, Silverman DT, Terracini B. Effects of timing and type of tobacco in cigarette-induced bladder cancer. Cancer Res. 1988;48(13):3849-52.

30. Burch J, Rohan T, Howe G, Risch H, Hill G, Steele R, et al. Risk of bladder cancer by source and type of tobacco exposure: A case-control study. Int J Cancer. 1989;44(4):622-8.

31. Helzlsouer KJ, Comstock GW, Morris JS. Selenium, lycopene, alpha-tocopherol, betacarotene, retinol, and subsequent bladder cancer. Cancer Res. 1989;49(21):6144-8.

32. Ross RK, Paganini-Hill A, Landolph J, Gerkins V, Henderson BE. Analgesics, cigarette smoking, and other risk factors for cancer of the renal pelvis and ureter. Cancer Res. 1989;49(4):10458.

33. D’Avanzo B, Negri E, La Vecchia C, Gramenzi A, Bianchi C, Franceschi S, et al. Cigarette smoking and bladder cancer. European journal of cancer (Oxford, England : 1990). 1990;26(6):7148.

34. Harris RE, Chen-Backlund JY, Wynder EL. Cancer of the urinary bladder in blacks and whites. A case-control study. Cancer. 1990;66(12):2673-80.

35. Hartge P, Harvey EB, Linehan WM, Silverman DT, Sullivan JW, Hoover RN, et al. Unexplained excess risk of bladder cancer in men. J Natl Cancer Inst. 1990;82(20):1636-40.

36. de Stefani E, Correa P, Fierro L, Fontham E, Chen V, Zavala D. Black tobacco, mate, and bladder cancer. A case-control study from Uruguay. Cancer. 1991;67(2):536-40.

37. La Vecchia C, Negri E, D'Avanzo B, Savoldelli R, Franceschi S. Genital and urinary tract diseases and bladder cancer. Cancer Res. 1991;51(2):629-31.

38. Lopez-Abente G, Gonzalez CA, Errezola M, Escolar A, Izarzugaza I, Nebot M, et al. Tobacco smoke inhalation pattern, tobacco type, and bladder cancer in Spain. Am J Epidemiol. 1991;134(8):830-9.

39. Mills PK, Beeson WL, Phillips RL, Fraser GE. Bladder cancer in a low risk population: results from the Adventist Health Study. Am J Epidemiol. 1991;133(3):230-9. 
40. D'Avanzo B, La Vecchia C, Franceschi S, Negri E, Talamini R, Buttino I. Coffee consumption and bladder cancer risk. European journal of cancer (Oxford, England : 1990). 1992;28A(89):1480-4.

41. Kunze E, Chang-Claude J, Frentzel-Beyrne R. Life style and occupational risk factors for bladder cancer in Germany. A case-control study. Cancer. 1992;69(7):1776-90.

42. McLaughlin JK, Silverman DT, Hsing AW, Ross RK, Schoenberg JB, Yu MC, et al. Cigarette smoking and cancers of the renal pelvis and ureter. Cancer Res. 1992;52(2):254-7.

43. Chyou P-H, Nomura AMY, Stemmermann GN. A prospective study of diet, smoking, and lower urinary tract cancer. Ann Epidemiol. 1993;3(3):211-6.

44. Cordier S, Clavel J, Limasset JC, Boccon-Gibod L, Le Moual N, Mandereau L, et al. Occupational risks of bladder cancer in France: a multicentre case-control study. Int J Epidemiol. 1993;22(3):403-11.

45. Hayes RB, Friedell GH, Zahm SH, Cole P. Are the known bladder cancer risk-factors associated with more advanced bladder cancer? Cancer causes \& control : CCC. 1993;4(2):157-62.

46. Barbone F, Franceschi S, Talamini R, Bidoli E, La Vecchia C. Occupation and bladder cancer in Pordenone (north-east Italy): a case-control study. Int J Epidemiol. 1994;23(1):58-65.

47. Sorahan T, Lancashire RJ, Sole G. Urothelial cancer and cigarette smoking: findings from a regional case-controlled study. Br J Urol. 1994;74(6):753-6.

48. Sturgeon SR, Hartge P, Silverman DT, Kantor AF, Linehan WM, Lynch C, et al. Associations between bladder cancer risk factors and tumor stage and grade at diagnosis. Epidemiology. 1994;5(2):218-25.

49. D'Avanzo B, La Vecchia C, Negri E, Decarli A, Benichou J. Attributable risks for bladder cancer in northern Italy. Ann Epidemiol. 1995;5(6):427-31.

50. Tremblay C, Armstrong B, Theriault G, Brodeur J. Estimation of risk of developing bladder cancer among workers exposed to coal tar pitch volatiles in the primary aluminum industry. Am J Ind Med. 1995;27(3):335-48.

51. Bruemmer $B$, White $E$, Vaughan $T L$, Cheney $C L$. Nutrient intake in relation to bladder cancer among middle-aged men and women. Am J Epidemiol. 1996;144(5):485-95.

52. Engeland A, Andersen A, Haldorsen T, Tretli S. Smoking habits and risk of cancers other than lung cancer: 28 years' follow-up of 26,000 Norwegian men and women. Cancer causes $\&$ control : CCC. 1996;7(5):497-506.

53. Bedwani R, el-Khwsky F, Renganathan E, Braga C, Abu Seif HH, Abul Azm T, et al. Epidemiology of bladder cancer in Alexandria, Egypt: tobacco smoking. International journal of cancer Journal international du cancer. 1997;73(1):64-7.

54. Donato F, Boffetta P, Fazioli R, Aulenti V, Gelatti U, Porru S. Bladder cancer, tobacco smoking, coffee and alcohol drinking in Brescia, northern Italy. Eur J Epidemiol. 1997;13(7):795-800.

55. Teschke K, Morgan MS, Checkoway H, Franklin G, Spinelli JJ, van Belle G, et al. Surveillance of nasal and bladder cancer to locate sources of exposure to occupational carcinogens. Occup Environ Med. 1997;54(6):443-51.

56. Koivusalo M, Hakulinen $T$, Vartiainen T, Pukkala E, Jaakkola JJ, Tuomisto J. Drinking water mutagenicity and urinary tract cancers: a population-based case-control study in Finland. Am J Epidemiol. 1998;148(7):704-12.

57. Sorahan T, Hamilton L, Wallace DM, Bathers S, Gardiner K, Harrington JM. Occupational urothelial tumours: a regional case-control study. Br J Urol. 1998;82(1):25-32.

58. Pohlabeln $\mathrm{H}$, Jockel $\mathrm{KH}$, Bolm-Audorff $\mathrm{U}$. Non-occupational risk factors for cancer of the lower urinary tract in Germany. Eur J Epidemiol. 1999;15(5):411-9. 
59. Pommer W, Bronder E, Klimpel A, Helmert U, Greiser E, Molzahn M. Urothelial cancer at different tumour sites: role of smoking and habitual intake of analgesics and laxatives. Results of the Berlin Urothelial Cancer Study. Nephrol Dial Transplant. 1999;14(12):2892-7.

60. Pesch B, Haerting J, Ranft U, Klimpel A, Oelschlagel B, Schill W. Occupational risk factors for urothelial carcinoma: agent-specific results from a case-control study in Germany. MURC Study Group. Multicenter Urothelial and Renal Cancer. Int J Epidemiol. 2000;29(2):238-47.

61. Serra C, Bonfill X, Sunyer J, Urrutia G, Turuguet $D$, Bastus $R$, et al. Bladder cancer in the textile industry. Scand J Work Environ Health. 2000;26(6):476-81.

62. Castelao JE, Yuan J-M, Skipper PL, Tannenbaum SR, Gago-Dominguez M, Crowder JS, et al. Gender-and smoking-related bladder cancer risk. Journal of the National Cancer Institute. 2001;93(7):538-45.

63. Chiu BC, Lynch CF, Cerhan JR, Cantor KP. Cigarette smoking and risk of bladder, pancreas, kidney, and colorectal cancers in Iowa. Ann Epidemiol. 2001;11(1):28-37.

64. Vineis P, Marinelli D, Autrup H, Brockmoller J, Cascorbi I, Daly AK, et al. Current Smoking, Occupation, N-Acetyltransferase-2 and Bladder Cancer A Pooled Analysis of Genotypebased Studies. Cancer Epidemiol Biomarkers Prev. 2001;10(12):1249-52.

65. Pelucchi C, La Vecchia C, Negri E, Dal Maso L, Franceschi S. Smoking and other risk factors for bladder cancer in women. Prev Med. 2002;35(2):114-20.

66. Tripathi A, Folsom AR, Anderson KE. Risk factors for urinary bladder carcinoma in postmenopausal women. The Iowa Women's Health Study. Cancer. 2002;95(11):2316-23.

67. Zeegers MP, Goldbohm RA, van den Brandt PA. A prospective study on active and environmental tobacco smoking and bladder cancer risk (The Netherlands). Cancer Causes Control. 2002;13(1):83-90.

68. Gaertner RR, Trpeski L, Johnson KC. A case-control study of occupational risk factors for bladder cancer in Canada. Cancer Causes Control. 2004;15(10):1007-19.

69. Jee SH, Samet JM, Ohrr H, Kim JH, Kim IS. Smoking and cancer risk in Korean men and women. Cancer Causes Control. 2004;15(4):341-8.

70. Karagas MR, Tosteson TD, Morris JS, Demidenko E, Mott LA, Heaney J, et al. Incidence of transitional cell carcinoma of the bladder and arsenic exposure in New Hampshire. Cancer Causes Control. 2004;15(5):465-72.

71. Quirk JT, Li Q, Natarajan N, Mettlin CJ, Cummings KM. Cigarette smoking and the risk of bladder cancer in men and women. Tob Induc Dis. 2004;2(3):1-4.

72. Cao W, Cai L, Rao JY, Pantuck A, Lu ML, Dalbagni G, et al. Tobacco smoking, GSTP1 polymorphism, and bladder carcinoma. Cancer. 2005;104(11):2400-8.

73. Chen Y-C, Su H-JJ, Guo Y-LL, Houseman EA, Christiani DC. Interaction between environmental tobacco smoke and arsenic methylation ability on the risk of bladder cancer. Cancer Causes Control. 2005;16(2):75-81.

74. Bjerregaard BK, Raaschou-Nielsen O, Sørensen M, Frederiksen K, Christensen J, Tjønneland $\mathrm{A}$, et al. Tobacco smoke and bladder cancer-in the European Prospective Investigation into Cancer and Nutrition. Int J Cancer. 2006;119(10):2412-6.

75. Cantwell MM, Lacey JV, Schairer C, Schatzkin A, Michaud DS. Reproductive factors, exogenous hormone use and bladder cancer risk in a prospective study. Int J Cancer. 2006;119(10):2398-401.

76. Samanic C, Kogevinas M, Dosemeci M, Malats N, Real FX, Garcia-Closas M, et al. Smoking and bladder cancer in Spain: effects of tobacco type, timing, environmental tobacco smoke, and gender. Cancer Epidemiol Biomarkers Prev. 2006;15(7):1348-54. 
77. Terry PD, Umbach DM, Taylor JA. APE1 genotype and risk of bladder cancer: evidence for effect modification by smoking. Int J Cancer. 2006;118(12):3170-3.

78. Alberg AJ, Kouzis A, Genkinger JM, Gallicchio L, Burke AE, Hoffman SC, et al. A prospective cohort study of bladder cancer risk in relation to active cigarette smoking and household exposure to secondhand cigarette smoke. Am J Epidemiol. 2007;165(6):660-6.

79. Jiang X, Yuan J-M, Skipper PL, Tannenbaum SR, Mimi CY. Environmental tobacco smoke and bladder cancer risk in never smokers of Los Angeles County. Cancer Res. 2007;67(15):75405.

80. McGrath M, Wong JY, Michaud D, Hunter DJ, De Vivo I. Telomere length, cigarette smoking, and bladder cancer risk in men and women. Cancer Epidemiol Biomarkers Prev. 2007;16(4):815-9.

81. Demirel F, Cakan M, Yalçınkaya F, Topcuoglu M, Altug U. The association between personal habits and bladder cancer in Turkey. Int Urol Nephrol. 2008;40(3):643-7.

82. Baris D, Karagas MR, Verrill C, Johnson A, Andrew AS, Marsit CJ, et al. A case-control study of smoking and bladder cancer risk: emergent patterns over time. Journal of the National Cancer Institute. 2009;101(22):1553-61.

83. Cassidy A, Wang W, Wu X, Lin J. Risk of urinary bladder cancer: a case-control analysis of industry and occupation. BMC Can. 2009;9(1):443.

84. Stern MC, Van Den Berg D, Yuan J-M, Conti DV, Gago-Dominguez M, Pike MC, et al. Sequence variant on $3 q 28$ and urinary bladder cancer risk: findings from the los angeles-shanghai bladder case-control study. Cancer Epidemiol Biomarkers Prev. 2009;18(11):3057-61.

85. Wen H, Ding Q, Fang Z-j, Xia G-w, Fang J. Population study of genetic polymorphisms and superficial bladder cancer risk in Han-Chinese smokers in Shanghai. Int Urol Nephrol. 2009;41(4):855-64.

86. Srivastava P, Gangwar R, Kapoor R, Mittal RD. Bladder cancer risk associated with genotypic polymorphism of the matrix metalloproteinase- 1 and 7 in North Indian population. Dis Markers. 2010;29(1):37-46.

87. Tao L, Xiang Y-B, Wang R, Nelson HH, Gao Y-T, Chan KK, et al. Environmental tobacco smoke in relation to bladder cancer risk - the Shanghai bladder cancer study. Cancer Epidemiol Biomarkers Prev. 2010;19(12):3087-95.

88. Freedman ND, Silverman DT, Hollenbeck AR, Schatzkin A, Abnet CC. Association between smoking and risk of bladder cancer among men and women. JAMA. 2011;306(7):737.

89. Gangwar R, Mandhani A, Mittal RD. Functional polymorphisms of cyclooxygenase-2 (COX2) gene and risk for urinary bladder cancer in North India. Surgery. 2011;149(1):126-34.

90. MacKenzie T, Zens MS, Ferrara A, Schned A, Karagas MR. Diabetes and risk of bladder cancer: evidence from a case-control study in New England. Cancer. 2011;117(7):1552-6.

91. Grant EJ, Ozasa K, Preston D, Suyama A, Shimizu Y, Sakata R, et al. Effects of radiation and lifestyle factors on risks of urothelial carcinoma in the life span study of atomic bomb survivors. Radiat Res. 2012;178(1):86-98.

92. Jiang X, Castelao JE, Yuan JM, Stern MC, Conti DV, Cortessis VK, et al. Cigarette smoking and subtypes of bladder cancer. Int J Cancer. 2012;130(4):896-901.

93. Liu $Y$, Wang $H$, Lin $T$, Wei $Q$, Zhi $Y$, Yuan F, et al. Interactions between cigarette smoking and XPC-PAT genetic polymorphism enhance bladder cancer risk. Oncol Rep. 2012;28(1):337-45.

94. Welty CJ, Wright JL, Hotaling JM, Bhatti P, Porter MP, White E, editors. Persistence of urothelial carcinoma of the bladder risk among former smokers: Results from a contemporary, 
prospective cohort study. Urologic Oncology: Seminars and Original Investigations; 2012: Elsevier; 2012.

95. Ferreccio C, Yuan Y, Calle J, Benítez H, Parra RL, Acevedo J, et al. Arsenic, tobacco smoke, and occupation: associations of multiple agents with lung and bladder cancer. Epidemiology. 2013;24(6):898-905.

96. Isa F, Xie L-P, Hu Z, Zhong Z, Hemelt M, Reulen RC, et al. Dietary consumption and diet diversity and risk of developing bladder cancer: results from the South and East China case-control study. Cancer Causes Control. 2013;24(5):885-95.

97. Matic M, Pekmezovic T, Djukic T, Mimic-Oka J, Dragicevic D, Krivic B, et al., editors. GSTA1, GSTM1, GSTP1, and GSTT1 polymorphisms and susceptibility to smoking-related bladder cancer: A case-control study. Urologic Oncology: Seminars and Original Investigations; 2013: Elsevier.

98. Amr S, Dawson R, Saleh DaA, Magder LS, Mikhail NN, St. George DM, et al. Agricultural workers and urinary bladder cancer risk in Egypt. Arch Environ Health. 2014;69(1):3-10.

99. Polesel J, Bosetti C, di Maso M, Montella M, Libra M, Garbeglio A, et al. Duration and intensity of tobacco smoking and the risk of papillary and non-papillary transitional cell carcinoma of the bladder. Cancer Causes Control. 2014;25(9):1151-8.

100. Vermeulen S, Hanum N, Grotenhuis A, Castaño-Vinyals G, van der Heijden A, Aben K, et al. Recurrent urinary tract infection and risk of bladder cancer in the Nijmegen bladder cancer study. Br J Cancer. 2014.

101. Baena AV, Allam MF, Del Castillo AS, Díaz-Molina C, Tapia MJR, Abdel-Rahman AG, et al. Urinary bladder cancer risk factors in men: a Spanish case-control study. Eur J Cancer Prev. 2006;15(6):498-503.

102. Sadetzki S, Bensal D, Blumstein T, Novikov I, Modan B. Selected risk factors for transitional cell bladder cancer. Med Oncol. 2000;17(3):179-82.

103. Hours M, Dananche B, Fevotte J, Bergeret A, Ayzac L, Cardis E, et al. Bladder cancer and occupational exposures. Scand J Work Environ Health. 1994:322-30.

104. Jiang X, Castelao JE, Groshen S, Cortessis VK, Ross RK, Conti DV, et al. Alcohol consumption and risk of bladder cancer in Los Angeles County. Int J Cancer. 2007;121(4):839-45.

105. Hartge P, Hoover R, Kantor A. Bladder cancer risk and pipes, cigars, and smokeless tobacco. Cancer. 1985;55(4):901-6.

106. Vineis P, Frea B, Uberti E, Ghisetti V, Terracini B. Bladder cancer and cigarette smoking in males: a case-control study. Tumori. 1983;69(1):17-22.

107. Jensen OM, Wahrendorf J, Blettner M, Knudsen J, Sørensen B. The Copenhagen case-control study of bladder cancer: role of smoking in invasive and non-invasive bladder tumours. J Epidemiol Community Health. 1987;41(1):30-6.

108. Lin J, Spitz MR, Dinney CP, Etzel CJ, Grossman HB, Wu X. Bladder cancer risk as modified by family history and smoking. Cancer. 2006;107(4):705-11.

109. Wang $\mathrm{Y}-\mathrm{H}$, Yeh S-D, Wu M-M, Liu C-T, Shen $\mathrm{C}-\mathrm{H}$, Shen $\mathrm{K}-\mathrm{H}$, et al. Comparing the joint effect of arsenic exposure, cigarette smoking and risk genotypes of vascular endothelial growth factor on upper urinary tract urothelial carcinoma and bladder cancer. J Hazard Mater. 2013;262:1139-46.

110. McCormack VA, Agudo A, Dahm CC, Overvad K, Olsen A, Tjonneland A, et al. Cigar and pipe smoking and cancer risk in the European Prospective Investigation into Cancer and Nutrition (EPIC). Int J Cancer. 2010;127(10):2402-11. 
111. Godschalk RW, Van Schooten F-J, Bartsch H. A critical evaluation of DNA adducts as biological markers for human exposure to polycyclic aromatic compounds. Biochem Mol Biol Int. 2003;36(1):1-11.

112. Poirier MC, Fullerton NF, Smith BA, Beland FA. DNA adduct formation and tumorigenesis in mice during the chronic administration of 4-aminobiphenyl at multiple dose levels. Carcinogenesis. 1995;16(12):2917-21.

113. Dallinga JW, Pachen D, Wijnhoven S, Breedijk A, van't Veer L, Wigbout G, et al. The use of 4-aminobiphenyl hemoglobin adducts and aromatic DNA adducts in lymphocytes of smokers as biomarkers of exposure. Cancer Epidemiol Biomarkers Prev. 1998;7(7):571-7.

114. Lee PN, Forey BA, Coombs KJ. Systematic review with meta-analysis of the epidemiological evidence in the 1900s relating smoking to lung cancer. BMC Can. 2012;12(1):385.

115. Wyss A, Hashibe M, Chuang S-C, Lee Y-CA, Zhang Z-F, Yu G-P, et al. Cigarette, cigar, and pipe smoking and the risk of head and neck cancers: pooled analysis in the International Head and Neck Cancer Epidemiology Consortium. Am J Epidemiol. 2013;178(5):679-90.

116. Maasland DH, van den Brandt PA, Kremer B, Goldbohm RAS, Schouten LJ. Alcohol consumption, cigarette smoking and the risk of subtypes of head-neck cancer: results from the Netherlands Cohort Study. BMC Can. 2014;14(1):187.

117. De Vries H, Mudde AN, Dijkstra A, Willemsen MC. Differential beliefs, perceived social influences, and self-efficacy expectations among smokers in various motivational phases. Prev Med. 1998;27(5):681-9.

118. Department of Health and Human Services US. How tobacco smoke causes disease: The biology and behavioral basis for smoking-attributable disease: A report of the surgeon general: Centers for Disease Control and Prevention (US); 2010.

119. Gandini S, Botteri E, Iodice S, Boniol M, Lowenfels AB, Maisonneuve P, et al. Tobacco smoking and cancer: A meta-analysis. Int J Cancer. 2008;122(1):155-64.

120. Benowitz NL, Pérez-Stable EJ, Herrera B, Jacob P. Slower metabolism and reduced intake of nicotine from cigarette smoking in Chinese-Americans. Journal of the National Cancer Institute. 2002;94(2):108-15.

121. Yin $P$, Jiang $C$, Cheng $K$, Lam $T$, Lam $K$, Miller $M$, et al. Passive smoking exposure and risk of COPD among adults in China: the Guangzhou Biobank Cohort Study. Lancet. 2007 Sep 1;370(9589):751-7.

122. Parkin DM, Bray F, Ferlay J, Pisani P. Global cancer statistics, 2002. CA Cancer. 2005;55(2):74108.

123. Dreyer L, Winther J, Pukkala E, Andersen A. Tobacco smoking. Apmis. 1997;105(S76):9-47.

124. Hedges LV, Vevea JL. Fixed-and random-effects models in meta-analysis. Psychol Methods. 1998;3(4):486.

125. Hartmann A, Schlake G, Zaak D, Hungerhuber E, Hofstetter A, Hofstaedter F, et al. Occurrence of chromosome 9 and p53 alterations in multifocal dysplasia and carcinoma in situ of human urinary bladder. Cancer Res. 2002;62(3):809-18.

126. Spruck CH, Rideout WM, Olumi AF, Ohneseit PF, Yang AS, Tsai YC, et al. Distinct pattern of p53 mutations in bladder cancer: relationship to tobacco usage. Cancer Res. 1993;53(5):1162-6.

127. García-Closas M, Malats N, Silverman D, Dosemeci M, Kogevinas M, Hein DW, et al. NAT2 slow acetylation, GSTM1 null genotype, and risk of bladder cancer: results from the Spanish Bladder Cancer Study and meta-analyses. Lancet. 2005;366(9486):649-59.

128. Knowles MA, Hurst CD. Molecular biology of bladder cancer: new insights into pathogenesis and clinical diversity. Nat Rev Cancer. 2015;15(1):25-41. 


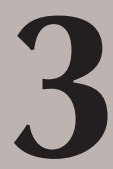

A stratified meta-analysis of the association between exposure to environmental tobacco smoke during childhood and adulthood and urothelial bladder cancer risk.

Frits H.M. van Osch, Sylvia H.J. Jochems, Anke Wesselius,

Frederik J. van Schooten, Richard T. Bryan, Maurice P. Zeegers

Adapted from:

Int. J. Environ. Res. Public Health (2018), 15(4), 569
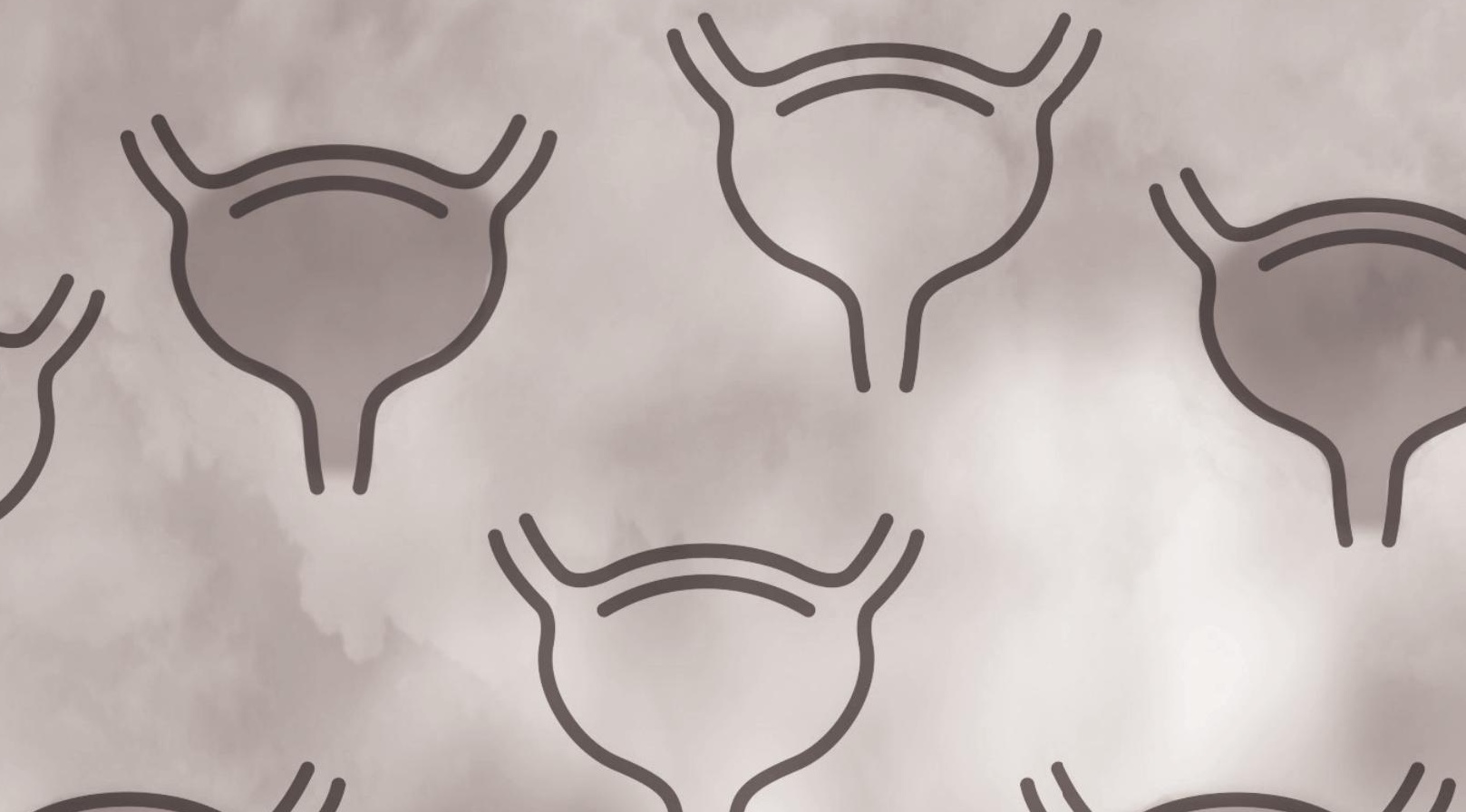


\section{ABSTRACT}

\section{Background}

Active smoking is a major risk factor for urothelial bladder cancer (UBC). However, the evidence that exposure to environmental tobacco smoke (ETS) either in childhood or adult life is also associated with UBC risk is ambiguous. With this meta-analysis, we aim to summarise how exposure to ETS is associated with UBC risk.

\section{Methods}

In total, 11 studies (3 cohort studies, 8 case-control studies) were included in this metaanalysis and summary odds ratios (SORs) for UBC risk were calculated for a total of 27.753 never smokers who were exposed to ETS during childhood at home, during adulthood at home, or during adulthood in a work environment compared to never smokers who were never exposed to ETS. Sensitivity analyses were conducted to test the robustness of findings.

\section{Results}

Never smokers exposed to ETS during childhood ( $\mathrm{SOR}=1.04,95 \%$ confidence interval $(C I)=0.82-1.26)$, during adulthood at work (SOR $=0.98,95 \% \mathrm{CI}=0.78-1.18)$ or at home (SOR $=0.99,95 \% \mathrm{CI}=0.83-1.15)$ were at a similar risk of UBC compared to never smokers who were never exposed to ETS. Results for males and females were similar. Also, when pooling all estimates during both childhood and adulthood, no effect was observed (SOR $=1.00,95 \% \mathrm{CI}=0.89-1.10)$.

\section{Conclusions}

Although measurement of exposure to ETS was imprecise, there does not seem to be an association between UBC risk and exposure to ETS during childhood or adulthood. However, the current body of evidence mostly overlooks the duration and intensity of exposure to ETS. 


\section{INTRODUCTION}

Cigarette smoking is a major risk factor for urothelial bladder cancer (UBC) and accountable for a large proportion of UBC cases (1). On average about $18 \%$ of adults smoke tobacco daily, with variation between countries worldwide (2). Although the number of smokers has decreased recently, there are still a lot of individuals potentially exposed to environmental tobacco smoke (ETS). Although fewer cases of cancer can be attributed to exposure to ETS compared to active smoking, it is a type of exposure that can be prevented to a large extent.

A comprehensive Surgeon General's report from 2006 on the health consequences of involuntary exposure to tobacco smoke in the United States described how homes and workplaces are the most common places for exposure to ETS, and that those with a relatively low income are more likely to be exposed to ETS (3). Moreover, a retrospective analysis of 192 countries showed that exposure to ETS was responsible for approximately $1 \%$ of global mortality in 2004 (4). Interestingly, in both large-scale reports, the association between exposure to ETS and UBC risk was not assessed, while associations with lung, breast, cervical and nasopharyngeal cancer are summarized (3). Although smoking is a major risk factor for UBC, the impact of exposure to ETS on UBC risk remains underreported compared to other smoking-related cancers.

A 2016 meta-analysis on exposure to ETS and the risks of developing cancers other than lung or breast revealed no significant association with UBC in cohort studies (OR $=0.99$, 95\% confidence interval $(C I)=0.75-1.31)$, case-control studies $(\mathrm{OR}=1.17,95 \% \mathrm{CI}=$ $0.99-1.39$ ) or all included studies (OR $=1.13,95 \% C I=0.98-1.30)(5)$. However, in this analysis childhood exposure was not assessed specifically, and not all studies that were pooled indicated whether exposure to ETS was at home (e.g., from a spouse or cohabitant) or at work. Moreover, there are several reports that exposure to ETS is common in both childhood and adolescents in for example the U.S. (6) and in adults in Greece (7). With our meta-analysis, we aim to provide and in-depth analysis of the effects of the exposure to ETS on UBC risk stratified by timing of exposure (childhood vs. adulthood exposure) and location of adulthood exposure to ETS (workplace or domestic exposure).

\section{METHODS}

\section{Literature Search}

Several online databases (Medline and Embase) were used to search for epidemiologic studies on exposure to ETS and UBC incidence. Search strategies included search terms 
such as "urinary bladder neoplasms", "incidence", "risk", "passive smoking", or "exposure to environmental tobacco smoke", and resulted in a total count of 110 articles after removal of duplicates. Additionally, cited articles in relevant reviews were checked to see whether any publications were missed. Articles were only included when they concerned human research on the association between ETS and the risk of UBC (primarily bladder cancer) and when risk estimates for UBC with 95\% confidence intervals (CIs) were provided in tables or were potentially derivable from the text.

\section{Data Collection}

All relevant papers published until December 2017 were assessed. In order to extract information on possible sources of heterogeneity and assess quality of included observational studies the Newcastle Ottawa scale (8) was applied to included publications by two authors (Frits H. M. van Osch and Sylvia H. J. Jochems). Data were either extracted directly from publications or ORs were estimated using manual calculation. When 95\% CI's had to be estimated an online tool was used (9). Exposure to ETS was defined as exposure to tobacco smoke from cigarettes, cigars or pipes which were smoked by someone else. If estimates for ETS exposure were only presented at different exposure levels the Excel spreadsheet described by Hamling et al. was used to obtain an overall risk estimate (10). To establish the effect of ETS on UBC risk, all relevant data on risk estimates of UBC for exposure to ETS was collected by two independent researchers (i.e., Frits H. M. van Osch and Sylvia H. J. Jochems). These include estimates on childhood and adulthood separately as well as combined lifetime exposure estimates. For the stratified analysis, the data had to strictly state where (at home, by a spouse, parent or other co-habitant or at work) and when (during childhood or adulthood) exposure took place for inclusion. Furthermore, data on year of publication, geographic area (North America, Europe, Asia, Africa, South America), exposure to ETS assessment (interview or questionnaire) and case and control source (hospital, population or both) was extracted.

\section{Statistical Analysis}

A random effects meta-analysis was performed because some heterogeneity in true effect of exposure to ETS is to be expected between study populations who were exposed to different types of tobacco. Additionally, funnel plots investigating publication bias and the Egger's test for small study effects were employed, as well as the $\mathrm{I}^{2}$ statistic describing the percentage of variation due to between-study heterogeneity. All analyses were performed stratified for timing of exposure (childhood or adulthood) and for location of exposure (domestic or at work). Adjusted ORs that were pooled had to be at least adjusted for age when taking the questionnaire and gender. Sensitivity analyses were performed by pooling all different types of exposure to ETS in one analysis and by pooling only case-control 
studies. All analyses were performed using Stata statistical software (version 14; Stata Corp., College Station, TX, USA).

\section{RESULTS}

\section{Study Characteristics}

Following full text evaluation, 14 articles initially met the inclusion criteria. None of the articles were excluded based on their quality assessment as all studies scored at least 7 out of 9 on the Newcastle-Ottawa scale. Of these 14 articles, two were excluded because it was not explicitly mentioned what the nature (timing and location) of exposure to ETS was $(11,12)$. Another study only showed results for urinary tract cancer and was therefore excluded (13). The remaining 11 publications, containing data from 12 populations, were included in our final analysis (Table 1).

Studies were mostly from Western countries, except for one study from China (14). Three cohort studies (15-17) and eight case-control studies (14,18-24) were identified. Of these studies, the majority focussed on (urothelial) bladder cancer, although one study combined all urothelial cancers (bladder, ureter, renal pelvis or urethra) (15). Furthermore, in the analysis domestic exposure to ETS data was pooled for any household members; studies which indicated spouses and other household members specifically were pooled to provide one risk estimate.

\section{Pooled Results from Stratified Analysis}

Only seven studies reported estimates on childhood exposure to ETS. Pooling UBC risk estimates from these studies resulted in a summary odds ratio (SOR) of 1.04 (95\% CI = 0.82-1.26) (Figure 1, panel A) for both genders combined. There were also seven studies that provided estimates of UBC risk (both genders combined) for never smokers exposed to ETS at work compared to those who were never exposed to ETS at work, which also showed no significant differences in UBC risk (SOR $=0.98,95 \% \mathrm{CI}=0.78-1.18$ ) (Figure 1, panel B).

Ten of the included studies estimated UBC risk for those exposed to ETS at home because of living with a spouse or any other cohabitant. Pooling the results from these studies resulted in a SOR of $0.99(95 \% \mathrm{CI}=0.83-1.15)$, also indicating no significant impact on UBC risk for those exposed to ETS (Figure 1, panel C). 
A. Risk of UBC - exposed to ETS during childhood

Study

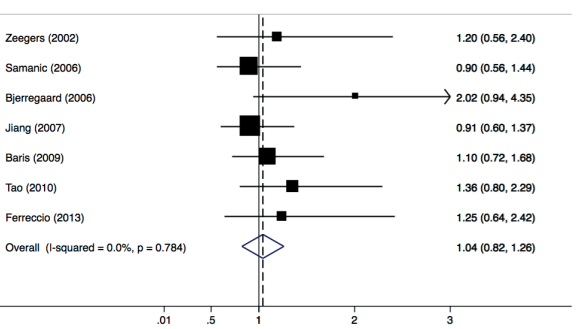

C. Risk of UBC - exposed to ETS at home (adulthood)

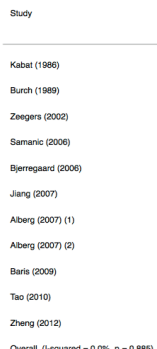

Overall (1.-9quared $=0.0 \%$, $p=0.88$

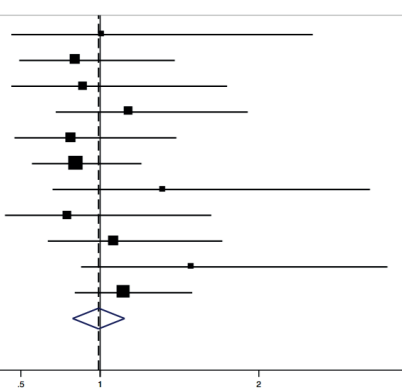

B. Risk of UBC - exposed to ETS at work (adulthood)

Stud

OR $(95 \% \mathrm{Cl})$

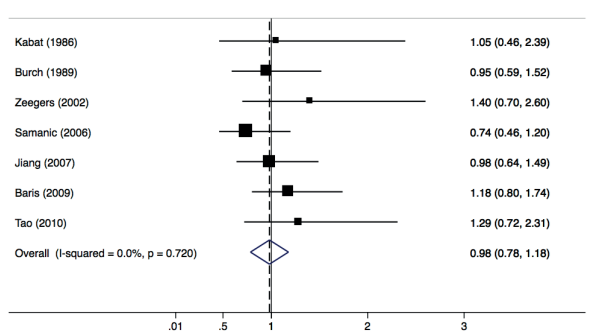

OR(195\% CD)

$1.01(0.44,234)$

$0.85(0.48,1.47)$

$0.89(0.44,1.80)$

$1.18(0.72,1.99)$

$0.82(0.46,1.48)$

$0.05(0.57 .126$

$1.40(0.70,2.70)$

$0.80(0.40,1.70)$

$1.09(0.67,1.7)$

$158(0.88,281)$

$1.15(0.84,1.58)$

$0.99(0.89,1.15)$

Figure 1. Meta-analysis results showing pooled risk estimates for urothelial bladder cancer (UBC) stratified by timing (childhood or adulthood) and location (work-related or domestic) of exposure to ETS for males and females combined.

\section{Heterogeneity and Publication Bias}

Heterogeneity between studies included in the analyses was very low, with an I2 of $0.0 \%$ ( $p$-value $>0.05$ in all three analyses) (Figure 1). Results were similar for males (Figure 2) and females (Figure 3). Although in men only, those exposed to workplace exposure to ETS seemed to have a lower risk of UBC (SOR $=0.69,95 \%$ CI $=0.40-0.99)$. However, this was strongly driven by a low risk estimate obtained from one study (Figure 2). However, this further stratification of the pooled risk estimates also showed the uncertainty in the analysis, for example in the broad confidence intervals for UBC risk in those exposed to ETS during childhood in males ( $\mathrm{SOR}=0.86,95 \% \mathrm{CI}=0.55-1.18)$ and females (SOR = $1.04,95 \% \mathrm{CI}=0.30-1.78)$. Generally, the pooled estimates for those exposed to ETS at home (panel $C$ in Figures $1-3$ ) were most stable (SORtotal $=0.99$, SORmales $=0.88$ and SORfemales $=0.94$ ). 
A. Risk of UBC - exposed to ETS during childhood

Study$$
\text { Study }
$$

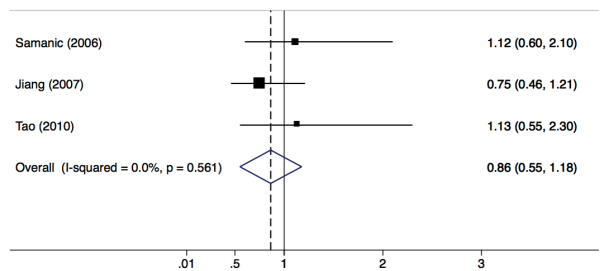

C. Risk of UBC - exposed to ETS at home (adulthood)

$$
\text { study }
$$

Kabat (1986)

Burch (1989)

Samanic (2006)

Jiang (2007)

Alberg (2007) (1)

Alberg (2007) (2)

Tao (2010)

Zheng (2012)

Overall (1-squared $-0.0 \%, p-0.556)$
OR $(95 \% \mathrm{Cl})$

Sudy

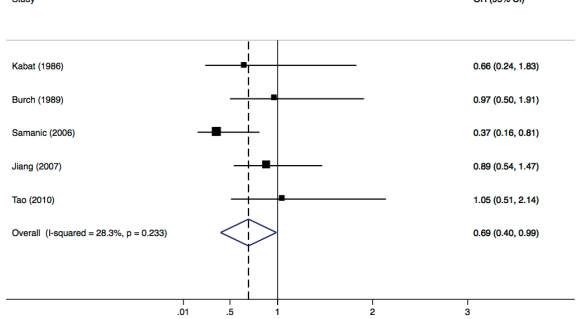

Figure 2. Meta-analysis results showing pooled risk estimates for urothelial bladder cancer (UBC) stratified by timing (childhood or adulthood) and location (work-related or domestic) of exposure to ETS for males only.

A. Risk of UBC - exposed to ETS during childhood

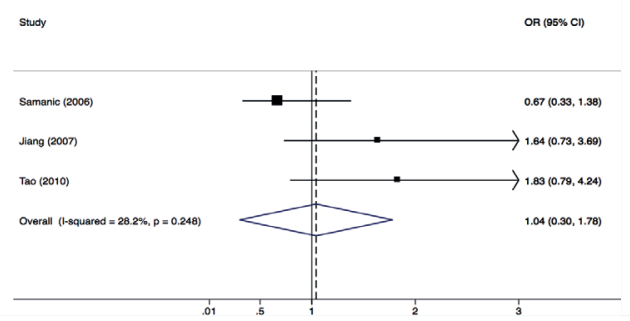

C. Risk of UBC - exposed to ETS at home (adulthood)

Study

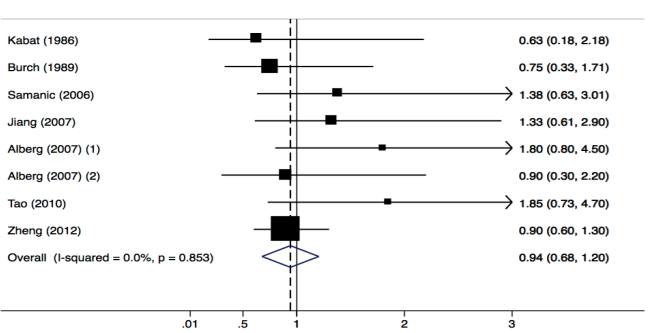

Figure 3. Meta-analysis results showing pooled risk estimates for urothelial bladder cancer (UBC) stratified by timing (childhood or adulthood) and location (work-related or domestic) of exposure to ETS for females only.
B. Risk of UBC - exposed to ETS at work (adulthood)

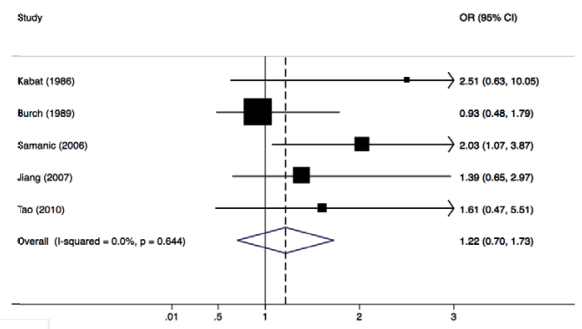

OR $(95 \% \mathrm{Cl})$ 
Egger's test for small-study effects indicated no publication bias by excluding estimates for smaller studies compared to larger studies in all three stratified analyses ( $p>0.05$ for all three analyses). Funnel plots also showed that all extracted risk estimates were within expected range of standard error of the pooled estimate based on their study's sample size (Supplemental Figure S1). When excluding risk estimates from the three included cohort studies and thus analysing only case-control studies, the SOR remained the same as in the overall analysis (SORchildhood $=1.01,95 \% \mathrm{CI}=0.79-1.24$, SORwork $=0.98$, $95 \% \mathrm{CI}=0.77-1.18$ and SORhome $=1.02,95 \% \mathrm{CI}=0.83-1.21)$, as shown in Supplemental Figure S2. Furthermore, when pooling all estimates of UBC risk regardless of timing or location of exposure to ETS there also did not seem to be any significant impact of exposure to ETS on UBC risk ( $S O R=1.00,95 \% C I=0.89-1.10)$ or any heterogeneity caused by pooling estimates of exposure at different times in life (I2 $=0 \%, p=0.978$ ). Furthermore, as there are no biological reasons to assume that there is a substantial difference between exposure to ETS at work or at home during adulthood, an additional analysis pooling all risk estimates obtained during adulthood showed similar results as the stratified analysis for males and females combined ( $S O R=0.99,95 \% C I=0.86-1.11)$ and for males and females separately (Figure S3).

A. Funnel plot - exposed to ETS during childhood

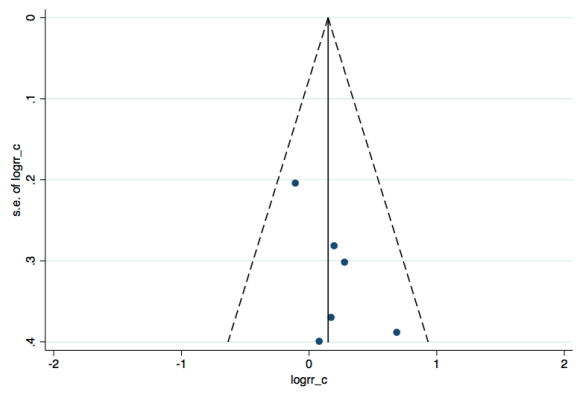

C. Funnel plot - exposed to ETS at home (adulthood)

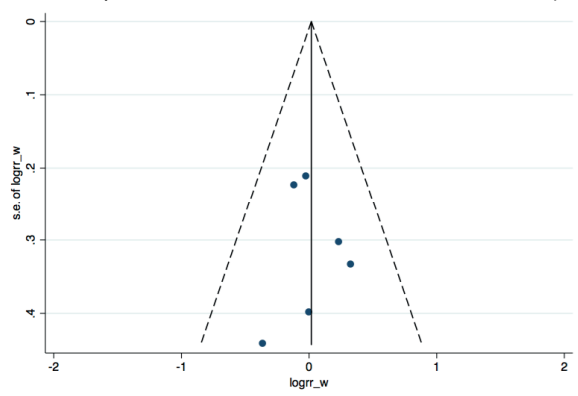

B. Funnel plot - exposed to ETS at work (adulthood)

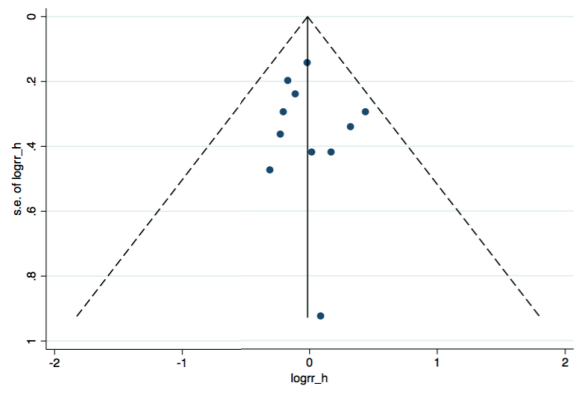

Figure S1. Funnel plots showing risk estimates from individual studies relative to the pooled OR for both analysis on childhood exposure to ETS and adulthood exposure to ETS (both males and females). 
A. Risk of UBC - exposed to ETS during childhood

study

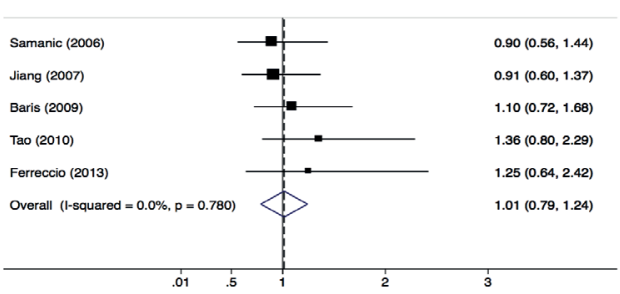

C. Risk of UBC - exposed to ETS at home (adulthood)

Study

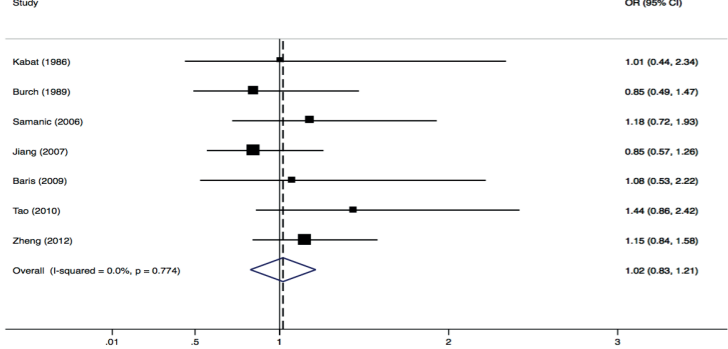

B. Risk of UBC - exposed to ETS at work (adulthood)

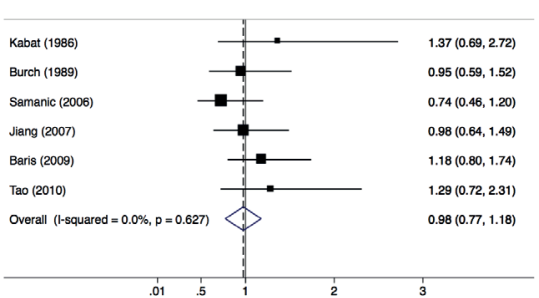

Figure S2. Meta-analysis results showing pooled risk estimates for urothelial bladder cancer (UBC) stratified by timing (childhood or adulthood) and location (work-related or domestic) of exposure to ETS for males and females combined, for case-control studies only.
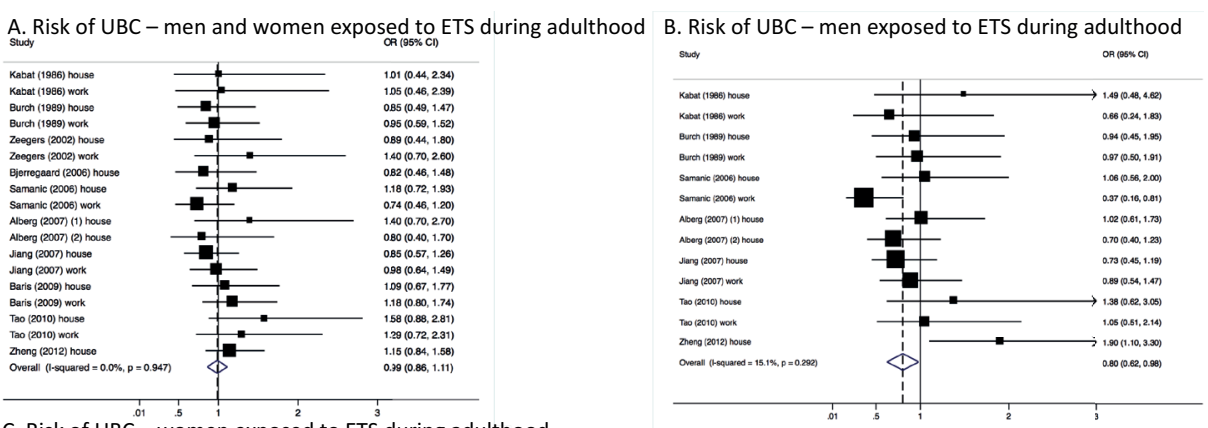

C. Risk of UBC - women exposed to ETS during adulthood

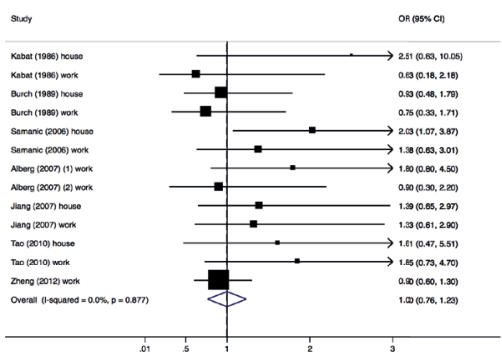

Figure S3. Meta-analysis results showing pooled risk estimates for urothelial bladder cancer (UBC) for males and females combined and males and females separately, combining all adulthood estimates. 


\section{DISCUSSION}

The results from this meta-analysis indicate no substantial effect of exposure to ETS during either childhood or adulthood on UBC risk in never smokers.

The heterogeneity among the included studies was very low and statistical power (assuming alpha $=0.05$ and 1 -beta $=0.80$ ) sufficient to observe a SOR of at least 1.18 in all estimates during childhood (observed SOR was $1.04,95 \% \mathrm{CI}=0.82-1.26$ ) and 1.17 in all estimates during adulthood at home (observed SOR was $0.99,95 \% \mathrm{CI}=0.83-1.15$ ). We used statistical programme $R$ to estimate the minimally detectable SOR when including 7 (childhood) or 12 (adulthood at home) estimates from the currently included articles in a random effects meta-analysis (25).

The pooled UBC risk estimates obtained on exposure to ETS are very likely influenced by recall bias (especially when estimating childhood exposure). It is often demonstrated that large, prospective studies that report results for exposure to ETS and lung cancer risk do not report corresponding results for UBC risk (5). Moreover, detailed information on the nature of exposure is often lacking. Studies rarely assess for how many years never smokers were exposed to ETS and whether the active smoker smoked daily or only sporadically. Therefore, risk estimates in the included studies are certainly confounded by the length of exposure and the smoking behaviour of the active smoker(s) providing the exposure to the never smoking subject.

Some of the included studies on exposure to ETS and UBC risk (included in this metaanalysis) have attempted to assess lifetime exposure to ETS and correct for length of exposure. Tao et al. described a combined index estimating lifetime exposure to ETS where different scores were added up for each member of the household that smoked (based on the number of cigarettes they smoked) and the hours of exposure to workplace ETS. The highest exposure category ( 5 or higher on a scale from 0-10) compared to never exposed never smokers showed an OR of 3.00 (1.24-7.26) (14). Jiang (2007) also estimated a cumulative index of ETS exposure (i.e., sum of childhood exposure and three levels of adulthood exposure (domestic, workplace and social). However, they showed no statistically significant associations with UBC risk either at intermediate exposure level (OR = $1.61,95 \% \mathrm{CI}=0.81-3.08$ ) or at highest exposure level ( $\mathrm{OR}=1.28,95 \% \mathrm{CI}=0.61-2.48)$. Also, Baris et al. found no association between a combined index of adulthood exposure with $U B C$ risk (high versus low exposure $O R=0.9,95 \% C I=0.4-2.0$ ) (22). Interestingly, adult men that did not smoke cigarettes or water pipe and were exposed to ETS both outside and at home gad a three times increased risk of UBC (95\% CI $=1.5-5.9)$ compared to other nontobacco-using men who were not exposed to ETS in Egypt which as statisti- 
cally significant (23). Because of the different ways of calculating cumulative exposure (e.g., only in adulthood or different weights to scores concerning number of cigarettes smoked) these data could not be pooled. However, it is noticeable that all studies that estimated some form of cumulative exposure showed an increased UBC risk, often being statistically significant, and with higher risk estimates than any of the individual estimates pooled in Figure 1. More research is warranted in cumulative exposure to ETS to see whether those in the highest cumulative exposure categories during both childhood and adulthood might be at an increased risk of UBC.

Additionally, two studies that were not included in the meta-analysis because they only reported on lifetime exposure to ETS (so not childhood or adulthood specifically) or reported ORs for UBC risk for both ever smokers and never smokers who were exposed to ETS combined $(12,16)$. In a Taiwanese case-control study the observed OR was 1.90 (95\% CI $=1.42-2.55)$ when comparing both never smokers and current smokers exposed to ETS to those who were not. In a separate analysis in only the never smokers exposed to ETS with low urinary arsenic levels the OR is not significant however (OR=1.72, 95\% $\mathrm{CI}=0.75-3.94)$, so the relatively strong point estimate can probably be explained by the active smokers included in the primary analysis (12). In a large European-wide cohort study the estimated OR for UBC risk in those exposed to ETS compared to those who were not was 1.38 (95\% CI = 1.00-1.90). Even though this estimate is probably overestimated, since both current smokers as well as never smokers exposed to ETS were considered in the exposed group (16). It would be meaningful to see more future research focussing on the effects of exposure to ETS in all subjects regardless of their smoking status like in these two studies and especially in current smokers who were also exposed to ETS.

Apart from the limited information that can be drawn from retrospectively gathered data, there are also possible confounders and effect modifiers that were not considered in the pooled studies. There is evidence of an interaction effect between arsenic methylation and exposure to ETS in determining UBC risk where only those with high total urinary arsenic level are at an increased risk of $\operatorname{UBC}(11,12)$, however both studies investigating this interaction were not included in the meta-analysis since they did not indicate what the timing and location of exposure to ETS was. Also, children of parents who smoke are more likely to start smoking themselves (26), possibly because nicotine receptors are also stimulated in the brain by second-hand smoke (27). Therefore, the never smokers that were exposed to ETS during childhood but never started smoking themselves are probably a biased reference group which is less susceptible to nicotine addiction compared to those who started smoking after being exposed to ETS. However, more research is needed in ever smokers who were exposed to ETS during childhood to confirm this. 


\section{CONCLUSIONS}

The current evidence suggests no substantial association between UBC risk and exposure to ETS either during childhood or adulthood. Nevertheless, the measurement of exposure to ETS was biased since data was retrospectively collected and using different questionnaires in the included studies. More detailed information on duration and intensity of exposure to ETS is needed to answer the question whether there is also no association with UBC risk in high lifetime cumulative exposure to ETS categories or in ever smokers who were exposed to ETS. 


\section{REFERENCES}

1. van Osch FH, Jochems SH, van Schooten F-J, Bryan RT, Zeegers MP. Quantified relations between exposure to tobacco smoking and bladder cancer risk: a meta-analysis of 89 observational studies. Int J Epidemiol [Internet]. 2016;45(3):857-70. Available from: https:// academic.oup.com/ije/article-lookup/doi/10.1093/ije/dyw044

2. Health at a Glance 2017 [Internet]. OECD Publishing; 2017 [cited 2017 Dec 19]. Available from: http://www.oecd-ilibrary.org/social-issues-migration-health/health-at-aglance-2017_health_glance-2017-en

3. US O on $\mathrm{S}$ and $\mathrm{H}$. The Health Consequences of Involuntary Exposure to Tobacco Smoke [Internet]. The Health Consequences of Involuntary Exposure to Tobacco Smoke: A Report of the Surgeon General. Centers for Disease Control and Prevention (US); 2006 [cited 2018 Jan 31]. Available from: http://www.ncbi.nlm.nih.gov/pubmed/20669524

4. Oberg $M$, Jaakkola MS, Woodward A, Peruga A, Prüss-Ustün A. Worldwide burden of disease from exposure to second-hand smoke: a retrospective analysis of data from 192 countries. Lancet (London, England) [Internet]. Elsevier; 2011 Jan 8 [cited 2018 Feb 5];377(9760):139-46. Available from: http://www.ncbi.nlm.nih.gov/pubmed/21112082

5. Lee PN, Thornton AJ, Hamling JS, Lee PN. Epidemiological evidence on environmental tobacco smoke and cancers other than lung or breast. Regul Toxicol Pharmacol [Internet]. 2016 Oct [cited 2016 Nov 28];80:134-63. Available from: https://ac.els-cdn.com/ S0273230016301702/1-s2.0-S0273230016301702-main.pdf?_tid=d016fdec-e4c4-11e7b7b1-00000aab0f02\&acdnat $=1513692141 \_84459$ e16b0959b16b1743af6a58ab6fd

6. Agaku IT, Singh T, Rolle I, Olalekan A-Y, King BA. Prevalence and Determinants of Secondhand Smoke Exposure Among Middle and High School Students. Pediatrics [Internet]. 2016 Feb 1 [cited 2018 Mar 6];137(2):e20151985. Available from: http://pediatrics.aappublications.org/cgi/doi/10.1542/peds.2015-1985

7. Rachiotis G, Barbouni A, Katsioulis A, Antoniadou E, Kostikas K, Merakou K, et al. Prevalence and determinants of current and secondhand smoking in Greece: results from the Global Adult Tobacco Survey (GATS) study. BMJ Open [Internet]. 2017 Jan 19 [cited 2018 Mar 6];7(1):e013150. Available from: http://bmjopen.bmj.com/lookup/doi/10.1136/bmjopen-2016-013150

8. Wells G, Shea B, O 'connell D, Peterson J, Welch V, Losos M, et al. The Newcastle-Ottawa Scale (NOS) for assessing the quality of nonrandomised studies in meta- analyses. [cited 2018 Jan 31]; Available from: http://www.medicine.mcgill.ca/rtamblyn/Readings\%5CThe Newcastle - Scale for assessing the quality of nonrandomised studies in meta-analyses.pdf

9. MedCalc. MedCalc's Odds ratio calculator [Internet]. [cited 2018 Mar 20]. Available from: https://www.medcalc.org/calc/odds_ratio.php

10. Hamling J, Lee $P$, Weitkunat $R$, Ambühl M. Facilitating meta-analyses by deriving relative effect and precision estimates for alternative comparisons from a set of estimates presented by exposure level or disease category. Stat Med [Internet]. 2008 Mar 30 [cited 2018 Mar 6];27(7):954-70. Available from: http://www.ncbi.nlm.nih.gov/pubmed/17676579

11. Chen Y-C, Su H-JJ, Guo Y-LL, Houseman EA, Christiani DC. Interaction between environmental tobacco smoke and arsenic methylation ability on the risk of bladder cancer. Cancer Causes Control [Internet]. 2005 Mar [cited 2018 Feb 2];16(2):75-81. Available from: http:// www.ncbi.nlm.nih.gov/pubmed/15868449 
12. Wu C-C, Chen M-C, Huang Y-K, Huang C-Y, Lai L-A, Chung C-J, et al. Environmental tobacco smoke and arsenic methylation capacity are associated with urothelial carcinoma. J Formos Med Assoc [Internet]. Elsevier; 2013 Sep 1 [cited 2018 Feb 2];112(9):554-60. Available from: https://www.sciencedirect.com/science/article/pii/S0929664613001794?via\%3Dihub

13. Sandler DP, Everson RB, Wilcox AJ. Passive smoking in adulthood and cancer risk. Am J Epidemiol [Internet]. 1985 Jan [cited 2018 Mar 6];121(1):37-48. Available from: http://www. ncbi.nlm.nih.gov/pubmed/3964991

14. Tao L, Xiang Y-B, Wang R, Nelson HH, Gao Y-T, Chan KK, et al. Environmental tobacco smoke in relation to bladder cancer risk-the Shanghai bladder cancer study. Cancer Epidemiol Biomarkers Prev. 2010;19(12):3087-95.

15. Zeegers MPA, Goldbohm RA, van den Brandt PA. A prospective study on active and environmental tobacco smoking and bladder cancer risk (The Netherlands). Cancer Causes Control [Internet]. 2002 [cited 2017 Dec 7];13(1):83-90. Available from: https://link.springer.com/ content/pdf/10.1023\%2FA\%3A1013954932343.pdf

16. Bjerregaard BK, Raaschou-Nielsen O, Sørensen M, Frederiksen K, Christensen J, Tjønneland $A$, et al. Tobacco smoke and bladder cancer-in the European prospective investigation into cancer and nutrition. Int J Cancer [Internet]. Wiley Subscription Services, Inc., A Wiley Company; 2006 Nov 15 [cited 2018 Feb 2];119(10):2412-6. Available from: http://doi.wiley. com/10.1002/ijc.22169

17. Alberg AJ, Kouzis A, Genkinger JM, Gallicchio L, Burke AE, Hoffman SC, et al. A prospective cohort study of bladder cancer risk in relation to active cigarette smoking and household exposure to secondhand cigarette smoke. Am J Epidemiol. 2007;165(6):660-6.

18. Kabat GC, Dieck GS, Wynder EL. Bladder cancer in nonsmokers. Cancer [Internet]. Wiley Subscription Services, Inc., A Wiley Company; 1986 Jan 15 [cited 2018 Feb 2];57(2):362-7. Available from: http://doi.wiley.com/10.1002/1097-0142\%2819860115\%2957\%3A2\%3C362 \%3A\%3AAID-CNCR2820570229\%3E3.0.CO\%3B2-F

19. Burch JD, Rohan TE, Howe GR, Risch HA, Hill GB, Steele R, et al. Risk of bladder cancer by source and type of tobacco exposure: a case-control study. Int J cancer [Internet]. 1989 Oct 15 [cited 2017 Dec 20];44(4):622-8. Available from: http://www.ncbi.nlm.nih.gov/ pubmed/2793235

20. Samanic C, Kogevinas M, Dosemeci M, Malats N, Real FX, Garcia-Closas M, et al. Smoking and bladder cancer in Spain: effects of tobacco type, timing, environmental tobacco smoke, and gender. Cancer Epidemiol Biomarkers Prev. 2006;15(7):1348-54.

21. Jiang $X$, Yuan J-M, Skipper PL, Tannenbaum SR, Mimi CY. Environmental tobacco smoke and bladder cancer risk in never smokers of Los Angeles County. Cancer Res. 2007;67(15):7540-5.

22. Baris D, Karagas MR, Verrill C, Johnson A, Andrew AS, Marsit CJ, et al. A case-control study of smoking and bladder cancer risk: emergent patterns over time. J Natl Cancer Inst [Internet]. Oxford University Press; 2009 Nov 18 [cited 2016 Feb 24];101(22):1553-61. Available from: http://jnci.oxfordjournals.org/content/101/22/1553.full

23. Zheng Y-L, Amr S, Saleh DA, Dash C, Ezzat S, Mikhail NN, et al. Urinary bladder cancer risk factors in Egypt: a multicenter case-control study. Cancer Epidemiol Biomarkers Prev [Internet]. American Association for Cancer Research; 2012 Mar 6 [cited 2018 Feb 2];21(3):537-46. Available from: http://www.ncbi.nlm.nih.gov/pubmed/22147365

24. Ferreccio C, Yuan Y, Calle J, Benítez H, Parra RL, Acevedo J, et al. Arsenic, tobacco smoke, and occupation: associations of multiple agents with lung and bladder cancer. Epidemiology. 2013;24(6):898-905. 
25. Valentine, J.C., Pigott, T.D. \& Rothstein, H.R., 2010. How Many Studies Do You Need? Journal of Educational and Behavioral Statistics, 35(2), pp.215-247.

26. Hill KG, Hawkins JD, Catalano RF, Abbott RD, Guo J. Family influences on the risk of daily smoking initiation. J Adolesc Health [Internet]. Elsevier; 2005 Sep 1 [cited 2018 Feb 7];37(3):202-10. Available from: http://www.ncbi.nlm.nih.gov/pubmed/16109339

27. Brody AL, Mandelkern MA, London ED, Khan A, Kozman D, Costello MR, et al. Effect of Secondhand Smoke on Occupancy of Nicotinic Acetylcholine Receptors in Brain. Arch Gen Psychiatry [Internet]. American Medical Association; 2011 Sep 1 [cited 2018 Feb 7];68(9):953. 



\section{4 Tar, nicotine and carbon monoxide yield of UK cigarettes and the risk of non-muscle-invasive and muscle- invasive bladder cancer.}

Frits H.M. van Osch, Charlotte G.G.M. Pauwels, Sylvia H.J. Jochems, Ranti Fayokun, Nicholas James, Michael Wallace, KK Cheng,

Richard T. Bryan, Frederik J. van Schooten, Maurice P. Zeegers

Adapted from:

European Journal of Cancer Prevention, Vol. 1 (2017)
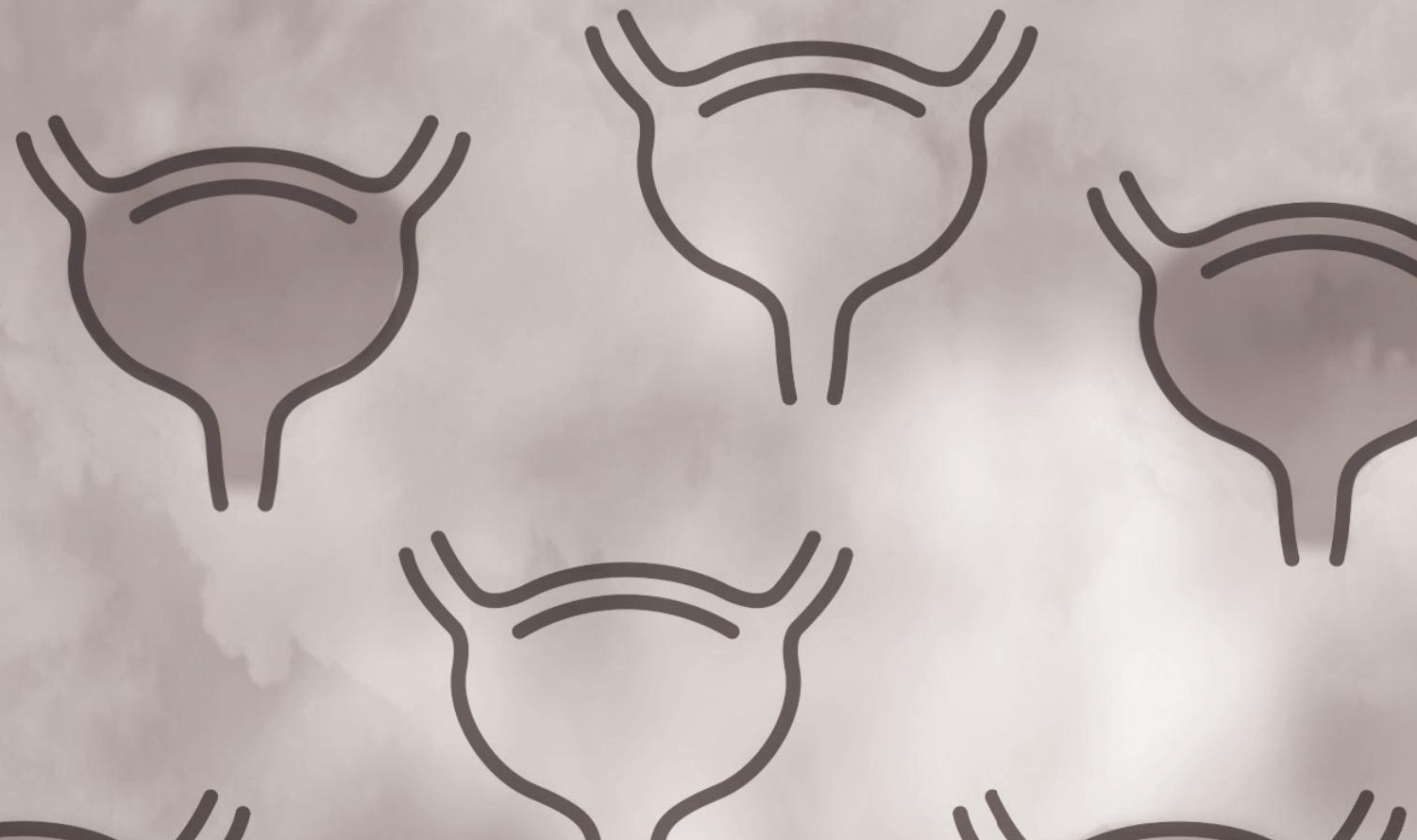


\section{ABSTRACT}

\section{Objective}

Cigarette smoking is a major risk factor for bladder cancer (BC), however the impact of cigarette content remains unclear. This study aims to investigate tar, nicotine and carbon monoxide (TNCO) yields of different filtered cigarettes in relation to BC risk.

\section{Methods}

From the Bladder Cancer Prognosis Programme 575 non-muscle-invasive BC (NMIBC) cases, 139 muscle-invasive BC (MIBC) cases and 130 BC-free hospital-based controls (who visited the urology clinic with symptoms indicative of bladder cancer) with retrospective data on smoking behaviour and cigarette brand were identified. Independently measured TNCO yields of cigarettes sold in the UK were obtained through the UK Department of Health and merged with the BCPP dataset to estimate daily intake of TNCO.

\section{Results}

$B C$ risk increased by TNCO intake category for NMIBC cases ( $p$ for trend $<0.050$ in all multivariate models) with the highest OR observed in the $>200 \mathrm{mg} /$ day category for $\operatorname{tar}(\mathrm{OR}=3.00,95 \% \mathrm{CI}=1.36-6.63)$. For MIBC, the linear trend was only significant in with increasing tar intake $(p=0.046)$ in multivariate models. No difference in risk is observed between smokers of low tar/low nicotine and high tar/high nicotine cigarettes compared to never smokers, neither for NMIBC $(p=0.544)$ nor MIBC $(p=0.449)$.

\section{Conclusion}

High daily intake of TNCO additionally increases both NMIBC and MIBC risk compared to low daily intake. However, since there is no difference in BC risk between low tar/low nicotine and high tar/high nicotine cigarette smokers it remains unclear whether smoking behaviour or TNCO yield of cigarettes explains this association. 


\section{BACKGROUND}

Active smoking is indicated as the most common risk factor for bladder cancer together with occupational exposure to carcinogenic chemicals and some diet-related factors $(1,2)$. The impact of cigarette smoking has been quantified in a large number of studies, and a recent meta-analysis showed that current smokers have a three-fold increased risk of developing BC compared to never smokers (3). The relation between the amount of smoking and cancer risk has been investigated extensively, and is mostly characterised by smoking duration in years, smoking intensity in cigarettes per day, or pack years (an amalgamation of duration and intensity).

However, the type of cigarette or cigarette composition is considered less often. Therefore, the evidence on the impact of different types of cigarettes, regarding the composition of the cigarette smoke, on BC risk remains weak. One case-control study has shown a decreased $B C$ risk for filter versus non-filter cigarette smokers $(R R=0.3,95 \% C I$ not given, for filter-tip only cigarette smokers compared to non-filter-tip smokers) (4). However, this has not been shown consistently as another large case-control study showed no risk difference $(\mathrm{OR}=1.00,95 \% \mathrm{CI}$ 0.62-1.63) (5). Additionally, several case-control studies seem to suggest that smokers of black tobacco, which is hypothesised to contain more aromatic amines due to the long (about 8 weeks) air-curing process for the tobacco leaves when smoked compared to blond tobacco which is flue-cured (takes about 1 week and tobacco leaves are exposed to heat during the curing process instead of the lower temperature of outside), are at an approximately two-fold increased risk of BC (4-7). Two observational studies quantified BC risk for different intakes of tar and nicotine, of which one showed a linearly increasing trend in risk related to the amount of tar and nicotine and the other study showed no association between BC risk and cumulative tar intake $(8,9)$. By introducing the filter tip, which changed cigarette design but not the tar and nicotine contents in most cases, smoking-related mortality has moderately decreased (10), although there are studies indicating that the levels of carcinogens in contemporary cigarettes might have become higher (11). Nevertheless, it remains unclear whether differences in cigarette content are related to meaningful differences in BC risk at population level. Therefore, we calculated the levels of tar, nicotine and carbon monoxide (TNCO) in mainstream smoke in a UK-based cohort study and aimed to investigate whether these levels influence BC risk. 


\section{METHODS}

\section{Study population}

This case-control study was conducted within the framework of the West Midlands Bladder Cancer Prognosis Programme (BCPP), an ongoing BC patient cohort study conducted in multiple centres in the West Midlands, United Kingdom. Further details of the BCPP are described elsewhere (12) and in chapter 1 of this thesis. In summary, the study population contained 1,544 adult individuals who were referred to one of the participating urology centres because of symptoms indicative of BC (predominantly haematuria). Of these 1,544 individuals, there were 1008 patients diagnosed with non-muscle-invasive bladder cancers (NMIBC), 275 muscle-invasive bladder cancer (MIBC) patients and 205 individuals were subsequently diagnosed as free from any form of cancer after histological tests at the urology clinic and selected as controls. Additionally, 57 patients were diagnosed with other primary cancers (e.g. prostate cancer) or had missing data on important staging data so could not be confirmed to have BC (Figure 1).

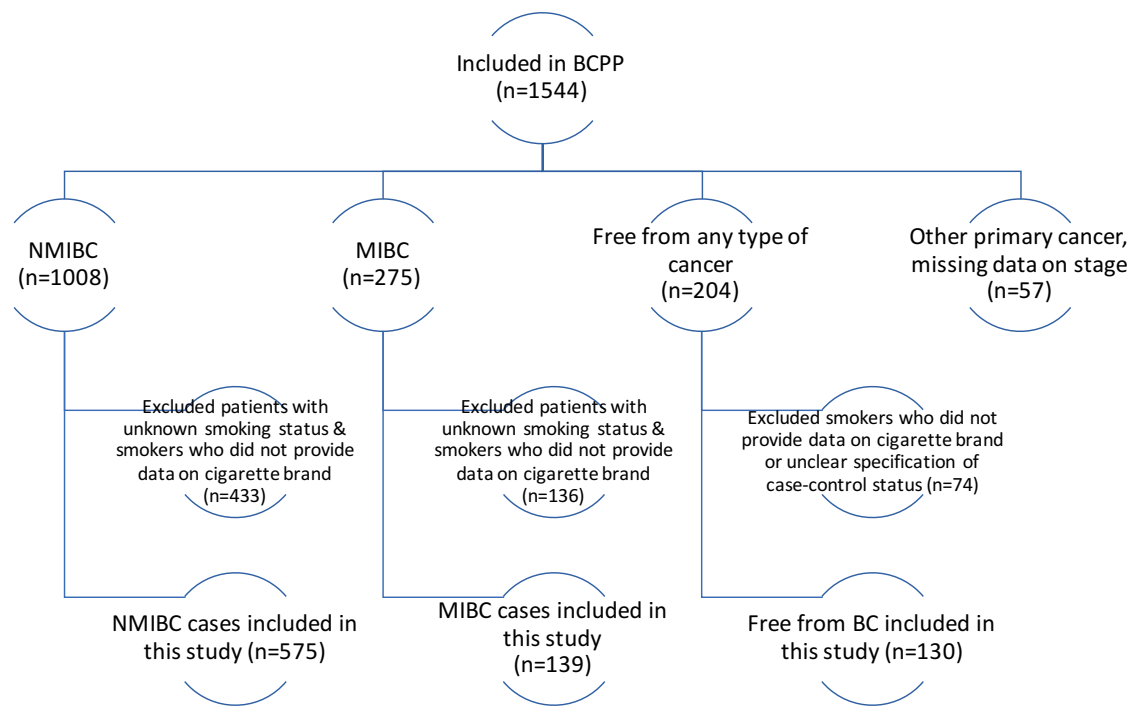

Figure 1. Flow chart of case and control selection from bladder cancer prognosis. BC, bladder cancer; BCPP, Bladder Cancer Prognosis Programme; MIBC, muscle-invasive bladder cancer; NMIBC, non-muscle-invasive bladder cancer.

Cases and controls whom did not provide data on cigarette brand and smoking status were excluded for analysis. Those who did not report data on cigarette brand were more often female ( $40 \%$ versus $21 \%$ in those reporting, chi-square $p$ value $<0.001)$, and slightly older (69.3 years versus 67.7 years, $p=0.058$ ). Of the 205 potential controls, 130 had a clear specification of control status and provided data on smoking status and cigarette brand. 
Of these 130 controls, 34 had benign papillomas, 25 a normal urothelium, 24 cystitis and 20 urothelial inflammation. In addition, for 27 BCPP participants in the control group, the urologist did not provide a description apart from "no bladder cancer present" (Figure 1). All participants received a baseline questionnaire including questions to assess demographic characteristics, occupation and retrospectively characterise smoking and dietary behaviour.

\section{TNCO data from the UK Department of Health}

In the UK, an approved and accredited laboratory appointed by the UK Department of Health periodically and independently analyses the yields of $\operatorname{tar}(T)$, nicotine $(N)$ and carbon monoxide (CO) in smoke of random samples of cigarette brands sold in the UK according to the International Organisation for Standardisation (ISO) standards (13). This examination verifies the TNCO yields declared on cigarette packs by manufacturers and ensures that the TNCO yields of cigarettes on the UK market do not exceed the maximum allowed levels as set out in the relevant Tobacco regulation $(10 \mathrm{mg} / \mathrm{cig}$ for tar, $1 \mathrm{mg} / \mathrm{cig}$ for nicotine and $10 \mathrm{mg} / \mathrm{cig}$ for $\mathrm{CO}$ ). This is a legal obligation in all Member States of the EU, and is set out in the UK in the Tobacco Products (Manufacture, Presentation, Presentation and Sale) (Safety) Regulations 2002 (Statutory Instrument 3041) (13). For tar, measurements were made in line with ISO 4387 and for nicotine and CO, ISO 10315 and ISO 8454 were used respectively, with the accuracy of measurements determined by ISO 8243 (14).

By combining these data with the filter cigarette brand(s) currently or previously smoked in BCPP and the number of cigarettes smoked per day, daily intake of TNCO was estimated. Intake is a proxy measure for absolute TNCO exposure, since it is an estimation of the amount of TNCO that reaches the lungs which is also influenced by smoking behaviour (e.g. puff volume and whether the cigarette is smoked completely). Patients who smoked brands which were not in the UK Department of Health database were either excluded (88 out of $602,15 \%)$ or the TNCO values were based on the original packaging as determined by the manufacturer (40 out of $602,7 \%$ ).

\section{Statistical analysis}

From the BCPP questionnaire data daily TNCO intake was estimated through multiplying the number of cigarettes smoked per day (smoking intensity) with the TNCO levels. Based on these TNCO levels, cigarettes were classified as either low tar/low nicotine (tar $<9 \mathrm{mg} /$ cigarette, nicotine $<0.9 \mathrm{mg} /$ cigarette) or high tar/high nicotine (tar $\geq 9 \mathrm{mg} /$ cigarette, nicotine $\geq 0.9 \mathrm{mg} /$ cigarette). Odds ratios (OR) and $95 \%$ confidence intervals (CI) estimating $\mathrm{BC}$ risk were calculated using logistic regression models. Potentially confounding factors included in multivariate analyses were restricted to age, sex, and smoking duration. Ideally, smoking intensity would also be included as a possible confounder but this was not 
possible due to collinearity issues because smoking intensity is used to estimate daily TNCO intake. Furthermore, data on occupation was sparse in controls ( $\mathrm{n}=2$ for controls, $\mathrm{n}=186$ for NMIBC cases) so occupational exposure could not be included as a covariate. Tests for linear dose-response trends in ORs between TNCO intake categories were performed by comparing logistic regression models with categorical variables for TNCO intake to models with a continuous variable for TNCO intake by using likelihood-ratio (LR) tests.

Table 1. Baseline characteristics of NMIBC cases, MIBC cases and BC-free controls

\begin{tabular}{|c|c|c|c|}
\hline & NMIBC $(n=575)$ & $\begin{array}{c}\text { MIBC } \\
(n=139)\end{array}$ & BC-free $(n=130)$ \\
\hline Age at diagnosis $(95 \% \mathrm{CI})$ & $68.0(67.1-68.8)$ & $70.1(68.2-71.9)$ & $65.2(63.0-67.5)$ \\
\hline $\operatorname{Sex}(M / F)$ & $442 / 133$ & $99 / 40$ & $91 / 39$ \\
\hline \multicolumn{4}{|l|}{ Smoking status } \\
\hline Never & 127 & 31 & 59 \\
\hline Former & 299 & 67 & 45 \\
\hline Current & 149 & 41 & 26 \\
\hline
\end{tabular}

\section{RESULTS}

After exclusion of cases and controls in the analysis because of missing data on cigarette brand or the number of cigarettes smoked per day 575 NMIBC, 139 MIBC and 130 BC-free participants were included in the analysis. Figure 1 summarises the inclusion of participants for this case-control study recruited from the BCPP participants. Table 1 shows the baseline characteristics of the included NMIBC, MIBC and BC-free controls who were included in the analysis.

Table 2 shows linearly increasing dose-response relationships between daily tar, nicotine and $\mathrm{CO}$ intake and NMIBC risk compared to never smokers in both adjusted and unadjusted models ( $p$-values below 0.05 in all models). The adjusted logistic regression models show mitigated associations compared to the unadjusted model. The highest OR was observed in the highest intake category for $\operatorname{tar}(\mathrm{OR}=3.00,95 \% \mathrm{CI}=1.36-6.63)$, although the 95\% confidence interval was wide.

The results were similar when looking at MIBC risk albeit the $95 \%$ confidence intervals were wider due to the smaller number of MIBC cases (Table 3). Furthermore, the only increasing trend in a multivariate model was observed for daily tar intake $(p=0.046)$ where the highest OR was 2.88 (95\% CI=1.10-7.55). 
Furthermore, there does not seem to be a meaningful difference in $\mathrm{BC}$ risk between smokers of low tar/low nicotine cigarettes and smokers of high tar/high nicotine cigarettes $(p=0.544$ for NMIBC and $p=0.449$ for MIBC). Additionally, smokers of low tar/low nicotine cigarettes did not smoke more filter cigarettes than high tar/high nicotine cigarette smokers daily ( $p=0.516$, data not shown).

Table 2. Adjusted and unadjusted odds ratios (OR) estimating NMIBC risk for daily tar, nicotine and $\mathrm{CO}$ intake and cigarette type comparing ever smokers to never smokers.

\begin{tabular}{|c|c|c|c|c|}
\hline & $\begin{array}{c}\text { Cases in } \\
\text { cohort }\end{array}$ & $\begin{array}{l}\text { Controls } \\
\text { in cohort }\end{array}$ & OR $(95 \% \mathrm{CI})$ crude & $\begin{array}{c}\text { OR (95\% CI) } \\
\text { multivariate } \\
\text { adjusted model* }\end{array}$ \\
\hline Never smoker & 127 & 59 & 1.00 (reference) & 1.00 (reference) \\
\hline Ever smoker & 448 & 71 & $2.93(1.97-4.36)$ & $2.14(1.11-4.11)$ \\
\hline \multicolumn{5}{|l|}{ Tar (mg/day) } \\
\hline$<100$ & 130 & 30 & $2.01(1.22-3.33)$ & $1.57(0.78-3.15)$ \\
\hline $100-<200$ & 154 & 21 & $3.41(1.96-5.91)$ & $2.73(1.23-6.03)$ \\
\hline$>200$ & 161 & 19 & $3.94(2.23-6.94)$ & $3.00(1.36-6.63)$ \\
\hline$p$-value for linear trend & & & $<0.001$ & 0.007 \\
\hline \multicolumn{5}{|l|}{ Nicotine (mg/day) } \\
\hline$<5$ & 70 & 18 & $1.81(0.99-3.30)$ & $1.48(0.69-3.18)$ \\
\hline $5-<10$ & 93 & 16 & $2.70(1.46-4.99)$ & $2.02(0.90-4.55)$ \\
\hline $10-<15$ & 113 & 15 & $3.50(1.88-6.51)$ & $2.71(1.15-6.41)$ \\
\hline$>15$ & 169 & 21 & $3.74(2.16-6.47)$ & $2.85(1.32-6.19)$ \\
\hline $\mathrm{p}$-value for linear trend & & & $<0.001$ & 0.030 \\
\hline \multicolumn{5}{|l|}{ CO (mg/day) } \\
\hline$<50$ & 68 & 16 & $1.97(1.06-3.69)$ & $1.62(0.73-3.56)$ \\
\hline $50-<100$ & 71 & 14 & $2.36(1.23-4.52)$ & $1.69(0.74-3.83)$ \\
\hline $100-<150$ & 103 & 14 & $3.42(1.81-6.47)$ & $2.76(1.15-6.61)$ \\
\hline$>150$ & 203 & 26 & $3.63(2.17-6.05)$ & $2.75(1.30-5.84)$ \\
\hline $\mathrm{p}$-value for linear trend & & & $<0.001$ & 0.034 \\
\hline \multicolumn{5}{|l|}{ Ever smoker cigarette type } \\
\hline Low tar/low nicotine & 52 & 7 & $3.45(1.48-8.05)$ & $2.80(0.97-8.06)$ \\
\hline High tar/high nicotine & 396 & 64 & $2.87(1.91-4.32)$ & $2.14(1.11-4.12)$ \\
\hline $\mathrm{p}$-value & & & 0.667 & 0.544 \\
\hline
\end{tabular}

*adjusted for age, sex and smoking duration 
Table 3. Adjusted and unadjusted odds ratios (OR) estimating MIBC risk for daily tar, nicotine and $\mathrm{CO}$ intake and cigarette type comparing ever smokers to never smokers.

\begin{tabular}{|c|c|c|c|c|}
\hline & $\begin{array}{c}\text { Cases in } \\
\text { cohort }\end{array}$ & $\begin{array}{c}\text { Controls in } \\
\text { cohort }\end{array}$ & OR $(95 \% \mathrm{CI})$ crude & $\begin{array}{c}\text { OR }(95 \% \mathrm{CI}) \\
\text { multivariate } \\
\text { adjusted model* }\end{array}$ \\
\hline Never smoker & 31 & 59 & 1.00 (reference) & 1.00 (reference) \\
\hline Ever smoker & 108 & 71 & $2.90(1.71-4.91)$ & $1.82(0.79-4.21)$ \\
\hline \multicolumn{5}{|l|}{ Tar (mg/day) } \\
\hline$<100$ & 33 & 30 & $2.09(1.08-4.04)$ & $1.31(0.52-3.28)$ \\
\hline $100-<200$ & 28 & 21 & $2.54(1.24-5.18)$ & $1.42(0.51-3.99)$ \\
\hline$>200$ & 44 & 19 & $4.41(2.21-8.80)$ & $2.88(1.10-7.55)$ \\
\hline $\mathrm{p}$-value for linear trend & & & $>0.001$ & 0.046 \\
\hline \multicolumn{5}{|l|}{ Nicotine (mg/day) } \\
\hline$<5$ & 19 & 18 & $1.89(0.92-4.37)$ & $1.30(0.48-3.50)$ \\
\hline $5-<10$ & 19 & 16 & $2.26(1.02-5.00)$ & $1.26(0.43-3.70)$ \\
\hline $10-<15$ & 19 & 15 & $2.41(1.08-5.39)$ & $1.34(0.43-4.20)$ \\
\hline$>15$ & 48 & 21 & $4.35(2.22-8.52)$ & $2.75(1.07-7.11)$ \\
\hline $\mathrm{p}$-value for linear trend & & & $>0.001$ & 0.105 \\
\hline \multicolumn{5}{|l|}{ CO (mg/day) } \\
\hline$<50$ & 18 & 16 & $2.14(0.96-4.77)$ & $1.40(0.51-3.83)$ \\
\hline $50-<100$ & 17 & 14 & $2.31(1.01-5.30)$ & $1.19(0.39-3.60)$ \\
\hline $100-<150$ & 12 & 14 & $1.63(0.67-3.95)$ & $0.96(0.29-3.16)$ \\
\hline$>150$ & 58 & 26 & $4.25(2.25-8.01)$ & $2.60(1.03-6.56)$ \\
\hline $\mathrm{p}$-value for linear trend & & & $>0.001$ & 0.061 \\
\hline \multicolumn{5}{|l|}{ Ever smoker cigarette type } \\
\hline Low tar/low nicotine & 13 & 7 & $3.53(1.27-9.77)$ & $2.69(0.73-9.84)$ \\
\hline High tar/high nicotine & 95 & 64 & $2.83(1.64-4.84)$ & $1.80(0.77-4.18)$ \\
\hline$p$-value & & & 0.265 & 0.449 \\
\hline
\end{tabular}

*adjusted for age, sex and smoking duration 


\section{DISCUSSION}

This study is the first to investigate all TNCO levels from cigarettes in relation to BC risk within a single study sample. Our results confirm the findings of another study, indicating a linearly increasing dose-response relationship for daily tar and nicotine intake. Additionally, we showed a similar association with daily CO intake (8). Another study investigating cumulative tar intake did not show any association with BC risk (9). Our results indicate that especially the highest daily intake categories of TNCO values are associated with an increased risk of $\mathrm{BC}$ compared to the lower categories.

Smokers persist in their smoking habits because of the addictive properties associated with nicotine intake. Nicotine is in itself not a strong carcinogen, but with each puff a smoker inhales a mixture of chemical carcinogens, including polycyclic aromatic hydrocarbons (PAHs), tobacco-specific nitrosamines (TSAs) as well as many other carcinogens, that can bind with DNA to form DNA adducts, which drive the carcinogenic process (15) For TSAs and PAHs, biomarker studies in smokers have shown corresponding 206 high levels of adducts to DNA and haemoglobin adducts, as well as for metabolites in urine (16-18). Further, nicotine might be involved in tumour cell proliferation through activation of Stat3 and possibly also the PI3K/Akt/mTOR pathway (19), indicating that it might play a role in disease progression rather than in carcinogenesis itself, although the association with BC risk seems slightly less strong compared to tar. Tar from cigarette smoke is believed to be associated with cancer risk because it is a fraction that contains a high concentration of polycyclic aromatic compounds, oxidants and free radicals which all play an important role in inducing DNA damage, possibly leading to carcinogenesis (20).

The results might be driven by the number of cigarettes smoked and to a lesser extent by TNCO values of cigarettes, since we did not observe any meaningful differences in $\mathrm{BC}$ risk between smokers of low tar/low nicotine and high tar/high nicotine cigarettes. More importantly though, this analysis was underpowered because of the low number of controls smoking low tar/low nicotine cigarettes $(n=7)$ and therefore no conclusions can be drawn from this analysis. A post hoc power calculation, using statistical power programme $\mathrm{G}^{*}$ Power 3 (21) and assuming an alpha of 0.05 and a power of 0.80 , indicated that the smallest detectable OR for low tar/low nicotine smokers compared to never smokers was 2.86 for the crude analysis in NMIBC patients (the largest group), so the multivariate analysis also adjusting for confounders age, sex and smoking duration was clearly underpowered since including confounders would only increase the minimally detectable OR. Furthermore, the low statistical power of this comparison is also reflected in the wide $95 \%$ confidence interval (0.97-8.06). Future studies with sufficient statistical power should investigate whether smokers of low tar/low nicotine cigarettes do not 
smoke more cigarettes than high tar/high nicotine cigarette smokers or whether they might alter their smoking behaviour (e.g. larger puff volume or more puffs) to increase nicotine intake (22), as has been observed in other studies. Our estimates of daily TNCO intake might be confounded by this compensation behaviour but could not be corrected for as detailed smoking behaviour data was not collected.

Furthermore, the controls were selected from the BCPP cohort in which all participants were under suspicion of bladder cancer at inclusion. Therefore, the control group included individuals with chronic urothelial inflammation (23) and benign papilloma (including some inverted papillomas) (24) which could be considered risk factors for BC development. Hence, the presented ORs are probably underestimated because our control group is more similar to the case group than a hypothetical, completely healthy control group because of the presence of these risk factors. In addition to this, the control group is small,

\section{CONCLUSION}

High daily intake of TNCO increases NMIBC risk compared to low daily intake. However, it remains unclear whether smoking behaviour or cigarette type causes this association. More research with larger sample sizes is needed to corroborate these results and to shed light on whether smoking behaviour outplays cigarette content in determining BC risk. 


\section{REFERENCES}

1. Antoni S, Ferlay J, Soerjomataram I, Znaor A, Jemal A, Bray F. Bladder Cancer Incidence and Mortality: A Global Overview and Recent Trends. Eur Urol. 2017;71: 96-108. doi:10.1016/j. eururo.2016.06.010

2. Al-Zalabani AH, Stewart KFJ, Wesselius A, Schols AMWJ, Zeegers MP. Modifiable risk factors for the prevention of bladder cancer: a systematic review of meta-analyses. Eur J Epidemiol. Springer Netherlands; 2016;31: 811-851. doi:10.1007/s10654-016-0138-6

3. van Osch FH, Jochems SH, van Schooten F-J, Bryan RT, Zeegers MP. Quantified relations between exposure to tobacco smoking and bladder cancer risk: a meta-analysis of 89 observational studies. Int J Epidemiol. 2016;45: 857-870. doi:10.1093/ije/dyw044

4. Vineis $P$, Estève J, Terracini B. Bladder cancer and smoking in males: Types of cigarettes, age at start, effect of stopping and interaction with occupation. Int J Cancer. 1984;34: 165-170. doi:10.1002/ijc.2910340205

5. Momas I, Daures JP, Festy B, Bontoux J, Gremy F. Bladder cancer and black tobacco cigarette smoking. Some results from a French case-control study. Eur J Epidemiol. 1994 Oct; 10(5):599-604.

6. Clavel J, Cordier S, Boccon-Gibod L, Hemon D. Tobacco and bladder cancer in males: Increased risk for inhalers and smokers of black tobacco. Int J Cancer. 1989;44: 605-610. doi:10.1002/ijc.2910440408

7. Vineis P, Esteve J, Hartge P, Hoover R, Silverman DT, Terracini B. Effects of timing and type of tobacco in cigarette-induced bladder cancer. Cancer Res. 1988;48(13):3849-52.

8. Zeegers MPA, Goldbohm RA, van den Brandt PA. A prospective study on active and environmental tobacco smoking and bladder cancer risk (The Netherlands). Cancer Causes Control. 2002;13: 83-90. Available: https://link.springer.com/content/ pdf/10.1023\%2FA\%3A1013954932343.pdf

9. Castelao JE, Yuan J-M, Skipper PL, Tannenbaum SR, Gago-Dominguez M, Crowder JS, et al. Gender-and smoking-related bladder cancer risk. J Natl Cancer Inst. 2001;93: 538-545.

10. Tang J-LL, Morris JK, Wald NJ, Hole D, Shipley M, Tunstall-Pedoe H. Mortality in relation to tar yield of cigarettes: a prospective study of four cohorts. BMJ. 1995;311: 1530-1533. doi:10.1136/bmj.311.7019.1530

11. Baris D, Karagas MR, Verrill C, Johnson A, Andrew AS, Marsit CJ, et al. A case-control study of smoking and bladder cancer risk: emergent patterns over time. J Natl Cancer Inst. Oxford University Press; 2009;101: 1553-61. doi:10.1093/jnci/djp361

12. Zeegers MP, Bryan RT, Langford C, Billingham L, Murray P, Deshmukh NS, et al. The West Midlands Bladder cancer prognosis programme: Rationale and design. BJU Int. 2010;105: 784-788. doi:10.1111/j.1464-410X.2009.08849.x

13. Legislation UK. Tobacco Products (Manufacture, Presentation and Sale) (Safety) Regulations 2002 (Internet). 2002 (cited 30 May 2016). Available: http://www.legislation.gov.uk/ uksi/2002/3041/regulation/1/made

14. International Organization for Standardization (ISO). ISO protocols TNCO determination (Internet). (cited 6 Apr 2016). Available: http://www.iso.org/iso/iso_catalogue/catalogue_tc/ catalogue_detail.htm?csnumber=28323 https://www.iso.org/obp/ui/\#iso:std:60154:en http://www.iso.org/iso/catalogue_detail.htm?csnumber=41168 http://www.iso.org/iso/ iso_catalogue/catalogue_tc/cat 
15. Yalcin E, Monte S de la (2016) Tobacco nitrosamines as culprits in disease: 267 mechanisms reviewed. J. Physiol. Biochem.

16. Bryant MS, Vineis P, Skipper PL, Tannenbaum SR (1988) Hemoglobin adducts of aromatic amines: associations with smoking status and type of tobacco. Proc Natl Acad Sci USA 85:9788-91.

17. Yershova K, Yuan J, Wang R, et al (2016) Tobacco-specific N -nitrosamines and polycyclic aromatic hydrocarbons in cigarettes smoked by the participants of the Shanghai Cohort Study. Int J Cancer. doi: 10.1002/ijc.30178

18. Godschalk RWL, Van Schooten F-J, Bartsch H (2003) A critical evaluation of DNA adducts as biological markers for human exposure to polycyclic aromatic compounds. J Biochem Mol Biol 36:1-11.

19. Chen RJ, Ho YS, Wu CH, Wang YJ (2011) Molecular mechanisms of nicotine-induced bladder cancer. J Exp Clin Med 3:252-256. doi: 10.1016/j.jecm.2011.10.001

20. Van Schooten F., Godschalk RW., Breedijk A, et al (1997) 32P-Postlabelling of aromatic DNA adducts in white blood cells and alveolar macrophages of smokers: saturation at high exposures. Mutat Res Mol Mech Mutagen 378:65-75. doi:10.1016/S0027-5107(97)00098-5

21. Faul, F. et al., 2007. G*Power 3: A flexible statistical power analysis program for the social, behavioral, and biomedical sciences. Behavior Research Methods, 39(2), pp.175-191.

22. Scherer G. Smoking behaviour and compensation: a review of the literature. Psychopharmacology (Berl). Springer-Verlag; 1999;145: 1-20. doi:10.1007/s002130051027

23. Michaud DS. Chronic inflammation and bladder cancer. Urol Oncol Semin Orig Investig. 2007;25: 260-268. doi:10.1016/j.urolonc.2006.10.002

24. Picozzi S, Casellato S, Bozzini G, Ratti D, Macchi A, Rubino B, et al. Inverted papilloma of the bladder: A review and an analysis of the recent literature of 365 patients. Urol Oncol Semin Orig Investig. 2013;31: 1584-1590. doi:10.1016/j.urolonc.2012.03.009 


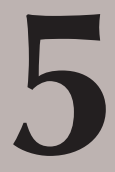

\section{Modelling the complex exposure history of smoking behaviour in predicting bladder cancer: a pooled analysis of $\mathbf{1 5}$ case-control studies.}

Frits H.M. van Osch, Jelle Vlaanderen, Sylvia H.J. Jochems,

BLEND consortium, Richard T. Bryan, Frederik J. van Schooten, Anke Wesselius, Maurice P. Zeegers

Adapted from:

Epidemiology pp:1 (2018)
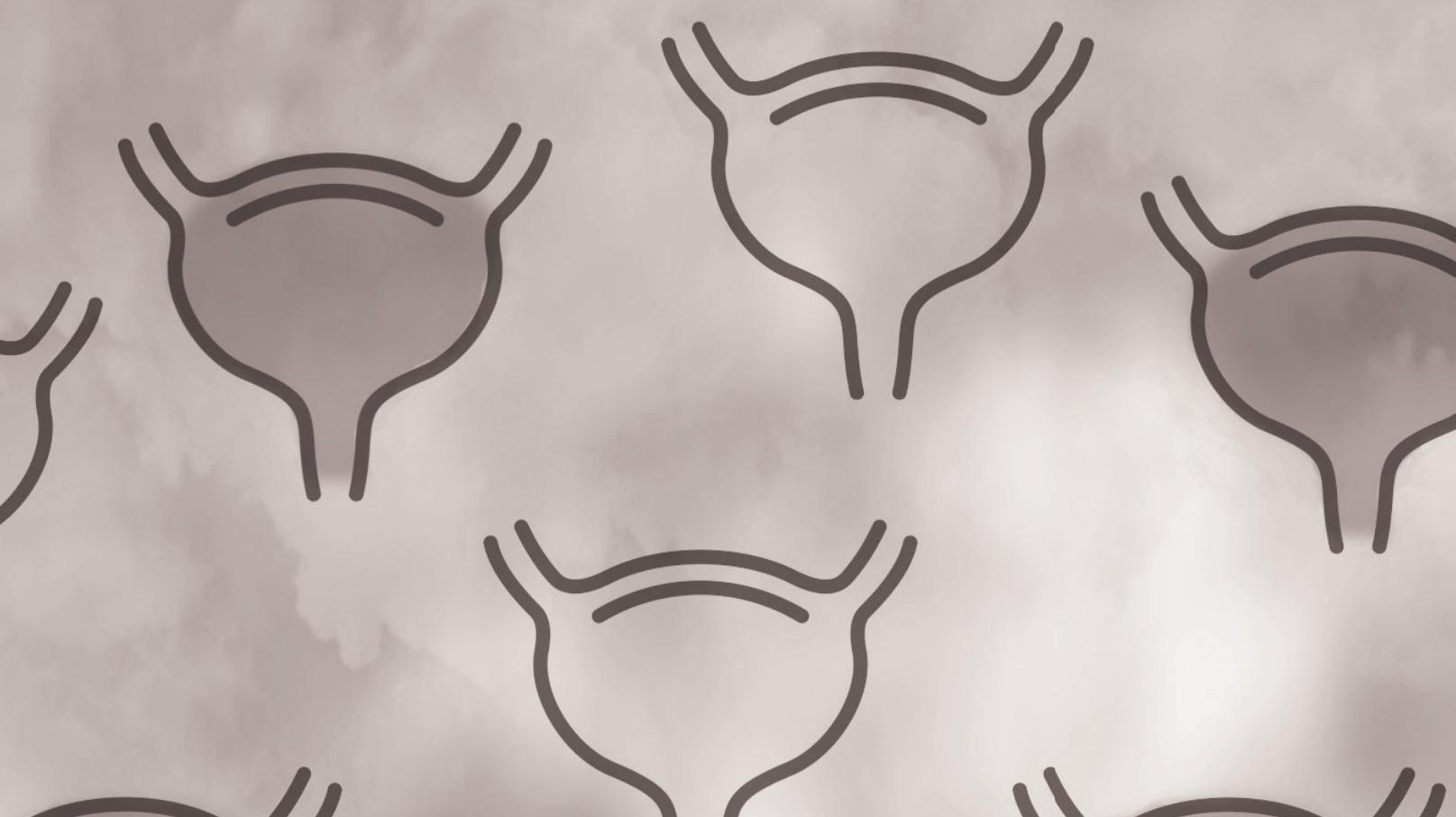


\section{ABSTRACT}

\section{Background}

Only few studies have modelled smoking histories by combining smoking intensity and duration to show what profile of smoking behaviour is associated with highest risk of bladder cancer. This study aims to provide insight into the association between smoking exposure history and bladder cancer risk by modelling both smoking intensity and duration in a pooled analysis.

\section{Methods}

Data from 15 case-control studies included in the BLadder cancer Epidemiology and Nutritional Determinants (BLEND) study were used, including a total of 6,874 cases and 17,727 controls. To jointly interpret the effects of intensity and duration of smoking, excess odds ratios (EOR) per pack-year were modelled by intensity continuously to estimate the risk difference between smokers with long duration/low intensity and short duration/ high intensity.

\section{Results}

The pooled EOR model indicated that for a fixed number of pack-years, smoking for a longer duration at lower intensity was more deleterious for bladder cancer risk than smoking more cigarettes/day for a shorter duration. Similar patterns were observed within individual study samples.

\section{Conclusions}

This pooled analysis shows that long duration/low intensity smoking increases bladder cancer risk more than short duration/ high intensity smoking within equal pack-year categories, thus confirming studies in other smoking-related cancers and demonstrating that reducing exposure history to a single metric such as pack-years is too restrictive. 


\section{INTRODUCTION}

Smoking is a significant modifiable risk factor for urothelial bladder cancer (UBC) and studies demonstrate a differential dose-response pattern for intensity and duration (1). Many studies have investigated smoking behaviour in relation to UBC, showing separate risk estimates for intensity, duration and pack-years; but only a few studies have modelled complex smoking histories including all aspects of exposure $(2,3)$.

Most studies establishing the association between smoking exposure and various diseases use cumulative exposure (i.e. pack-years) or adjust for it as a confounder when investigating smoking duration of intensity. However, more recently, consensus has been reached that modelling pack-years alone is not sufficient to identify possible mechanisms underlying such associations (4). Several researchers have discussed whether pack-years should be used to measure effects of smoking or whether pack-years can be useful in making biologically credible models that provide unbiased information on complex smoking exposure histories $(4,5)$, and circumventing multicollinearity issues (6). Although, these issues have been a research topic for several decades for other diseases, they have been infrequently investigated in UBC research $(7,8)$.

Two case-control studies in UBC both suggested that among equal pack-year categories, individuals who had smoked relatively fewer cigarettes per day for longer duration were at a higher risk of UBC compared to those who smoked more cigarettes per day over a shorter duration $(2,3)$. In these studies, estimates of the excess odds ratio (EOR) per packyear were compared across categories of smoking intensity. Recently, similar models have been further developed and tested to also include time since smoking cessation (9). Using an alternative approach, two other case-control studies data also showed that duration is the over-riding factor in determining the risk of bladder cancer $(10,11)$.

The aim of this study was to investigate the association between cumulative smoking exposure and UBC risk, in a uniquely large pooled sample of case-control studies.

\section{METHODS}

\section{Study data}

The BLadder cancer Epidemiology and Nutritional Determinants (BLEND) consortium currently consists of 19 case-control studies and 14 cohort studies investigating the association between lifestyle behaviours and UBC risk. For this analysis, we included 15 casecontrol studies providing complete data on smoking behaviour, including; smoking status, 
intensity and duration, These included 6,824 cases and 17,727 controls originating from Italy (11-13), Germany (14,15), Belgium (16), Sweden (17), Canada (18), the USA (19-24) and China (25). All smoking data were either collected through interview-administered questionnaires $(n=6)$ or self-administered questionnaires $(n=9)$. Further details on the methodology of this consortium have been described (26).

\section{Statistical analysis and delivery rate of exposure}

A statistical approach described by Vlaanderen et al. was utilised (9). The pooled smoking data were divided into quintile categories of pack-years, years of smoking, cigarettes per day and time since smoking cessation (TSC). Odds ratios (ORs) for these categories were obtained using a multilevel random effect logistic regression model adjusting for study, age and sex as covariates. Subsequently, total pack-years were cross-classified by cigarettes smoked per day and years of smoking to estimate the ORs in combined exposure categories with never smokers as the reference group. Finally, we fitted an exponential model to estimate the EOR per pack-year by smoking intensity to investigate the independent effect of cigarette smoking duration and intensity of cigarette smoking on UBC risk. We used the model:

$$
O R(d)=1+B d x \exp (g 1(n))
$$

where the model was fitted using continuous pack-years (d), continuous intensity (n) and g1 as a 3-knot restricted cubic spline function of continuous smoking intensity (knots located at 20th, 50th and 80th percentile of the distribution of intensity of all smokers) and $\mathrm{n}$ is a subject's smoking intensity. This model was applied to each of the 15 studies.

The results from such models describe delivery rate patterns of exposure to tobacco smoking in relation to $U B C$ risk. The delivery rate is described through estimating how increasing intensity or duration within a fixed number of pack-years influences UBC risk. For example, an inverse exposure rate effect for intensity would mean that the EOR/pack-year decreases with more cigarettes smoked per day, showing that within increasing intensity within fixed pack-years, and thereby automatically decreasing duration, decreases risk compared to those with a longer duration and lower intensity.

A sensitivity analysis was performed with data from 5 studies that provided detailed data on TSC by adding an extra 3-knot restricted cubic spline (knots at the 20th, 50th and 80th percentiles of the distribution of TSC of all former smokers) to the model, since incorporating TSC into these models might provide a better fit with the data (9). Additionally, different knot locations (at the 10th, 50th and 90th and 5th, 50th and 95th percentiles) were applied to assess the robustness of the associations. The fit of the models with 
different knot locations were tested using the Akaike information criterion (AIC). 95\% confidence intervals (CIs) for the EOR models were estimated through bootstrapping via 1,000 replications of the original data. The 2.5 th and the 97.5 th percentile of the subsequent distribution are shown in the fitted model. To assess the level of heterogeneity underlying this EOR model, it was also repeated in individual BLEND study populations.

\section{RESULTS}

\section{Smoking characteristics in included studies}

Table 1 shows baseline characteristics for all included case-control studies. In most studies, at least $80 \%$ of current smokers at baseline smoked more than 10 cigarettes a day. The only study in which this proportion was much lower than the mean proportion for both current smokers (14\%) and former smokers (4\%) was the Swedish study, with $14 \%$ and $4 \%$ respectively (17) (Table 1 ). Nine of the 15 studies demonstrated that $90 \%$ of current smokers had smoked for at least 20 years. This percentage was lower among former smokers (between $70 \%$ and $80 \%$ ) (Table 1). One study from the USA (20) provided details on smoking behaviour among current smokers only.

\section{Risk estimates for smoking behaviour}

Based on the pooled results, current smokers had a higher UBC risk than never smokers $(\mathrm{OR}=2.23,95 \% \mathrm{CI}=2.05-2.42)$ (Table 2). Tests for linear trend showed increasing risks across quintile categories of intensity, duration and pack-years ( $p$-values $<0.001$ ). Furthermore, smoking cessation was related to a lower UBC risk compared to current smokers (Table 2), with an OR of $0.40(95 \% \mathrm{CI}=0.32-0.51)$ for those who had quit smoking more than 30 years before UBC diagnosis. UBC risk for those who had quit smoking 30 years prior to diagnosis was very similar compared to those who had never smoked $(O R=1.04$, $95 \% \mathrm{CI}=0.81-1.32)$.

\section{DELIVERY RATE PATTERNS OF EXPOSURE TO SMOKING IN RELATION TO UBC RISK}

Fifteen ORs, with never smokers as reference category, were calculated in the analysis stratified by intensity quintile (Figure 1), whilst 20 ORs were estimated in the analysis stratified by duration quintile (Figure 2) because data were sparse in the intensity categories. None of the associations showed any departures from linearity ( $p>0.05$ for all categories), which means that the EOR model as it is presented is valid in meeting the assumption about linearity of association between exposure and disease. 


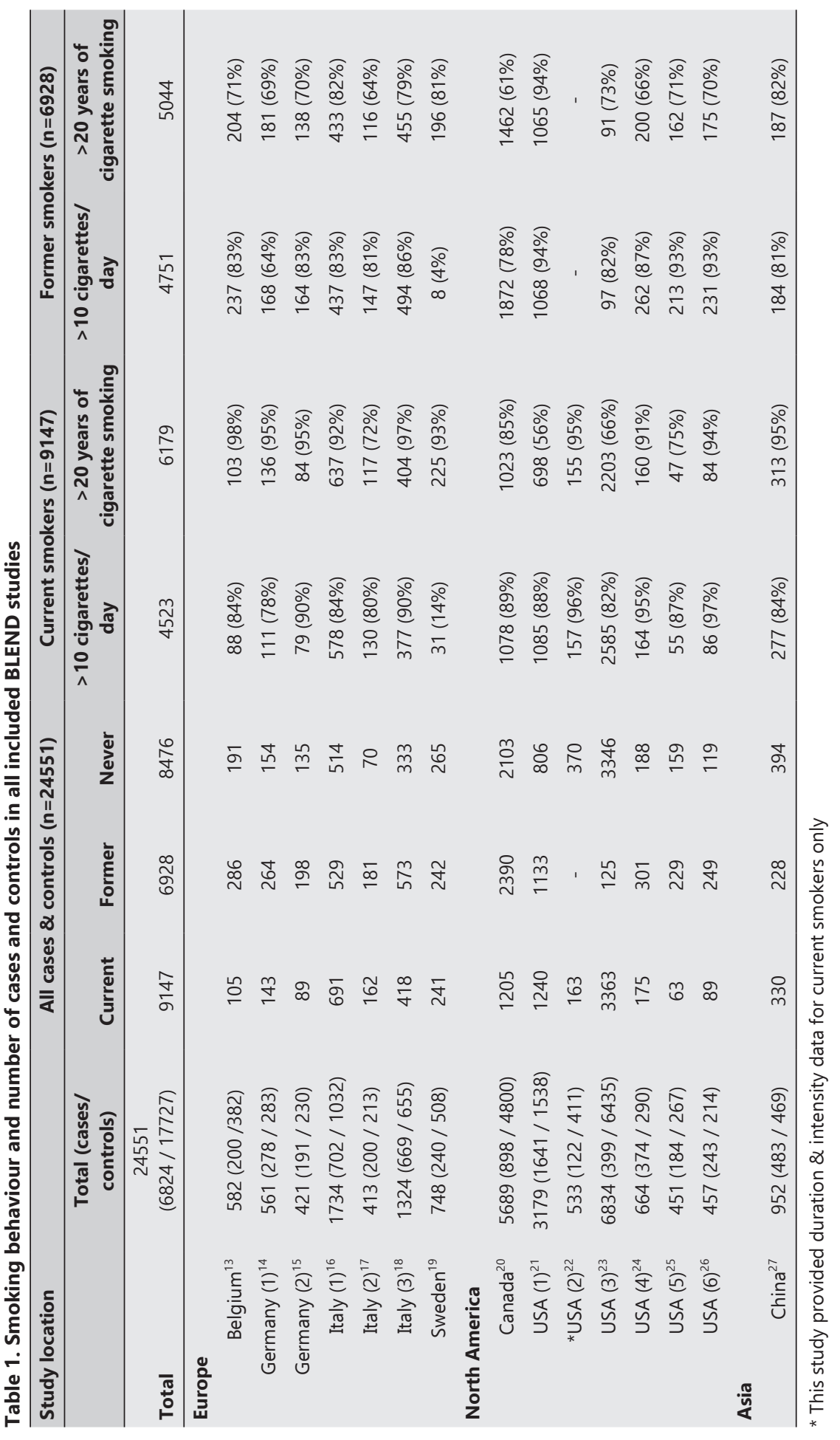




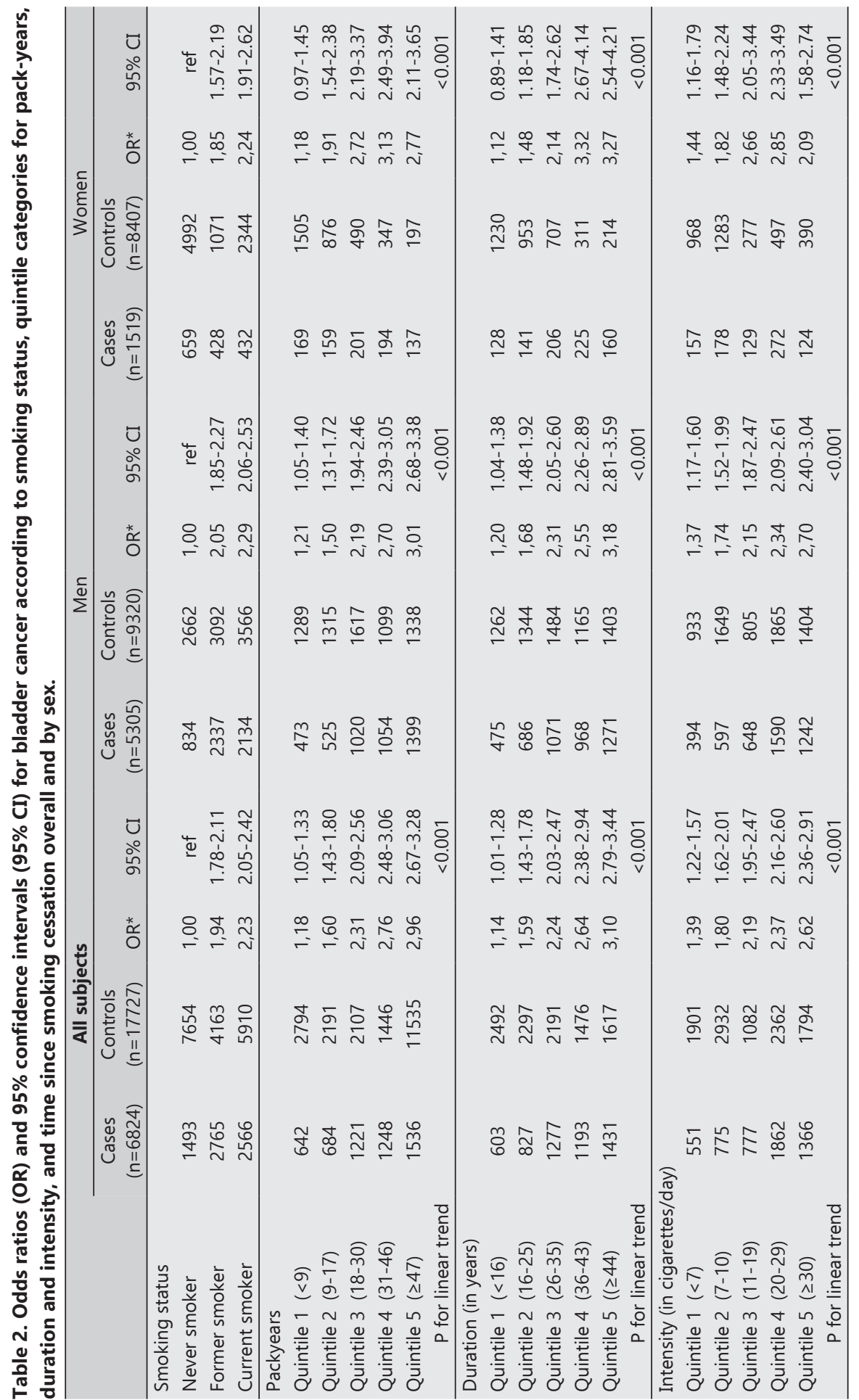




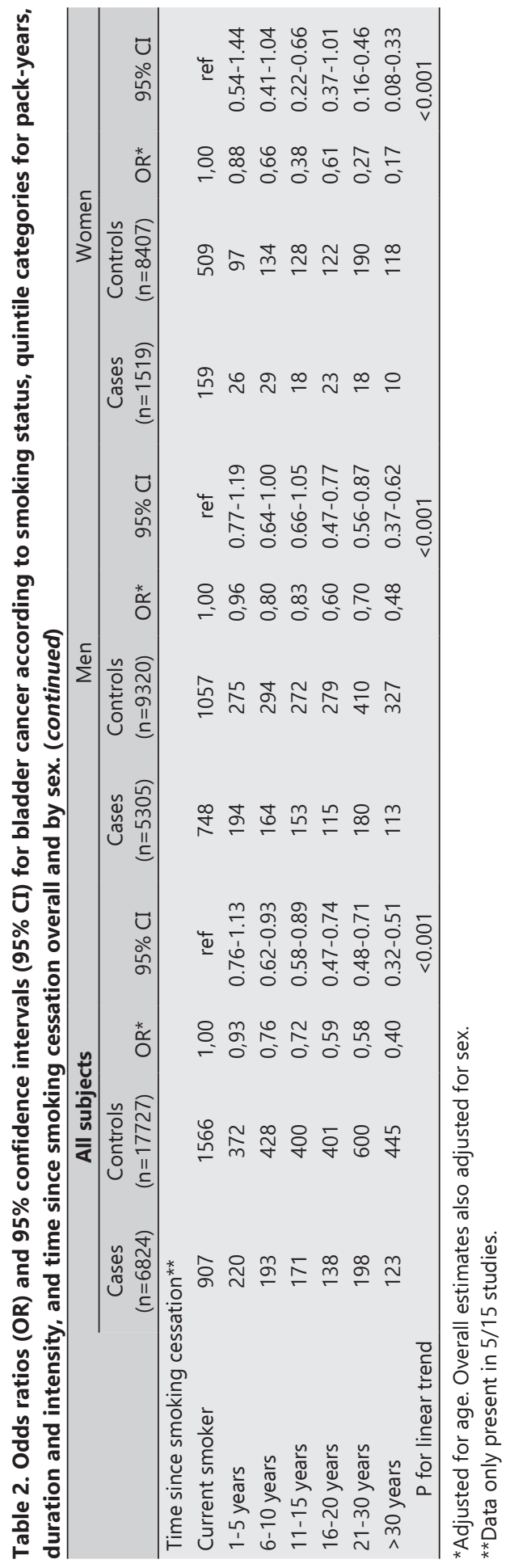




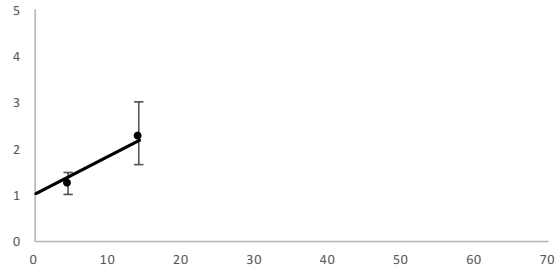

CPD: $11-19$
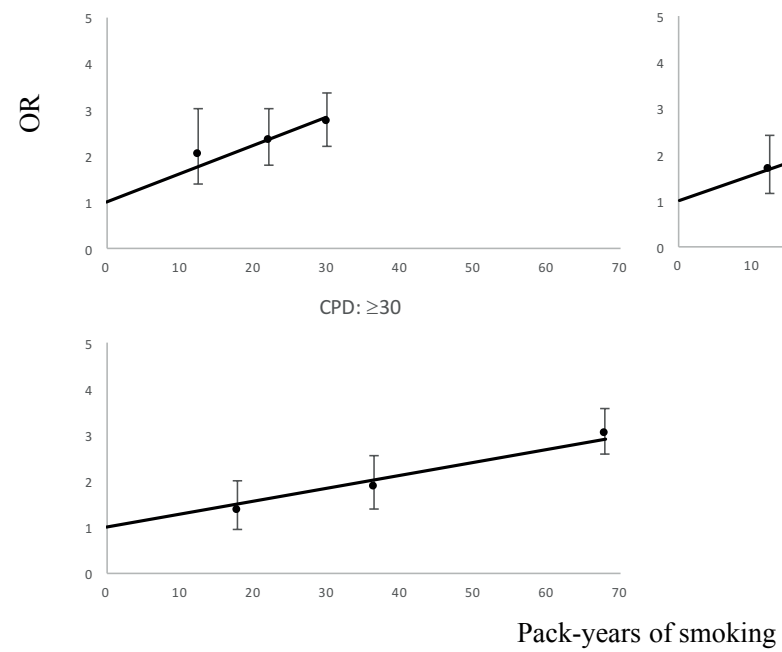

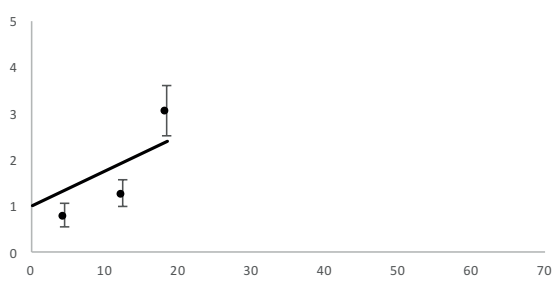

CPD: $20-29$

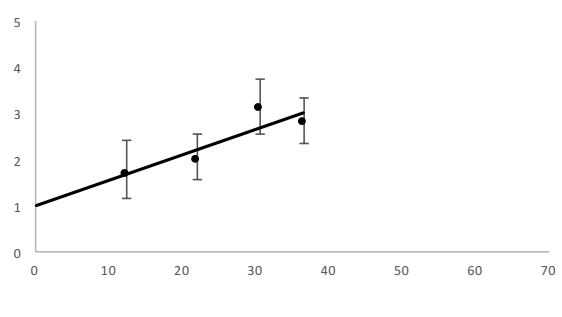

Figure 1. Odds ratios (OR) for bladder cancer by cross-classified categories of pack-years and quintile categories of number of cigarettes smoked per day (CPD). Lines indicate fitted linear odds ratio models in pack-years, bars indicate $95 \%$ confidence intervals. Pooled data was limited to never and current smokers.

The EOR per pack-year and 95\% CI by continuous smoking intensity (cigarettes/day) resulting from the cubic spline model are plotted in Figure 3. Additionally, the slope resulting from the model including splines for TSC is also shown. The model excluding TSC had a slightly better fit to the data (AIC $=23,140$ ) compared to the model including TSC (AIC=24,219), probably because the effect of TSC was heterogeneous between the few included studies. Both curves show an inverse delivery rate pattern, whereby with increasing cigarettes smoked per day the EOR per pack-year decreases, indicating that for equal pack-years, smoking for a longer duration is more strongly associated with UBC risk than smoking more cigarettes per day. As can be observed from the bootstrapped 95\% $\mathrm{CI}$, the plotted curve had the highest statistical power (highest number of participants) for individuals smoking between 10 and 40 cigarettes per day which included $79 \%$ of all smokers in this consortium. 

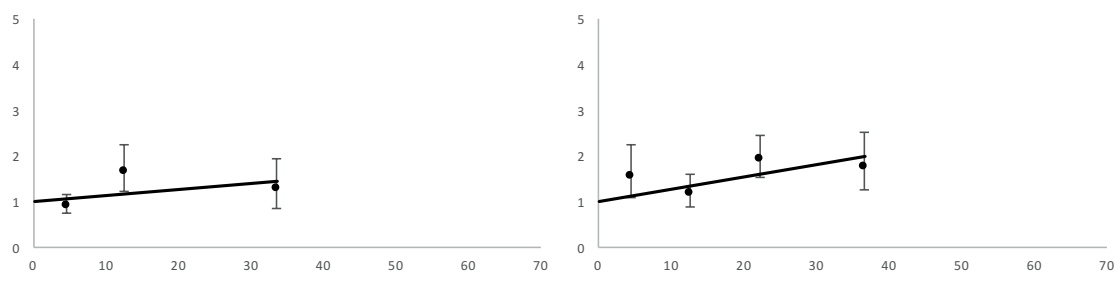

Duration: 26 - 35 years

Duration: 36 - 43 years
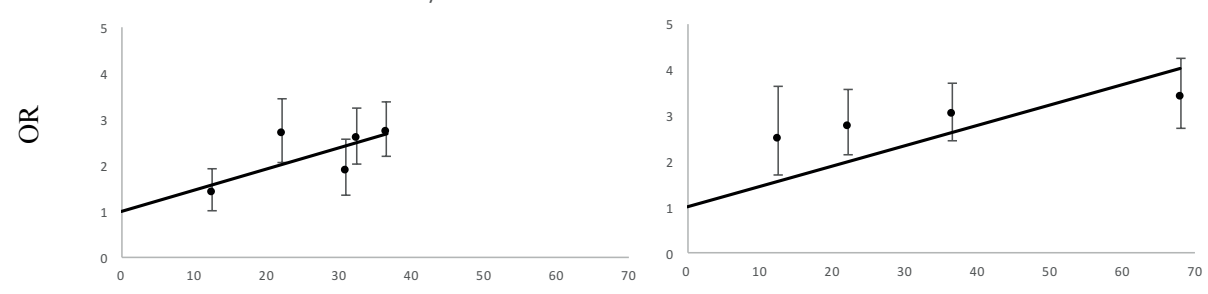

Duration: $\geq 44$ years

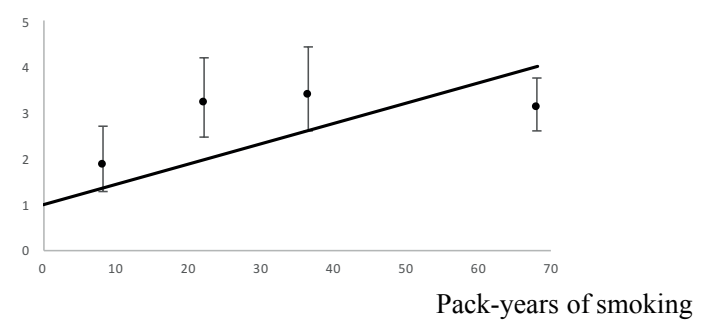

Figure 2. Odds ratios (OR) for bladder cancer by cross-classified categories of pack-years and quintile categories of years of smoking. Lines indicate fitted linear odds ratio models in packyears, bars indicate $95 \%$ confidence intervals. Pooled data was limited to never and current smokers.

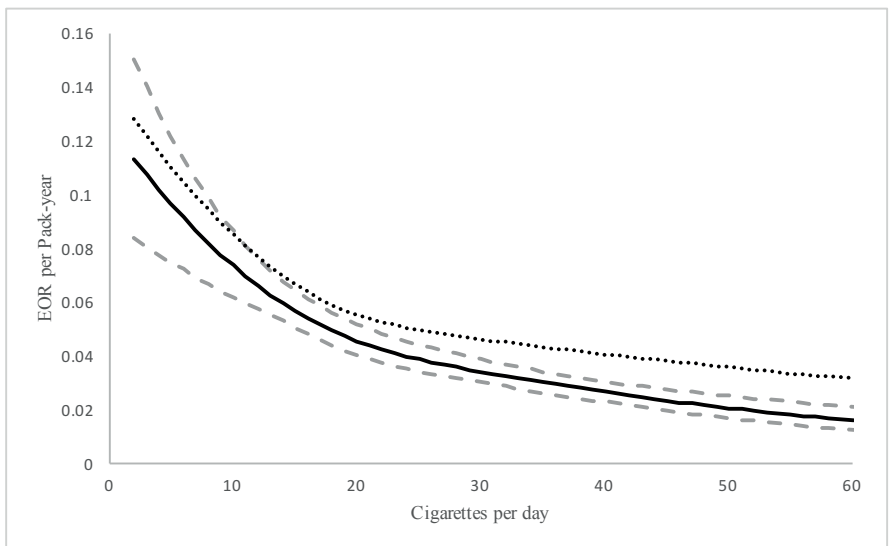

Figure 3. Estimated excess odds ratio (EOR) per pack-year for bladder cancer by cigarettes per day with bootstrapped $95 \%$ confidence intervals. The dotted line indicates a model including an extra spline for time since smoking cessation. Triangles depict locations of the knots of the restricted cubic splines $\left(20^{\text {th }}, 50^{\text {th }}\right.$ and $80^{\text {th }}$ percentile). 
Heterogeneity was small among the 10 individual studies in which EOR models were fit with the original spline settings (Figure $4 A$ ). For three studies $(12,21,23)$ the model did not fit because of their data distribution (e.g. 19 cigarettes per day represented the 44th percentile and 20 cigarettes per day represented the 82th percentile of the data), and there was limited power within 2 studies $(14,25)$ (too many levels of intensity with no cases). When moving the splines to positions fitting the data distribution in the three studies with a different data distribution, the three added curves show a similar shape to the EOR curves from the 10 studies that were estimated with the original spline settings (Figure 5). Additionally, the EOR models within the 3 studies that included sufficient data on TSC $(13,16,18)$ were also similar (Figure 4B).
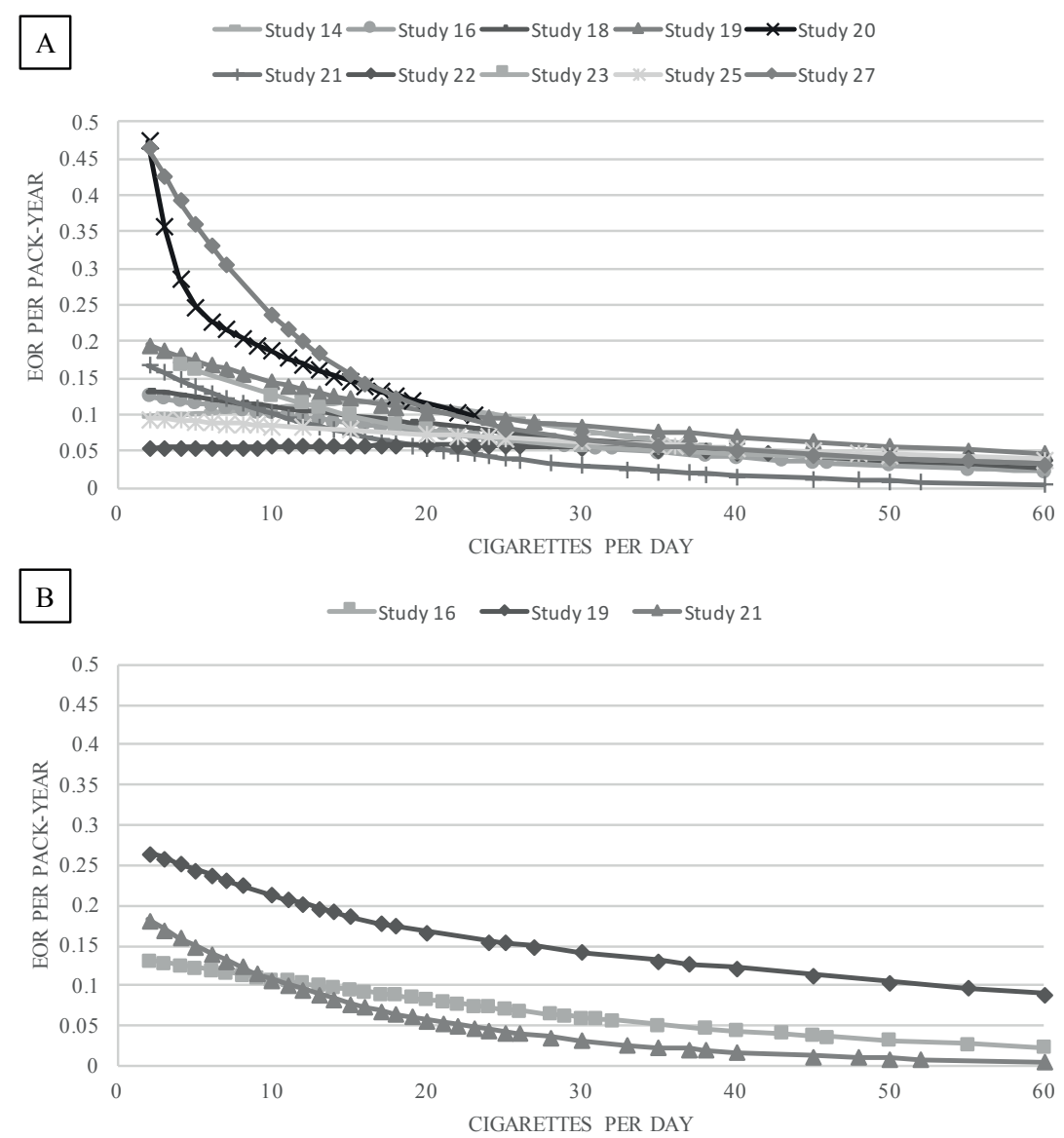

Figure 4. Excess odds ratio (EOR) per pack-year by smoking intensity (cigarettes/day) stratified by study. Model without time since smoking cessation spline (panel $A$ ) and model with time since smoking cessation spline (panel B). Study numbers refer to reference number within this paper (see Table 1). 


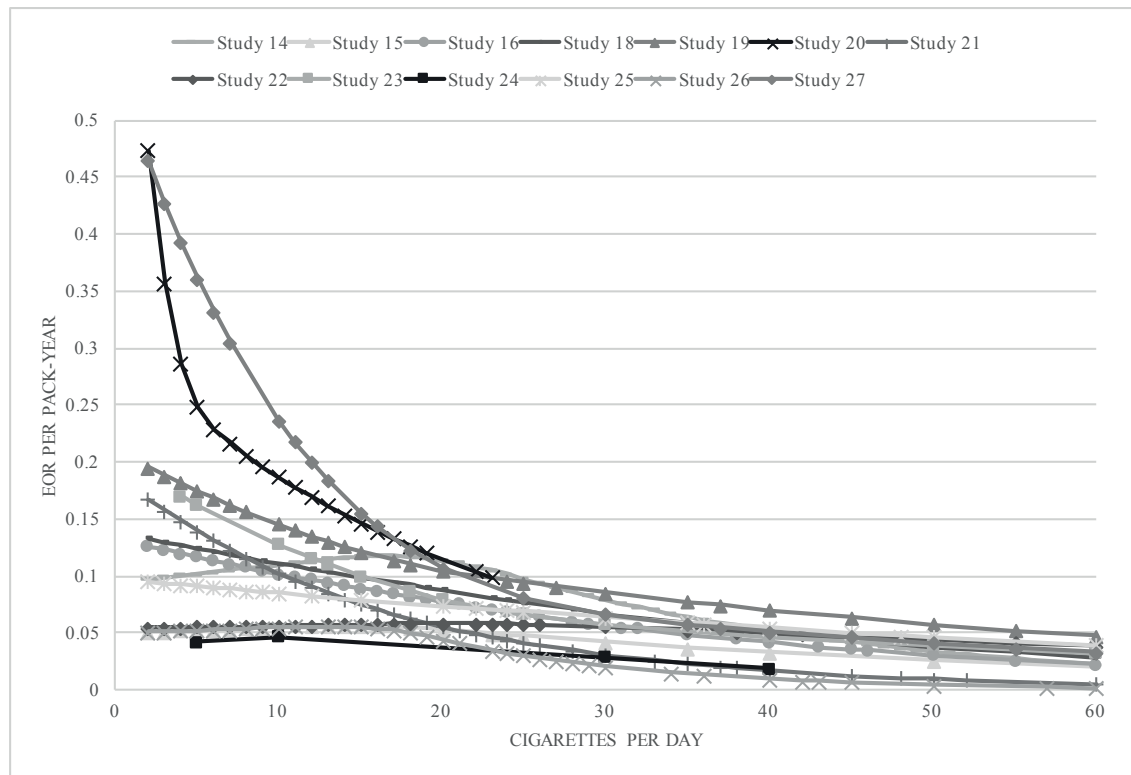

Figure 5. Excess odds ratio (EOR) per pack-year by smoking intensity stratified by study, including curves for three studies $(15,24,26)$ that had to be fit with alternative spline locations. Study numbers refer to reference number within this paper (see Table 1).

\section{DISCUSSION}

We have provided insight into the complex exposure patterns of lifetime smoking behaviour and the impact on UBC risk. We have shown an inverse delivery rate pattern indicating that, for equal pack-years of smoking, less cigarettes per day over a longer duration is more deleterious for UBC risk than smoking more cigarettes per day over a shorter duration. The results of this large pooled analysis of case-control studies are in line with data from previous case-control studies on $\operatorname{UBC}(2,3,11)$, which applied a similar model as well as results from a pooled analysis of 11 case-control studies which used a different modelling approach to assess duration and intensity simultaneously (10).

\section{Robustness of results}

We applied the model as described by Vlaanderen et al, but a similar approach was first described in a lung cancer study (27), known as the L-C (Lubin-Caparaso) model, which has also been applied in a pooled analysis of case-control studies on head and neck cancer (28) and in two individual UBC case-control studies $(2,3)$. Alongside these models, Brennan et al described a different approach in 2000 which is based on stratification of both duration and intensity and estimating ORs in all strata. They also observed that duration was more important in predicting UBC risk than intensity (10). 
Similar ORs were observed for both women and men, although more men smoked at least 10 cigarettes per day (86\%) compared to women (73\%), possibly explaining differences in risk estimates, in addition to the smaller sample of women in the included studies. Furthermore, observed ORs for smokers might be underestimated since the pooled OR for current smokers was markedly lower than observed in a large meta-analysis (1) $(O R=2.23$ in the current sample vs $\mathrm{OR}=3.14$ in the meta-analysis). This might be explained by some misclassification of smoking information collected through self-administered questionnaires in the 15 included studies or differences in data collection in the meta-analysis.

Little heterogeneity in the range of predicted EORs per pack-year by cigarettes per day between the included studies was observed (Figure 4). However, some heterogeneity in magnitude of estimated EORs per pack-year remains between the studies, which may be explained by several factors such as geographical location (1) and calendar year in which cases and controls were recruited (29). Since only 5 studies provided sufficient data on TSC, this pooled analysis might not have had sufficient power to include TSC as an extra spline.

\section{Strengths and limitations of the EOR model and interpretation of results}

Although the EOR model can provide a more detailed insight into the association between smoking behaviour and disease risk, there are some other factors not in this model that also need to be considered. Since a more vigorous inhalation pattern has been shown to be associated with a higher UBC risk $(30,31)$, the observed inverse delivery rate pattern might reflect differences in inhalation patterns among cigarette smokers. It is generally believed that light smokers inhale more vigorously compared to heavier smokers to achieve the same amount of nicotine consumption $(32,33)$, therefore possibly confounding the risk estimates comparing heavy to light smokers. However, inhalation was not found to be a confounder of pack-years-adjusted cigarettes per day patterns in a lung cancer study (27). Data on inhalation patterns was not available for the study participants within BLEND.

Moreover, since no data were available on time periods during which study participants might have smoked less (or more) than their average estimated intensity we could not account for this. Also, the more deleterious effect of longer duration of smoking that we observed might be explained by these individuals smoking well after middle age, which is a critical period for avoiding cancer risk. Individuals who smoked more cigarettes per day but for a shorter period may have stopped smoking before middle age. Due to the retrospective nature of data collection in case-control studies including such detailed data on smoking behaviour would not have been possible in this pooled analysis; however, in prospective studies such periodical changes in smoking intensity could be accounted 
for when applying the EOR models by adding TSC or time since moderation splines if data is gathered. This EOR model provides one of the most detailed UBC risk prediction following different durations and intensities of smoking. Nevertheless, there have been other methods to model smoking history in relation to cancer such as the comprehensive smoking index which also incorporates intensity, duration and time since cessation (34).

\section{Smoking intensity compared to duration in bladder carcinogenesis}

Tobacco smoke contains many carcinogens that can contribute to carcinogenesis in the bladder. These carcinogens can form DNA adducts and, when multiple types of DNA adducts are combined, they contribute greatly to human cancer risk (35). Several studies have shown that nicotine-derived nitrosamine ketones (NNK), methyl and other DNA adducts are more frequently present in UBC patients who have smoked compared to those who have never smoked $(36,37)$. Moreover, there is heterogeneity in the efficiency of DNA repair pathways between individuals; for example, those who have a slow Nacetyltransferase phenotype have a higher risk of UBC when they smoke (38), and DNA repair processes can also be negatively influenced by smoking (39). This indicates that the DNA adduct pathway of UBC pathogenesis is important in smoking-related UBC. This is corroborated by our data showing that a longer exposure time to accumulate smoking-related DNA adducts, and thus resulting in a higher total burden of DNA adducts, contributes the most to a higher risk of UBC. The results from our study, as well as of other studies in $\operatorname{UBC}(2,3)$, lung cancer $(9,27)$, and head and neck cancer $(28)$, are consistent in showing that smoking behaviour characterised by long smoking duration at low intensity is associated with an increased cancer risk compared to a short duration at higher intensity. These results have major implications for prevention at public health level and can impact the public's perception on smoking and health risks.

\section{CONCLUSION}

We have demonstrated that long duration/low intensity smoking behaviour is most strongly associated with UBC risk within equal pack-year categories in this pooled analysis, thereby confirming studies in two case-control studies on UBC as well as other smokingrelated cancers. Furthermore, with this model we found that reducing complex exposure history to a single metric such as pack-years is too restrictive, and future research should focus on interpretable ways to model complex cumulative exposures such as lifetime smoking behaviour. 


\section{REFERENCES}

1. van Osch FH, Jochems SH, van Schooten F-J, Bryan RT, Zeegers MP. Quantified relations between exposure to tobacco smoking and bladder cancer risk: a meta-analysis of 89 observational studies. Int J Epidemiol. 2016;45 (3):857-70.

2. Lubin JH, Kogevinas M, Silverman D, Malats N, Garcia-Closas M, Tardón A, et al. Evidence for an intensity-dependent interaction of NAT2 acetylation genotype and cigarette smoking in the Spanish Bladder Cancer Study. Int J Epidemiol. 2007 Feb 1;36 (1):236-41.

3. Baris D, Karagas MR, Verrill C, Johnson A, Andrew AS, Marsit CJ, et al. A case-control study of smoking and bladder cancer risk: emergent patterns over time. J Natl Cancer Inst. 2009 Nov 18;101 (22):1553-61.

4. de Vocht F, Burstyn I, Sanguanchaiyakrit N. Rethinking cumulative exposure in epidemiology, again. J Expo Sci Environ Epidemiol. 2015 Sep 20;25 (5):467-73.

5. Thomas DC. Invited Commentary: Is It Time to Retire the \&quot;Pack-Years\&quot; Variable? Maybe Not! Am J Epidemiol. 2014 Feb 1;179 (3):299-302.

6. Leffondre K, Abrahamowicz M, Siemiatycki J, Rachet B. Modeling Smoking History: A Comparison of Different Approaches. Am J Epidemiol. 2002 Nov 1;156 (9):813-23.

7. Moolgavkar SH, Dewanji A, Luebeck G. Cigarette smoking and lung cancer: reanalysis of the British doctors' data. J Natl Cancer Inst. 1989;81 (6):415-20.

8. Thomas D. Statistical methods in environmental epidemiology. 2009;

9. Vlaanderen J, Portengen L, Schüz J, Olsson A, Pesch B, Kendzia B, et al. Effect Modification of the Association of Cumulative Exposure and Cancer Risk by Intensity of Exposure and Time Since Exposure Cessation: A Flexible Method Applied to Cigarette Smoking and Lung Cancer in the SYNERGY Study. Am J Epidemiol. 2014 Feb 1;179 (3):290-8.

10. Brennan $P$, Bogillot $O$, Cordier S, Greiser E, Schill W, Vineis $P$, et al. Cigarette smoking and bladder cancer in men: A pooled analysis of 11 case-control studies. Int J Cancer. $2000 \mathrm{Apr}$ 15;86 (2):289-94.

11. Polesel J, Bosetti C, di Maso M, Montella M, Libra M, Garbeglio A, et al. Duration and intensity of tobacco smoking and the risk of papillary and non-papillary transitional cell carcinoma of the bladder. Cancer Causes Control. 2014 Sep 26;25 (9):1151-8.

12. Hung RJ, Boffetta $P$, Brennan $P$, Malaveille $C$, Hautefeuille $A$, Donato $F$, et al. GST, NAT, SULT1A1, CYP1B1 genetic polymorphisms, interactions with environmental exposures and bladder cancer risk in a high-risk population. Int J Cancer. 2004 Jul 1;110 (4):598-604.

13. Randi G, Pelucchi C, Negri E, Talamini R, Galeone C, Franceschi S, et al. Family history of urogenital cancers in patients with bladder, renal cell and prostate cancers. Int J Cancer. 2007 Dec 15;121 (12):2748-52.

14. Pohlabeln $\mathrm{H}$, Jöckel K-H, Bolm-Audorff U. Non-occupational risk factors for cancer of the lower urinary tract in Germany. Eur J Epidemiol. 1999;15 (5):411-9.

15. Golka K, Heitmann P, Gieseler F, Hodzic J, Masche N, Bolt HM, et al. Elevated Bladder Cancer Risk Due to Colorants-A Statewide Case-Control Study in North Rhine-Westphalia, Germany. J Toxicol Environ Heal Part A. 2008 Jun 3;71 (13-14):851-5.

16. Kellen $E$, Zeegers $M$, Paulussen $A$, Van Dongen $M$, Buntinx F. Fruit consumption reduces the effect of smoking on bladder cancer risk. The Belgian case control study on bladder cancer. Int J Cancer. 2006 May 15;118 (10):2572-8. 
17. Augustsson K, Skog K, Jägerstad M, Dickman PW, Steineck G. Dietary heterocyclic amines and cancer of the colon, rectum, bladder, and kidney: a population-based study. Lancet. 1999 Feb 27;353 (9154):703-7.

18. Gaertner RRW, Trpeski L, Johnson KC. A case-control study of occupational risk factors for bladder cancer in Canada. Cancer Causes Control. 2004 Dec;15 (10):1007-19.

19. Jiang X, Castelao JE, Yuan JJ-M, Stern MC, Conti D V., Cortessis VK, et al. Cigarette smoking and subtypes of bladder cancer. Int J Cancer. 2012 Feb 15;130 (4):896-901.

20. Tang L, Zirpoli GR, Guru K, Moysich KB, Zhang Y, Ambrosone CB, et al. Consumption of Raw Cruciferous Vegetables is Inversely Associated with Bladder Cancer Risk. Cancer Epidemiol Biomarkers Prev. 2008 Apr 1;17 (4):938-44.

21. Quirk JT, Li Q, Natarajan N, Mettlin CJ, Cummings KM. Cigarette Smoking and the Risk of Bladder Cancer in Men and Women. Tob Induc Dis. 2004 Sep 15;2 (3):141.

22. Karagas MR, Tosteson TD, Blum J, Morris JS, Baron JA, Klaue B. Design of an epidemiologic study of drinking water arsenic exposure and skin and bladder cancer risk in a U.S. population. Environ Health Perspect. 1998 Aug;106 Suppl 4 (Suppl 4):1047-50.

23. Cao W, Cai L, Rao JJ-YJ, Pantuck A, Lu MM-LM, Dalbagni G, et al. Tobacco smoking, GSTP1 polymorphism, and bladder carcinoma. Cancer. 2005 Dec 1;104 (11):2400-8.

24. Taylor JA, Umbach DM, Stephens E, Castranio T, Paulson D, Robertson C, et al. The role of $\mathrm{N}$-acetylation polymorphisms in smoking-associated bladder cancer: evidence of a genegene-exposure three-way interaction. Cancer Res. 1998 Aug 15;58 (16):3603-10.

25. Hemelt M, Hu Z, Zhong Z, Xie L-P, Wong YC, Tam P-C, et al. Fluid intake and the risk of bladder cancer: Results from the South and East China case-control study on bladder cancer. Int J Cancer. 2010 Feb 1;127 (3):638-45.

26. Goossens $M E$, Isa F, Brinkman $M$, Mak $D$, Reulen $R$, Wesselius $A$, et al. International pooled study on diet and bladder cancer: the bladder cancer, epidemiology and nutritional determinants (BLEND) study: design and baseline characteristics. Arch Public Heal. 2016 Dec 6;74 (1):30.

27. Lubin JH, Caporaso NE. Cigarette smoking and lung cancer: modeling total exposure and intensity. Cancer Epidemiol Biomarkers Prev. 2006 Mar 1;15 (3):517-23.

28. Lubin JH, Purdue M, Kelsey K, Zhang Z-F, Winn D, Wei Q, et al. Total Exposure and Exposure Rate Effects for Alcohol and Smoking and Risk of Head and Neck Cancer: A Pooled Analysis of Case-Control Studies. Am J Epidemiol. 2009 Oct 15;170 (8):937-47.

29. Bryan RT, Zeegers MP, van Roekel EH, Bird D, Grant MR, Dunn JA, et al. A comparison of patient and tumour characteristics in two UK bladder cancer cohorts separated by 20 years. BJU Int. 2013 Jul;112 (2):169-75.

30. Zeegers MPA, Goldbohm RA, van den Brandt PA. A prospective study on active and environmental tobacco smoking and bladder cancer risk (The Netherlands). Cancer Causes Control. 2002;13 (1):83-90.

31. López-Abente G, González CA, Errezola M, Escolar A, Izarzugaza I, Nebot M, et al. Tobacco Smoke Inhalation Pattern, Tobacco Type, and Bladder Cancer in Spain. Am J Epidemiol. 1991 Oct 15;134 (8):830-9.

32. Fidler JA, Stapleton JA, West R. Variation in saliva cotinine as a function of self-reported attempts to reduce cigarette consumption. Psychopharmacology (Berl). 2011 Oct 10;217 (4):587-93. 
33. Patterson $F$, Benowitz $N$, Shields $P$, Kaufmann $V$, Jepson $C$, Wileyto $P$, et al. Individual differences in nicotine intake per cigarette. Cancer Epidemiol Biomarkers Prev. 2003;12 (5):468-71.

34. Leffondré K, Abrahamowicz M, Xiao Y, Siemiatycki J. Modelling smoking history using a comprehensive smoking index: application to lung cancer. Stat Med. 2006 Dec 30;25 (24):4132-46.

35. Poirier MC. Chemical-induced DNA damage and human cancer risk. Discov Med. 2012 Oct; 14 (77):283-8.

36. Jin F, Thaiparambil J, Ramya Donepudi S, Vantaku V, Waduge D, Piyarathna B, et al. Tobaccospecific carcinogens induce hypermethylation, DNA adducts and DNA damage in Bladder Cancer. 2017;

37. Talaska G, al-Juburi AZ, Kadlubar FF. Smoking related carcinogen-DNA adducts in biopsy samples of human urinary bladder: identification of $\mathrm{N}$ - (deoxyguanosin-8-yl)-4-aminobiphenyl as a major adduct. Proc Natl Acad Sci U S A. 1991 Jun 15;88 (12):5350-4.

38. Vineis P, Marinelli D, Autrup H, Brockmoller J, Cascorbi I, Daly AK, et al. Current smoking, occupation, N-acetyltransferase-2 and bladder cancer: a pooled analysis of genotype-based studies. Cancer Epidemiol Biomarkers Prev. 2001;10 (12):1249-52.

39. Corral R, Lewinger JP, Van Den Berg D, Joshi AD, Yuan J-M, Gago-Dominguez M, et al. Comprehensive analyses of DNA repair pathways, smoking and bladder cancer risk in Los Angeles and Shanghai. Int J Cancer. 2014 Jul 15;135 (2):335-47. 

Significant Role of Lifetime Cigarette Smoking in Worsening Bladder Cancer and Upper Tract Urothelial Carcinoma Prognosis: A Meta-Analysis

Frits H. M. van Osch, Sylvia H. J. Jochems, Frederik J. van Schooten, Richard T. Bryan, Maurice P. Zeegers

Adapted from:

The Journal of Urology, Vol. 195 (2016), 872-879
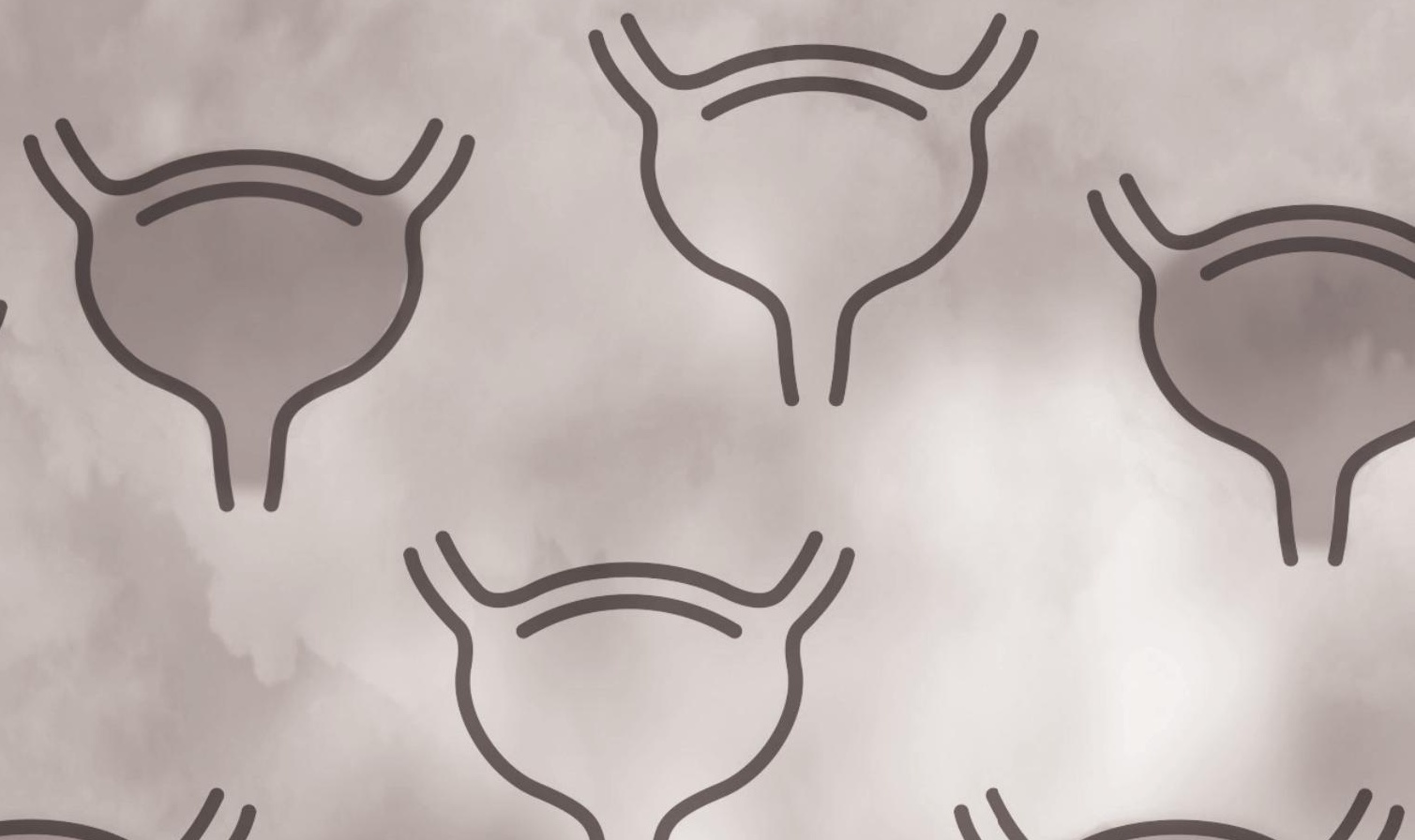


\section{ABSTRACT}

\section{Background}

Although cigarette smoking is a well-established risk factor for urothelial cancer (UC), its role in UC prognosis is still undetermined. This meta-analysis aimed to quantify the role of lifetime smoking history on bladder cancer recurrence, progression and survival, by pooling available data on non-muscle-invasive bladder cancer (NMIBC), muscle-invasive bladder cancer (MIBC) and upper tract urothelial carcinoma (UTUC).

\section{Materials and methods}

A total of 24 studies, comprising data from 13,114 BC and 2,259 UTUC patients, were included in this meta-analysis. Publication bias was addressed through Eggers test and the heterogeneity between studies was assessed by the $\mathrm{I}^{2}$ test statistic and subgroup analyses.

\section{Results}

Current smokers at diagnosis are at an increased risk of developing local recurrences in NMIBC $(H R=1.27,95 \%$ C.I. $=1.09-1.46)$ and smoking MIBC patients are at an increased risk of dying due to $B C(H R=1.23,95 \%$ C.I. = 1.02-1.44). In the UTUC population smokers have both an increased risk of recurrence in the operative bed $(H R=1.57,95 \%$ C.I. $=1.19-1.95)$ and of dying due to UTUC $(H R=1.53,95 \%$ C.I. $=1.13-1.92)$. We did not identify significant heterogeneity between included studies.

\section{Conclusions}

The body of evidence is limited due to the absence of prospective studies. However, the results from this meta-analysis unambiguously support the hypothesis that lifetime cigarette smokers are at an increased risk of developing a more malignant phenotype of urothelial carcinoma associated with worse prognosis. 


\section{BACKGROUND}

Smoking is a major risk factor for the development of urothelial cancer as has been shown repeatedly in several case-control and cohort studies (1). However, there has been little research into the influence of smoking status at diagnosis, and continuation of smoking after diagnosis, on urothelial cancer recurrence, progression and survival. Several reviews have highlighted the potential effect that smoking status might have on disease recurrence in non-muscle-invasive bladder cancer (NMIBC) and possibly progression to muscle-invasive bladder cancer (MIBC) (2-4) as well as worse upper tract urothelial carcinoma (UTUC) prognosis $(2,5)$.

Lifetime smoking history seems to be associated with increased tumour size and aggressiveness of disease at first diagnosis $(4,6)$. However, it remains unclear whether this is also reflected in different clinical outcomes from urothelial carcinoma (UC), a definition which encompasses both BC and UTUC, for patients who are smokers compared to never smokers. Although in lung cancer and oesophageal cancer, it has been shown that continuing smoking after diagnosis negatively affects oncological outcomes no studies have investigated smoking cessation after diagnosis yet for UC (3). Nevertheless, the association between current smoking at diagnosis and UC prognosis has been investigate in many (retrospective) studies $(2,3)$.

An improved understanding of smoking and its role in UC prognosis, which is characterised by recurrence of disease, progression to muscle-invasive disease after initial treatment or disease-specific death), has the potential to influence clinical decisions regarding UC patients and could possibly lead to evidence-based advice on smoking cessation in urology clinics (3). The most recent evidence on the relation between smoking and UC prognosis suggests that current smokers at diagnosis have higher NMIBC local recurrence rates compared to never smokers $(2,3)$. However, this association or the potentially significant association with disease progression has never been previously summarised in a meta-analysis.

This study aimed to quantify the role of lifetime smoking history on UC recurrence, progression and survival, by meta-analysis of available data on NMIBC, MIBC and UTUC. By quantifying the associations between lifetime smoking status and UC prognosis, this study will shed more light on whether smoking status should be incorporated in prognostication of BC and UTUC in clinical as well as non-clinical settings. 


\section{METHODS}

\section{Search strategy}

Medline, Embase, Web of Science and Scopus were used to search for studies on cigarette smoking and bladder cancer recurrence, progression and bladder-cancer related mortality. The search was restricted to only include studies involving humans and there was no restriction on publication date. Search terms included the (MeSH) terms "urinary bladder neoplasms", "neoplasm recurrence" "survival", "smoking" and "epidemiologic studies" which resulted in 1,528 hits on possible articles to include after removal of duplicates. Studies were excluded when no hazard ratio (HR) for either recurrence-free, progressionfree or disease-free survival for smoking status (current and former versus never smokers) was given. Disease recurrence had to be specified as local recurrence for NMIBC and MIBC and as recurrence in the operative bed of the tumour for UTUC. Furthermore, only studies which regarded never smokers as the reference category for calculation of HRs were included. Moreover, only studies which provided information or stratified for received therapy were included to avoid misinterpretation due to the effects of different therapies.

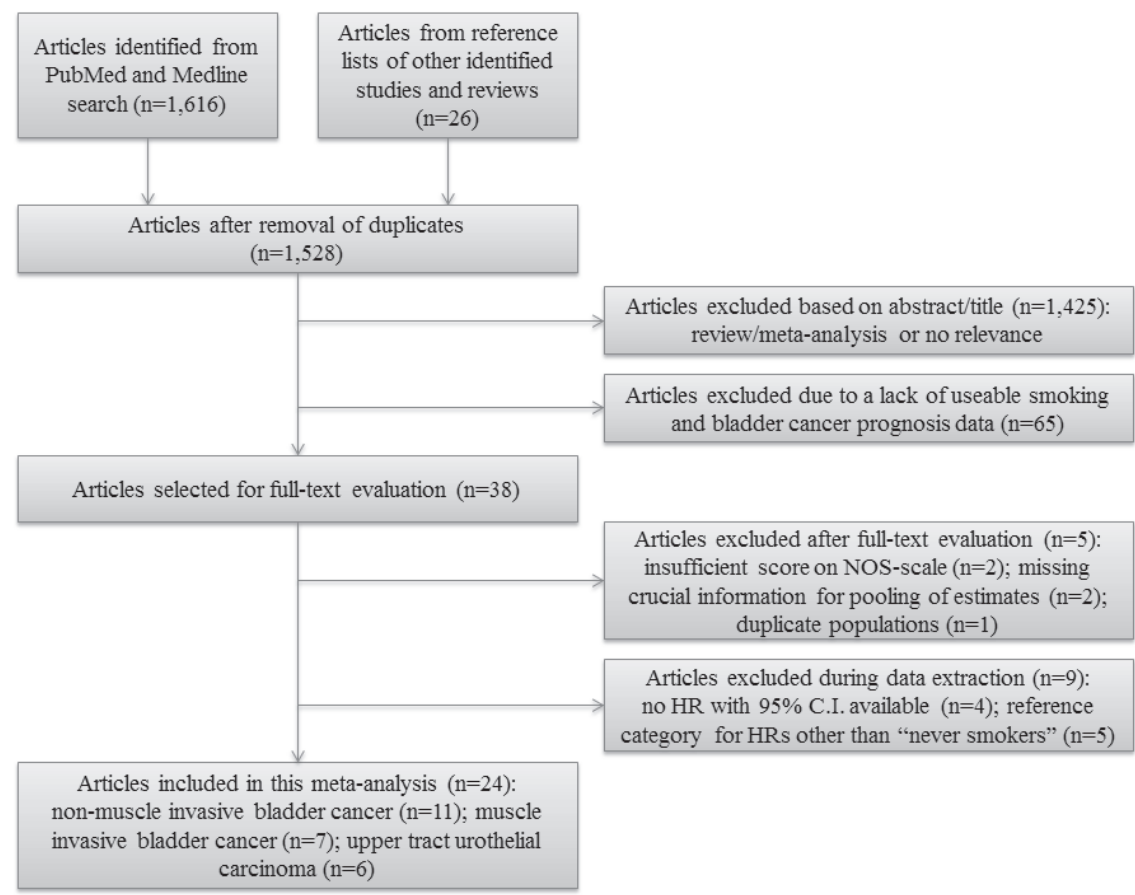

Figure 1. Flowchart of study selection and reasons for exclusion 


\section{Data collection}

To assess the risk of bias and identify possible sources of heterogeneity within individual studies selected for full text evaluation the Newcastle-Ottowa assessment scale (NOS) for cohort studies was applied (7) by two of the authors (FvO and SJ). Several variables were extracted from included articles including year of publication, geographic area (North-America, Europe, Asia, Africa, South-America or worldwide collaborative studies), disease type (NMIBC, MIBC or UTUC), cigarette smoking assessment (questionnaire, interview or patient records), factors adjusted for and median length of follow-up time. HRs were obtained directly from included articles and were divided in recurrence-free (RFS), progression-free (PFS) and disease-specific (DSS) survival HRs. When bladders were resected in MIBC populations, recurrence-free survival was specified by loco-regional recurrence; recurrence at the margins of the surgical field or in the lymph nodes. NMIBC and MIBC were not further specified or analysed within the included studies, so it is likely that a range of different types of malignant neoplasms (e.g. different sub-codes of ICD code (67) are included in the pooled analysis.

\section{Statistical analysis}

HRs were pooled comparing RFS, PFS and DSS for current and former smokers to never smokers in NMIBC, MIBC and UTUC patients. Because HRs could differ between studies, a random effects model was used to model potential heterogeneity. The $\mathrm{I}^{2}$ test statistic was used to estimate between-study variance. Furthermore, meta-regression analysis was performed to estimate the effect of possible sources of heterogeneity (smoking assessment, factors adjusted for, length of follow-up) on different outcome measures. Publication bias was explored by funnel plots and Egger's test for small study effects for the different analyses performed (e.g. RFS, PFS \& DSS) (8). Unfortunately, there was insufficient data to also stratify for gender. As sensitivity analysis, subgroup analyses were performed comparing pooled HRs across geographic area and length of follow-up quartile. Stata statistical software was used for all analyses (version 13; Stata Corp., College Station, TX).

\section{RESULTS}

\section{Study characteristics}

In total, 24 studies were included in this meta-analysis; 11 for NMIBC (9-19) including 2 trials on different intravesical chemotherapy schedules and 9 retrospective cohorts with a total of 7,210 cases, 7 retrospective cohorts for MIBC (20-26) investigating 2,259 cases, and 6 retrospective cohorts for UTUC (27-32) encompassing 5,904 cases (Table 1). During full-text evaluation 5 studies were excluded because of a lack of data in the study report (33-37). Furthermore, 9 articles were excluded during data extraction because no HR for 


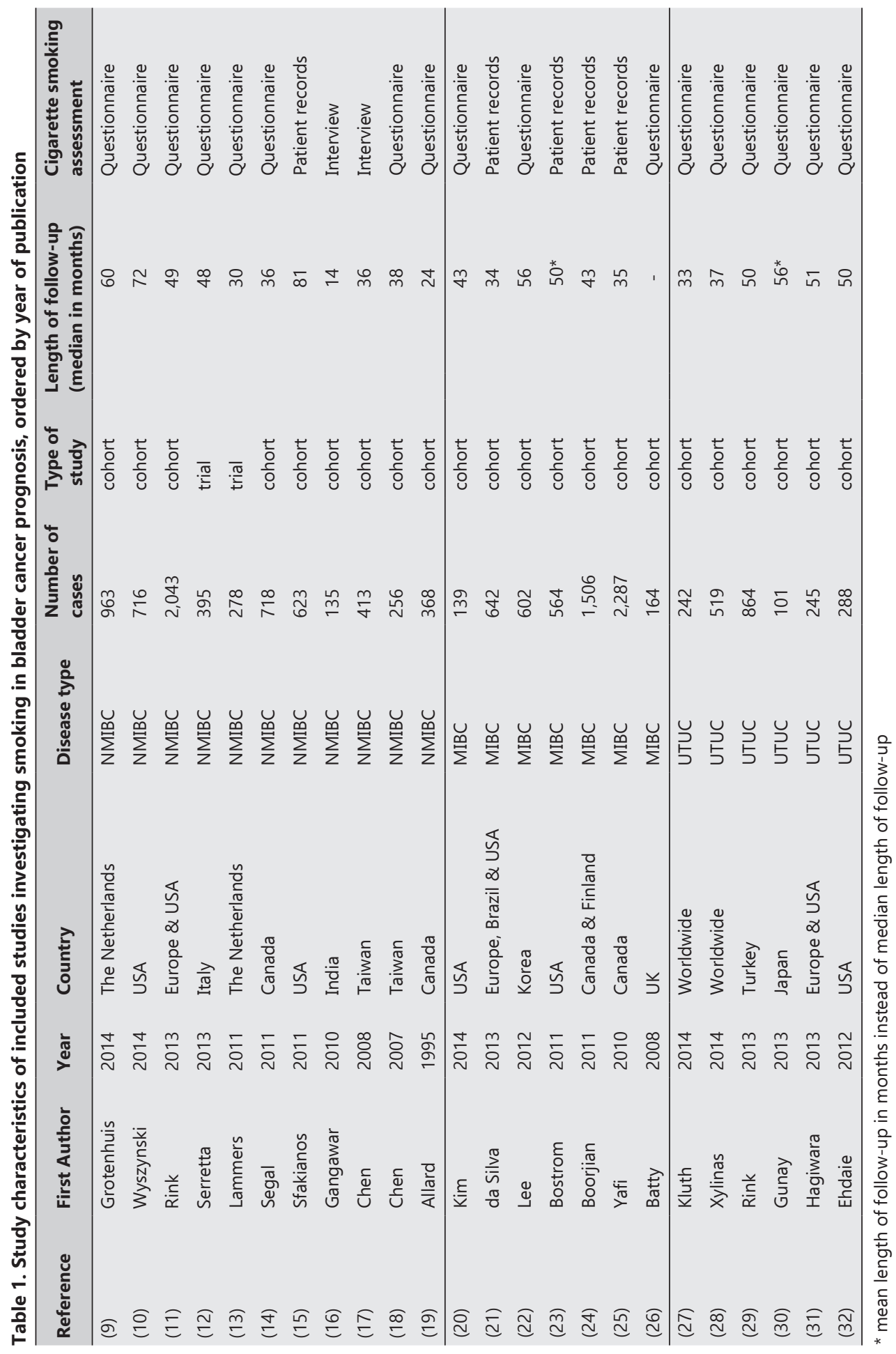


smoking status was given (38-42) or because the reference category was not comprised of never smokers (43-46) (Figure 1). All included studies were patient cohort studies, expect for two epirubicin trials in NMIBC $(12,13)$. Most studies which included HR estimates regarding smoking and UC prognosis were published after 2007. Smoking status was assessed either by a questionnaire $(9-14,18-20,22,26-32)$, reviewing patient records $(15,21,23-25)$ or an interview $(16,17)$. All included study populations for NMIBC had undergone full transurethral resection of a bladder tumour (TURBT) with some recorded to have received Bacillus Calmette-Guérin (BCG) treatment $(15,16)$. For MIBC, only studies in which patient populations had undergone radical cystectomy (complete removal of the bladder) could be included, with some populations receiving (neo)adjuvant chemotherapy $(20,23-25)$. Although radiation therapy is becoming more common as an alternative to radical cystectomy $(47,48)$, no studies investigating associations between smoking and outcomes were found in radiation therapy patient populations. In included UTUC study populations all patients underwent nephroureterectomy. Moreover, there was no data on studies that investigated smoking behaviour post-diagnosis.

\section{Risk estimates for smoking status in NMIBC}

The pooled HR of 1.27 (95\% C.I. $=1.09-1.46)$ shows that current smokers at diagnosis are at a slightly increased risk of developing local recurrences compared to non-smoking NMIBC patients. A mitigated effect is seen in former smokers compared to non-smokers where the pooled HR is 1.13 (95\% C.I. $=1.00-1.25$ ) based on 5,382 NMIBC cases. Similar (but not statistically significant) pooled HRs for PFS were obtained for both smokers ( $H R=1.21$, $95 \%$ C.I. $=0.81-1.61)$ and former smokers $(H R=1.13,95 \%$ C.I. $=0.81-1.45)$. Regarding DSS, only two studies investigating 925 NIMBC cases could be pooled and indicated no effect of being a current smoker at baseline $(H R=1.01$ (95\% C.I. $=0.93-1.10))$. 
Table 2. Pooled risk estimates for recurrence-free survival (RFS) and progression-free survival (PFS) in non-muscle invasive bladder cancer (NMIBC)

\begin{tabular}{|c|c|c|c|c|c|c|c|c|}
\hline \multirow{2}{*}{$\begin{array}{l}\text { NMIBC } \\
\text { Determinants }\end{array}$} & \multicolumn{4}{|c|}{ RFS } & \multicolumn{4}{|c|}{ PFS } \\
\hline & $\begin{array}{l}\text { No. of } \\
\text { studies }\end{array}$ & $\begin{array}{l}\text { No. of } \\
\text { events }\end{array}$ & HR & $95 \% \mathrm{CI}$ & $\begin{array}{l}\text { No. of } \\
\text { studies }\end{array}$ & $\begin{array}{l}\text { No. of } \\
\text { events }\end{array}$ & HR & $95 \% \mathrm{CI}$ \\
\hline \multicolumn{9}{|l|}{ Smoking status } \\
\hline Non-smoker & & & 1.00 & Reference & & & 1.00 & Reference \\
\hline Former smoker & $7 \mathrm{~A}$ & 1903 & 1.13 & $1.00-1.25$ & $4 C$ & 978 & 1.13 & $0.81-1.45$ \\
\hline Current smoker & $10 \mathrm{~B}$ & 1723 & 1.27 & $1.09-1.46$ & $6 \mathrm{D}$ & 617 & 1.21 & $0.81-1.61$ \\
\hline
\end{tabular}

RFS=recurrence free survival, $\mathrm{PFS}=$ progression free survival, $\mathrm{HR}=$ hazard ratio, $\mathrm{CI}=$ confidence interval

A

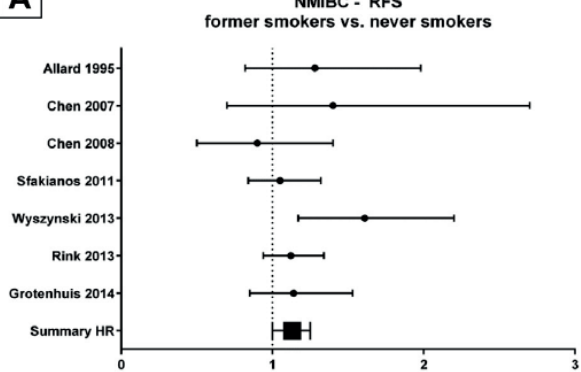

B

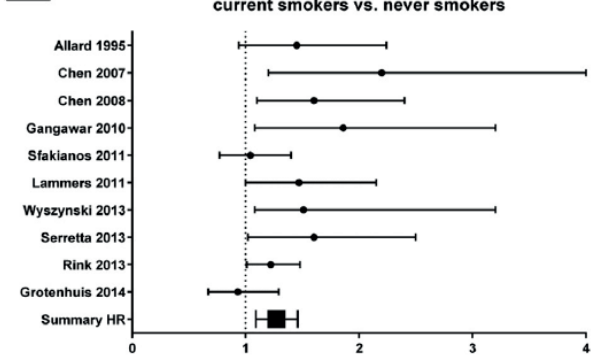

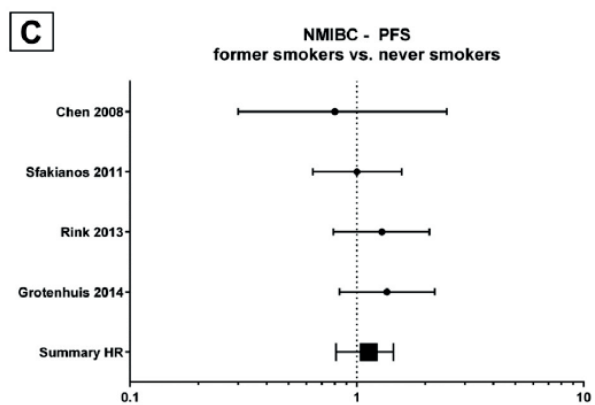

D

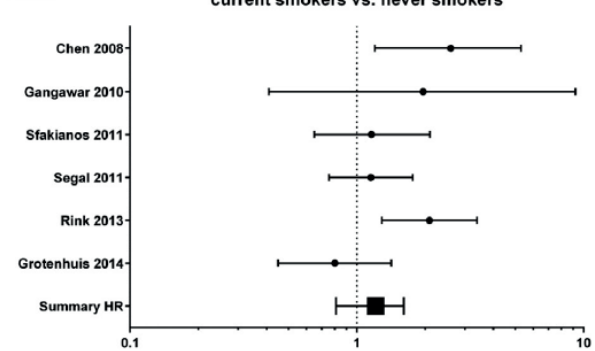

\section{Risk estimates for smoking status in MIBC}

For RFS only one of the four included studies reported a significantly increased risk of loco-regional recurrence in MIBC for current smokers at diagnosis (21), and two of three included studies showed an increased risk of local recurrence for former smokers $(20,21)$. Pooling these studies resulted in a pooled HR for recurrence of 1.09 (95\% C.I. $=0.78-1.40)$ for current smokers and a HR of $1.17(95 \%$ C.I. $=0.82-1.52)$ for former smokers compared to non-smokers at diagnosis. Current smokers at diagnosis seem to be at higher risk of dying due to $B C$ compared to non-smokers $(H R=1.23,95 \%$ C.I. $=1.02-1.44)$. A similar effect was observed for former smokers ( $H R=1.26,95 \%$ C.I. $=0.98-1.54)$. The HR for current smokers did not seem to differ between studies with different follow-up times. 
Table 3. Pooled risk estimates for recurrence-free survival (RFS) and disease-specific survival (DSS) in muscle invasive bladder cancer (MIBC)

\begin{tabular}{|c|c|c|c|c|c|c|c|c|}
\hline \multirow{2}{*}{$\begin{array}{l}\text { MIBC } \\
\text { Determinants }\end{array}$} & \multicolumn{4}{|c|}{ RFS } & \multicolumn{4}{|c|}{ DSS } \\
\hline & $\begin{array}{l}\text { No. of } \\
\text { studies }\end{array}$ & $\begin{array}{l}\text { No. of } \\
\text { events }\end{array}$ & HR & $95 \% \mathrm{CI}$ & $\begin{array}{l}\text { No. of } \\
\text { studies }\end{array}$ & $\begin{array}{l}\text { No. of } \\
\text { events }\end{array}$ & HR & $95 \% \mathrm{CI}$ \\
\hline \multicolumn{9}{|l|}{ Smoking status } \\
\hline Non-smoker & & & 1.00 & Reference & & & 1.00 & Reference \\
\hline Former smoker & $3 \mathrm{~A}$ & 360 & 1.17 & $0.82-1.52$ & $3 C$ & 402 & 1.26 & $0.98-1.54$ \\
\hline Current smoker & $4 B$ & 1206 & 1.09 & $0.78-1.40$ & $6 \mathrm{D}$ & 760 & 1.23 & $1.02-1.44$ \\
\hline
\end{tabular}

RFS=recurrence free survival, DSS=disease-specific survival, $\mathrm{HR}=$ hazard ratio, $\mathrm{CI}=$ confidence interval
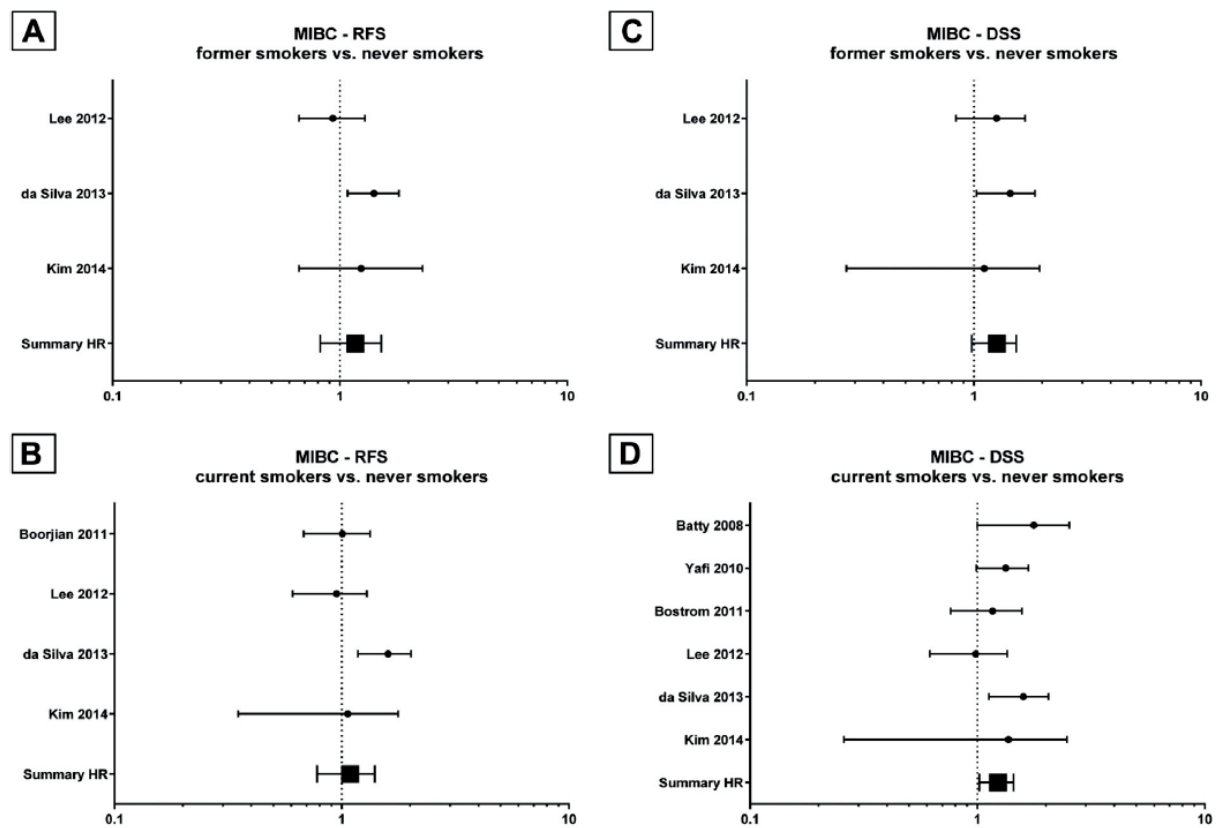

\section{Risk estimates for smoking status in UTUC}

No published studies on PFS for smokers in UTUC patient populations could be identified. Current smokers at diagnosis were at a significantly higher risk of both developing recurrences in the operative bed $(H R=1.57,95 \% C . I .=1.19-1.95)$ and dying due to UC $(H R=1.53$, $95 \%$ C.I. $=1.13-1.92)$. For former smokers, this effect was mitigated, both for RFS (HR=1.31, $95 \%$ C.I. $=0.85-1.78)$ and DSS (HR=1.20, 95\% C.I. $=0.80-1.61)$ (Table 4). 
Table 4. Pooled risk estimates for recurrence-free survival (RFS) and disease-specific survival (PFS) in upper tract urothelial carcinoma (UTUC)

\begin{tabular}{|c|c|c|c|c|c|c|c|c|}
\hline \multirow{2}{*}{$\begin{array}{l}\text { UTUC } \\
\text { Determinants }\end{array}$} & \multicolumn{4}{|c|}{ RFS } & \multicolumn{4}{|c|}{ DSS } \\
\hline & $\begin{array}{l}\text { No. of } \\
\text { studies }\end{array}$ & $\begin{array}{l}\text { No. of } \\
\text { events }\end{array}$ & HR & $95 \% \mathrm{CI}$ & $\begin{array}{l}\text { No. of } \\
\text { studies }\end{array}$ & $\begin{array}{l}\text { No. of } \\
\text { events }\end{array}$ & HR & $95 \% \mathrm{CI}$ \\
\hline \multicolumn{9}{|l|}{ Smoking status } \\
\hline Non-smoker & & & 1.00 & Reference & & & 1.00 & Reference \\
\hline Former smoker & $4 \mathrm{~A}$ & 415 & 1.31 & $0.85-1.78$ & $2 C$ & 331 & 1.20 & $0.80-1.61$ \\
\hline Current smoker & $5 B$ & 482 & 1.57 & $1.19-1.95$ & $2 \mathrm{D}$ & 330 & 1.53 & $1.13-1.92$ \\
\hline
\end{tabular}

RFS= recurrence free survival, DSS=disease-specific survival, $\mathrm{HR}=$ hazard ratio, $\mathrm{CI}=$ confidence interval
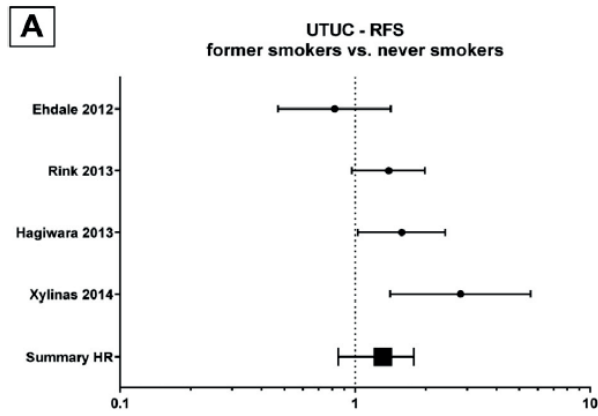

$\mathbf{B}$

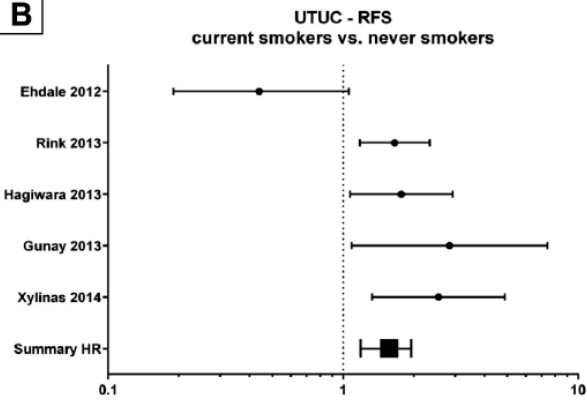

$\mathbf{C}$

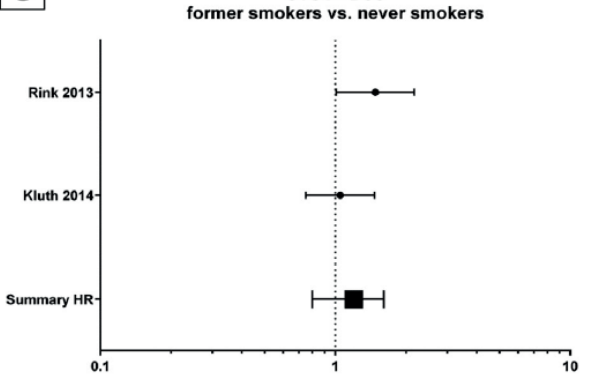

D

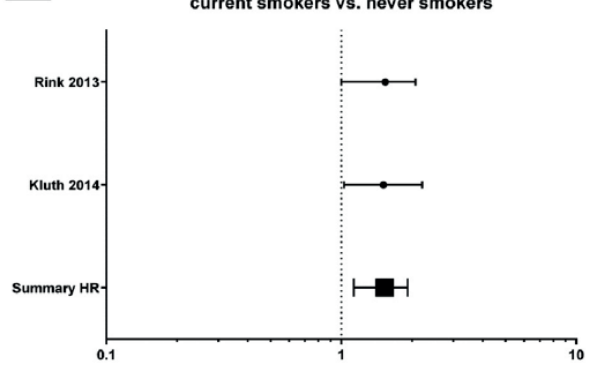

\section{Publication bias and heterogeneity between studies}

Both statistically and visually (as judged from several funnel plots), the amount of bias between studies seemed negligible within all three different disease categories. However, a statistically significant small study effect $(p=0.041)$ was observed for the NMIBC studies investigating RFS, indicating a possibility of publication bias. Meta-regression analyses showed that no significant heterogeneity was present due to mode of smoking assessment, number of adjusted factors (mostly multivariable) or months of median follow-up, and 12 test statistics were all under $30 \%$ except for comparing the five studies investigating RFS in UTUC (78\%). 

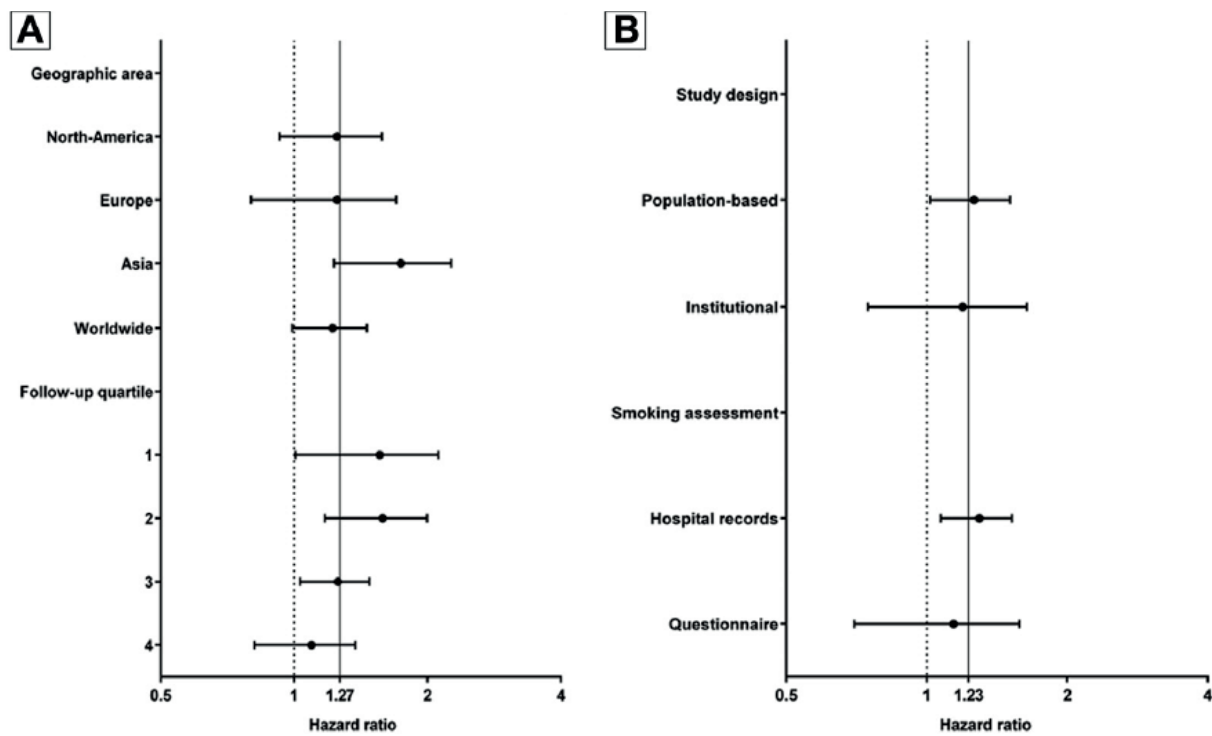

Figure 2. Forest plot depicting summary HR for RFS comparing current smokers vs non-smokers in NMIBC (A) and disease-free survival in MIBC (B) by geographic area, time of follow-up quartile, study design and smoking assessment, respectively. Broken line represents no effect and solid line indicates overall pooled HR.

\section{Sensitivity analyses}

Subgroup analyses in studies investigating RFS in NMIBC patients showed no significant heterogeneity between geographic areas or follow-up quartile in between studies (Figure 2). Additional inverse variance weighted regression analyses showed no significant change in observed HRs with increasing median follow-up time continuously. Current smokers from Asian populations (16-18) seemed to be at a higher risk of developing local recurrences compared to American, European and worldwide populations, although these differences were not statistically significant ( $p=0.452, p=0.447$ and $p=0.452$ respectively). The results of all sensitivity analyses in both NMIBC and MIBC studies are summarised in Supplemental Table 1. 
Supplemental Table 1. All results from sensitivity analysis stratifying results on geographic area, follow-up quartile, study design and mode of smoking assessment for all studies investigating RFS in NMIBC and DFS in MIBC.

\begin{tabular}{|c|c|c|c|c|c|c|}
\hline & \multicolumn{3}{|c|}{ NMIBC - RFS } & \multicolumn{3}{|c|}{ MIBC - DFS } \\
\hline Geographic area & HR & $95 \% \mathrm{CI}$ & $\begin{array}{c}\text { no. of } \\
\text { studies }\end{array}$ & HR & $95 \% \mathrm{CI}$ & $\begin{array}{c}\text { no. of } \\
\text { studies }\end{array}$ \\
\hline North-America & 1.25 & $0.93-1.58$ & 3 & 1.28 & $0.96-1.61$ & 2 \\
\hline Europe & 1.25 & $0.80-1.70$ & 3 & 1.66 & $0.90-2.43$ & 1 \\
\hline Asia & 1.74 & $1.23-2.26$ & 3 & 0.94 & $0.58-1.30$ & 1 \\
\hline Worldwide & 1.22 & $0.99-1.46$ & 1 & 1.30 & $0.87-1.73$ & 2 \\
\hline \multicolumn{7}{|l|}{ Follow-up quartile } \\
\hline 1 & 1.56 & $1.01-2.12$ & 2 & - & - & 0 \\
\hline 2 & 1.59 & $1.17-2.00$ & 3 & 1.39 & $1.11-1.66$ & 2 \\
\hline 3 & 1.26 & $1.03-1.48$ & 2 & 1.10 & $0.72-1.47$ & 2 \\
\hline 4 & 1.09 & $0.81-1.38$ & 3 & 0.94 & $0.58-1.31$ & 1 \\
\hline \multicolumn{7}{|l|}{ Study design } \\
\hline Population-based & 1.29 & $1.12-1.47$ & 9 & 1.19 & $0.75-1.64$ & 3 \\
\hline Institutional & 1.18 & $0.61-1.74$ & 2 & 1.26 & $1.02-1.51$ & 3 \\
\hline \multicolumn{7}{|l|}{ Smoking assessment } \\
\hline Hospital records & 1.31 & $1.09-1.53$ & 8 & 1.30 & $1.07-1.52$ & 3 \\
\hline Questionnaire & 1.04 & $0.73-1.36$ & 1 & 1.14 & $0.70-1.58$ & 3 \\
\hline
\end{tabular}

\section{DISCUSSION}

This meta-analysis indicates a role for lifetime smoking behaviour in BC and UTUC prognosis, showing an increased risk for disease recurrence and increased risk of death for current smokers at different stages of BC and UTUC.

\section{Significantly higher local recurrence rates for smokers at diagnosis in NMIBC}

Previous reviews have already suggested that current smokers at diagnosis are at an increased risk of developing local recurrences compared to non-smokers in NMIBC patient populations (2-4); however, this is the first study to quantify these risks at diagnosis. We observed an increased risk of developing local recurrences for current smokers compared to never smokers. Former smokers had a lower (but still increased) risk of developing local recurrences. These results are in-line with other studies indicating a potentially more malignant disease type for smokers at diagnosis $(4,6)$. The associations between smoking status at diagnosis and PFS were comparable to the RFS estimates, although not statistically significant. 
In NMIBC, smoking appears to promote a recurrence phenotype but it is not associated with a progression/death phenotype. Mechanistically, there is thus likely to be an influence of smoking on the hallmark capabilities of BC such as self-sufficiency in growth signals and delimiting replicative potential $(49,50)$. Although evidence on the effects of smoking regarding $B C$ prognosis is limited, including smoking status in panels of molecular markers (including e.g. p53, cyclooxygenase and vascular endothelial growth factor) has shown to improve prognostication in several studies $(45,51)$.

\section{More deaths due to BC in smokers at diagnosis compared to never smokers in MIBC}

Compared to NMIBC there were considerably fewer studies investigating the role of smoking in MIBC prognosis, although one other meta-analysis also showed significantly increased BC mortality for current smokers compared to never smokers ( $R R=1.89$ 95\% C.I. $=1.29-2.78$ ) not adjusting for stage of disease in the analysis (52). We did not demonstrate a relationship between smoking and RFS in MIBC patients; however, both current and former smokers at diagnosis are at a higher risk of dying due to $\mathrm{BC}$ compared to never smokers. There were also noticeably fewer studies investigating RFS compared to DSS in MIBC patient populations, emphasizing the need for more studies investigating RFS also in MIBC patients. Although there have not been specific studies investigating this association biologically or mechanistically, it is possible that the higher mortality due to bladder cancer for smokers can be attributed to a more malignant phenotype of BC at diagnosis, as suggested by other authors $(4,6)$.

Regarding smoking and survival in MIBC, there are several malignant processes in which smoking is suspected to play a role and which might explain the observed association with poor survival. Smokers have been shown to have a significantly higher expression of Twist, a transcription factor regulating epithelial-mesenchymal transition which is an important event in tumour invasion (53). Also, positive expression of haeme-oxygenase-1 (HO-1) may be dependent on smoking intensity as measured at diagnosis (54). A study by The Cancer Genome Atlas indicated that altered chromatin remodelling (which plays a role in gene expression and apoptosis) is a common event in MIBC (55), and has also been shown to be associated with smoking status in several in vitro studies $(56,57)$ and animal models (58). Moreover, it is probable that chronic exposure to cigarette smoke induces a phenotype of reduced sensitivity to cisplatin treatment, a well-known phenomenon in the management of MIBC (59). 


\section{Significant associations between smoking and both RFS and DSS in UTUC patients}

Interestingly, current smokers at diagnosis in the UTUC population were approximately at a $50 \%$ increased risk of both RFS and DSS compared to never smokers. Although the number of events was the smallest from the three meta-analyses performed, significant associations were observed. This indicates that also for UTUC patients, the risk of developing disease recurrences in the operative bed and dying due to UTUC is increased for smokers. Although similar associations are observed and many disease characteristics are shared, UTUC is a different disease than BC because there are several anatomical, biological and molecular-genetic differences (60). For example, microsatellite instability (MSI) and hypermethylation are more often observed in UTUC than in BC, which might lead to somatic inactivation of DNA mismatch repair genes representing a different pathway of initiating events $(61,62)$. Furthermore, the proportion of tumours that are invasive at diagnosis is about 50\% for UTUC (63) whereas for BC these numbers are lower at approximately $20-30 \%$ (64), possibly explaining why the observed associations with RFS and DSS are stronger compared to those found in NMIBC and MIBC.

\section{Study limitations}

One of the limitations of this study was the lack of prospective data on smoking behaviour after diagnosis. Even though current smokers at diagnosis could have quit smoking in the period prior to recurrence, dose-response meta-analyses show that smoking cessation only results in risk reduction at least 15 years before diagnosis, indicating a long latency effect of cigarette smoke in determining UC risk (unpublished results van Osch et al., manuscript currently under review). When considering recurrence as an incident event which usually occurs within 15 years of diagnosis, looking at lifetime smoking status at diagnosis could be a good proxy measure (with relatively high consistency between included studies for the effect of smoking on the development of recurrence). The same arguments hold for progression and UC mortality events. However, since UC is extremely heterogeneous biologically (65), studies prospectively investigating smoking within strata of molecular subtype and stage will provide a more thorough quantification of the effect of cigarette smoking in UC prognosis (and could additionally correct for smoking cessation after diagnosis in analyses to further enhance the biological plausibility of these results). Furthermore, such studies will be better able to address the question of whether smoking status should be considered in predictive nomograms (e.g. EORTC or CUETO) to improve decision-making in $\mathrm{BC}$ treatment. 


\section{CONCLUSION}

This meta-analysis supports the hypothesis that lifetime cigarette smokers are at an increased risk of developing a more malignant phenotype of UC. Smoking NMIBC and MIBC patients at diagnosis are at an approximately $25 \%$ increased risk of developing local recurrences and dying due to $B C$ respectively. Furthermore, smoking UTUC patients are at an approximately $55 \%$ increased risk of both developing recurrences in the operative bed of the tumour and dying due to UTUC compared to never smokers. These results indicate a significant role for lifetime smoking status in both BC and UTUC prognosis. 


\section{REFERENCES}

1. Zeegers $\mathrm{M}$, Tan FE, Dorant $\mathrm{E}$, van den Brandt PA. The impact of characteristics of cigarette smoking on urinary tract cancer risk. Cancer. 2000;89(3):630-9.

2. Crivelli JJ, Xylinas E, Kluth LA, Rieken M, Rink M, Shariat SF. Effect of smoking on outcomes of urothelial carcinoma: a systematic review of the literature. Eur Urol. 2014;65(4):742-54.

3. Simonis K, Shariat SF, Rink M. Smoking and smoking cessation effects on oncological outcomes in nonmuscle invasive bladder cancer. Curr Opin Urol. 2014;24(5):492-9.

4. Pietzak EJ, Malkowicz SB. Does quantification of smoking history correlate with initial bladder tumor grade and stage? Curr Urol Rep. 2014;15(7):1-6.

5. Lughezzani G, Burger M, Margulis V, Matin SF, Novara G, Roupret M, et al. Prognostic factors in upper urinary tract urothelial carcinomas: a comprehensive review of the current literature. Eur Urol. 2012;62(1):100-14.

6. van Roekel EH, Cheng KK, James ND, Wallace DMA, Billingham LJ, Murray PG, et al. Smoking is associated with lower age, higher grade, higher stage, and larger size of malignant bladder tumors at diagnosis. Int J Cancer. 2013;133(2):446-54.

7. Wells G, Shea B, O'Connell D. The Newcastle-Ottawa Scale (NOS) for assessing the quality of nonrandomised studies in meta-analyses. Ottawa, ON-Ottawa Hospital Research Institute, 2013. 2014.

8. Egger M, Smith GD, Schneider M, Minder C. Bias in meta-analysis detected by a simple, graphical test1997 1997-09-13 07:00:00. 629-34 p.

9. Grotenhuis AJ, Ebben CW, Aben KK, Witjes JA, Vrieling A, Vermeulen SH, et al., editors. The effect of smoking and timing of smoking cessation on clinical outcome in non-muscleinvasive bladder cancer. Urologic Oncology: Seminars and Original Investigations; 2014: Elsevier.

10. Wyszynski A, Tanyos SA, Rees JR, Marsit CJ, Kelsey KT, Schned AR, et al. Body mass and smoking are modifiable risk factors for recurrent bladder cancer. Cancer. 2014;120(3):40814.

11. Rink $M$, Furberg $H$, Zabor EC, Xylinas $E$, Babjuk $M$, Pycha $A$, et al. Impact of smoking and smoking cessation on oncologic outcomes in primary non-muscle-invasive bladder cancer. Eur Urol. 2013;63(4):724-32.

12. Serretta V, Altieri V, Morgia G, Di Lallo A, Carrieri G, Allegro R. Cigarette Smoking Status at Diagnosis and Recurrence in Intermediate-risk Non-muscle-invasive Bladder Carcinoma. Urology. 2013;81(2):277-82.

13. Lammers RJ, Witjes WP, Hendricksen K, Caris C, Janzing-Pastors MH, Witjes JA. Smoking status is a risk factor for recurrence after transurethral resection of non-muscle-invasive bladder cancer. Eur Urol. 2011;60(4):713-20.

14. Segal R, Yafi FA, Brimo F, Tanguay S, Aprikian A, Kassouf W. Prognostic factors and outcome in patients with $\mathrm{T} 1 \mathrm{high}$-grade bladder cancer: can we identify patients for early cystectomy? BJUI. 2012;109(7):1026-30.

15. Sfakianos JP, Shariat SF, Favaretto RL, Rioja J, Herr HW. Impact of smoking on outcomes after intravesical bacillus Calmette-Guérin therapy for urothelial carcinoma not invading muscle of the bladder. BJUI. 2011;108(4):526-30.

16. Gangawar R, Ahirwar D, Mandhani A, Mittal RD. Impact of nucleotide excision repair ERCC2 and base excision repair APEX1 genes polymorphism and its association with recurrence 
after adjuvant BCG immunotherapy in bladder cancer patients of North India. Med Oncol. 2010;27(2):159-66.

17. Chen C-H, Shun C-T, Huang K-H, Huang C-Y, Yu H-J, Pu Y-S. Characteristics of Female Non-Muscle-Invasive Bladder Cancer in Taiwan: Association with Upper Tract Urothelial Carcinoma and End-Stage Renal Disease. Urology. 2008;71(6):1155-60.

18. Chen $\mathrm{CH}$, Shun $\mathrm{CT}$, Huang $\mathrm{KH}$, Huang $\mathrm{CY}$, Tsai $\mathrm{YC}$, Yu HJ, et al. Stopping smoking might reduce tumour recurrence in nonmuscle-invasive bladder cancer. BJUI. 2007;100(2):281-6.

19. Allard $P$, Fradet $Y$, Tetu $B$, Bernard P. Tumor-associated antigens as prognostic factors for recurrence in 382 patients with primary transitional cell carcinoma of the bladder. Clin Cancer Res. 1995;1(10):1195-202.

20. Kim PH, Kent M, Zhao P, Sfakianos JP, Bajorin DF, Bochner BH, et al. The impact of smoking on pathologic response to neoadjuvant cisplatin-based chemotherapy in patients with muscle-invasive bladder cancer. World J Urol. 2014;32(2):453-9.

21. da Silva RD, Xylinas E, Kluth L, Crivelli JJ, Chrystal J, Chade D, et al. Impact of statin use on oncologic outcomes in patients with urothelial carcinoma of the bladder treated with radical cystectomy. J Urol. 2013;190(2):487-92.

22. Lee $\mathrm{C}$, Kim KH, You D, Jeong IG, Hong B, Hong JH, et al. Smoking and survival after radical cystectomy for bladder cancer. Urology. 2012;80(6):1307-12.

23. Boström PJ, Alkhateeb S, Trottier G, Athanasopoulos PZ, Mirtti T, Kortekangas H, et al. Sex differences in bladder cancer outcomes among smokers with advanced bladder cancer. BJUI. 2012;109(1):70-6.

24. Boorjian SA, Kim SP, Weight CJ, Cheville JC, Thapa P, Frank I. Risk factors and outcomes of urethral recurrence following radical cystectomy. Eur Urol. 2011;60(6):1266-72.

25. Yafi FA, Aprikian AG, Chin JL, Fradet Y, Izawa J, Estey E, et al. Contemporary outcomes of 2287 patients with bladder cancer who were treated with radical cystectomy: a Canadian multicentre experience. BJUI. 2011;108(4):539-45.

26. Batty G, Kivimaki M, Gray L, Smith GD, Marmot M, Shipley M. Cigarette smoking and sitespecific cancer mortality: testing uncertain associations using extended follow-up of the original Whitehall study. Ann Oncol. 2008;19(5):996-1002.

27. Kluth LA, Xylinas E, Kent M, Hagiwara M, Kikuchi E, Ikeda M, et al. Predictors of survival in patients with disease recurrence after radical nephroureterectomy. BJUI. 2014;113(6):911-7.

28. Xylinas E, Kluth LA, Rieken M, Lee RK, Elghouayel M, Ficarra V, et al. Impact of smoking status and cumulative exposure on intravesical recurrence of upper tract urothelial carcinoma after radical nephroureterectomy. BJUI. 2013.

29. Rink M, Xylinas E, Margulis V, Cha EK, Ehdaie B, Raman JD, et al. Impact of smoking on oncologic outcomes of upper tract urothelial carcinoma after radical nephroureterectomy. Eur Urol. 2013;63(6):1082-90.

30. Gunay LM, Akdogan B, Koni A, Inci K, Bilen CY, Ozen H. Upper urinary tract transitional cell carcinoma: is there a best? Clin Genitourinary Cancer. 2013;11(1):39-44.

31. Hagiwara M, Kikuchi E, Tanaka N, Matsumoto K, Ide H, Miyajima A, et al. Impact of smoking status on bladder tumor recurrence after radical nephroureterectomy for upper tract urothelial carcinoma. J Urol. 2013;189(6):2062-8.

32. Ehdaie B, Furberg H, Zabor EC, Ostroff JS, Shariat SF, Bochner BH, et al. Impact of smoking status at diagnosis on disease recurrence and death in upper tract urothelial carcinoma. BJUI. 2013;111(4):589-95. 
33. Shiels MS, Gibson T, Sampson J, Albanes D, Andreotti G, Freeman LB, et al. Cigarette Smoking Prior to First Cancer and Risk of Second Smoking-Associated Cancers Among Survivors of Bladder, Kidney, Head and Neck, and Stage I Lung Cancers. JCO. 2014;32(35):3989-95.

34. Koch M, Hill GB, McPhee MS. Factors affecting recurrence rates in superficial bladder cancer. Journal of the National Cancer Institute. 1986;76(6):1025-9.

35. Wakai K, Ohno Y, Obata K, Aoki K. Prognostic significance of selected lifestyle factors in urinary bladder cancer. Cancer Sci. 1993;84(12):1223-9.

36. Tseng $\mathrm{C}-\mathrm{H}$. Insulin use and smoking jointly increase the risk of bladder cancer mortality in patients with type 2 diabetes. Clin Genitourinary Cancer. 2013;11(4):508-14.

37. Wennersten C, Andersson G, Boman K, Nodin B, Gaber A, Jirström K. Incident urothelial cancer in the Malmö Diet and Cancer Study: cohort characteristics and further validation of ezrin as a prognostic biomarker. Diagn Pathol. 2014;9(1):189.

38. Miyamoto $H$, Brimo F, Schultz L, Ye H, Miller JS, Fajardo DA, et al. Low-grade papillary urothelial carcinoma of the urinary bladder. Arch Pathol Lab Med. 2010;134:1160-3.

39. Cheng L, Neumann RM, Weaver AL, Spotts BE, Bostwick DG. Predicting cancer progression in patients with stage T1 bladder carcinoma. JCO. 1999;17(10):3182-7.

40. Simsir A, Sarsik B, Cureklibatir I, Sen S, Gunaydin G, Cal C. Prognostic factors for upper urinary tract urothelial carcinomas: stage, grade, and smoking status. Int Urol Nephrol. 2011;43(4):1039-45.

41. Gee JR, Jarrard DF, Bruskewitz RC, Moon TD, Hedican SP, Leverson GE, et al. Reduced bladder cancer recurrence rate with cardioprotective aspirin after intravesical bacille CalmetteGuérin. BJUI. 2009;103(6):736-9.

42. Michalek AM, Cummings KM, Pontes JE. Cigarette smoking, tumor recurrence, and survival from bladder cancer. Prev Med. 1985;14(1):92-8.

43. Fleshner N, Garland J, Moadel A, Herr H, Ostroff J, Trambert R, et al. Influence of smoking status on the disease-related outcomes of patients with tobacco-associated superficial transitional cell carcinoma of the bladder. Cancer. 1999;86(11):2337-45.

44. Ajili F, Kourda N, Karay S, Darouiche A, Chebil M, Boubaker S. Impact of Smoking intensity on Outcomes of Patients with Non Muscle Invasive Bladder Cancer Treated by BCG Immunotherapy. Ultrastruct Pathol. 2013;37(4):273-7.

45. Mitra AP, Castelao JE, Hawes D, Tsao-Wei DD, Jiang X, Shi SR, et al. Combination of molecular alterations and smoking intensity predicts bladder cancer outcome. Cancer. 2013;119(4):756-65.

46. Rink M, Zabor EC, Furberg H, Xylinas E, Ehdaie B, Novara G, et al. Impact of smoking and smoking cessation on outcomes in bladder cancer patients treated with radical cystectomy. Eur Urol. 2013;64(3):456-64.

47. James ND, Hussain SA, Hall E, Jenkins P, Tremlett J, Rawlings C, et al. Radiotherapy with or without chemotherapy in muscle-invasive bladder cancer. NEJM. 2012;366(16):1477-88.

48. Stenzl A, Cowan NC, De Santis M, Kuczyk MA, Merseburger AS, Ribal MJ, et al. Treatment of muscle-invasive and metastatic bladder cancer: update of the EAU guidelines. Eur Urol. 2011;59(6):1009-18.

49. Bryan RT, Hussain SA, James ND, Jankowski JA, Wallace DMA. Molecular pathways in bladder cancer: part 1. BJUI. 2005;95(4):485-90.

50. Bryan RT, Hussain SA, James ND, Jankowski JA, Wallace DMA. Molecular pathways in bladder cancer: part 2. BJUI. 2005;95(4):491-6. 
51. Wang LC, Xylinas E, Kent MT, Kluth LA, Rink M, Jamzadeh A, et al. Combining smoking information and molecular markers improves prognostication in patients with urothelial carcinoma of the bladder. Urol Oncol. 2014;32(4):433-40.

52. Cumberbatch MG, Rota M, Catto JW, La Vecchia C. The Role of Tobacco Smoke in Bladder and Kidney Carcinogenesis: A Comparison of Exposures and Meta-analysis of Incidence and Mortality Risks. Eur Urol. 2015.

53. Fondrevelle ME, Kantelip B, Reiter RE, Chopin DK, Thiery JP, Monnien F, et al. The expression of Twist has an impact on survival in human bladder cancer and is influenced by the smoking status. Urologic Oncology: Seminars and Original Investigations. 2009;27(3):268-76.

54. Miyata Y, Kanda S, Mitsunari K, Asai A, Sakai H. Heme oxygenase-1 expression is associated with tumor aggressiveness and outcomes in patients with bladder cancer: a correlation with smoking intensity. Translational Research. 2014;164(6):468-76.

55. Network CGAR. Comprehensive molecular characterization of urothelial bladder carcinoma. Nature. 2014;507(7492):315-22.

56. Moodie FM, Marwick JA, Anderson CS, Szulakowski P, Biswas SK, Bauter MR, et al. Oxidative stress and cigarette smoke alter chromatin remodeling but differentially regulate $\mathrm{NF}-\mathrm{KB}$ activation and proinflammatory cytokine release in alveolar epithelial cells. The FASEB journal. 2004;18(15):1897-9.

57. Chen D, Fang L, Li H, Tang M-s, Jin C. Cigarette smoke component acrolein modulates chromatin assembly by inhibiting histone acetylation. Journal of Biological Chemistry. 2013;288(30):21678-87.

58. Marwick JA, Kirkham PA, Stevenson CS, Danahay H, Giddings J, Butler K, et al. Cigarette smoke alters chromatin remodeling and induces proinflammatory genes in rat lungs. Am J Respir Cell Mol Biol. 2004;31(6):633-42.

59. Chang X, Ravi R, Pham V, Bedi A, Chatterjee A, Sidransky D. Adenylate kinase 3 sensitizes cells to cigarette smoke condensate vapor induced cisplatin resistance. PloS one. 2011;6(6):e20806.

60. Green DA, Rink M, Xylinas E, Matin SF, Stenzl A, Roupret M, et al. Urothelial carcinoma of the bladder and the upper tract: disparate twins. J Urol. 2013;189(4):1214-21.

61. Yates DR, Catto JW. Distinct patterns and behaviour of urothelial carcinoma with respect to anatomical location: how molecular biomarkers can augment clinico-pathological predictors in upper urinary tract tumours. World J Urol. 2013;31(1):21-9.

62. Azémar $M-D$, Comperat $E$, Richard $F$, Cussenot $O$, Rouprêt $M$, editors. Bladder recurrence after surgery for upper urinary tract urothelial cell carcinoma: frequency, risk factors, and surveillance. Urologic Oncology: Seminars and Original Investigations; 2011: Elsevier.

63. Kang $\mathrm{CH}, \mathrm{Yu} \mathrm{TJ}$, Hsieh HH, Yang JW, Shu K, Huang CC, et al. The development of bladder tumors and contralateral upper urinary tract tumors after primary transitional cell carcinoma of the upper urinary tract. Cancer. 2003;98(8):1620-6.

64. Kirkali Z, Chan T, Manoharan M, Algaba F, Busch C, Cheng L, et al. Bladder cancer: epidemiology, staging and grading, and diagnosis. Urology. 2005;66(6):4-34.

65. Knowles MA, Hurst CD. Molecular biology of bladder cancer: new insights into pathogenesis and clinical diversity. Nature Reviews Cancer. 2015;15(1):25-41. 

The association between smoking cessation before and after diagnosis and non-muscle-invasive bladder cancer recurrence: a prospective cohort study

Disclaimer: this study was underpowered and therefore nothing can be inferred from the exploratory analysis presented in this dissertation

Frits H.M. van Osch, Sylvia H.J. Jochems, Duncan Nekeman, Sarah Pirrie, Anke Wesselius, Raoul C. Reulen, Nicholas James, D Michael A. Wallace, Frederik J. van Schooten, KK Cheng, Richard T. Bryan, Maurice P. Zeegers

Adapted from: Cancer Causes \& Control, Vol. 29 (2018), 675-683
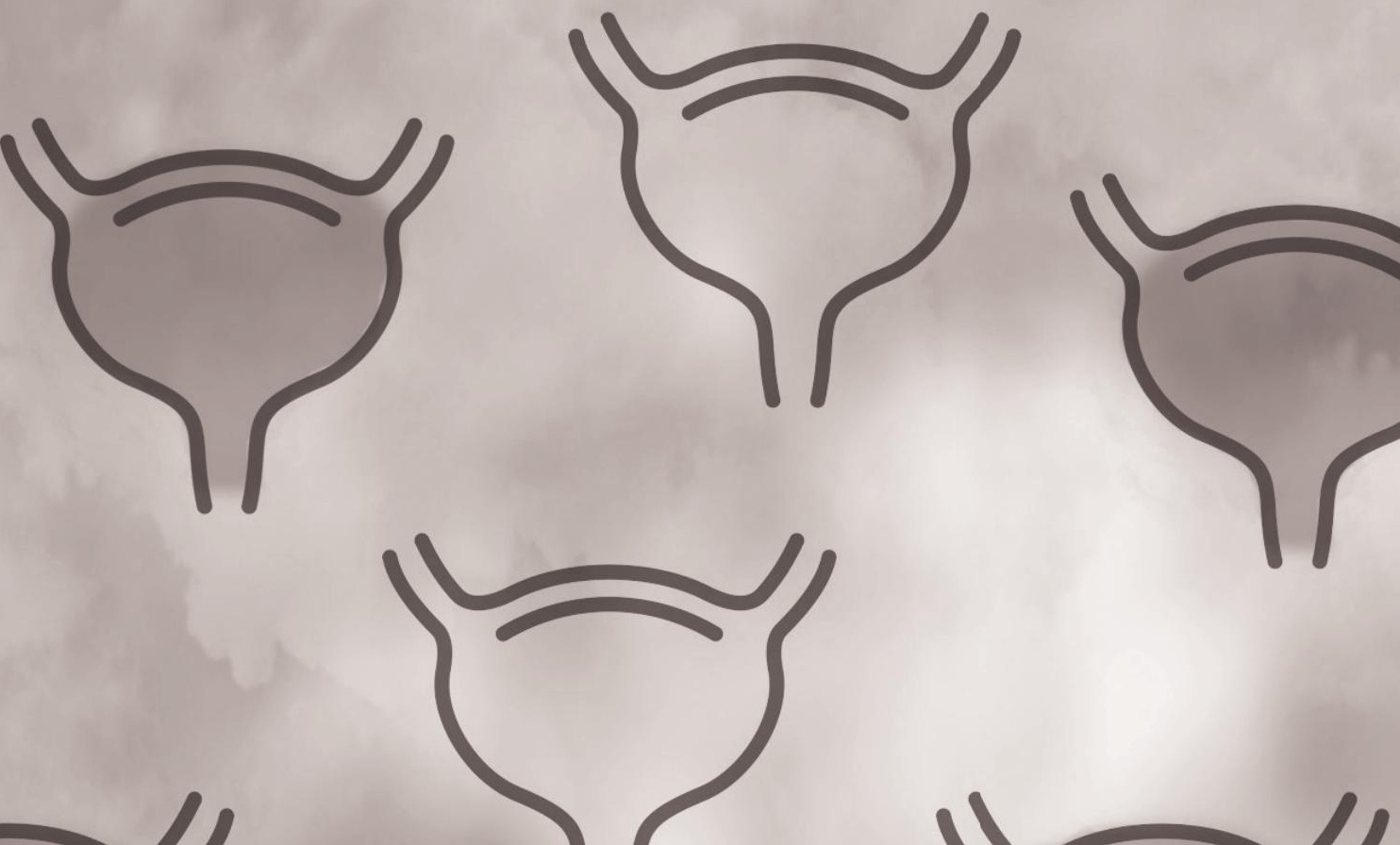


\section{ABSTRACT}

\section{Background}

Smoking is a major risk factor for bladder cancer, but the relationship between smoking cessation after initial treatment and bladder cancer recurrence has been investigated less frequently and not prospectively yet.

\section{Methods}

722 non-muscle-invasive bladder cancer (NMIBC) patients (pTa, pT1 and CIS) from the prospective Bladder Cancer Prognosis Programme (BCPP) cohort, selected in the UK between 2005-2011, provided complete data on smoking behaviour before and up to 5 years after diagnosis. The impact of smoking behaviour on NMIBC recurrence was explored by multivariable Cox regression models investigating time-to-first NMIBC recurrence.

\section{Results}

Over a median follow-up period of 4.21 years, 403 pathologically confirmed NMIBC recurrences occurred in 210 patients. Only 25 current smokers at diagnosis quit smoking (14\%) during follow-up and smoking cessation after diagnosis did not decrease risk of recurrence compared to continuing smokers $(p=0.352)$.

\section{Conclusions}

Although quitting smoking after diagnosis might reduce the risk of recurrence based on retrospective evidence, this could not be confirmed in this prospective study because the number of NMIBC patients quitting smoking before their first recurrence was too low. 


\section{INTRODUCTION}

Bladder cancer $(B C)$ is estimated to be the ninth most frequent cancer worldwide with approximately 400,000 newly diagnosed cases per year [1]. Compared to other cancers, mortality rates are generally lower for $\mathrm{BC}$ [1] since the majority of $\mathrm{BCs}$ diagnosed are nonmuscle-invasive bladder cancers (NMIBC) [2]. However, NMIBC often recurs [3] and has a risk of progressing to muscle-invasive bladder cancer (MIBC) [4], events which impact on the quality of life of the patient [5] and generate high disease management costs [6].

Although smoking is an established risk factor for $B C$, its effects have been less frequently investigated in relation to $B C$ prognosis [7-10]. Although many studies investigated effectiveness of treatment for NMIBC and MIBC with regard to recurrence, progression and mortality, most studies did not investigate the effect of smoking or other factors modifiable by patients on BC prognosis [11]. Nevertheless, the number of studies also reporting hazard ratios (HRs) for BC recurrence by smoking status at diagnosis has increased recently and the current body of evidence consistently shows that there is a small association between smoking and $\mathrm{BC}$ recurrence when comparing current smokers to never smokers at diagnosis $[10,12]$. However, the impact of smoking cessation after $B C$ diagnosis on recurrence and mortality has not yet been quantified prospectively [13]. Studies have investigated the impact of smoking cessation within one year after diagnosis on $B C$ recurrence, showing a slight decrease in risk of recurrence $[14,15]$, and one study indicating no effect of quitting after diagnosis on overall or bladder cancer-specific mortality [16].

The Bladder Cancer Prognosis Programme (BCPP) followed-up BC patients for five years post-diagnosis and investigated changes in smoking behaviour in relation to the course of the disease [17]. The principal aim of this study was to investigate whether smoking cessation post-diagnosis and smoking behaviour pre-diagnosis influences $B C$ recurrence.

\section{METHODS}

\section{The Bladder Cancer Prognosis programme}

This study was conducted within the framework of the West Midlands Bladder Cancer Prognosis Programme (BCPP), a cohort study in the United Kingdom. Details of the study are described elsewhere [17]. In brief, individuals were included between December 2005 and October 2011 after referral to participating urology centres due to symptoms suspicious of $B C$ and followed for a maximum of 5 years from diagnosis. Patients with previous cancer of the urethra, bladder, ureter, or renal pelvis within the last decade were 
excluded. The study was ethically-approved (06/MRE04/65) and all participants gave written informed consent.

\section{Data collection}

At or around time of diagnosis, trained research nurses used semi-structured face-to-face interviews and questionnaires to collect data on social support, health-related quality of life, sociodemographics, medical history, and health-related behaviours including smoking behaviour. Variables on smoking behaviour included current smoking status (never, former, current), duration (years of smoking), intensity (cigarettes per day), smoking cessation (in years) and tobacco type (filter, non-filter or rolled cigarettes, cigar or pipe). Monthly smoking status was also assessed retrospectively by postal questionnaires that were sent out to participants yearly until the end of follow-up.

\section{Smoking status at diagnosis and during follow-up}

A combined smoking status variable was created indicating continuing smokers, former smokers who consistently abstained, never smokers, former smokers who started smoking again, and current smokers who quit smoking post-diagnosis. Patients were considered quitters when they abstained consistently, so smokers who quit for 3 months and then started again were considered as continuing smokers. Furthermore, for each participant that reported smoking cessation during follow-up it was confirmed whether this occurred before or after their first recurrence. If patients quit smoking after their first recurrence, they were considered as continuing smokers in the time-to-first recurrence analysis.

\section{Population at risk}

Of the 1,550 cases who agreed to participate, 231 were subsequently identified as not having BC. Patients who presented with MIBC $(n=275)$ disease at diagnosis were excluded from analysis because they are fundamentally different from NMIBC with regard to recurrence. Patients with squamous or adeno-carcinomas of non-urothelial origin or with bladder cancer as secondary carcinoma were excluded $(n=41)$. In addition to patients presenting with Ta and T1 tumours, carcinoma in situ (CIS) tumours were included $(n=16)$ since they have an increased risk of recurrence [18]. In total, 846 (84\%) of these patients had provided data on smoking behaviour at diagnosis and during follow-up and remained under follow-up within the cohort study. Of the included 846 NMIBC patients, there were 116 patients with unknown recurrent tumour stage. These 116 unconfirmed events were excluded for other analyses as well as 8 cases who had radiotherapy (on suspicion of being MIBC cases) resulting in a NMIBC patient population at risk of recurrence of 722 . No systematic guidance or tools were provided to enable patients to quit smoking after diagnosis, so care as usual was applied by all participating urologists. 


\section{Statistical analysis}

$B C$ recurrence was defined as a new tumour that was the same stage as the primary tumour (Ta or T1) but also when a primary Ta patient had a T1 recurrence. Patients that progressed from $\mathrm{T} 1$ to $\mathrm{T} 2$ disease were not counted as a recurrence but as a progression event. Unfortunately, there were not enough events to also consider biological progression within this sample of NMIBC patients, as defined in the BCPP cohort [19]. Therefore, this study only focussed on confirmed recurrence events and patients who experienced a progression event were censored in the survival analysis when the progression event was diagnosed.

The impact of smoking behaviour on $B C$ recurrence was explored by Cox regression models - with time since initial transurethral resection of the bladder tumour (TURBT) as the time-metric-investigating possible differences in likelihood of a first recurrence. We explored two different Cox regression models: one adjusted for age at diagnosis and sex (model 1) and one additionally adjusted for BC stage, grade, tumour size and number of tumours at diagnosis (model 2). This set of confounders was chosen since they are markers of NMIBC prognosis and are factors that contribute to European Association of Urology (EAU) risk stratification for clinical decisions [20]. Moreover, they are potentially associated with smoking behaviour at diagnosis [21]. Consequently, conditional risk set modelling was applied to investigate time between multiple recurrent events and analysis time was reset at each event [22]. For this analysis, reresection of tumours was added to model 2 as a confounder. The proportional hazards assumption was checked in all models using Schoenfeld residuals. Cumulative incidence functions (CIF) corrected for competing risks (death) were made [23].

Furthermore, the differences in mean number of recurrences over 5 years between never smokers, former smokers and continuing smokers were compared using a multivariable ANOVA model correcting for pairwise comparisons using Tukey's HSD. There were not enough BC-related death events (45) or confirmed progression events (19) to allow for separate analyses. A similarly low number of progression events has been observed in a large $(n=718)$ NMIBC patient sample before [24].

NMIBC patients who died before the end of follow-up $(n=157)$ were censored at time of death and patients who underwent cystectomy $(n=15)$ were censored at the date of cystectomy (13). Other patients were considered lost to follow-up when the date on which patients were last seen in the hospital for bladder cancer-related therapy or the date on which they filled in their last follow-up questionnaire was before the end of follow-up (5 years). 


\section{RESULTS}

\section{Number of recurrences and characteristics of population at risk}

All 722 patients at risk of recurrence were followed over a median period of 4.21 years (IQR $=2.64-5.00$ years). The majority of patients $(506,70 \%)$ were followed for at least 3 years. Over this period of follow-up, 210 NMIBC patients experienced at least one confirmed recurrence event. These 210 NMIBC patients accumulated a total of 403 confirmed recurrence events in the cohort.

Most cases were male (79\%) and around the age of 70 (Table 1). Furthermore, continuing smokers seemed to be underrepresented in the low EAU risk group (12\%), those who quit smoking seemed more likely to be younger and female, and continuing smokers seemed more likely to present with multiple tumours at diagnosis (Table 1). In the multivariate models, 26 patients were not included in the analysis due to missing data on age $(n=7)$, number of tumours at diagnosis $(n=15)$ and tumour size $(n=4)$. Because participants were recruited from multiple centers, patients were treated by multiple urologists with different individual thresholds to perform certain therapies. Therefore, not all patients were treated exactly according to the EAU guidelines [20], which is often the case in actual clinical practice [25].

\section{Associations between smoking behaviour pre-and post- diagnosis and $B C$ recurrence}

Although HR estimates for smoking cessation pre-diagnosis indicated a protective association with BC recurrence, the $\mathrm{p}$ for linear trend was not statistically significant (ptrend $=0.126$ ) and therefore the association cannot be considered as strong (Table 2). No association between smoking status and risk of recurrence was observed in the multivariable model (Table 2). Interestingly, when compared to continuing smokers ( $H R=1.04$, $95 \% \mathrm{CI}=0.65-1.66) \mathrm{HRs}$ were similar for those who quit smoking $(\mathrm{p}=0.352)$ and former smokers who started again post-diagnosis $(p=0.431)$ (Table 2$)$. Additionally, the cumulative incidence function shows that cumulative incidence of $B C$ recurrence was lowest for former smokers and never smokers (Figure 1). 


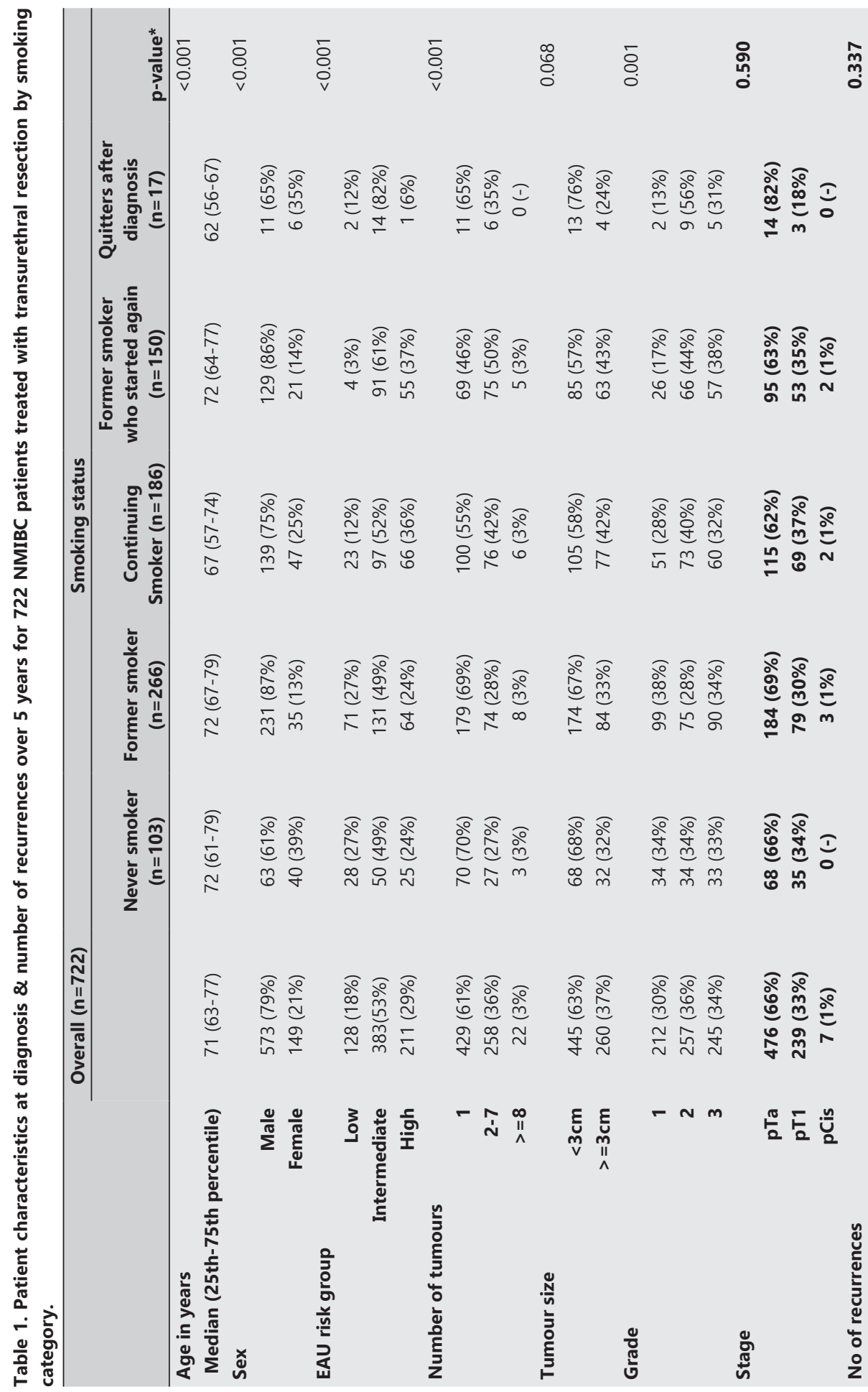




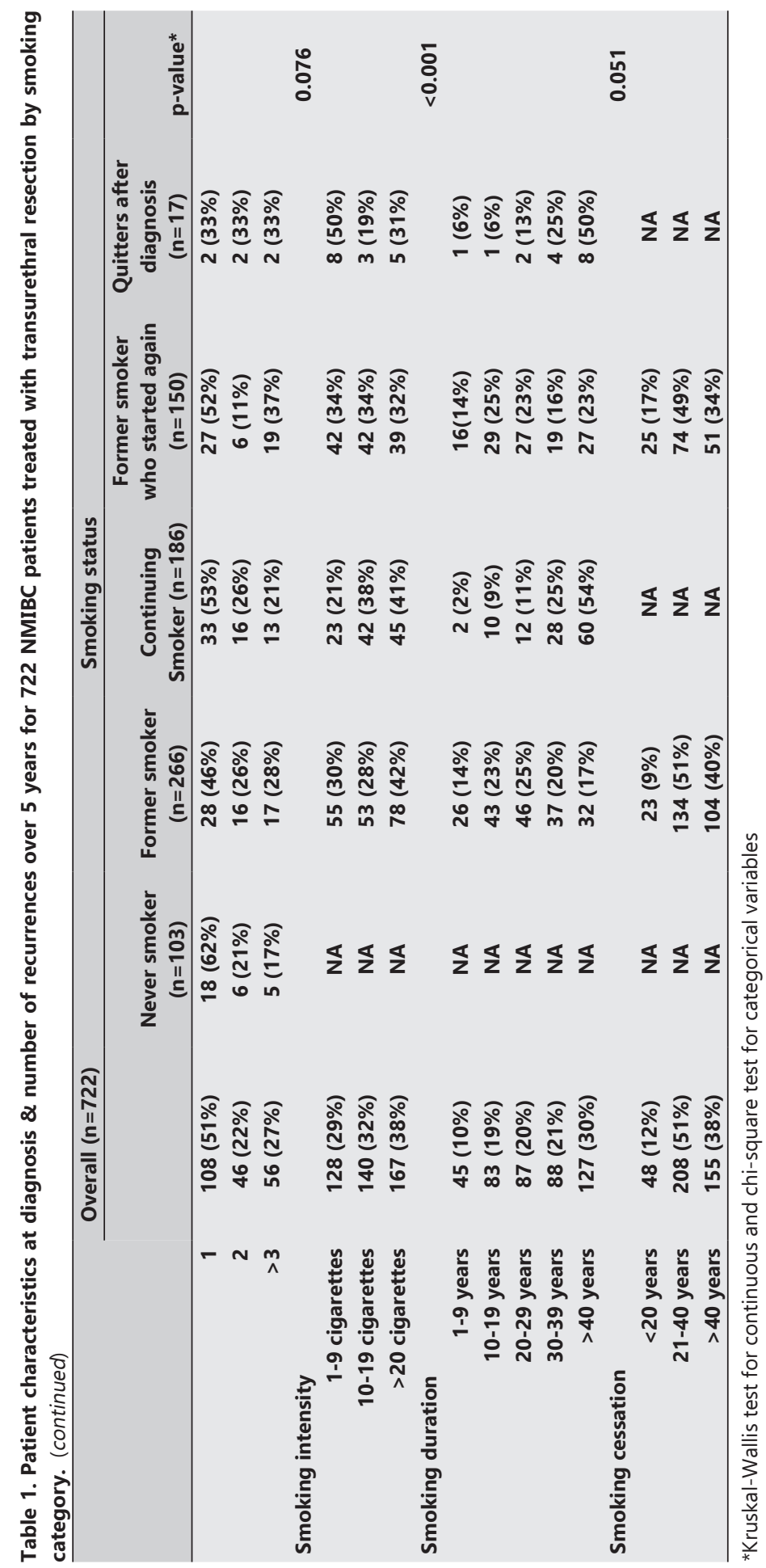




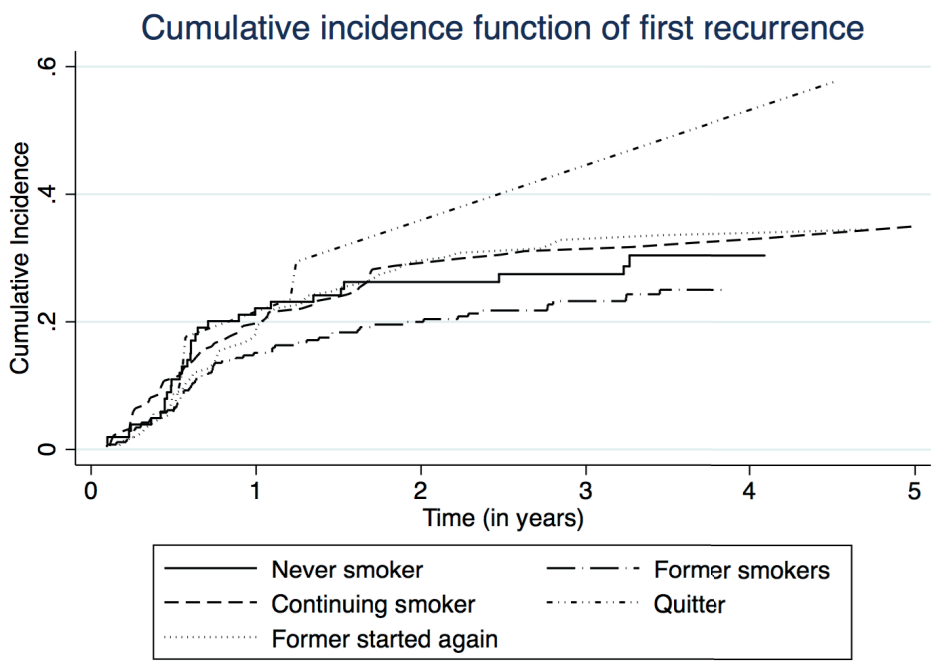

Figure 1. Cumulative incidence functions with correction for competing risk (death) indicating cumulative incidence of first recurrence per category of smoking status in NMIBC patients treated with TURBT.

Only 25 smokers (14\%) of the 174 current smokers originally recorded at diagnosis quit smoking at any point during follow-up. Three quitters were excluded for full analysis for not having information on their date last seen and another five had missing data regarding the invasiveness of their recurrent events. Of the $\mathbf{4 8 0}$ former smokers at diagnosis, $172(36 \%)$ started smoking (any form of tobacco) again post-diagnosis in all included 846 NMIBC patients. Exposure to environmental tobacco smoke during childhood $(H R=1.17$, $95 \% \mathrm{CI}=0.81-1.68)$ or adulthood $(\mathrm{HR}=1.02,95 \% \mathrm{CI}=0.76-1.36)$ did not seem to have any impact on time to first recurrence (Table 2).

Table 3 shows HRs for time to first recurrence by smoking intensity, duration and packyears. No linear trends were observed although the highest categories showed the highest point estimates for both smoking intensity and pack years. For smoking duration, the HRs were divergent and did not indicate any trend (ptrend=0.729) at all. 
Table 2. Cox regression analysis investigating smoking status at diagnosis, smoking behaviour after diagnosis, smoking cessation and passive smoking regarding risk of recurrence in NMIBC patients treated with TURBT.

\begin{tabular}{|c|c|c|c|c|c|c|}
\hline & \multicolumn{3}{|c|}{ Age \& sex adjusted } & \multicolumn{3}{|c|}{ Multivariable model* } \\
\hline & HR & $95 \% \mathrm{CI}$ & $\begin{array}{c}\text { number of } \\
\text { events / } \\
\text { patients at risk }\end{array}$ & HR & $95 \% \mathrm{CI}$ & $\begin{array}{c}\text { number of } \\
\text { events / } \\
\text { patients at risk }\end{array}$ \\
\hline \multicolumn{7}{|l|}{ Smoking status } \\
\hline Never smoker & 1.00 & ref & $29 / 103$ & 1.00 & ref & $28 / 99$ \\
\hline Former smoker & 0.79 & $0.51-1.24$ & $61 / 266$ & 0.78 & $0.48-1.24$ & $59 / 254$ \\
\hline Continuing smoker & 1.17 & $0.75-1.83$ & $62 / 186$ & 1.04 & $0.65-1.66$ & $61 / 180$ \\
\hline $\begin{array}{r}\text { Former smoker who started } \\
\text { again*** }\end{array}$ & 1.04 & $0.65-1.64$ & $51 / 150$ & 0.87 & $0.53-1.41$ & $49 / 146$ \\
\hline $\begin{array}{r}\text { Current smoker who quit } \\
\text { smoking }\end{array}$ & 1.25 & $0.52-3.00$ & $6 / 17$ & 1.47 & $0.63-3.41$ & $6 / 17$ \\
\hline \multicolumn{7}{|l|}{$\begin{array}{l}\text { Smoking cessation (in years) } \\
* * * *\end{array}$} \\
\hline$<20$ years & 0.81 & $0.46-1.43$ & $15 / 48$ & 0.82 & $0.46-1.46$ & $15 / 47$ \\
\hline $21-40$ years & 0.76 & $0.53-1.08$ & $57 / 208$ & 0.74 & $0.51-1.08$ & $54 / 200$ \\
\hline$>40$ years & 0.67 & $0.44-1.02$ & $39 / 155$ & 0.71 & $0.46-1.09$ & $38 / 148$ \\
\hline$p$ for trend & 0.070 & & & 0.126 & & \\
\hline \multicolumn{7}{|l|}{$\begin{array}{l}\text { Exposed to passive smoking } \\
\text { during childhood? }\end{array}$} \\
\hline No & 1.00 & ref & $36 / 142$ & 1.00 & ref & $35 / 138$ \\
\hline Yes & 1.23 & $0.86-1.75$ & $173 / 576$ & 1.17 & $0.81-1.68$ & $168 / 554$ \\
\hline \multicolumn{7}{|l|}{$\begin{array}{l}\text { Exposed to passive smoking } \\
\text { during adulthood? }\end{array}$} \\
\hline No & 1.00 & ref & $74 / 261$ & 1.00 & ref & $74 / 261$ \\
\hline Yes & 1.03 & $0.77-1.38$ & $135 / 454$ & 1.02 & $0.76-1.36$ & $135 / 454$ \\
\hline
\end{tabular}

* All estimates adjusted for age, sex, stage, grade, tumour size and number of tumours

** Former smoker who started again and current smoker who quit smoking not included in former smokers at diagnosis

*** Smokers who quit after their first event are considered as current smokers

**** Reference category = current smokers at diagnosis, estimates also include former smokers who started again after diagnosis 
Table 3. Multivariable Cox regression analysis concerning the association between smoking pack-years, intensity and duration (recorded at diagnosis) with time to first recurrence in NMIBC patients treated with TURBT.

\begin{tabular}{|c|c|c|c|c|c|c|c|}
\hline & & \multicolumn{3}{|c|}{ Age \& sex adjusted } & \multicolumn{3}{|c|}{ Multivariable model* } \\
\hline & & HR & $95 \% \mathrm{CI}$ & $\begin{array}{c}\text { number of } \\
\text { events / } \\
\text { patients at risk }\end{array}$ & HR & $95 \% \mathrm{CI}$ & $\begin{array}{c}\text { number of } \\
\text { events / } \\
\text { patients at risk }\end{array}$ \\
\hline Never smoker & & 1.00 & ref & $29 / 103$ & 1.00 & ref & 28/99 \\
\hline \multicolumn{8}{|l|}{ Pack-years } \\
\hline & 1-9 packyears & 0.86 & $0.53-1.42$ & $36 / 141$ & 0.81 & $0.48-1.37$ & $34 / 134$ \\
\hline & 10-19 packyears & 0.95 & $0.54-1.67$ & $22 / 81$ & 0.92 & $0.51-1.65$ & $22 / 80$ \\
\hline & 20-29 packyears & 0.93 & $0.49-1.77$ & $15 / 58$ & 0.81 & $0.42-1.60$ & $15 / 57$ \\
\hline & 30-39 packyears & 0.70 & $0.35-1.43$ & $11 / 55$ & 0.60 & $0.30-1.22$ & $11 / 53$ \\
\hline & $>40$ packyears & 1.28 & $0.76-2.14$ & $30 / 86$ & 1.14 & $0.66-1.97$ & $29 / 83$ \\
\hline$p$ for trend & & 0.365 & & & 0.688 & & \\
\hline \multicolumn{8}{|c|}{$\begin{array}{l}\text { Smoking intensity (cigarettes/ } \\
\text { day) }\end{array}$} \\
\hline & 1-9 cigarettes & 0.83 & $0.50-1.38$ & $32 / 128$ & 0.81 & $0.47-1.38$ & $30 / 122$ \\
\hline & $10-19$ cigarettes & 0.75 & $0.45-1.28$ & $31 / 140$ & 0.61 & $0.35-1.07$ & $31 / 138$ \\
\hline & $20+$ cigarettes & 1.24 & $0.79-1.96$ & $55 / 167$ & 1.16 & $0.72-1.85$ & $54 / 160$ \\
\hline$p$ for trend & & 0.112 & & & 0.198 & & \\
\hline \multicolumn{8}{|c|}{ Smoking duration (in years) } \\
\hline & $1-9$ years & 1.03 & $0.52-2.05$ & $12 / 45$ & 0.97 & $0.48-1.95$ & $12 / 43$ \\
\hline & $10-19$ years & 0.94 & $0.54-1.62$ & $22 / 83$ & 0.85 & $0.48-1.50$ & $21 / 78$ \\
\hline & $20-29$ years & 0.79 & $0.45-1.39$ & $21 / 87$ & 0.79 & $0.44-1.44$ & $20 / 85$ \\
\hline & 30-39 years & 1.08 & $0.61-1.89$ & $26 / 88$ & 0.93 & $0.52-1.66$ & $25 / 85$ \\
\hline & $40+$ years & 1.00 & $0.60-1.64$ & $36 / 127$ & 0.88 & $0.52-1.49$ & $36 / 124$ \\
\hline$p$ for trend & & 0.917 & & & 0.729 & & \\
\hline
\end{tabular}

* All estimates adjusted for age, sex, stage, grade, tumour size and number of tumours at diagnosis

When considering multiple events that have occurred in patients (Table 4) the HRs are similar to the time to first recurrence analysis (HR for continuing vs never smokers is $1.10,95 \% \mathrm{CI}=0.72-1.69)$. However, continuing smokers seemed to have experienced more recurrences than never smokers on average over 5 years on average, however not significantly $(0.64$ vs $0.45, p=0.308)$. 
Table 4. Conditional risk set model investigating time between multiple recurrence events in NMIBC patients treated with TURBT by smoking status at diagnosis and after diagnosis.

\begin{tabular}{|c|c|c|c|c|}
\hline & & $\begin{array}{l}\text { HR* }^{*} \\
5 \% \text { CI }\end{array}$ & $\begin{array}{c}\text { number of } \\
\text { events / patients } \\
\text { at risk }\end{array}$ & $\begin{array}{l}\text { Mean number of } \\
\text { recurrences over } 5 \\
\text { years }(95 \% \mathrm{CI})\end{array}$ \\
\hline \multicolumn{5}{|l|}{ Smoking status } \\
\hline Never smoker & 1.00 & ref & $43 / 99$ & $0.45(0.28-0.63)$ \\
\hline Former smoker & 0.71 & $0.47-1.08$ & $108 / 254$ & $0.45(0.33-0.57)$ \\
\hline Continuing smoker & 1.10 & $0.72-1.69$ & $116 / 180$ & $0.64(0.47-0.81)$ \\
\hline Former smoker who started again & 0.89 & $0.56-1.43$ & $108 / 146$ & $0.82(0.57-1.06)$ \\
\hline Current smoker who quit smoking** & 0.85 & $0.35-2.04$ & $18 / 19$ & $0.84(0.10-1.58)$ \\
\hline
\end{tabular}

* All estimates adjusted for age, sex, stage, grade, tumour size, number of tumours and reresection of recurrent tumour

** Smokers who have quit after their first event $(n=2)$ are also included

\section{DISCUSSION}

\section{Smoking cessation post-diagnosis and BC recurrence \& clinical implications}

The reported HRs give reason to believe that quitting smoking does not influence the likelihood of NMIBC recurrence over 5 years when compared to continuing smokers in our sample. However, the number of quitters in our prospective sample was small which complicates drawing conclusions for this group. Another (retrospective) patient cohort study which assessed smoking cessation post-diagnosis concluded that quitting smoking significantly reduced risk of recurrence $(\mathrm{HR}=0.45,95 \% \mathrm{CI}=0.25-0.83$, comparing quitters to continuing smokers), however the proportion of quitters ( $43 \%$ of current smokers at diagnosis) was also considerably larger [14]. In another retrospective cohort study, Fleshner et al concluded that it remained unclear whether smoking cessation at time of diagnosis is beneficial with regard to $B C$ recurrence [15] although Aveyard et al. estimated that the Fleshner study shows a HR of 0.71 (95\% $C I=0.48-1.05)$ when comparing quitters to continuing smokers[26], which is similar to the estimate observed in the study by Chen et al. Taken together, the limited evidence at this point seems to indicate that quitting smoking at or closely after diagnosis could reduce risk of recurrence. However, even across several smoking-related cancer sites such as lung cancer where this association is stronger, evidence to imply a strong, causal relationship between smoking behaviour after diagnosis and recurrence is still limited [27] so more prospective research is needed.

Considering the prolonged latency period for the development of BC after exposures [2], it is credible that the association between altering smoking behaviour post-diagnosis and 
likelihood of a first recurrence or multiple recurrences over 5 years is not as strong as the association between smoking and carcinogenesis. Similarly, epidemiological evidence suggests that pre-diagnostic smoking cessation does not immediately lower the risk of $B C$ [28], also indicating a longer latency period than 5 years. Furthermore, it is considered that a first $B C$ recurrence is often the result of incomplete resection and/or tumour cell re-implantation, and that genuine new tumour formation only plays a more important role in later recurrences [29]. It is therefore reasonable to suggest that, because of the DNA-damaging effects of cigarette smoke [30], modifying smoking behaviour may only influence later recurrences and possibly those that may occur beyond the follow-up period of 5 years reported here.

Notwithstanding the results from our study, when considering the impact of comorbidities on overall survival in BC patients [31] which include several smoking-related diseases [32] and other evidence indicating beneficial and significant results of post-diagnostic smoking cessation in retrospective studies $[14,15]$, it is evident that smoking cessation should be encouraged for NMIBC patients at diagnosis.

It is striking that only $14 \%$ of current smokers at diagnosis in our sample quit smoking post-diagnosis. There are examples of succesful smoking cessation interventions in urology [33], and several studies found that when patients were diagnosed with BC they were more likely to quit smoking $[34,35]$. Therefore, urologists should continue to improve smoking cessation counselling in newly diagnosed NMIBC patients and to be current on the available tools to improve smoking cessation figures. Moreover, more intervention clinical research investigating smoking cessation programmes in NMIBC patients is warranted.

\section{Smoking behaviour pre-diagnosis \& exposure to environmental tobacco smoke}

Smoking cessation was most beneficial, with regard to reducing the risk of recurrence, the longer before diagnosis it happened compared to continuing smokers. This was the strongest association observed in our study and has been observed in other studies as well, although not consistently [12]. Other results were in line with earlier studies investigating smoking status at diagnosis and BC recurrence as well, by indicating a slightly increased risk of recurrence in NMIBC patients for current smokers compared to never smokers in a meta-analysis [10].

Another recent study not included in the aforementioned meta-analysis shows similar HRs $(H R=1.49,95 \% C . I=0.95-2.33)$ for current smokers at diagnosis [8]. However, when including this study and our study (data from continuing smokers) in the meta-analysis 
the pooled HR barely changes from $1.27(95 \% \mathrm{CI}=1.09-1.46)$ to $1.26(95 \% \mathrm{CI}=1.12-1.40)$ [10], indicating a significantly increased risk of recurrence for current smokers at diagnosis compared to never smokers. Possibly, the lack of association for continuing smokers in this study can be explained through multiple synchronous tumours being present at diagnosis in epithelial tumours. This theory of "field cancerization" proposes that (pre-) malignant transformation of cells has already occurred at different sites across the urothelium, explaining why (changing) smoking exposure will not have a large impact on disease prognosis [36].

Additionally, given that recent reviews indicate no considerable heterogeneity between studies that do not show an association between environmental tobacco smoke and risk of $B C$, it is unlikely that we would have shown any substantial association with $B C$ recurrence either $[37,38]$.

Because no substantial association between smoking status pre-diagnosis and $\mathrm{BC}$ recurrence was observed in adjusted models it is possible that the tumour characteristics associated with BC recurrence (stage, grade, tumour size, number of tumours) included as confounders in these models overshadow the effects of smoking behaviour in determining risk of $B C$ recurrence [21] and possible also mortality since no association between quitting smoking after diagnosis and all-cause or bladder-cancer-specific mortality was observed in a large retrospective cohort study[16]. Moreover, since current smokers at diagnosis in our cohort have been associated with having a higher stage, higher grade and larger tumour size compared to never smokers [39], smoking behaviour might play a more crucial role in determining risk of recurrence already before diagnosis through promoting unfavourable tumour characteristics associated with $B C$ recurrence at diagnosis, although in a Dutch cohort of 323 UBC patients there was only a weak association between smoking intensity and increased risk of a more aggressive tumour type [40].

\section{Strengths and weaknesses}

Despite the prospective nature of our study there were some limitations restricting the analyses. Due to the relatively short follow-up of this study, long term effects of smoking cessation post-diagnosis could not be assessed and the number of deaths due to BC in the NMIBC patients within our cohort was too low for Cox regression analysis. Also, it was not possible to obtain detailed information on adjuvant therapy for all patients, so differences in adjuvant therapy could not be considered in the statistical analysis. Additionally, we did not correct for biomarkers of BC recurrence such as mutations in the FGFR3 or TP53 genes [41], although they might work together with smoking intensity in predicting BC outcome [42]. 
Furthermore, one of the caveats of using only self-reported questionnaire data to assess smoking exposure was likely demonstrated in our sample of NMIBC patients. The large proportion (about 1 in 3 ) of former smokers pre-diagnosis who reported to have started smoking again post-diagnosis is implausible and is probably observed due to misclassification of either the questionnaire at baseline or during follow-up. A high misclassification rate $(47 \%)$ when comparing self-reported data on smoking behaviour to cotinine values in blood was also shown in another sample of bladder cancer patients undergoing surveillance [43]. Preferably, future studies should consider more reliable ways of verifying smoking exposure through biochemical analysis.

Unfortunately, at the start of the study we did not anticipate this small proportion of quitters after diagnosis which is why the analysis concerning quitters is underpowered.

\section{CONCLUSION}

Although quitting smoking after diagnosis might reduce probability of recurrence based on retrospective evidence, the number of NMIBC patients quitting smoking in our prospective study was low. Based on the current evidence, smoking cessation pre-diagnosis seems to have the largest impact on reducing risk of recurrence after NMIBC diagnosis. More prospective studies with adequate sample size are required to further investigate the possible effect of smoking cessation after diagnosis of NMIBC.

Disclaimer: this study was underpowered and therefore nothing can be inferred from the exploratory analysis presented in this dissertation 


\section{REFERENCES}

1. Antoni S, Ferlay J, Soerjomataram I, Znaor A, Jemal A, Bray F. Bladder Cancer Incidence and Mortality: A Global Overview and Recent Trends. Eur Urol. 2017;71: 96-108. doi:10.1016/j. eururo.2016.06.010

2. Bryan RT, Zeegers MP, van Roekel EH, Bird D, Grant MR, Dunn JA, et al. A comparison of patient and tumour characteristics in two UK bladder cancer cohorts separated by 20 years. BJU Int. 2013;112: 169-175. doi:10.1111/bju.12032

3. Yan Y, Andriole GL, Humphrey PA, Kibel AS. Patterns of multiple recurrences of superficial ( $\mathrm{Ta} / \mathrm{T} 1$ ) transitional cell carcinoma of bladder and effects of clinicopathologic and biochemical factors. Cancer. Wiley Subscription Services, Inc., A Wiley Company; 2002;95: 1239-1246. doi:10.1002/cncr.10822

4. Kaufman DS, Shipley WU, Feldman AS. Bladder cancer. Lancet. 374: 239-249. doi:http:// dx.doi.org/10.1016/S0140-6736(09)60491-8

5. Roychowdhury DF, Hayden A, Liepa AM. Health-related quality-of-life parameters as independent prognostic factors in advanced or metastatic bladder cancer. J Clin Oncol. 2003;21: 673-678.

6. Svatek RS, Hollenbeck BK, Holmäng S, Lee R, Kim SP, Stenzl A, et al. The Economics of Bladder Cancer: Costs and Considerations of Caring for This Disease. Eur Urol. 2014;66: 253-262. doi:10.1016/j.eururo.2014.01.006

7. Hou L, Hong X, Dai M, Chen P, Zhao H, Wei Q, et al. Association of smoking status with prognosis in bladder cancer: A meta-analysis. Oncotarget. Impact Journals; 2016;5. doi:10.18632/ oncotarget.13606

8. Li HM, Azhati B, Rexiati M, Wang WG, Li XD, Liu Q, et al. Impact of smoking status and cumulative smoking exposure on tumor recurrence of non-muscle-invasive bladder cancer. Int Urol Nephrol. 2016; doi:10.1007/s11255-016-1441-6

9. Wilcox AN, Silverman DT, Friesen MC, Locke SJ, Russ DE, Hyun N, et al. Smoking status, usual adult occupation, and risk of recurrent urothelial bladder carcinoma: data from The Cancer Genome Atlas (TCGA) Project. Cancer Causes Control. Springer International Publishing; 2016;27: 1429-1435. doi:10.1007/s10552-016-0821-7

10. van Osch FHM, Jochems SHJ, van Schooten FJ, Bryan RT, Zeegers MP. Significant Role of Lifetime Cigarette Smoking in Worsening Bladder Cancer and Upper Tract Urothelial Carcinoma Prognosis: A Meta-Analysis. J Urol. 2016;195: 872-879. doi:10.1016/j.juro.2015.10.139

11. Gritz ER, Dresler C, Sarna L. Smoking, The Missing Drug Interaction in Clinical Trials: Ignoring the Obvious. Cancer Epidemiol Biomarkers Prev. 2005;14: 2287-93. doi:10.1158/1055-9965. EPI-05-0224

12. Simonis K, Shariat SF, Rink M. Smoking and smoking cessation effects on oncological outcomes in nonmuscle invasive bladder cancer. Curr Opin Urol. 2014;24: 492-499.

13. Crivelli JJ, Xylinas E, Kluth LA, Rieken M, Rink M, Shariat SF. Effect of Smoking on Outcomes of Urothelial Carcinoma: A Systematic Review of the Literature. Eur Urol. 2014;65: 742-754. doi:10.1016/j.eururo.2013.06.010

14. Chen $\mathrm{C}-\mathrm{H}$, Shun $\mathrm{C}-\mathrm{T}$, Huang $\mathrm{K}-\mathrm{H}$, Huang $\mathrm{C}-\mathrm{Y}$, Tsai $\mathrm{Y}-\mathrm{C}$, Yu H-J, et al. Stopping smoking might reduce tumour recurrence in nonmuscle-invasive bladder cancer. doi:10.1111/j.1464410X.2007.06873.x 
15. Fleshner N, Garland J, Moadel A, Herr H, Ostroff J, Trambert R, et al. Influence of Smoking Status on the Disease-Related Outcomes of Patients with Tobacco-Associated Superficial Transitional Cell Carcinoma of the Bladder. 1998;

16. Koshiaris C, Aveyard P, Oke J, Ryan R, Szatkowski L, Stevens R, et al. Smoking cessation and survival in lung, upper aero-digestive tract and bladder cancer: cohort study. $\mathrm{Br} J$ Cancer. Nature Publishing Group; 2017;117: 1224-1232. doi:10.1038/bjc.2017.179

17. Zeegers MP, Bryan RT, Langford C, Billingham L, Murray P, Deshmukh NS, et al. The West Midlands Bladder cancer prognosis programme: Rationale and design. BJU Int. 2010;105: 784-788. doi:10.1111/j.1464-410X.2009.08849.x

18. Sylvester RJ, van der Meijden APM, Oosterlinck W, Witjes JA, Bouffioux C, Denis L, et al. Predicting Recurrence and Progression in Individual Patients with Stage Ta T1 Bladder Cancer Using EORTC Risk Tables: A Combined Analysis of 2596 Patients from Seven EORTC Trials. Eur Urol. 2006;49: 466-477. doi:10.1016/j.eururo.2005.12.031

19. Bryan RT, Cheng KK, James ND, Zeegers MP, Wallace DMA. Re: Defining Progression in Nonmuscle Invasive Bladder Cancer: It is Time for a New, Standard Definition: D. Lamm, R. Persad, M. Brausi, R. Buckley, J. A. Witjes, J. Palou, A. Böhle, A. M. Kamat, M. Colombel and M. Soloway J Urol 2014; 191: 20-27. [Internet]. The Journal of Urology. 2014. pp. 1930-1931. doi:10.1016/j.juro.2014.01.011

20. Babjuk M, Böhle A, Burger M, Capoun O, Cohen D, Compérat EM, et al. EAU Guidelines on Non-Muscle-invasive Urothelial Carcinoma of the Bladder: Update 2016 [Internet]. European Urology. 2017. doi:10.1016/j.eururo.2016.05.041

21. Babjuk M, Oosterlinck W, Sylvester R, Kaasinen E, Böhle A, Palou-Redorta J, et al. EAU guidelines on non-muscle-invasive urothelial carcinoma of the bladder, the 2011 update. Actas Urológicas Españolas (English Ed. 2012;36: 389-402.

22. Amorim LDAF, Cai J. Modelling recurrent events: A tutorial for analysis in epidemiology. Int J Epidemiol. 2015;44: 324-333. doi:10.1093/ije/dyu222

23. Latouche A, Allignol A, Beyersmann J, Labopin M, Fine JP. A competing risks analysis should report results on all cause-specific hazards and cumulative incidence functions. J Clin Epidemiol. 2013;66: 648-653. doi:10.1016/j.jclinepi.2012.09.017

24. Lammers RJM, Witjes WPJ, Hendricksen K, Caris CTM, Janzing-Pastors MHC, Witjes JA. Smoking Status Is a Risk Factor for Recurrence After Transurethral Resection of Non-MuscleInvasive Bladder Cancer. Eur Urol. 2011;60: 713-720. doi:10.1016/j.eururo.2011.07.010

25. Hendricksen K, Aziz A, Bes P, Chun FK-H, Dobruch J, Kluth LA, et al. Discrepancy Between European Association of Urology Guidelines and Daily Practice in the Management of Non-muscle-invasive Bladder Cancer: Results of a European Survey. Eur Urol Focus. 2017; doi:10.1016/j.euf.2017.09.002

26. Aveyard P, Adab P, Cheng KK, Wallace DMA, Hey K, Murphy MFG. Does smoking status influence the prognosis of bladder cancer? A systematic review. BJU Int. Wiley/Blackwell (10.1111); 2002;90: 228-239. doi:10.1046/j.1464-410X.2002.02880.x

27. Warren GW, Sobus S, Gritz ER. The biological and clinical effects of smoking by patients with cancer and strategies to implement evidence-based tobacco cessation support. Lancet Oncol. 2014;15: e568-80. doi:10.1016/S1470-2045(14)70266-9

28. van Osch FH, Jochems SH, van Schooten F-J, Bryan RT, Zeegers MP. Quantified relations between exposure to tobacco smoking and bladder cancer risk: a meta-analysis of 89 observational studies. Int J Epidemiol. 2016;45: 857-870. doi:10.1093/ije/dyw044 
29. Bryan RT, Collins SI, Daykin MC, Zeegers MP, Cheng K, Wallace DMA, et al. Mechanisms of recurrence of Ta/T1 bladder cancer. Ann R Coll Surg Engl. The Royal College of Surgeons of England ; 2010;92: 519-524. doi:10.1308/003588410X12664192076935

30. Corral R, Lewinger JP, Van Den Berg D, Joshi AD, Yuan J-M, Gago-Dominguez M, et al. Comprehensive analyses of DNA repair pathways, smoking and bladder cancer risk in Los Angeles and Shanghai. Int J Cancer. 2014;135: 335-347. doi:10.1002/ijc.28693

31. Megwalu II, Vlahiotis A, Radwan M, Piccirillo JF, Kibel AS. Prognostic Impact of Comorbidity in Patients with Bladder Cancer. Eur Urol. 2008;53: 581-589. doi:10.1016/j.eururo.2007.10.069

32. Piccirillo JF, Tierney RM, Costas I, Grove L, Edward L. Spitznagel J, AR F, et al. Prognostic Importance of Comorbidity in a Hospital-Based Cancer Registry. JAMA. American Medical Association; 2004;291: 2441. doi:10.1001/jama.291.20.2441

33. Bjurlin MA, Cohn MR, Kim DY, Freeman VL, Lombardo L, Hurley SD, et al. Brief Smoking Cessation Intervention: A Prospective Trial in the Urology Setting. J Urol. 2013;189: 1843-1849. doi:10.1016/j.juro.2012.11.075

34. Bassett JC, Gore JL, Chi AC, Kwan L, McCarthy W, Chamie K, et al. Impact of a bladder cancer diagnosis on smoking behavior. J Clin Oncol. 2012;30: 1871-8. doi:10.1200/JCO.2011.36.6518

35. Ostroff J, Garland J, Moadel A, Fleshner N, Hay J, Cramer L, et al. Cigarette smoking patterns in patients after treatment of bladder cancer. J Cancer Educ. 2000;15: 86-90. doi:10.1080/08858190009528663

36. Braakhuis BJM, Tabor MP, Kummer JA, Leemans CR, Brakenhoff RH. A genetic explanation of Slaughter's concept of field cancerization: evidence and clinical implications. Cancer Res. 2003;63: 1727-30. Available: http://www.ncbi.nlm.nih.gov/pubmed/12702551

37. Osch F van, Jochems S, Wesselius A, Schooten F van, Bryan R, Zeegers M. A Stratified MetaAnalysis of the Association between Exposure to Environmental Tobacco Smoke during Childhood and Adulthood and Urothelial Bladder Cancer Risk. Int J Environ Res Public Heal 2018, Vol 15, Page 569. Multidisciplinary Digital Publishing Institute; 2018;15: 569. doi:10.3390/IJERPH15040569

38. Lee PN, Thornton AJ, Hamling JS, Lee PN. Epidemiological evidence on environmental tobacco smoke and cancers other than lung or breast. Regul Toxicol Pharmacol. 2016;80: 134-163. doi:10.1016/j.yrtph.2016.06.012

39. van Roekel EH, Cheng KK, James ND, Wallace DMA, Billingham LJ, Murray PG, et al. Smoking is associated with lower age, higher grade, higher stage, and larger size of malignant bladder tumors at diagnosis. Int J Cancer. 2013;133: 446-454. doi:10.1002/ijc.28017

40. Barbosa ALA, Vermeulen SHHM, Aben KK, Grotenhuis AJ, Vrieling A, Kiemeney LA. Smoking intensity and bladder cancer aggressiveness at diagnosis. Real FX, editor. PLoS One. Public Library of Science; 2018;13: e0194039. doi:10.1371/journal.pone.0194039

41. Bryan RT, Zeegers MP, James ND, Wallace DMA, Cheng KK. Biomarkers in bladder cancer. BJU Int. Blackwell Publishing Ltd; 2010;105: 608-613. doi:10.1111/j.1464-410X.2009.08880.x

42. Mitra AP, Castelao JE, Hawes D, Tsao-Wei DD, Jiang X, Shi S-R, et al. Combination of molecular alterations and smoking intensity predicts bladder cancer outcome. Cancer. Wiley Subscription Services, Inc., A Wiley Company; 2013;119: 756-765. doi:10.1002/cncr.27763

43. Thong AE, Petruzella S, Orlow I, Zabor EC, Ehdaie B, Ostroff JS, et al. Accuracy of Self-reported Smoking Exposure Among Bladder Cancer Patients Undergoing Surveillance at a Tertiary Referral Center. Eur Urol Focus. Elsevier; 2016;2: 441-444. doi:10.1016/j.euf.2015.12.002 
02 Summary and general discussion
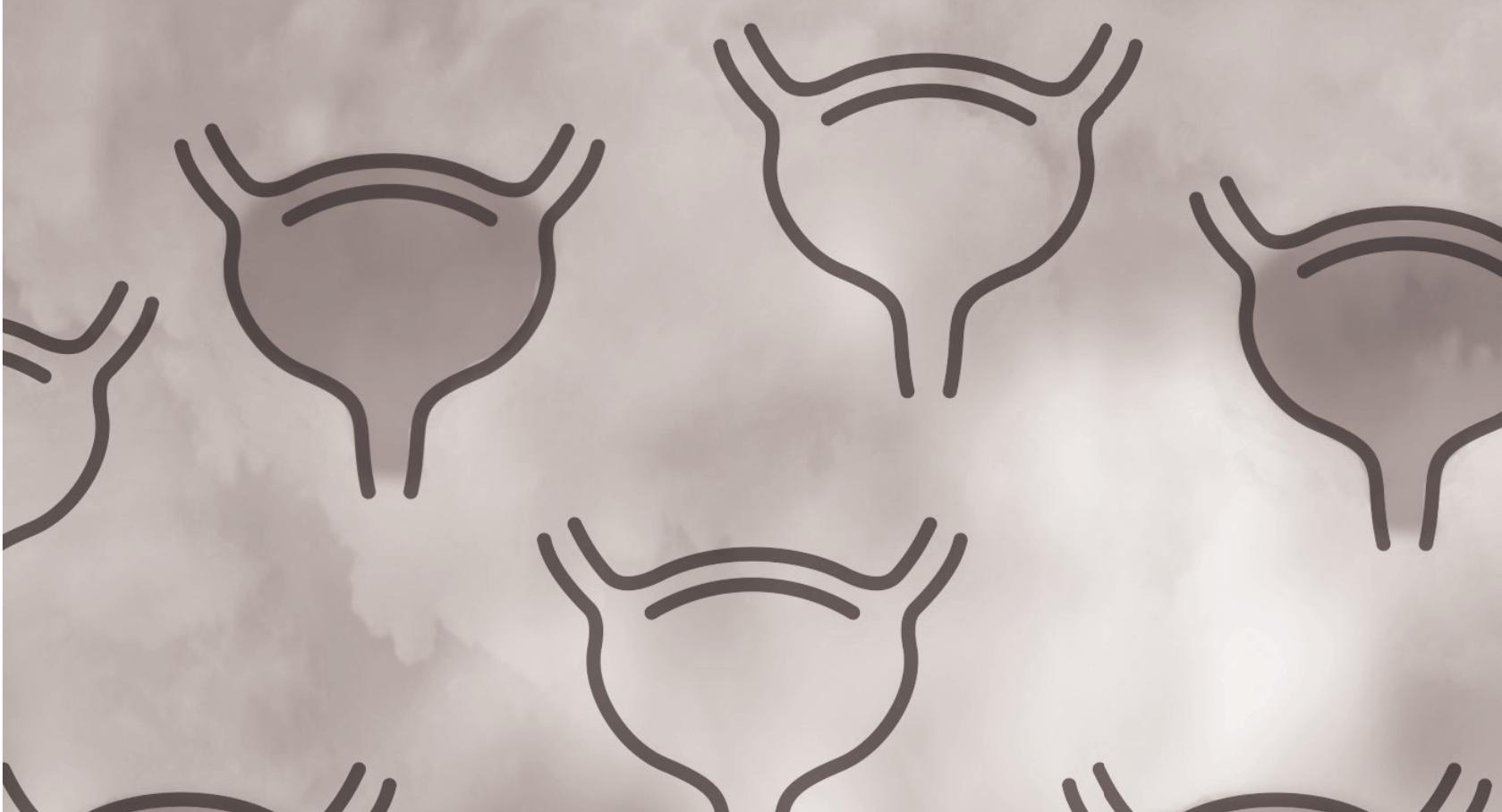

The aim of this dissertation was to provide detailed evidence on the association between smoking behaviour pre-and post-diagnosis and bladder cancer risk and prognosis, contributing to a more thorough understanding of how smoking is related to bladder cancer. The hypotheses for this thesis were that smoking duration is more important than intensity in predicting risk of developing $B C$ and that smoking cessation even after $B C$ diagnosis could have a beneficial effect on BC prognosis. To investigate these hypotheses, the current body of evidence was summarised first by using a meta-analysis approach. Second, the observed knowledge gaps were filled by analysing data from both the prospective BCPP cohort of bladder cancer cases and the BLEND consortium of observational studies on bladder cancer risk.

\section{SUMMARY OF MAIN FINDINGS}

This thesis can be divided in two parts; the investigation of the relationship between smoking and a) bladder cancer risk (chapters 2 to 5 ) and b) bladder cancer prognosis (chapters $6 \& 7$ ).

The extensive meta-analysis presented in chapter 2 , showed a threefold higher risk of BC for cigarette smokers, which is in line with results from earlier meta-analyses and systematic reviews. Interestingly, however, the proportions of BC cases attributable to smoking (PARs) were noticeably lower (43\% compared to $50 \%$ in males) than estimated in 2000 , possibly driven by the decreasing number of smokers in Western countries. Furthermore, the meta-analysis showed that those who have quit smoking for more than 35 years are still at an increased risk of bladder cancer compared to never smokers $(O R=1.48$, $95 \% \mathrm{CI}=1.39-1.58)$.

In chapter 3 all available evidence on the association between exposure to environmental tobacco smoke (ETS) and bladder cancer risk were combined. Results from this metaanalysis showed no substantial association between exposure to ETS, either during childhood or adulthood, and bladder cancer risk. However, detail on the smoking behaviour of active smokers to whom never smokers were exposed in these studies was often lacking. Therefore, it was not possible to identify whether there were groups of participants in studies that were highly exposed to ETS from a heavy smoker, and possibly showing different results than those exposed to a less heavy active smoker.

The unique collaboration between the UK Department of Health and the BCPP cohort study made it possible to investigate tar, nicotine and CO content of different brands of cigarettes smoked by BCPP participants. Results showed that increasing daily intake of tar, 
nicotine and CO linearly increases the risk of non-muscle-invasive bladder cancer linearly compared to a lower intake (chapter 4). Nevertheless, individual smoking behaviour might differ regarding the number of cigarettes smoked and depth of inhalation, which in turn might be correlated with cigarette type, possibly confounding this association.

In chapter 5, the effect of smoking duration and intensity on bladder cancer risk was analysed by making use of the BLEND data. This pooled data from 15 case-control studies confirmed that smoking duration is the overriding factor in determining bladder cancer risk. Since this study showed very strong evidence that smokers should stop as early as possible to substantially reduce risk of bladder cancer, this result might have a major impact on future prevention programmes/interventions.

The meta-analysis in chapter 6 , which summarises results from studies investigating the association between smoking status at diagnosis and bladder cancer prognosis (recurrence, progression and death) showed that bladder cancer patients who smoke at diagnosis are at an approximately $25 \%$ increased risk of recurrence and dying due to bladder cancer. Unfortunately, all included studies in this meta-analysis were retrospective in nature and therefore did not consider smoking cessation after diagnosis. Therefore, chapter 7 aims to fill this gap in knowledge by prospectively following non-muscle-invasive bladder cancer patients in BCPP. However, the proportion of quitters after diagnosis was very small (14\%) and therefore conclusions concerning smoking cessation after diagnosis were limited.

\section{INTERPRETATION OF MAIN FINDINGS}

\section{Smoking behaviour (intensity, duration and cessation) and bladder cancer risk}

Although it has been known for decades that smoking is a major risk factor for bladder cancer [1], and that those who have the highest cumulative exposure (e.g. total number of cigarettes smoked over a lifetime) are at the highest risk of developing bladder cancer [2], the exact dose-response relationship between smoking behaviour (intensity, duration and cessation) and carcinogenesis remains disputable $[3,4]$. With the dose-response curves based on the meta-analysis research presented in chapter 2 of this thesis [5], an overview is provided for the association between different smoking behaviours and bladder cancer risk. Currently, this is the most detailed summary to date. Nevertheless, results might be biased by the fact that it could not be considered that smoking duration and intensity are highly correlated because those who have smoked many years are often also heavier smokers. Because of this high correlation, the individual curves do not predict risk based on the number of cigarettes, but rather only show the strength of association between 
smoking intensity and duration and bladder cancer risk separately. More detailed data collection on smoking behaviour would be needed for moving towards individual risk prediction.

In an attempt to go beyond a classical epidemiological estimation of the association between smoking behaviour and bladder cancer risk and the identification of factors related to smoking behaviour, a state of the art technique was used to model pack-years together with smoking intensity in chapter 5 . Here, it was found that smoking duration is the overriding factor in determining bladder cancer risk, indicating that the length of the period that a person smoked is more important than the number of cigarettes smoked during that period. Although risk in the lowest pack-year categories is still low for those with a relatively long duration as can be seen in supplemental Figure 1 in chapter 5 . In addition, different cigarette types (heavy and light) and their contents were investigated on their association with bladder cancer in chapter 4 [6]. Although bladder cancer risk was increased for high total intake of tar, nicotine and $\mathrm{CO}$, no difference between high tar and low tar cigarettes could be shown because of the low statistical power in this analysis. Especially due to the small number of controls smoking light cigarettes $(n=7)$ the minimally detectable OR was smaller than the observed point estimate and not reliable. Furthermore, it could not be distinguished whether these associations were possibly confounded by smoking behaviour such as increasing inhalation volume when smoking light cigarettes, which is shown to be a prevalent compensation mechanism in light smokers [7]. In addition to these different aspects of smoking behaviour and the use of different cigarettes that could explain differences in bladder cancer risk between smokers, the current evidence on the association between exposure to environmental tobacco smoke and bladder cancer risk was also summarised by timing of exposure in chapter 3 . For this, however, no noticeable association could be observed, although a power analysis showed that the current meta-analysis was able to detect a SOR of 1.17 to 1.18 with the current number of included studies [8]. Nevertheless, given the low heterogeneity between study results, where most studies found risk estimates very close to 1.00 , it is unlikely that repeating this meta-analysis when more study estimates are available in the future will detect any meaningful (e.g. a SOR of 1.10 or less) impact of exposure to ETS on bladder cancer risk.

In summary, the research presented in this thesis shows that different smoking behaviours (i.e. smoking duration and intensity) determine bladder cancer risk. Notably, a longer smoking duration is important in increasing risk, but also cigarette contents or inhalation pattern could potentially modify risk. 
Overall, smoking initiation should be prevented at any age, but for those who already smoke all results in this thesis strongly imply that smoking cessation should happen as early in life as possible. Nevertheless, ex-smokers will likely always be at an increased bladder cancer risk compared to never smokers. Therefore, prevention efforts should focus on preventing smoking initiation in childhood, an approach which is already applied commonly [9]. This will likely have the largest effect on decreasing incident cases of smoking-related cancers on a population level since those who start smoking at a young age are often also longer exposed to cigarette smoke [10]. Many efforts have been taken to reduce smoking worldwide and it is encouraging to see the number of smokers decrease overall [11]; however, many countries still struggle with a high prevalence of smoking, especially in men (e.g. $>50 \%$ of men in China [12] and $>40 \%$ of men in Turkey [13]).

\section{Smoking and bladder cancer prognosis}

Bladder cancer is one of the most expensive malignancies because of the high recurrence rates and ongoing surveillance and treatment costs [14]. Therefore, it is highly relevant to investigate (modifiable) risk factors that could decrease the risk of recurrence in bladder cancer patients. Since smoking is the major risk factor for bladder cancer development, most studies on identifying modifiable risk factors for bladder cancer recurrence also focus on smoking, yet only retrospectively.

The pooled analysis of retrospective studies investigating smoking status and bladder cancer prognosis, described in chapter 6 , indicates that current smokers at diagnosis of bladder cancer are at an increased risk of recurrence (in non-muscle-invasive patients) and of dying due to bladder cancer (in muscle-invasive patients) [15]. This is in line with results from a previous meta-analysis, providing evidence that smoking cessation before diagnosis reduces the risk of dying due to bladder cancer [16]. The observed risk estimates for recurrence were not as strong as for bladder cancer risk (e.g. approximately 3 times higher risk for current smokers at diagnosis compared to never smokers, while current smokers have an approximately 1.25 -fold increased risk of recurrence). This difference in strength of association between risk of primary tumour and risk of recurrence might be explained by the theory of "field cancerization". This theory proposes that (pre-)malignant transformation of cells has already occurred at different sites across the urothelium before diagnosis, explaining why (changing) smoking exposure after diagnosis will not have a large impact on disease prognosis [17].

Since all available studies on smoking and bladder cancer prognosis were retrospective, the impact of smoking behaviour on bladder cancer recurrence was investigated prospectively within the BCPP cohort. Unfortunately, the number of patients who had stopped 
smoking during follow-up was too low to assess the impact of smoking cessation on the recurrence of bladder cancer (chapter 7 ). The number of quitters after diagnosis found in BCPP was surprisingly low when compared to other observational studies. In California, for example, $48 \%$ of the smokers diagnosed with bladder cancer quitted smoking and it was also shown that the most important reasons for cessation were diagnosis of bladder cancer, as well as the advice of the urologist [18]. Other studies also showed that brief interventions (such as continued advice on quitting or congratulating people on abstaining) applied by clinicians in the urology clinic can be effective in increasing the number of bladder cancer patients quitting smoking $[19,20]$. Since the number of quitters in BCPP was very low, it is highly recommended that urologists in the West Midlands area give smoking cessation advice or apply novel brief interventions to increase cessation rates in bladder cancer patients from the West Midlands.

Taken together, the current evidence indicates that smoking cessation before diagnosis has a larger impact on reducing risk of recurrence and mortality due to bladder cancer than smoking cessation after diagnosis. Nonetheless, smoking cessation after diagnosis should also be promoted in the urology clinic since the diagnosis of bladder cancer is a life-changing event that might trigger smokers to quit successfully. Moreover, smoking cessation might not only help in reducing risk of recurrence for bladder cancer, but can also prevent many smoking-related co-morbidities that occur often in bladder cancer patients [21].

\section{METHODOLOGICAL CONSIDERATIONS}

\section{Misclassification of active and passive smoking exposure}

Obtaining information on smoking behaviour from self-reported questionnaires often leads to underreporting of current smoking status [22]. In our study within the BCPP cohort (chapter 7), there was a considerable number of bladder cancer patients with presumably conflicting data on smoking behaviour. Where at baseline these patients reported to have never smoked, they reported smoking at the first follow-up measurement. Moreover, about 1 in 3 former smokers also seemed to have "started" again after 3 months. Although misclassification was not ascertained within BCPP, a previous study that compared urinary cotinine levels to self-reported smoking history in 145 bladder cancer patients, showed a misclassification rate of 33\% for current smoking status [23]. Therefore, the results shown in chapter 7 are likely biased and underestimate the true effect of continuing smoking, especially through misclassification of current smokers at diagnosis [24]. 
The same misclassification could also have led to biased results in chapter 3 , in which the exposure to ETS was assessed among never smokers. If again, a substantial proportion of the never smokers are former or current smokers, the strength of association might have been underestimated as the contrast between case and control group is possibly smaller than it could have been without any misclassification [25]. Nevertheless, since most reported studies on exposure to ETS and bladder cancer risk showed no statistically significant effects, this possible misclassification only makes it more likely that there is no substantial effect of exposure to ETS on bladder cancer risk.

\section{Interpretation of statistical models and implications of selection of confounders}

In this thesis, results from several types of statistical models such as Cox regression models (chapter 7) or excess odds ratio (EOR) models (chapter 5) are presented. Cox regression analyses time-to-event data and there are several different options to reset survival time if multiple events occur. For example, within the Cox regression models used in BCPP in which multiple recurrence events were investigated, the risk of a second recurrence was estimated by calculating the time since the first event occurred (Chapter 7). Another option, however, is to consider time since diagnosis for every event that might occur, accumulating person-time at risk for second or third recurrences as if the previous recurrences did not happen, but adjusting for the other recurrences statistically [26]. The interpretation of the results from these two different methods would be different, since in the second scenario more time is counted for a second event than in the first. Nevertheless, applying both methods for estimating the risk of recurrence for continuing smokers compared to never smokers did not show different results within BCPP (HR=1.10, $95 \% \mathrm{CI}=0.72-1.69$ using the first method and $\mathrm{HR}=1.20,95 \% \mathrm{CI}=0.67-2.13$ using the second method). Therefore, the rationale for using a specific statistical approach should always be clear and will help researchers in interpreting results in the correct way that follows from the data that is behind it [27].

Similarly, when building a statistical model adjusting for a certain set of confounders, researchers aim to obtain unbiased estimates of a causal effect between exposure and outcome. However, since epidemiological risk estimates are based on comparing averages or probabilities between groups, causality can only be inferred from a population level [28]. This is problematic for the process of selecting relevant confounders because within a study sample, confounders are selected on their relevance from a population perspective. Also, confounders could be correlated with each other introducing bias where there was none [29]. Therefore, theoretical frameworks have been developed to also assess the interplay between selected confounders to estimate which variables should be included in the model and which ones probably only introduce more bias [29]. This directed acyclic 
graph method was used to formulate the final model in the Cox regression analysis presented in chapter 7 .

In summary, motivating choices for statistical models, selection of confounders and subsequent correct interpretation of results in papers is of paramount importance to maintain a high standard of interpretable research, especially in observational studies where many possibly confounding variables are not controlled.

\section{IMPLICATIONS AND IMPACT OF RESULTS}

The results of this thesis clearly and irrefutably show that the duration of exposure to cigarette smoke is the most important factor for the development of bladder cancer Although the current evidence is limited, it is also plausible that a longer duration of exposure to cigarette smoke before diagnosis could possibly increase the chances of a type of bladder cancer with a worse prognosis in those with relatively impaired DNA repair mechanisms, because more opportunities for smoking-related DNA damage occur [30]. More importantly, even those who stopped smoking for more than 30 years are still at an increased risk of bladder cancer compared to never smokers. Therefore, the results from this thesis mainly implicate that smoking prevention programmes in children should be promoted to decrease the burden of bladder cancer in the future. Since the proportion of smokers in many countries is still above 15\% [11], promoting smoking cessation will also have a considerable impact on decreasing the incidence of bladder cancer on a shorter term, although less drastically than preventing people from starting smoking at all. In addition to bladder cancer, smoking is also strongly associated with increased incidence and accounts for about $50 \%$ of mortality in many frequently occurring cancers [31]. Therefore, smoking prevention is not only important to reduce the burden of bladder cancer, but also on a much larger scale.

\section{FUTURE PERSPECTIVES}

\section{Prospective studies - reliable estimation of exposure to cigarette smoke}

It is evident from the meta-analysis presented in chapter 6 and the prospective study presented in chapter 7 that more prospective studies on bladder cancer prognosis, gathering data on modifiable risk factors are needed to provide a better evidence based lifestyle advice that urologists could give to their patients to prevent bladder cancer recurrence. 
An important issue that needs to be considered when designing a prospective study measuring smoking behaviour, is the under- or over reporting of unhealthy and healthy behaviour. To obtain reliable estimates on smoking status, future studies should consider determining cotinine levels in blood, urine or saliva instead of using self-reported questionnaires.

Therefore, future prospective studies in bladder cancer prognosis should focus on reliable estimation of smoking status after diagnosis to definitively show what impact smoking behaviour can have on recurrence, progression and mortality.

\section{Smoking and the molecular heterogeneity of bladder cancer}

Compared to most other common cancers, bladder cancer shows a large molecular heterogeneity compared to most other common cancers. The two major pathways with different molecular features that have been identified for the past two decades can generally be divided by showing hyperplasia and FGFR3 mutation or flat dysplasia and TP53 mutation [32]. However, in recent years, many more sub-pathways have been suggested that could possibly explain differences in bladder cancer prognosis [33]. Since smokers present with different bladder tumour characteristics at diagnosis [34], future studies investigating smoking in relation to bladder cancer (prognosis) should also focus on explaining different molecular subtypes which might be associated with smoking.

\section{Modelling lifetime exposures, the future of epidemiology?}

Establishing causal links between exposure and diseases has been one of the cornerstones of (bio)medical research for centuries. However, although epidemiology has identified a large proportion of major (causal) associations between exposure and disease over the past few decades, there is a need to reinvent itself as a research expertise to continue to contribute to understanding the causal associations between exposures and disease. In the past decades, epidemiology moved from the era of sanitary statistics, to an era focusing on infectious diseases towards chronic diseases and the "black box" paradigm [35]. At the beginning of the 1980's the field of molecular epidemiology emerged that has contributed a lot to opening the black box between exposure and disease by relating genetic susceptibility, biomarkers of exposure and of biologically effect dose, to cancer risk [36]. At that time, researchers predicted that the black box era would lead into an era of eco-epidemiology, where biomedical techniques are integrated with classical epidemiological methods [37], which is also what happened through genome-wide-association studies (GWAS) which emerged at the start of this century [38]. Currently, epidemiology is entering an era where new research methodologies need to be developed to analyse so-called "big data" (large databases of interlinkable datasets containing as much data as possible from every study participant [39]) and still obtain reliable and interpretable 
results. A promising example of how complex exposure data can be approached is the exposome approach. The exposome is defined as the conceptual framework of all exposures related to disease to which an individual is exposed during their lifetime [40]. In exposome wide association studies (EWAS), high throughput computational methods are applied to model the combination of all exposures related to disease simultaneously [41].

Hence, statistical methods like the EOR model (chapter 7) that can model highly correlated exposure variables simultaneously will likely be applied more often. As researchers can gather more data, the complexity of the analysis of the results also increases. Therefore, an important role for epidemiologists in the future will be in both applying and developing novel methodologies but, moreover, also be able to explain results from increasingly complex analyses to the public, clinicians and other public health professionals.

\section{CONCLUSION}

The research presented in this thesis intended to comprehensively explain why smokers get bladder cancer and how lifetime smoking behaviour could influence prognosis. Obviously, successful smoking prevention programmes will have the largest impact on reducing bladder cancer incidence. Nevertheless, the results across different studies indicate that for those already smoking, the total duration of exposure is most important in determining bladder cancer risk. Cigarette type and exposure to passive smoke seem to not have a significant impact on bladder cancer risk. Furthermore, smoking cessation before diagnosis will also help decrease the risk of recurrence for those who get bladder cancer most while more prospective research is needed to quantify the impact of smoking cessation on bladder cancer prognosis. 


\section{REFERENCES}

1. Burger, M.; Catto, J. W. F. F.; Dalbagni, G.; Grossman, H. B.; Herr, H.; Karakiewicz, P.; Kassouf, W.; Kiemeney, L. A.; La Vecchia, C.; Shariat, S.; Lotan, Y. Epidemiology and risk factors of urothelial bladder cancer. Eur. Urol. 2013, 63, 234-41, doi:10.1016/j.eururo.2012.07.033.

2. Zeegers, M. P. A.; Tan, F. E. S.; Dorant, E.; van den Brandt, P. A. The impact of characteristics of cigarette smoking on urinary tract cancer risk. Cancer 2000, 89, 630-639, doi:10.1002/10970142(20000801)89:3<630::AID-CNCR19>3.0.CO;2-Q.

3. Peto, J. That the effects of smoking should be measured in pack-years: misconceptions 4. Br. J. Cancer 2012, 107, 406-407, doi:10.1038/bjc.2012.97.

4. Lubin, J. H.; Caporaso, N. E. Misunderstandings in the misconception on the use of packyears in analysis of smoking. Br. J. Cancer 2013, 108, 1218-20, doi:10.1038/bjc.2013.76.

5. van Osch, F. H.; Jochems, S. H.; van Schooten, F.-J.; Bryan, R. T.; Zeegers, M. P. Quantified relations between exposure to tobacco smoking and bladder cancer risk: a meta-analysis of 89 observational studies. Int. J. Epidemiol. 2016, 45, 857-870, doi:10.1093/ije/dyw044.

6. van Osch, F. H. M.; Pauwels, C. G. G. M.; Jochems, S. H. J.; Fayokun, R.; James, N. D.; Wallace, D. M. A.; Cheng, K.; Bryan, R. T.; van Schooten, F. J.; Zeegers, M. P. Tar, nicotine and carbon monoxide yield of UK cigarettes and the risk of non-muscle-invasive and muscle-invasive bladder cancer. Eur. J. Cancer Prev. 2017, 1, doi:10.1097/CEJ.0000000000000404.

7. Scherer, G.; Lee, P. N. Smoking behaviour and compensation: A review of the literature with meta-analysis. Regul. Toxicol. Pharmacol. 2014, 70, 615-628, doi:10.1016/J. YRTPH.2014.09.008.

8. Osch, F. van; Jochems, S.; Wesselius, A.; Schooten, F. van; Bryan, R.; Zeegers, M. A Stratified Meta-Analysis of the Association between Exposure to Environmental Tobacco Smoke during Childhood and Adulthood and Urothelial Bladder Cancer Risk. Int. J. Environ. Res. Public Heal. 2018, Vol. 15, Page 569 2018, 15, 569, doi:10.3390/IJERPH15040569.

9. Thomas, R. E.; McLellan, J.; Perera, R. Effectiveness of school-based smoking prevention curricula: systematic review and meta-analysis. BMJ Open 2015, 5, e006976, doi:10.1136/ bmjopen-2014-006976.

10. Chen, J.; Millar, W. J. Age of smoking initiation: implications for quitting. Heal. reports 1998 , 9, 39-46(Eng); 39-48(Fre).

11. Reitsma, M. B.; Fullman, N.; Ng, M.; Salama, J. S.; Abajobir, A.; Abate, K. H.; Abbafati, C.; Abera, S. F.; Abraham, B.; Abyu, G. Y.; Adebiyi, A. O.; Al-Aly, Z.; Aleman, A. V; Ali, R.; Al Alkerwi, A.; Allebeck, P.; Al-Raddadi, R. M.; Amare, A. T.; Amberbir, A.; Ammar, W.; Amrock, S. M.; Antonio, C. A. T.; Asayesh, H.; Atnafu, N. T.; Azzopardi, P.; Banerjee, A.; Barac, A.; BarrientosGutierrez, T.; Basto-Abreu, A. C.; Bazargan-Hejazi, S.; Bedi, N.; Bell, B.; Bello, A. K.; Bensenor, I. M.; Beyene, A. S.; Bhala, N.; Biryukov, S.; Bolt, K.; Brenner, H.; Butt, Z.; Cavalleri, F.; Cercy, K.; Chen, H.; Christopher, D. J.; Ciobanu, L. G.; Colistro, V.; Colomar, M.; Cornaby, L.; Dai, X.; Damtew, S. A.; Dandona, L.; Dandona, R.; Dansereau, E.; Davletov, K.; Dayama, A.; Degfie, T. T.; Deribew, A.; Dharmaratne, S. D.; Dimtsu, B. D.; Doyle, K. E.; Endries, A. Y.; Ermakov, S. P.; Estep, K.; Faraon, E. J. A.; Farzadfar, F.; Feigin, V. L.; Feigl, A. B.; Fischer, F.; Friedman, J.; G/ hiwot, T. T.; Gall, S. L.; Gao, W.; Gillum, R. F.; Gold, A. L.; Gopalani, S. V.; Gotay, C. C.; Gupta, R. R.; Gupta, R. R.; Gupta, V.; Hamadeh, R. R.; Hankey, G.; Harb, H. L.; Hay, S. I.; Horino, M.; Horita, N.; Hosgood, H. D.; Husseini, A.; Ileanu, B. V.; Islami, F.; Jiang, G.; Jiang, Y.; Jonas, J. B.; Kabir, Z.; Kamal, R.; Kasaeian, A.; Kesavachandran, C. N.; Khader, Y. S.; Khalil, I.; Khang, Y.-H.; Khera, S.; Khubchandani, J.; Kim, D.; Kim, Y. J.; Kimokoti, R. W.; Kinfu, Y.; Knibbs, L. D.; 
Kokubo, Y.; Kolte, D.; Kopec, J.; Kosen, S.; Kotsakis, G. A.; Koul, P. A.; Koyanagi, A.; Krohn, K. J.; Krueger, H.; Defo, B. K.; Bicer, B. K.; Kulkarni, C.; Kumar, G. A.; Leasher, J. L.; Lee, A.; Leinsalu, M.; Li, T.; Linn, S.; Liu, P.; Liu, S.; Lo, L.-T.; Lopez, A. D.; Ma, S.; El Razek, H. M. A.; Majeed, A.; Malekzadeh, R.; Malta, D. C.; Manamo, W. A.; Martinez-Raga, J.; Mekonnen, A. B.; Mendoza, W.; Miller, T. R.; Mohammad, K. A.; Morawska, L.; Musa, K. I.; Nagel, G.; Neupane, S. P.; Nguyen, Q.; Nguyen, G.; Oh, I.-H.; Oyekale, A. S.; PA, M.; Pana, A.; Park, E.-K.; Patil, S. T.; Patton, G. C.; Pedro, J.; Qorbani, M.; Rafay, A.; Rahman, M.; Rai, R. K.; Ram, U.; Ranabhat, C. L.; Refaat, A. H.; Reinig, N.; Roba, H. S.; Rodriguez, A.; Roman, Y.; Roth, G.; Roy, A.; Sagar, R.; Salomon, J. A.; Sanabria, J.; de Souza Santos, I.; Sartorius, B.; Satpathy, M.; Sawhney, M.; Sawyer, S.; Saylan, M.; Schaub, M. P.; Schluger, N.; Schutte, A. E.; Sepanlou, S. G.; Serdar, B.; Shaikh, M. A.; She, J.; Shin, M.-J.; Shiri, R.; Shishani, K.; Shiue, I.; Sigfusdottir, I. D.; Silverberg, J. I.; Singh, J.; Singh, V.; Slepak, E. L.; Soneji, S.; Soriano, J. B.; Soshnikov, S.; Sreeramareddy, C. T.; Stein, D. J.; Stranges, S.; Subart, M. L.; Swaminathan, S.; Szoeke, C. E. I.; Tefera, W. M.; Topor-Madry, R.; Tran, B.; Tsilimparis, N.; Tymeson, H.; Ukwaja, K. N.; Updike, R.; Uthman, O. A.; Violante, F. S.; Vladimirov, S. K.; Vlassov, V.; Vollset, S. E.; Vos, T.; Weiderpass, E.; Wen, C.-P.; Werdecker, A.; Wilson, S.; Wubshet, M.; Xiao, L.; Yakob, B.; Yano, Y.; Ye, P.; Yonemoto, N.; Yoon, S.-J.; Younis, M. Z.; Yu, C.; Zaidi, Z.; El Sayed Zaki, M.; Zhang, A. L.; Zipkin, B.; Murray, C. J. L.; Forouzanfar, M. H.; Gakidou, E. Smoking prevalence and attributable disease burden in 195 countries and territories, 1990-2015: a systematic analysis from the Global Burden of Disease Study 2015. Lancet 2017, 389, 1885-1906, doi:10.1016/S0140-6736(17)30819-X.

12. Liu, S.; Zhang, M.; Yang, L.; Li, Y.; Wang, L.; Huang, Z.; Wang, L.; Chen, Z.; Zhou, M. Prevalence and patterns of tobacco smoking among Chinese adult men and women: findings of the 2010 national smoking survey. J. Epidemiol. Community Health 2017, 71, 154-161, doi:10.1136/jech-2016-207805.

13. Health at a Glance 2017; Health at a Glance; OECD Publishing, 2017; ISBN 9789264280397.

14. Sievert, K. D.; Amend, B.; Nagele, U.; Schilling, D.; Bedke, J.; Horstmann, M.; Hennenlotter, J.; Kruck, S.; Stenzl, A. Economic aspects of bladder cancer: what are the benefits and costs? World J. Urol. 2009, 27, 295-300.

15. van Osch, F. H. M.; Jochems, S. H. J.; van Schooten, F. J.; Bryan, R. T.; Zeegers, M. P. Significant Role of Lifetime Cigarette Smoking in Worsening Bladder Cancer and Upper Tract Urothelial Carcinoma Prognosis: A Meta-Analysis. J. Urol. 2016, 195, 872-879, doi:10.1016/j. juro.2015.10.139.

16. Cumberbatch, M. G.; Rota, M.; Catto, J. W. F.; La Vecchia, C. The Role of Tobacco Smoke in Bladder and Kidney Carcinogenesis: A Comparison of Exposures and Meta-analysis of Incidence and Mortality Risks. Eur. Urol. 2016, 70, 458-466, doi:10.1016/j.eururo.2015.06.042.

17. Braakhuis, B. J. M.; Tabor, M. P.; Kummer, J. A.; Leemans, C. R.; Brakenhoff, R. H. A genetic explanation of Slaughter's concept of field cancerization: evidence and clinical implications. Cancer Res. 2003, 63, 1727-30.

18. Bassett, J. C.; Gore, J. L.; Chi, A. C.; Kwan, L.; McCarthy, W.; Chamie, K.; Saigal, C. S. Impact of a bladder cancer diagnosis on smoking behavior. J. Clin. Oncol. 2012, 30, 1871-8, doi:10.1200/ JCO.2011.36.6518.

19. Sosnowski, R.; Bjurlin, M. A.; Verze, P.; De Nunzio, C.; Shariat, S. F.; Brausi, M.; Donin, N. M. Role of cigarette smoking in urological malignancies and clinical interventions for smoking cessation. Cent. Eur. J. Urol. 2016, 69, 366-369, doi:10.5173/ceju.2016.883. 
20. Bjurlin, M. A.; Cohn, M. R.; Kim, D. Y.; Freeman, V. L.; Lombardo, L.; Hurley, S. D.; Hollowell, C. M. P. Brief Smoking Cessation Intervention: A Prospective Trial in the Urology Setting. J. Urol. 2013, 189, 1843-1849, doi:10.1016/j.juro.2012.11.075.

21. Megwalu, I. I.; Vlahiotis, A.; Radwan, M.; Piccirillo, J. F.; Kibel, A. S. Prognostic Impact of Comorbidity in Patients with Bladder Cancer. Eur. Urol. 2008, 53, 581-589, doi:10.1016/j. eururo.2007.10.069.

22. Gorber, S. C.; Schofield-Hurwitz, S.; Hardt, J.; Levasseur, G.; Tremblay, M. The accuracy of self-reported smoking: A systematic review of the relationship between self-reported and cotinine-assessed smoking status. Nicotine Tob. Res. 2009, 11, 12-24, doi:10.1093/ntr/ ntn010.

23. Thong, A. E.; Petruzella, S.; Orlow, I.; Zabor, E. C.; Ehdaie, B.; Ostroff, J. S.; Bochner, B. H.; Furberg Barnes, H. Accuracy of Self-reported Smoking Exposure Among Bladder Cancer Patients Undergoing Surveillance at a Tertiary Referral Center. Eur. Urol. Focus 2016, 2, 441-444, doi:10.1016/j.euf.2015.12.002.

24. Copeland, K. T.; Checkoway, H.; McMichael, A. J.; Holbrook, R. H. Bias due to misclassification in the estimation of relative risk. Am. J. Epidemiol. 1977, 105, 488-95.

25. Lee, P. N. Lung cancer and passive smoking: association of an artefact due to misclassification of smoking habits? Toxicol. Lett. 1987, 35, 157-62.

26. Amorim, L. D. A. F.; Cai, J. Modelling recurrent events: A tutorial for analysis in epidemiology. Int. J. Epidemiol. 2015, 44, 324-333, doi:10.1093/ije/dyu222.

27. Greenland, S. Modeling and variable selection in epidemiologic analysis. Am. J. Public Health 1989, 79, 340-9.

28. Hernán, M. A. A definition of causal effect for epidemiological research. J. Epidemiol. Community Health 2004, 58, 265-71, doi:10.1136/JECH.2002.006361.

29. Shrier, I.; Platt, R. W. Reducing bias through directed acyclic graphs. BMC Med. Res. Methodol. 2008, 8, 70, doi:10.1186/1471-2288-8-70.

30. Phillips, D. H. Smoking-related DNA and protein adducts in human tissues. Carcinogenesis 2002, 23, 1979-2004, doi:10.1093/carcin/23.12.1979.

31. Siegel, R. L.; Jacobs, E. J.; Newton, C. C.; Feskanich, D.; Freedman, N. D.; Prentice, R. L.; Jemal, A. Deaths Due to Cigarette Smoking for 12 Smoking-Related Cancers in the United States. JAMA Intern. Med. 2015, 175, 1574, doi:10.1001/jamainternmed.2015.2398.

32. Knowles, M. A.; Hurst, C. D. Molecular biology of bladder cancer: new insights into pathogenesis and clinical diversity. Nat. Publ. Gr. 2015, 15, doi:10.1038/nrc3817.

33. van Roekel, E. H.; Cheng, K. K.; James, N. D.; Wallace, D. M. A.; Billingham, L. J.; Murray, P. G.; Bryan, R. T.; Zeegers, M. P. Smoking is associated with lower age, higher grade, higher stage, and larger size of malignant bladder tumors at diagnosis. Int. J. Cancer 2013, 133, 446-454, doi:10.1002/ijc.28017.

34. Maasland, D. H.; van den Brandt, P. A.; Kremer, B.; Goldbohm, R. A.; Schouten, L. J. Alcohol consumption, cigarette smoking and the risk of subtypes of head-neck cancer: results from the Netherlands Cohort Study. BMC Cancer 2014, 14, 187, doi:10.1186/1471-2407-14-187.

35. Susser, M.; Susser, E. Choosing a future for epidemiology: I. Eras and paradigms. Am. J. Public Health 1996, 86, 668-73.

36. Perera, F. P.; Weinstein, I. B. Molecular epidemiology: recent advances and future directions. Carcinogenesis 2000, 21, 517-24.

37. Susser, M.; Susser, E. Choosing a future for epidemiology: II. From black box to Chinese boxes and eco-epidemiology. Am. J. Public Health 1996, 86, 674-7. 
38. Manolio, T. A. Genomewide Association Studies and Assessment of the Risk of Disease. N. Engl. J. Med. 2010, 363, 166-176, doi:10.1056/NEJMra0905980.

39. Ehrenstein, V.; Nielsen, H.; Pedersen, A. B.; Johnsen, S. P.; Pedersen, L. Clinical epidemiology in the era of big data: new opportunities, familiar challenges. Clin. Epidemiol. 2017, 9, 245-250, doi:10.2147/CLEP.S129779.

40. Vineis, P.; Chadeau-Hyam, M.; Gmuender, H.; Gulliver, J.; Herceg, Z.; Kleinjans, J.; Kogevinas, M.; Kyrtopoulos, S.; Nieuwenhuijsen, M.; Phillips, D. H.; Probst-Hensch, N.; Scalbert, A.; Vermeulen, R.; Wild, C. P. The exposome in practice: Design of the EXPOsOMICS project. Int. J. Hyg. Environ. Health 2017, 220, 142-151, doi:10.1016/J.IJHEH.2016.08.001.

41. Patel, C. J. Introduction to Environment and Exposome-Wide Association Studies: A DataDriven Method to Identify Multiple Environmental Factors Associated with Phenotypes in Human Populations. In Chemical Mixtures and Combined Chemical and Nonchemical Stressors; Springer International Publishing: Cham, 2018; pp. 129-149. 

Dutch Summary

Nederlandse samenvatting

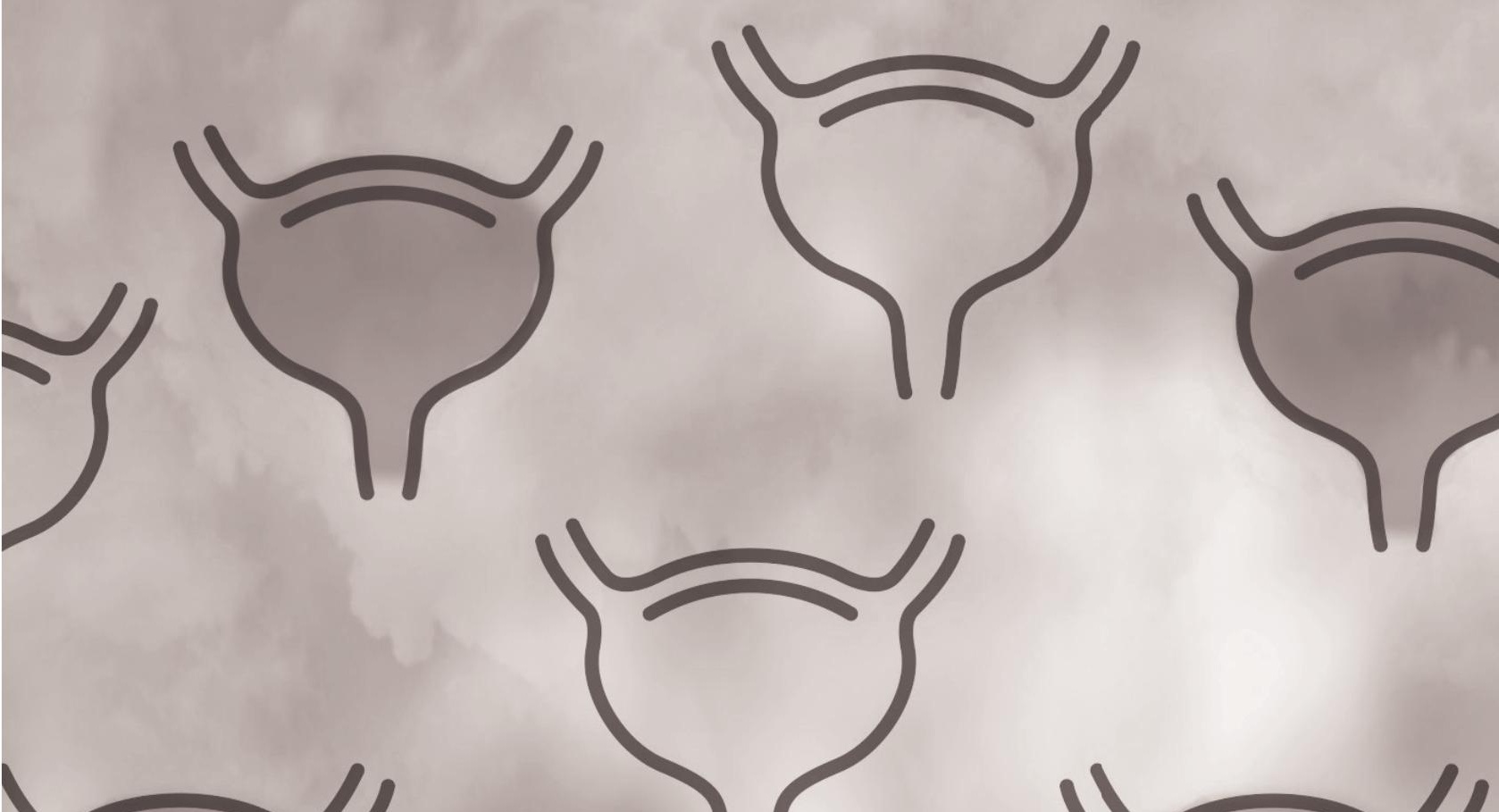



Het doel van dit proefschrift was om meer inzicht te krijgen in de reeds bekende associatie tussen rookgedrag en blaaskanker risico, alsmede prognose. Uit eerder onderzoek is bijvoorbeeld bekend dat rokers gemiddeld een driemaal zo hoog risico hebben op het ontwikkelen van blaaskanker, maar het is minder bekend hoe bijvoorbeeld sigaret-inhoud of de gehele blootstelling aan roken (o.a. aantal sigaretten per dag, rekening houdend met het aantal jaar) dit risico kan verhogen of verlagen. Er kan meer gerichte preventie plaatsvinden als deze details meer bekend zijn en urologen kunnen hun blaaskanker patiënten uitleggen wat eventueel de voordelen zijn van stoppen met roken na de diagnose. De hypotheses van dit proefschrift waren dat de totale duur aan blootstelling aan roken belangijker is om risico te voorspellen dan het aantal sigaretten per dag en dat stoppen met roken na de diagnosis van blaaskanker de prognose positief kan beïnvloeden. Om deze hypotheses te kunnen onderzoeken, is eerst alle huidige literatuur onderzocht en samengevat door middel van meta-analyses en zijn de uit deze studies voorkomende openstaande vragen beantwoordt door analyse van data uit het prospectieve patiënten cohort BCPP en uit het internationale consortium van observationele studies naar blaaskanker genaamd BLEND.

\section{Samenvatting van de bevindingen uit dit proefschrift}

Dit proefschrift kan onderverdeeld worden in twee delen; de onderzoeken naar de relatie tussen roken en a) blaaskanker risico (hoofdstuk 2 tot en met 5) en b) blaaskanker prognose (hoofdstuk 6 en 7).

De uitgebreide meta-analyse die in hoofdstuk 2 wordt gepresenteerd, bevestigt het reeds bekende driemaal hogere risico op blaaskanker voor rokers op het moment van diagnose. Opvallend genoeg is het aantal blaaskanker gevallen dat toe te wijzen is aan roken in mannen lager dan in 2000 (nu 43\% en nog 50\% in 2000). Dit is waarschijnlijk te verklaren door het dalende aantal rokers in Westerse landen, waar blaaskanker het meest voorkomt. Daarnaast laat deze meta-analyse zien dat ook degene die meer dan 35 jaar voor afname van de vragenlijst gestopt zijn met roken nog steeds een verhoogd risico (ongeveer 1.5 keer zo groot) hebben op blaaskanker ten opzichte van zij die nooit gerookt hebben.

In hoofdstuk 3 wordt al het wetenschappelijk bewijs samengevoegd wat er momenteel is naar blootstelling aan passief roken en blaaskanker risico. Aangezien er al recente analyses bestaan die dit hebben gedaan, hebben we in deze studie ervoor gekozen om te kijken naar blootstelling in specifieke fases van het leven. De resultaten van deze meta-analyse laten zien dat er geen noemenswaardig verhoogd (of verlaagd) risico op blaaskanker is bij blootstelling aan passief roken tijdens de kindertijd of tijdens het volwassen leven thuis of op het werk. Desalniettemin was gedetailleerde informatie over het rookgedrag van de actieve rokers waaraan de niet-rokers werden blootgesteld vaak onbekend en weten we 
dus niet of er misschien wel een effect is bij blootstelling aan zware rokers. Ook keken alle studies naar niet-rokers die blootgesteld waren aan rokers en niet of rokers die ook nog blootgesteld werden aan passief roken van een partner een extra verhoogd risico hadden.

Door een unieke samenwerking tussen de "UK Department of Health" en de BCPP cohort studie was het mogelijk om te kijken naar de invloed van de teer, nicotine en koolstofmonooxide (CO) inhoud van sigaretten op blaaskanker risico. De resultaten lieten zien dat een hogere dagelijkse inname van zowel teer, nicotine en CO lineair het risico op blaaskanker deden toenemen ten opzichte van de laagste inname groep onder rokers (hoofdstuk 4). Hiernaast werd geen verschil aangetoond tussen light en reguliere sigaretten. Los hiervan is het ook mogelijk dat individueel rookgedrag, bijvoorbeeld het wel of niet compleet oproken van de sigaret wat misschien vaker gebeurt bij zwaardere rokers, een vertekende factor geweest kan zijn in dit onderzoek en kan zorgen voor een overschatting van het effect van sigaret inhoud.

In hoofdstuk 5 wordt het effect van de duur van blootstelling aan roken en het aantal sigaretten, wat vaak sterk met elkaar samenhangt, tegelijk bekeken in het BLEND-consortium. In deze studie zijn data van 15 patiënt-controle onderzoeken samengevoegd en de resultaten laten zien dat duur van blootstelling belangrijker is in het bepalen van risico dan het aantal sigaretten dat per dag gerookt wordt. Dit geeft aan dat stoppen met roken het meest wenselijk is en dat alleen reductie van het aantal sigaretten waarschijnlijk niet het gewenste positieve effect op de publieke gezondheid op zal leveren, in ieder geval wat betreft het verminderen van het aantal blaaskanker gevallen.

De meta-analysis in hoofdstuk 6, die resultaten van studies naar het effect van rookstatus op het moment van diagnosis op blaaskanker prognose (recidief, progressie en overleving) samenvat, laat zien dat blaaskanker patiënten die roken op het moment van diagnosis ongeveer $25 \%$ meer kans hebben op een recidief en om door blaaskanker te sterven binnen 5 jaar. Helaas zijn alle studies op dit moment retrospectief van aard en was er weinig bewijs over stoppen met roken na de diagnose op langere termijn. Hoofdstuk 7 beschrijft de eerste prospectieve studie naar rookgedrag na de diagnose en de kans op blaaskanker recidieven. Opvallend genoeg was het aandeel blaaskanker patiënten dat stopte met roken na de diagnose te laag (14\%) om betrouwbare uitspraken te kunnen doen op basis van deze gegevens, maar het lijkt erop dat stoppen met roken vóór de diagnose van blaaskanker een groter positief effect heeft op het verlagen van de kans op recidieven dan stoppen na de diagnose. 


\section{Conclusie}

Het onderzoek gepresenteerd in dit proefschrift heeft getracht een uitgebreide uitleg te geven waarom rokers blaaskanker krijgen en hoe hun rookgedrag invloed kan hebben op hun prognose. Natuurlijk hebben succesvolle preventieprogramma's om te voorkomen dat mensen starten met roken de grootste impact op het verminderen van het aantal blaaskanker gevallen. Desalniettemin, geven onze resultaten uit verschillende studies aan dat de totale duur van de blootstelling aan roken dusdanig belangrijk is dat compleet stoppen met roken van groot belang is om het aantal blaaskanker gevallen in een populatie significant terug te dringen. Het type sigaret of blootstelling aan passief roken lijkt geen invloed te hebben op blaaskanker risico. Naast het verlagen van risico, zal stoppen met roken voor de diagnose waarschijnlijk ook ervoor zorgen dat de kans op recidieven na diagnose van blaaskanker ook kleiner wordt, maar meer prospectief onderzoek is nodig om dit te bevestigen. 



\section{Valorisation addendum}
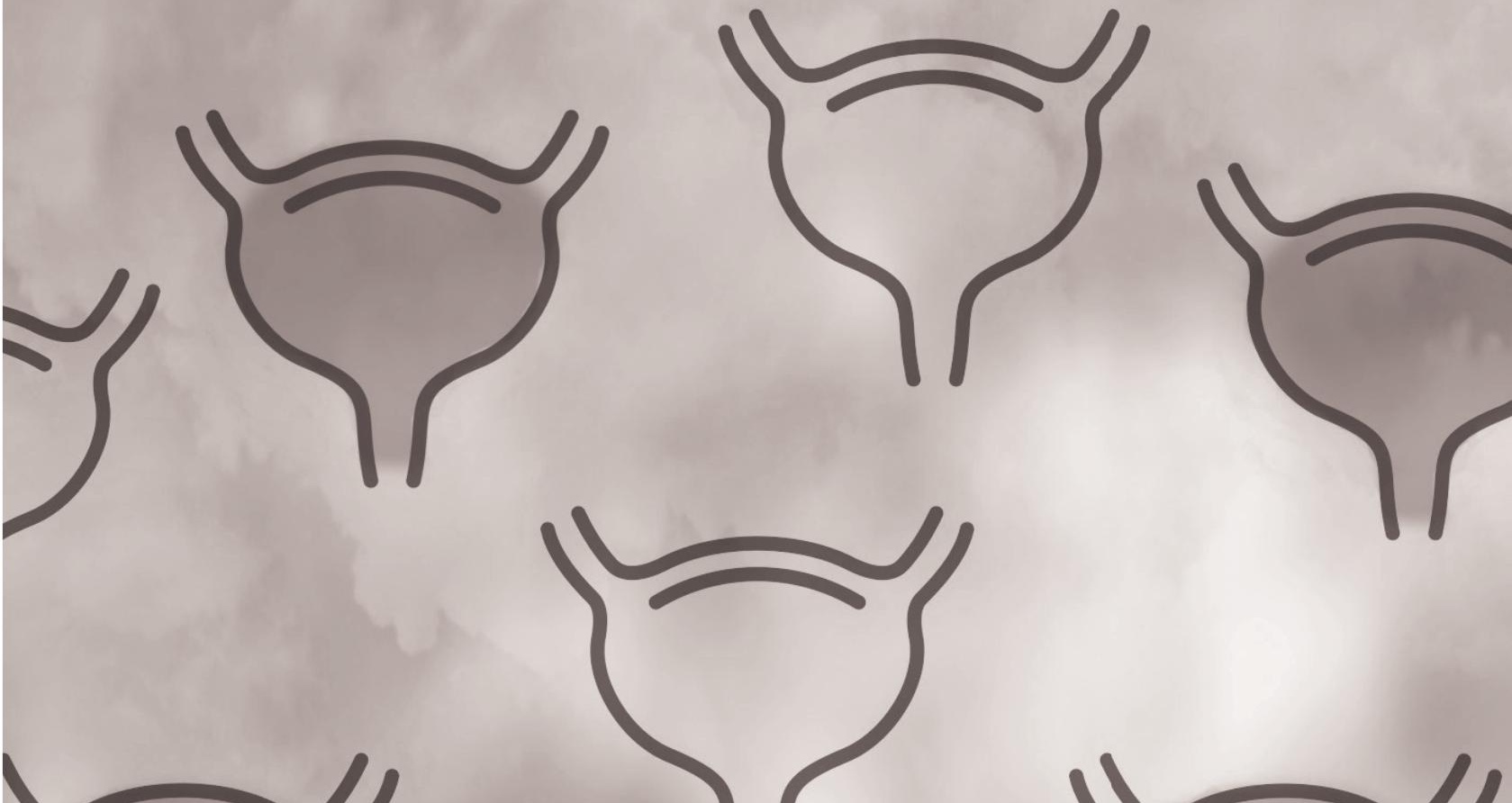

Bladder cancer is a common malignancy in the elderly from Western countries and will remain to have a significant social and economic impact on both individual lives as well as public health in general.

The findings of this thesis will mostly impact cancer prevention as the meta-analysis research and the pooled analysis from the BLEND consortium provide the most detailed summary of the available scientific evidence on the association between smoking and bladder cancer risk. The results from this research indicate that merely focussing on decreasing the number of cigarettes smoked per day is not enough and that only a large proportion of regular smokers completely quitting smoking is likely to have a meaningful impact on lowering bladder cancer rates.

Results of this thesis have been shared, after publication, with the UK-based bladder cancer charity "Fight Bladder Cancer". This charity is run by bladder cancer survivors and their families and aims to translate medical terms, scientific results and share tips and stories. By collaborating with such a patient-centred charity, I have attempted to help them keep their information up to date and to provide them with some of the most recent facts on smoking and bladder cancer.

Additionally, the Wikipedia page for "bladder cancer" (under heading: "causes") was updated in 2016 with results from the meta-analysis estimating the population attributable risk of bladder cancer among smokers, which decreased since the last published figures in 2000 .

Furthermore, results published in this thesis have been presented at the yearly Dutch conference for Epidemiology (WEON) and, while another paper on fluid intake and bladder cancer characteristics at diagnosis was presented, results were also discussed with several urologists at the European Association of Urology (EAU) conference 2018 in Copenhagen. It is important that both other researchers in the field and clinicians in the field are provided with the most reliable estimates of the impact of smoking on bladder cancer. In this way, other researchers can determine where more studies are needed and clinicians can use scientific facts to advise and treat their patients.

Summarising, the valorisation of the results of this epidemiological thesis is mainly in updating the facts on smoking and bladder cancer that can be read online by most people. Furthermore, providing reliable evidence on basic epidemiological associations lays the foundation for more translational research and provides clinicians with fact sheets to more efficiently interact with patients. 

Dankwoord

Acknowledgements

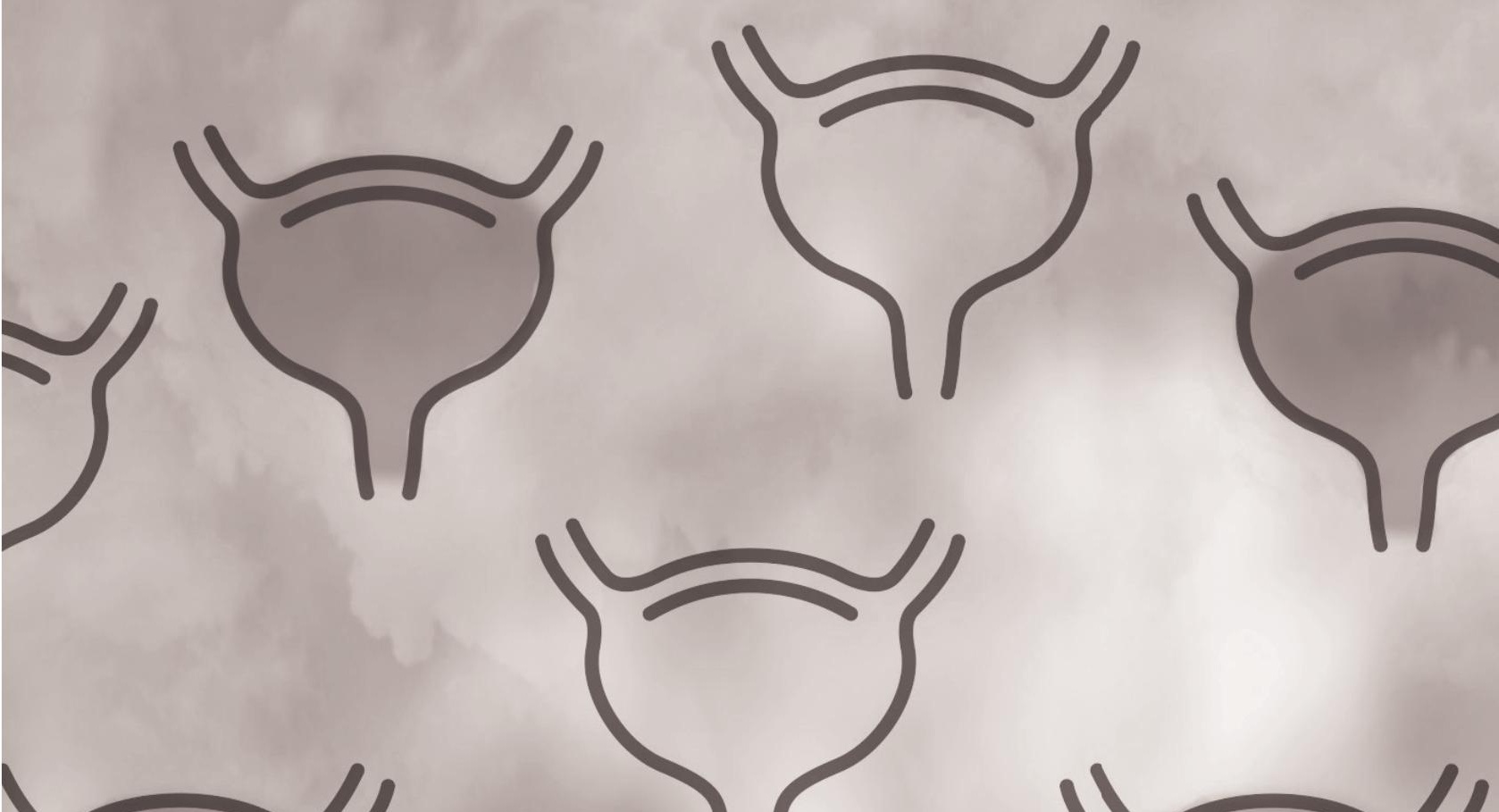



Ondanks dat alleen mijn naam op de voorkant van dit boekje staat, zijn er ook een heleboel mensen ik moet bedanken omdat ze me de afgelopen 4 jaar hebben bijgestaan en daardoor hebben bijgedragen aan dit mooie eindresultaat.

Op de eerste plaats mijn begeleidersteam Prof. Dr. Maurice Zeegers, Prof. Dr. Frederik-Jan van Schooten, Dr. Anke Wesselius \& Mr. Richard Bryan. Maurice, ik vind het een eer dat Sylvia en ik de testcases zijn geweest voor de joint PhD projecten met Birmingham. Volgens mij hebben we samen een mooie standaard neergezet! Bedankt voor je adviezen wanneer ik weer met een nieuw idee kwam om ons onderzoek verder uit te breiden en voor de gezellige Comgen BBQs in je achtertuin! Frederik-Jan, als epidemioloog die het grootste deel van de dag met andere epidemiologen praat was het geweldig om jouw input te krijgen vanuit een toxicologisch oogpunt. Ook waardeer ik je interesse in mijn persoonlijke ontwikkeling. Anke, ik vind het erg fijn dat we altijd zo snel op één lijn zitten als we het over onderzoek hebben en dat ik altijd bij je terecht kan als sparringpartner over onderwijs of statistiek! And last but certainly not least, Rik; thank you for teaching me so many things about urology and specifically about bladder cancer. You were always one of the first to congratulate me on happy occasions (such as publishing an article) and to provide valuable input on my manuscripts and I really appreciate your efforts in encouraging me to go to urology meetings, be it in Birmingham or in Copenhagen! I would also like to thank all members of the assessment committee, both in Birmingham and Maastricht, for assessing this dissertation.

As I am already typing in English now, I might as well start thanking all the people in Birmingham that have helped me during my stay there. I would like to thank Doug, Ben, Sarah, Gareth and Adam for their advice about the BCPP database and for their continued efforts in managing the data and adding new, genomic information to the cohort. Furthermore, I would like to thank my Brummy friends Marija, Marina, Bogdan and Giacomo for all our fun nights out watching Champions League matches or going to Popworld. Uiteraard waren er ook Nederlanders in Birmingham; ik weet niet of de groep Nederlanders bij University of Birmingham inmiddels nog steeds actief is maar Bram, Anke, Jasper en Martine, bedankt voor de gezellige etentjes! En natuurlijk mag ik Raoul niet vergeten; mijn grote rivaal tijdens de halve marathon van Birmingham in 2015. Ik denk niet dat ik je tegenwoordig nog bij zou kunnen houden! Naast de traktatie op pannenkoeken in Selly Oak, ook bedankt voor je gedetailleerde feedback op gezamenlijke artikelen en voor het uitleggen van de statistiek achter dose-response meta-analyses.

Graag wil ik ook andere collega's bedanken die een speciale bijdrage hebben geleverd aan dit proefschrift. Charlotte, bedankt dat je me hebt geholpen met al je toxicologische kennis over roken en dat we samen de BCPP-dataset hebben kunnen uitbreiden met 
de TNCO-data van alle sigarettenmerken. Ranti, thank you for providing linkage to the UK Department of Health data on cigarette contents to enhance the BCPP-data! Jelle, bedankt dat je open stond om het door jullie ontwikkelde EOR-model toe te passen in BLEND en dat ik altijd welkom was in Utrecht wanneer ik vastliep met de analyses in SAS.

Ook in Maastricht zijn er een heleboel collega's te bedanken. Ten eerste alle collega's op de afdeling Complex Genetics! Als eerste het ComGen secretariaat (Hanneke, Iris en Erika) voor alle hulp in het plannen van de vele afspraken en deze promotie. De ComGen social activities bij Miriam thuis en congresbezoeken waren altijd hoogtepunten met stagiaires Willem, Ben en Mitch (Mitch, ook bedankt voor het ontwerp van de cover van dit boekje!) en de andere PhD studenten van de oude garde, Bram, Nikos en Kelly. Although we have not been colleagues and roommates for very long in Maastricht, I enjoyed our critical discussions on the most diverse topics Nadia! Thank you for helping me out as a tutor in the course in Venlo Elena! Evan, thank you for all your gifts from China, I am sure you will be a good senior in the future! And of course, I also wish the best of luck to all the (relatively) new people at the department doing their internships or starting their PhDs (Anna-Roos, Panjun, Magdalena, Putri, Janneke \& Iris). Gerard, bedankt voor je analytische blik op mijn werk en dat van anderen en ik ben blij dat ik daarvoor soms iets terug kon doen door te helpen met ICT-gerelateerde zaken! Marij, bedankt dat je me geïntroduceerd hebt in het CAT-onderwijs en dat ik je altijd mocht lastigvallen met vragen daarover.

Het CAT-onderwijs is een mooi bruggetje naar de volgende collega's waar ik veel mee samen heb gewerkt en waar ik een heleboel van heb mogen leren op het gebied van epidemiologie en onderwijs. Alle collega's van CAT-onderwijs bedankt voor de inhoudelijke discussies tijdens de besprekingen en in het bijzonder iedereen die meehelpt in het organiseren van dit onderwijs. Hiernaast wil ik Martien bedanken voor onze samenwerking in Venlo, het was erg leuk om samen met degene die mij mijn eerste colleges epidemiologie heeft gegeven nu zelf een blok te organiseren. Hetzelfde geldt voor Bas, bedankt voor onze discussies over onderwijs en onderzoek. Matty, Leo, Colinda en Piet, bedankt voor alles wat ik tijdens mijn Master-stage heb mogen leren onder jullie supervisie binnen de NLCS. Zonder deze ervaring had ik zeker niet zo'n vliegende start kunnen maken met dit promotietraject! Uiteraard is er tussen alle bedankjes richting de afdeling Epidemiologie een apart stukje gereserveerd in dit dankwoord voor jou Christel. Zonder jouw enthousiasme voor epidemiologie tijdens de Bachelor had ik misschien wel iets heel anders gekozen en je adviezen over belangrijke carrièrekeuzes helpen me nog steeds! Ook wil ik hier mijn "aangetrouwde familie" op Campus Venlo en mijn "nieuwe werkfamilie" bij het Leerhuis in VieCuri bedanken voor jullie support! 
Paranimf Sylvia, dankjewel dat je mijn naam hebt genoemd als potentiële collega toen je begon aan het parallelle joint PhD project in Birmingham. Ik kan een heel boek schrijven over onze (of eigenlijk vooral jouw) avonturen in Birmingham en de gesprekken in het kantoor achter de tralies. Zonder jou was het een heel stuk saaier geweest in Birmingham en waren er ook een heleboel kleine foutjes niet ontdekt in verschillende datasets. Gelukkig let je altijd op de allerkleinste details en dat maakte ons ook zo'n dreamteam de afgelopen 4 jaar!

Paranimf Jeroen, ik vind het mooi dat we inmiddels als collega-epidemiologen nog beter significante woordgrappen kunnen maken. Bedankt dat ik altijd bij je terecht kan om nieuwe onderzoeksplannen te pitchen en te horen over jouw ideeën en ik hoop dat onze vriendschap in de toekomst nog eens vereeuwigd zal worden op Pubmed!

Ben, Jorn en Maikel, we zijn ondertussen al meer dan 10 jaar bevriend en wetenschappelijke studies beweren dat het dan vriendschap voor altijd is. Ik denk dat de kans daarop bij ons groter is dan 95\% en daarom verdienen de Heugemer Boys een speciale shout-out; als Jorn het niet doet op tv doe ik het wel via dit boekje. Andere vrienden die ik speciaal wil noemen zijn de bandleden van Dubbel Fout: Bas, Paul, HoiYau, Maarten en nog een keer Ben. We zijn de afgelopen jaren het hele land doorgereisd met onze foute medleys en covers wat voor mij altijd een geweldige uitlaatklep is om even alles van me af te laten glijden en te rocken!

Als laatste bedank ik graag mijn échte aangetrouwde familie; Fokke en Tine, Hilde \& Wilmer (en natuurlijk Rinse \& Hedser) en Jelke \& Elze. Bedankt dat jullie altijd geïnteresseerd zijn, het hele land door willen rijden om ons te zien en voor alle Friese woorden die ik nog steeds bij blijf leren! Papa en Mama, of Huub en Mieke, zoals alle andere mensen op de wereld jullie kennen, bedankt dat ik uit zo'n veilig nestje kom en dat jullie altijd achter me staan. Allerliefste Alie, wat is er veel moois gebeurd in ons leven het afgelopen jaar! Ik ben heel blij en trots dat jij altijd naast me staat. Ik ha dy leaf. 



Frits van Osch was born on the $24^{\text {th }}$ of October, 1990 in Schijndel, the Netherlands. After graduating from secondary school at Gymnasium Bernrode in 2008, he studied Health Sciences at Maastricht University and received his BSC. degree in 2012. During his studies, he developed an interest in epidemiological research, so Frits continued to study the Health Sciences Research Master. During his 1-year internship he did research on the association between mitochondrial DNA copy and colorectal cancer survival in

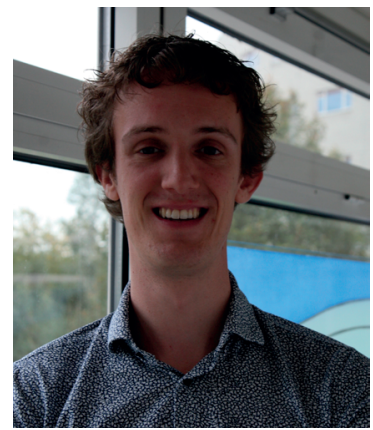
a hospital-based and population-based sample of tumours (and healthy tissue) and published the results in 2014.

After graduating, he started one of the first joint PhD projects (together with Sylvia Jochems) between the University of Birmingham and Maastricht University. After moving to Birmingham first to work on the meta-analyses and BCPP papers presented in this thesis, he moved back to Maastricht to work on the BLEND consortium. During his time at Maastricht University, Frits also took up various teaching roles teaching epidemiology, methodology and statistics in Medicine, Health Sciences, Psychology and several related Master's programmes. For this work, Frits received the Faculty's education prize for "best tutor" in 2017. Currently, Frits is also course coordinator for a methodological course in the Master's programme Health Food Innovation Management at Campus Venlo from Maastricht University. Furthermore, Frits is a registered Epidemiologist A and active member of the Dutch Society of Epidemiology ( $\mathrm{V} v \mathrm{E})$.

After finishing his $\mathrm{PhD}$ project, Frits will start his new position as senior research associate at the VieCuri Medical Center in Venlo (the Netherlands) where he will continue to work on his own research as well as assisting others in setting up theirs. 

List of publications \&

contributions to meetings

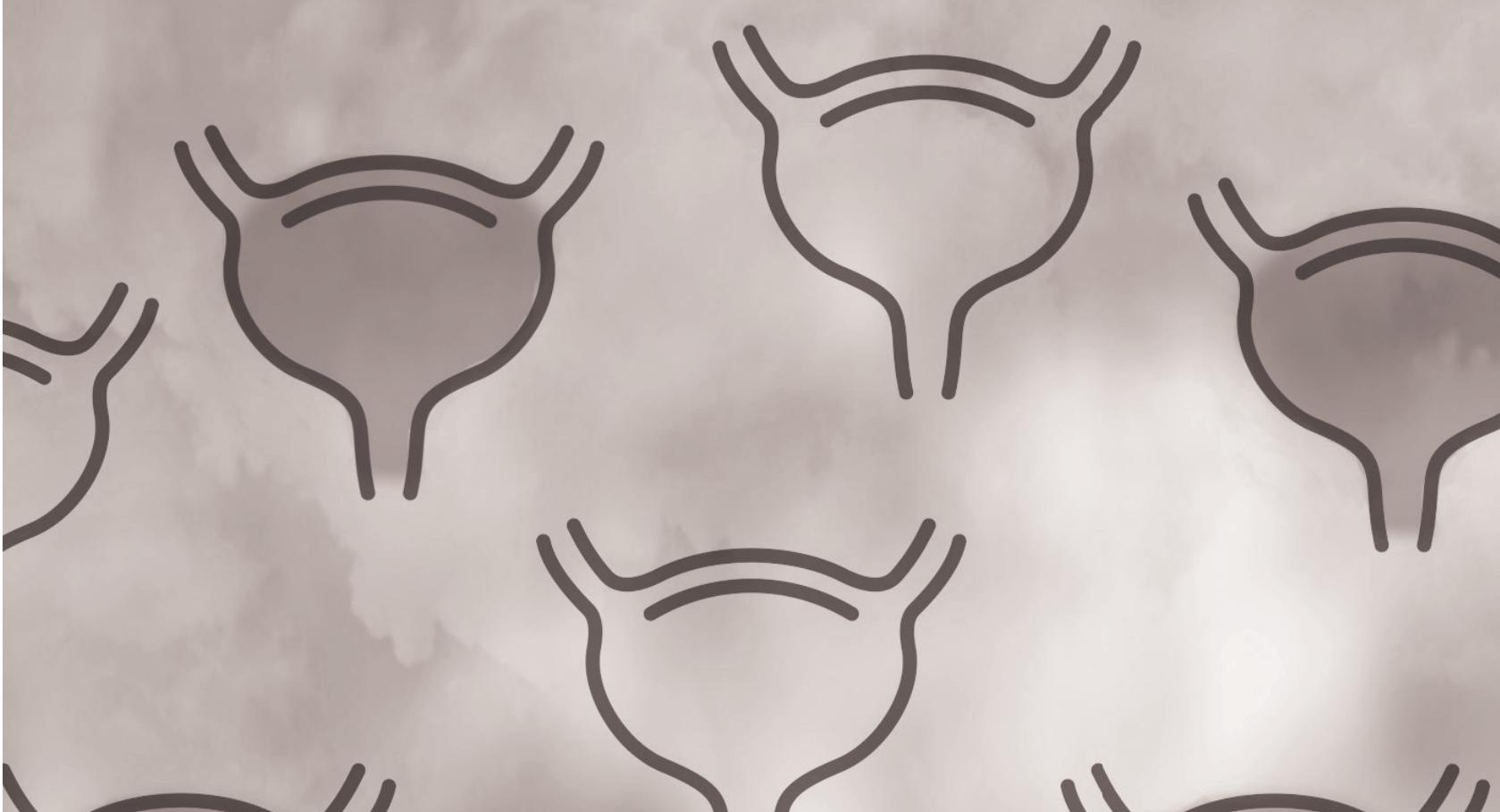





\section{PUBLISHED PAPERS (CHRONOLOGICAL ORDER)}

1. van Osch FHM, Voets AM, Schouten LJ, Gottschalk RWH, Simons CCJM, van Engeland $M$, Lentjes MHFM, van den Brandt PA, Smeets HJM, Weijenberg MP. Mitochondrial DNA copy number in colorectal cancer: Between tissue comparisons, clinicopathological characteristics and survival. Carcinogenesis. 2015;36: 1502-1510. doi:10.1093/carcin/ bgv151

2. van Osch FHM, Jochems SHJ, van Schooten F-J, Bryan RT, Zeegers MP. Quantified relations between exposure to tobacco smoking and bladder cancer risk: a meta-analysis of 89 observational studies. Int J Epidemiol. 2016;45: 857-870. doi:10.1093/ije/dyw044

3. van Osch FHM, Jochems SHJ, van Schooten FJ, Bryan RT, Zeegers MP. Significant Role of Lifetime Cigarette Smoking in Worsening Bladder Cancer and Upper Tract Urothelial Carcinoma Prognosis: A Meta-Analysis. J Urol. 2016;195: 872-879. doi:10.1016/j. juro.2015.10.139

4. van Osch FHM, Pauwels CGGM, Jochems SHJ, Fayokun R, James ND, Wallace DMA, Cheng KK, Bryan RT, van Schooten FJ, Zeegers MP.. Tar, nicotine and carbon monoxide yield of UK cigarettes and the risk of non-muscle-invasive and muscle-invasive bladder cancer. Eur J Cancer Prev. 2017; 1. doi:10.1097/CEJ.0000000000000404

5. Osch FHM van, Jochems S, Wesselius A, Schooten F van, Bryan R, Zeegers M. A Stratified Meta-Analysis of the Association between Exposure to Environmental Tobacco Smoke during Childhood and Adulthood and Urothelial Bladder Cancer Risk. Int J Environ Res Public Heal 2018, Vol 15, Page 569. Multidisciplinary Digital Publishing Institute; 2018;15: 569. doi:10.3390/IJERPH15040569

6. Jochems SHJ, van Osch FHM, Bryan RT, Wesselius A, van Schooten FJ, Cheng KK, Zeegers MP. Impact of dietary patterns and the main food groups on mortality and recurrence in cancer survivors: a systematic review of current epidemiological literature. BMJ Open. British Medical Journal Publishing Group; 2018;8: e014530. doi:10.1136/ bmjopen-2016-014530

7. Jochems SHJ, van Osch FHM, Reulen RC, van Hensbergen M, Nekeman D, Pirrie $S$, Wesselius A, van Schooten FJ, James ND, Wallace DMA, Bryan RT, Cheng KK, Zeegers MP. Fruit and vegetable intake and the risk of recurrence in patients with non-muscle invasive bladder cancer: a prospective cohort study. Cancer Causes Control. Springer International Publishing; 2018; 1-7. doi:10.1007/s10552-018-1029-9

8. van Osch, FHM; Jochems, S. H. J.; Reulen, R. C.; Pirrie, S. J.; Nekeman, D.; Wesselius, A.; James, N. D.; Wallace, D. M. A.; Cheng, K. K.; van Schooten, F. J.; Bryan, R. T.; Zeegers, M. P. The association between smoking cessation before and after diagnosis and non-muscleinvasive bladder cancer recurrence: a prospective cohort study. Cancer Causes Control 2018, 29, 675-683, doi:10.1007/s10552-018-1046-8. 
9. Jochems SHJ, van Osch FHM, Reulen RC, van Hensbergen M, Nekeman D, Pirrie SJ, et al. Total Fluid Intake and the Risk of Recurrence in Patients With Non-Muscle Invasive Bladder Cancer: A Prospective Cohort Study. Bladder Cancer. 2018 Jul 30;4(3):303-10.

10. van Osch FHM, Vlaanderen J, Jochems, SHJ, Bosetti C, Polesel J, Porru S, Carta A, Golka K, Jiang X, Stern MC, Zhong W, Kellen E, Pohlabeln H, Tang L, Marshall J, Steineck G, Karagas MR, Johnson KC, Zhang ZF, Taylor JA, La Vecchia C, Bryan RT, van Schooten FJ, Wesselius A, Zeegers MP, Modeling the complex exposure history of smoking in predicting bladder cancer. Epidemiology 2018, epub ahead of print, doi: 10.1097/ EDE.0000000000000964

11. Witlox WJA, van Osch FHM, Brinkman M, Jochems SHJ, Goossens ME, Weiderpass E, White E, van den Brandt PA, Giles GG, Milne RL, Huybrechts I, Adami HO, Bueno-deMesquita B, Wesselius A, Zeegers MP, An inverse association between the Mediterranean diet and bladder cancer risk: a pooled analysis of 13 cohort studies. European Journal of Nutrition 2019, doi: 10.1007/s00394-019-01907-8

\section{PRESENTATIONS \& OTHER CONTRIBUTIONS TO MEETINGS DURING PHD PROJECT}

2015 Healthy Living, European Epidemiology Conference. Poster presentation: Quantified relations between exposure to tobacco smoking and bladder cancer risk: a meta-analysis of 89 observational studies.

University of Birmingham, yearly PhD student presentations School of Cancer Sciences (2014/2015). Presentation prize: Quantified relations between exposure to tobacco smoking and bladder cancer risk: a meta-analysis of 89 observational studies.

2016 WEON, Dutch Epidemiology Conference. Oral presentation: Estimating doseresponse relationship in meta-analysis: The case of smoking and bladder cancer incidence.

Maastricht University, Genetics \& Cell Biology seminar \& Department of Toxicology Lab Meeting. Oral presentation: Dose-response association between smoking $\&$ bladder cancer.

2017 WEON, Dutch Epidemiology Conference. Oral presentation: Smoking cessation and bladder cancer recurrence.

2018 EAU 2018, Copenhagen. Poster presentation: Fluid intake and clinicopathological characteristics of bladder cancer; the West Midlands Bladder Cancer Prognosis Programme (BCPP) 
WEON, Dutch Epidemiology Conference. Poster presentation: Disentangling the collinearity between smoking duration and intensity in predicting bladder cancer: a pooled analysis of 15 case-control studies. 